\title{
ATLAS DO PÓLEN DE PLANTAS MEDICINAIS
}

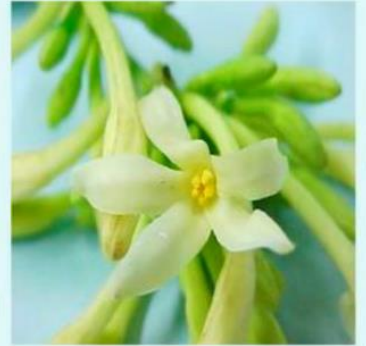

Carica papaya
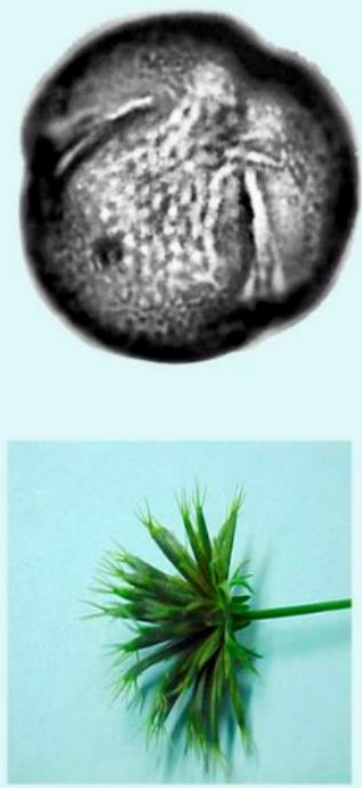

Bidens bipinnata

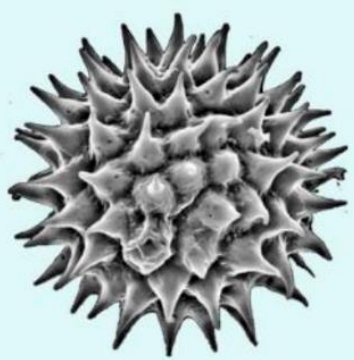

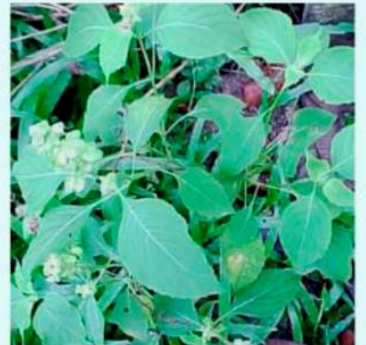

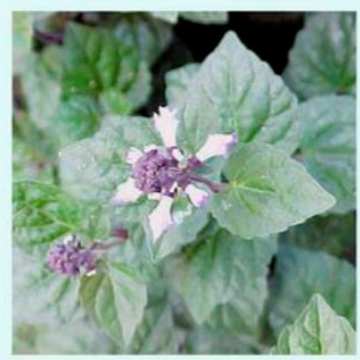

Ocimum micranthum Scuttelaria purpurascens
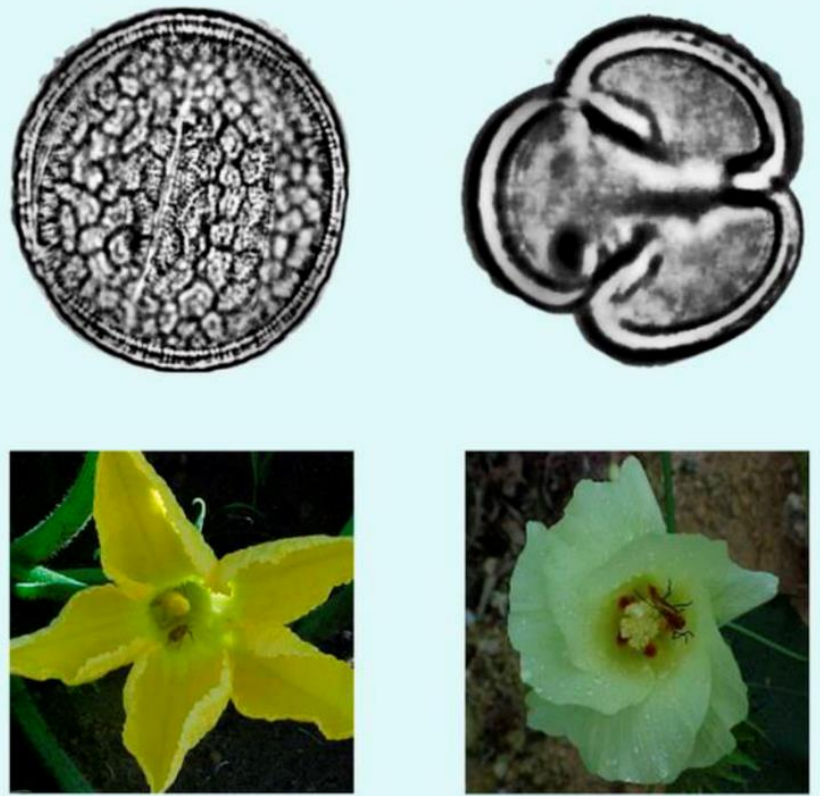

Cucurbita cf. moschata
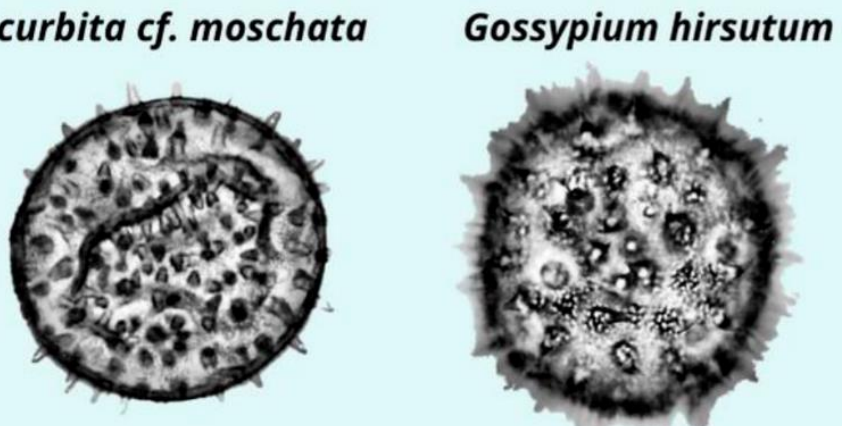

\section{Autores}

Ires Paula de Andrade Miranda Léa Maria Medeiros Carreira Maria Lúcia Absy

Flávia Cristina Araújo Lucas Edelcílio Marques Barbosa
Filomena Ferreira Santiago

David de Paula Andrade Miranda Luiz de Souza Coelho José Benayon Bessa de Moura

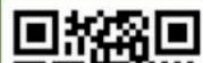


Ires Paula de Andrade Miranda

Lea Maria Medeiros Carreira

Maria Lucia Absy

Flavia Cristina Araujo Lucas

Edelcílio Marques Barbosa

Filomena Ferreira Santiago

David de Paula Andrade Miranda

Luiz de Souza Coelho

Jose Benayon Bessa de Moura

\section{Atlas do Pólen de Plantas Medicinais}

1a Ediçao

Belo Horizonte

Poisson

2020 
Editor Chefe: Dr. Darly Fernando Andrade

\section{Conselho Editorial}

Dr. Antônio Artur de Souza - Universidade Federal de Minas Gerais

Msc. Davilson Eduardo Andrade

Dra. Elizângela de Jesus Oliveira - Universidade Federal do Amazonas

Msc. Fabiane dos Santos

Dr. José Eduardo Ferreira Lopes - Universidade Federal de Uberlândia

Dr. Otaviano Francisco Neves - Pontifícia Universidade Católica de Minas Gerais

Dr. Luiz Cláudio de Lima - Universidade FUMEC

Dr. Nelson Ferreira Filho - Faculdades Kennedy

Msc. Valdiney Alves de Oliveira - Universidade Federal de Uberlândia

\begin{tabular}{|l} 
Dados Internacionais de Catalogação na Publicação (CIP) \\
A881 \\
Atlas do Pólen de Plantas Medicinais/ Organizadores: Ires Paula de Andrade Miranda, \\
Lea Maria Medeiros Carreira, Maria Lucia Absy Flavia Cristina Araujo Lucas, \\
Edelcílio Marques Barbosa, Filomena Ferreira Santiago, David de Paula Andrade \\
Miranda, Luiz de Souza Coelho, Jose Benayon Bessa de Moura Belo Horizonte - \\
MG: Poisson, 2020 \\
Formato: PDF \\
ISBN: 978-65-5866-030-9 \\
DOI: 10.36229/978-65-5866-030-9 \\
Modo de acesso: World Wide Web \\
Inclui bibliografia \\
I. MIRANDA, Ires Paula de Andrade. II. MARIA, Lea Maria Medeiros Carreira. III. \\
ABSY, Maria Lucia. IV. LUCAS, Flavia Cristina Araujo. V. BARBOSA, Edelcílio \\
Marques. VI. SANTIAGO, Filomena Ferreira. VII. MIRANDA, David de Paula Andrade. \\
VIII. COELHO, Luiz de Souza. IX. MOURA, Jose Benayon Bessa de. X. Título \\
Sônia Márcia Soares de Moura - CRB 6/1896
\end{tabular}

O conteúdo dos artigos e seus dados em sua forma, correção e confiabilidade são de responsabilidade exclusiva dos seus respectivos autores.

www.poisson.com.br

contato@poisson.com.br 


\section{SUMÁRIO}

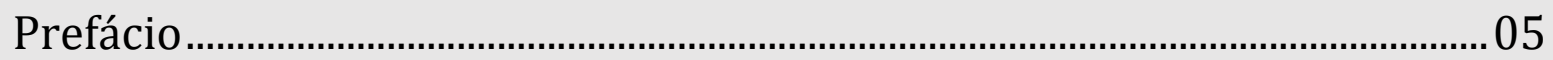

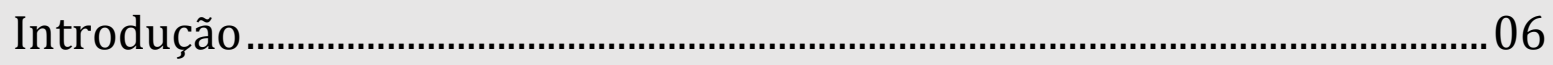

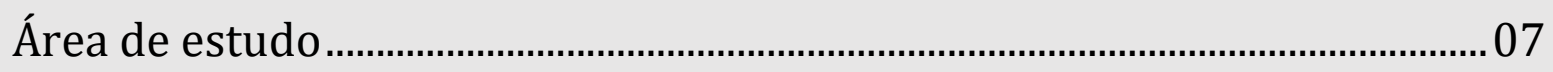

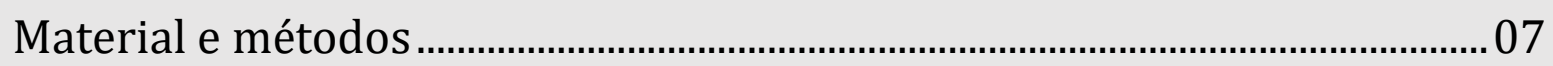

Resultados - Descrição das Espécies .................................................................... 08

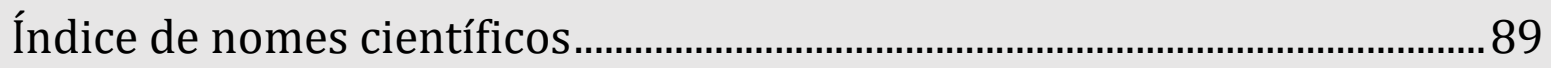

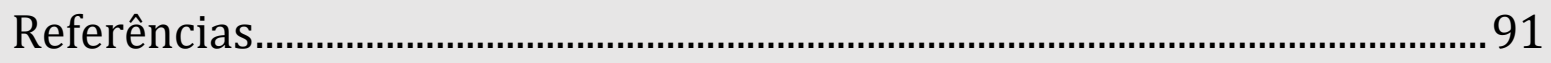

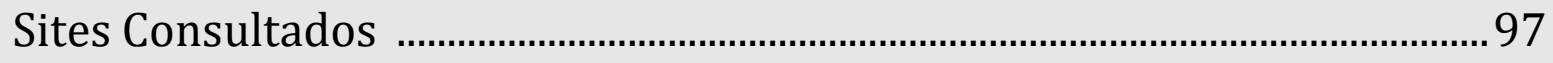

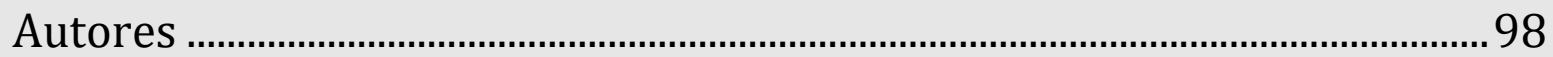




\section{PREFÁCIO}

A finalidade do presente Atlas diz respeito a contribuição de palinólogos renomados e experientes, trabalhando há décadas na Amazônia, para a construção da formação de recursos humanos qualificados no conhecimento da Palinologia Recente e Fóssil, em diversos aspectos como: Palinotaxonomia, melissopalinologia, paleocologia e biopalinologia.

Uma obra de referência para pesquisadores, estudantes e a sociedade em geral, de cunho científico e artístico, contêm lâminas explicativas e organizadas por famílias botânicas de espécies medicinais e a descrição do grão de pólen de cada representante descrito, tendo como objetivo principal a difusão da importância desses elementos, os quais representam o fenótipo e o genótipo masculino da planta, como forma de avaliar e caracterizar a influência do manejo dessas espécies cultivadas em quintais e no seu ambiente natural, comparada a forma do grão de pólen. Considerado uma ferramenta fundamental na elucidação de gêneros e espécies botânicas, no caso as plantas medicinais oferecem uma alternativa concreta de se evitar identificações equivocadas dessas espécies tão essenciais e promissores para a Farmacopeia Brasileira.

O conhecimento do pólen de plantas medicinais poderá contribuir sobremaneira de forma essencial para a definição de espécies nativas e cultivadas, além de tornar-se imprescindível como referência para o estudo de bases citológicas e fisiológicas da fecundação e de produção vegetal, bem como, subsidiar estudos de polinização.

Meu agradecimento especial as cientistas pioneiras dessa jornada de pesquisas palinológicas na Amazônia, duas das quais fazem parte da composição dessa obra (Dras.Maria Lúcia Absy e Léa Maria Medeiros Carreira), como também não poderia deixar de mencionar a grande mestra Dra. Monika Barth, que também trabalhou incansavelmente em cursos de pós-graduação na Amazônia oriental e ocidental.

Meus agradecimentos também a todos os autores que contribuíram tecnicamente no trabalho de campo, laboratorial e de composição diagramática, para que tivéssemos um resultado satisfatório do projeto.

Faço votos de que a referida obra oferecida de forma interativa, possa alcançar diversos leitores interessados na flora medicinal e estudos palinológicos fortalecendo o desejo de aprender, como resposta ao aproveitamento dos conhecimentos científicos e tradicionais das plantas medicinais e dos grãos de pólen das espécies aqui apresentadas.

Por último quero salientar que o trabalho aqui apresentado, reflete uma parceria dos diversos especialistas da área de Palinologia e do conhecimento da flora da Amazônia. Também meu agradecimento ao INPA e Museu Goeldi, nossas Instituições de origem e ao CNPq pelo apoio financeiro concedido ao projeto. 


\section{INTRODUÇÃO}

A floresta Amazônica abriga uma grande quantidade de plantas medicinais, as quais fornecem numerosos medicamentos. A Índia utiliza há mais de cinco mil anos plantas medicinais, possuindo uma gama de 8.000 medicamentos à base de ervas. Na China é utilizado por muito tempo, o ginseng, o ópio e diversas outras plantas na medicina. Em nossos dias, a humanidade depende ainda de medicamentos naturais, principalmente na Amazônia. Nos países em desenvolvimento, os produtos naturais são utilizados 75 à $90 \%$ pela população.

As indicações de substâncias medicinais naturais são utilizadas para diversos males como problemas estomacais, passando pelas micoses e tônicos para o coração, sendo que para estes fins mais de 6.000 espécies vegetais são utilizadas.

A pesquisa botânica aliada a medicina tradicional poderá contribuir para a criação de numerosos medicamentos, sendo inúmeros de origem vegetal os quais são utilizados pela medicina alopática e homeopática.

A identificação exata dessas espécies vegetais face à diversidade florística em países tropicais, principalmente na Amazônia é de suma importância para auxiliar protocolos corretos na fabricação de produtos oriundos da matéria vegetal. Uma das dificuldades da Inovação Tecnológica com insumos vegetais é a falta de conhecimento da variabilidade de princípios ativos nos indivíduos de espécies e gêneros, relacionados à plantas da Amazônia. Além disso, a comprovação de testes clínicos, dificulta a aceitação desses produtos pelas grandes empresas no mercado nacional e internacional.

Nos países desenvolvidos, pelo menos $25 \%$ dos especialistas receitam como ingredientes ativos substâncias provenientes de plantas medicinais. Esses ingredientes servem como modelo para a síntese química de várias outras substâncias. Pode-se estimar cerca de milhões de dólares o valor comercial anual de medicamentos extraídos dos vegetais.

A prospecção de plantas medicinais tem revelado uma enorme quantidade de espécies com propriedades terapêuticas conhecidas e utilizadas empiricamente pelos nativos, o que favorece uma contribuição científica para identificação e inventário dessas espécies.

Os grãos de pólen das plantas consideradas de caráter medicinal, sendo o elemento fecundante das plantas superiores, estabelece também por meio de sua identificação, análise e estocagem em um sistema eficiente e completo para a preservação do germoplasma, possibilitando sua utilização posterior em programas de melhoramento genético e estudo sistemático da variabilidade e heterogeneidade das plantas tropicais.

Pesquisas realizadas sobre o estudo dos grãos de pólen e sua interação com outras ciências, tem contribuído grandemente para o conhecimento da flora e o aumento do conhecimento científico e tecnológico, bem como a valorização da produção agrícola por meio de ações de desenvolvimento rural integrado (Miranda, 1990; 1993).

Baseados nesta perspectiva, uma das grandes alternativas para melhorar a produtividade ou rentabilidade de cultivos consiste em selecionar atraves do estudo do polen plantas com potencial medicinal, como proposiçao de preservaçao e exploraçao racional. Em face a essa perspectiva, o Atlas do polen de Plantas Medicinais visa contribuir por meio do inventario 
palinologico dessas especies, permitindo quantificar e qualificar 40 especies com esse potencial da biodiversidade amazonica, como contribuiçao ao arranjo de produtos naturais.

O contexto do Atlas do polen de Plantas Medicinais, abrange alem da descriçao taxonomica das especies estudadas, descriçoes da morfologia polí nica com material fotografico realizados em Microscopia Fotonica e Eletronica de Varredura de qualidade excepcional, o que contribui consideravelmente para que o leitor possa apreciar e utilizar os conhecimentos da presente obra.

0 produto oriundo da concepção de reunir informações em um banco de dados digital do pólen e flores de plantas medicinais coletadas na Amazônia, engloba a classificação botânica, georreferenciamento, descrição do pólen e outras informações adicionais as quais deram origem a confecção desse Atlas. A presente obra em primeira instância, oferece a oportunidade ímpar de levar até os leitores e estudiosos das plantas medicinais e palinólogos o compartilhamento de dados e resultados.

\section{ÁREA DE ESTUDO}

As áreas de estudo das espécies nativas estão localizadas nas reservas e estações experimentais do INPA e as introduzidas nas residências e sítios ao longo das rodovias AM-010, AM-020 e BR174 no Estado do Amazonas. As coordenadas geográficas do presente estudo foram: BR174-

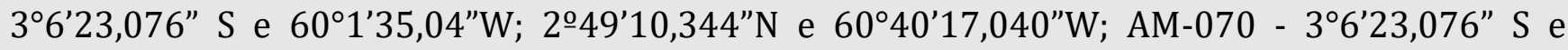

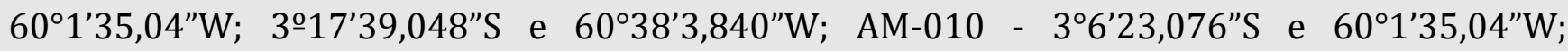
3ㅇ'31,128”S e $58^{\circ} 26^{\prime} 33,360^{\prime \prime} \mathrm{W}$.

\section{MATERIAL E MÉTODOS}

Foi realizado o mapeamento das espécies mais utilizadas na medicina popular nativa, nas áreas inventariadas. Em seguida, feita fotografias e coleta de flores, para a preparação das amostras das espécies inventariadas, sendo estas fotografias acondicionadas em um banco de dados do Laboratório de Estudo em Palmeiras da Amazônia do INPA (LABPALM)

Na preparação dos grãos de pólen para observação ao microscópio fotônico, foi utilizado o método da acetólise de Erdtman (1960). Os grãos de pólen foram submetidos à hidrólise ácida em anidrido acético e ácido sulfúrico na proporção de 9:1 para observação da parede externa do grão de pólen (exina), eliminando o seu conteúdo celular e permitindo com isso sua caracterização morfológica. As lâminas foram montadas em gelatina glicerinada e lutadas com parafina de acordo com os métodos convencionais utilizados em Palinologia.

As observações e medidas foram obtidas com o auxílio de um fotomicroscópio AXIOSKOP, munido de uma ocular micrométrica. Para as medidas utilizou-se uma objetiva de 40x, medindose 25 grãos de cada amostra.

Após serem feitas as medidas, elaborou-se um quadro de freqüências, partindo para os cálculos: média, variância, desvio padrão e coeficiente de variação. Nas medidas de espessura do grão calculou-se somente a média aritmética. A unidade amostral foi aleatória perfazendo um total de 
40 espécies. A metodologia referente a todos os parâmetros estudados foi conduzida no Laboratório de Palinologia e Fisiologia Vegetal do INPA (AM) e Laboratório de Microscopia Eletrônica de Varredura do Museu Emilio Goeldi (PA).

Com relação às descrições polínicas, a terminologia usada foi comparada com a literatura especializada.

As identificações das espécies no campo, procedeu-se por meio dos caracteres vegetativos e reprodutivos dos mesmos, previamente selecionados, coletados, fotografados e por último comparados com o material testemunho herborizado e identificados por especialistas.

\section{RESULTADOS}

Foram identificadas nas áreas de coleta 40 espécies de plantas medicinais. Além da descrição das propriedades fitoterápicas das plantas levantadas, foram descritos os tipos polínicos, que foram o foco principal da presente obra sendo considerado um aporte para as informações do conhecimento sistemático das plantas medicinais. A fonte de todas as fotos apresentadas são os próprios autores. Além disso, um sistema de referência para estudos eventuais no que concerne a pesquisa do pólen de plantas melíferas, medicinais e da farmacopéia da Amazônia. 


\section{Família: AMARANTHACEAE}

\section{Nome Científico: Celosia argentea L.}

Nomes Comuns: Crista de galo

Descrição Botânica: Planta anual, ereta, glabra, até 1 metro de altura; folhas sésseis, alternas pecioladas, linear lanceoladas com ápice acuminado, sem estípulas; flores pequenas, não vistosas, reunidas em inflorescências tipo espiga ou panícula terminal, vermelho roxas com brácteas e bractéolas lanceoladas, acuminadas, subiguais; sépalas lanceoladas, agudas; estames unidos na base; 4-8 sementes lenticulares, pontuadas e pretas.

Origem: Índia

Distribuição Geográfica: Propagou-se pela África e América do Sul.

Uso Medicinal: 0 chá desta flor ou de suas folhas alivia as dores de cabeça, gripe e rouquidão, cura aftas, regula os intestinos, combate a insônia, prisão de ventre. É analgésico. No uso tradicional é indicada para sangramento de nariz, diarreias, desinfectantes, inflamações, e desordens hematológicas e ginecológicas. Suas sementes para tratar doenças do ovário e útero.

Referências: Brako, L. et al. 1995, Chase, M.W. \& Reveal, J.L. 2009, Ling, K.H. et al. 2009, Nidavani, R.B. et al. 2013.

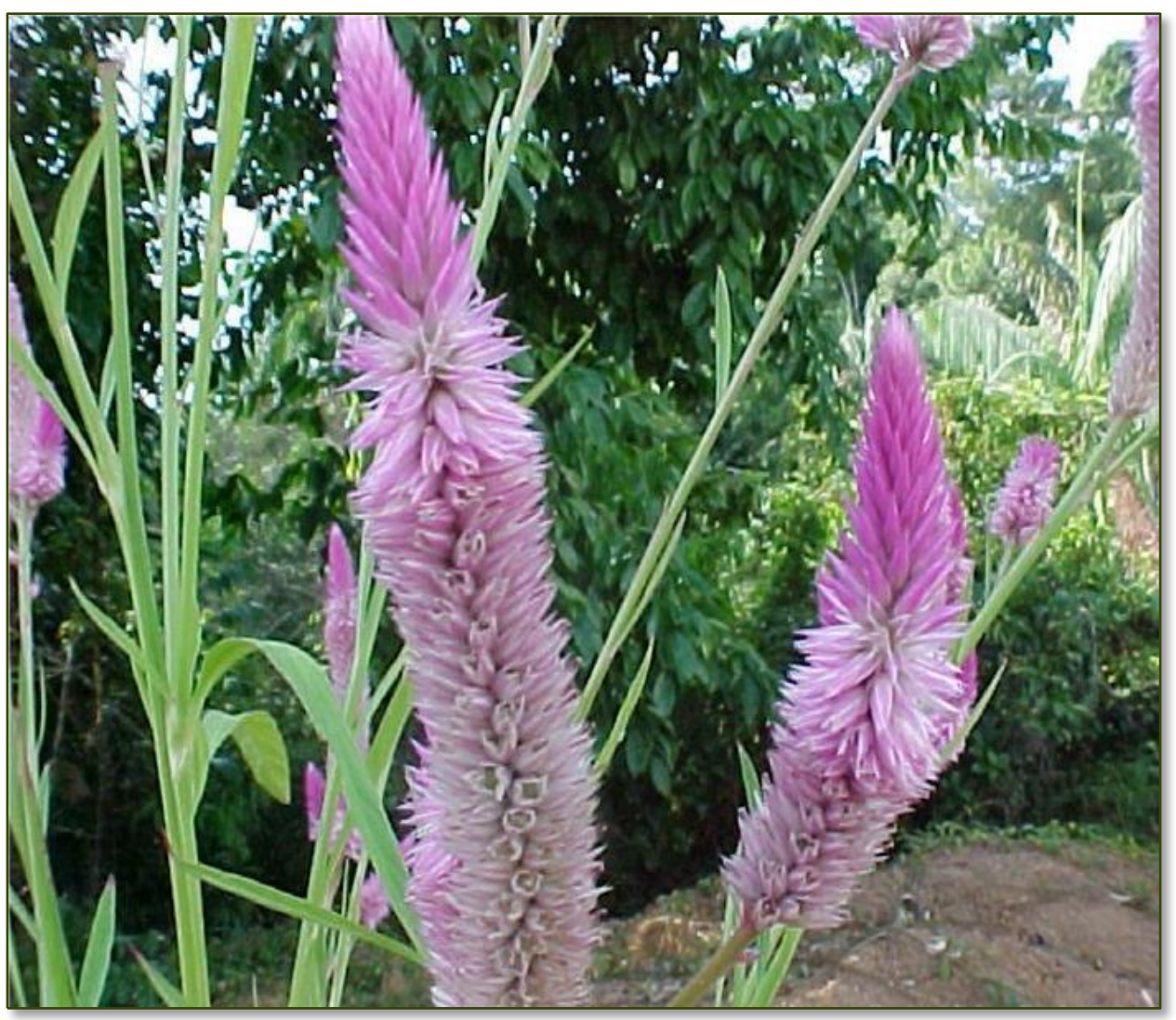

Fonte: Os autores (2015) 


\section{Descrição polínica}

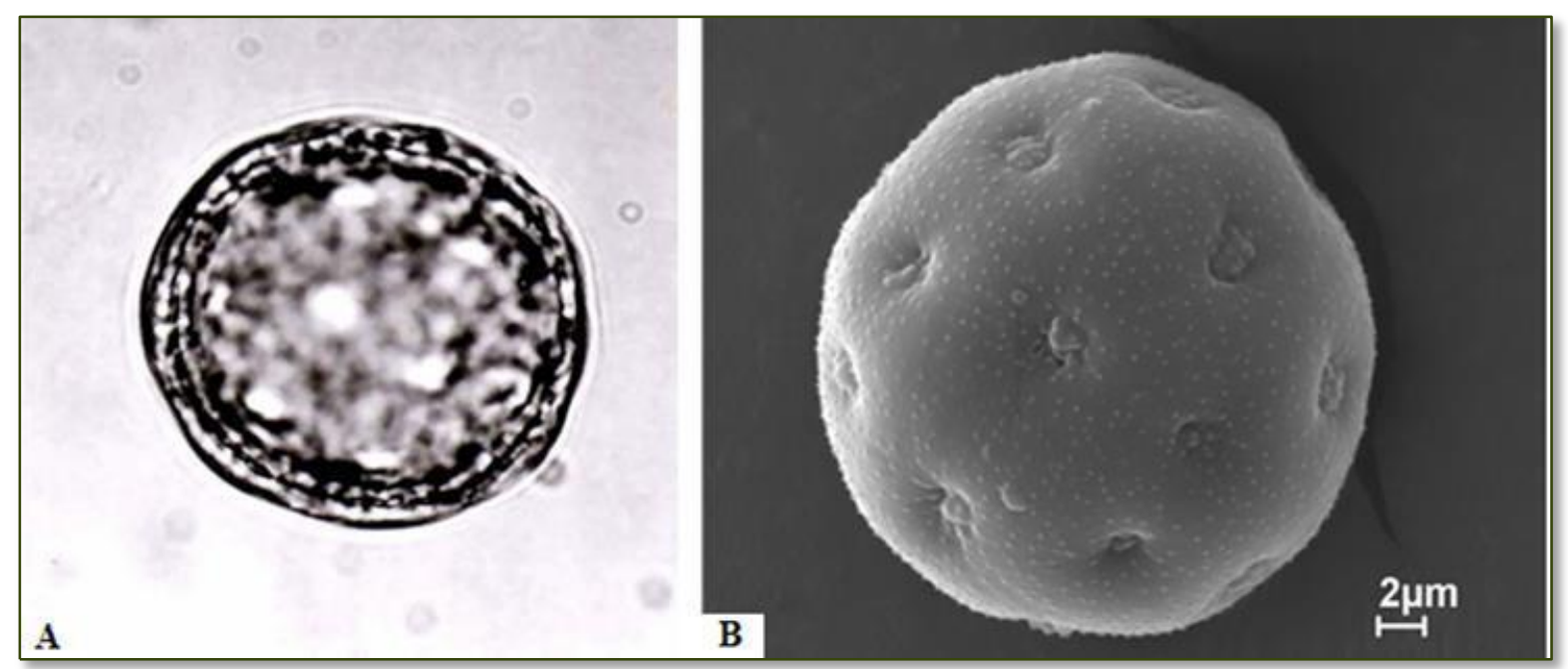

Fonte: Os autores (2015)

Forma - grãos de polén de pequenos a médio, poliedro arrendondado, de 12 a mais de 60 faces. Corte óptico superficial (A) e MEV (B).

Aberturas - grãos pantoporados com 12 poros circulares, um em cada lúmem.

Exina $- \pm 2,5 \mu \mathrm{m}$ de espessura, espessa em toda superfície do grão.

Sexina - reticulada com malhas pentagonais ou hexagonais. Muro tegilado com espículos.

Medidas - (micra) diâmetro do grão $\pm 18 \mu \mathrm{m}$.

Material examinado - flores frescas coletadas em quintais de agricultores familiares. Referências - Carreira \& Barth, 2003, Erdtman, 1952, Melhem et al. 1993, SalgadoLabouriau, 1971.

Microscopia eletrônica de varredura 
Família: AMARANTHACEAE

\section{Nome Científico: Pfaffia glomerata ( Sprengel) Pedersen}

Nomes Comuns: Maranthaceae, Para-tudo, Ginseng brasileiro, batata-do-mato, corango, corrente, sempre-viva.

Descrição Botânica: Erva perene de até 2 metros de altura. Possui caule ereto, roliço, estriado, muitas vezes oco na parte superior, com nós engrossados e entrenós, com até $23 \mathrm{~cm}$ de comprimento, ramificações predominantemente dicotômicas, glabras ou pubescentes, principalmente nos ramos jovens e nós. As folhas possuem pecíolos muito curtos com até $2 \mathrm{~cm}$ de comprimento; as lâminas têm forma e tamanho variáveis de linear-oblongas até largo ovaladas, de 1 a $14 \mathrm{~cm}$ de comprimento e 0,3 a 4,5 $\mathrm{cm}$ de largura, sendo as superiores sempre menores. As inflorescências são capitulares, paleáceas, branco-amareladas; têm pedúnculos de 3 a $20 \mathrm{~cm}$ de comprimento, pubescentes, simples, dicotômicas ou tricotômicas; são cimosas, com capítulos menores de $8 \mathrm{~mm}$ de diâmetro, têm capítulos globosos, passando a espiciformes, nas flores inferiores, possuem raque lanosa. As flores são todas completas. 0 fruto é do tipo aquênio; as sementes apresentam formato cordiforme, coloração verde-clara, quando imaturas e marrom acastanhado, quando maduras, medindo $1 \mathrm{~mm}$ de diâmetro e cerca de 1,5 $\mathrm{mm}$ de comprimento; o embrião é envolvido por endosperma farináceo e abundante. Os órgãos subterrâneos são compostos por uma raiz tuberosa que apresenta na parte superior uma parte caulinar de tamanho variável, o colo, no qual ocorrem gemas endógenas e exógenas são utilizadas como material de propagação.

Origem: Originária do Brasil, também encontrada no Paraguai, Argentina, Bolívia e Colômbia.

Distribuição Geográfica: Campos rupestres, barranca de rios, especialmente nos estados de SP, PR, MT e GO.

Uso Medicinal: Tem ação antiinflamatória, cicatrizante, imuno estimulante, funcionando como tônico para o organismo em geral, auxiliar no caso de perda gradativa de memória. É eficiente contra estresse e envelhecimento. Também tem propriedades afrodisíacas, combate as afecções hepáticas, anemia, ajuda a circulação, diabete, contra febre, gripe, resfriado, bronquite, hemorróida, tumor do sarcoma e varizes, atua também na inibição de células cancerígenas.

Referências: Marques, L.C. et al. 2004, Oliveira, C.M.F. 1998, Pederson, T.M. 1967.

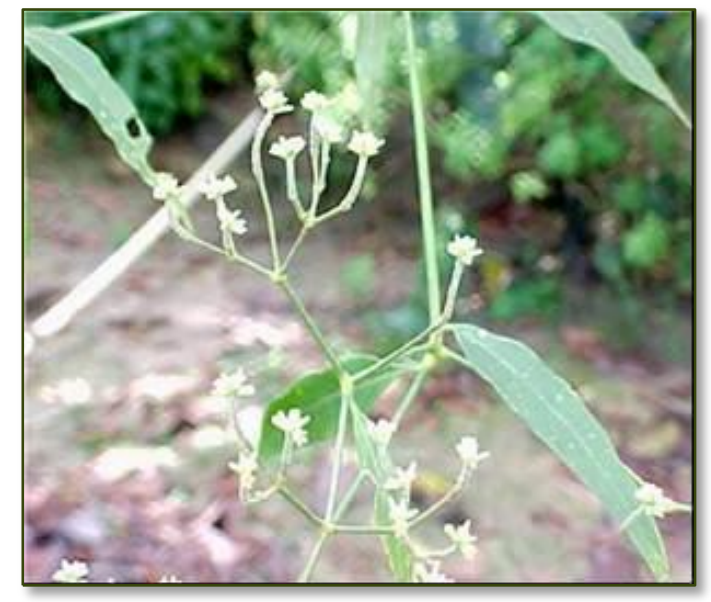

Fonte: Os autores (2015) 


\section{Descrição polínica}

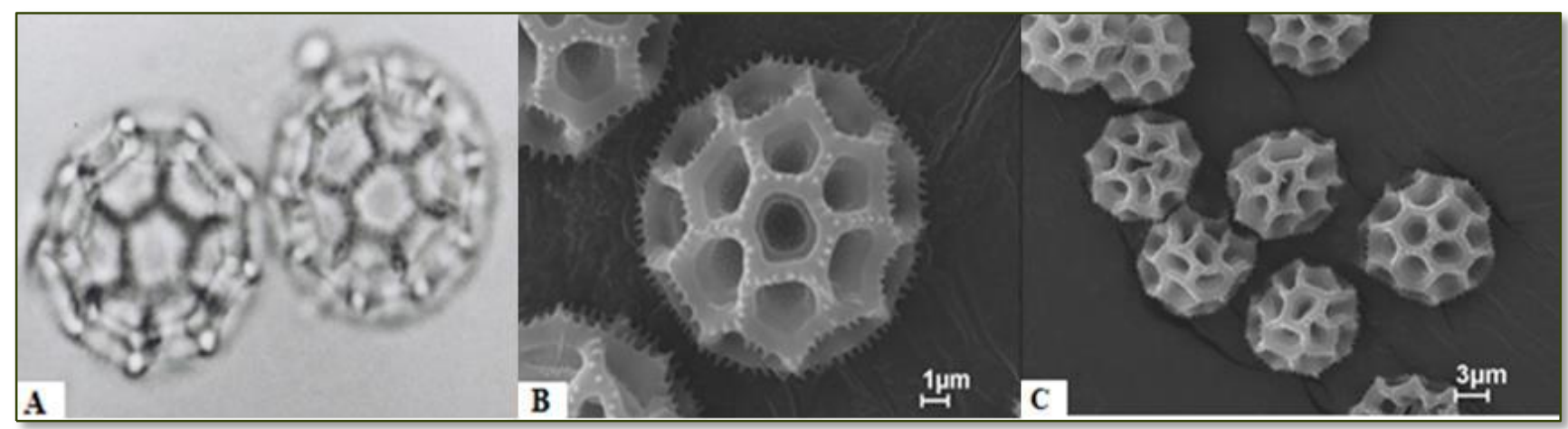

Fonte: Os autores (2015)

Forma - grãos de pólen esféricos, poliédricos, de 10 a 12 malhas visíveis numa face. Corte óptico superficial (A) e MEV (B e C).

Aberturas - grãos porados com \pm 12 poros circulares, um em cada lúmem.

Exina - $\pm 2,4 \mu \mathrm{m}$ de espessura, espessa em toda superfície do grão com malhas pentagonais e hexagonais, muros com espículos, MEV (B e C).

Sexina - reticulada com malhas pentagonais ou hexagonais. Muro tegilado com espículos.

Medidas - (micra) diâmetro do grão $\pm 16 \mu \mathrm{m}$.

Material examinado - flores frescas coletadas em quintais de agricultores familiares. Referências - Carreira \& Barth, 2003, Erdtman, 1952, Melhem et al. 1993, SalgadoLabouriau, 1971.

Microscopia eletrônica de varredura 
Família: ANACARDIACEAE

\section{Nome Científico: Anacardium occidentale L.}

Nomes Comuns: Caju, acajaíba e caju manso em Marajó.

Descrição Botânica: Árvore com ramos contorcidos e folhas alternas, pecioladas, ovadas, onduladas, reticuladas e nervadas em ambas as faces; flores pequenas e de coloração pálida, pedicelada e disposta em panículas terminais ramificadas, com um só estame fértil, ovário unilocular; fruto tipo aquênio reniforme, pendente de um receptáculo carnoso e aromático.

Origem: América Tropical

Distribuição Geográfica: Primeiramente introduzida e cultivada na África. Desde o México até Brasil e Peru.

Uso Medicinal: Adstringente, antidiabético, anti-hemorrágico, antiinflamatório, antireumático, antitérmico, contra úlceras, cáustico, diurético, laxante, purgante, tônico, vermífugo. Utilizado para: afta, asma, avitaminose c, calo, cárie, catarro, congestão, constipação, debilidade, dermatose rebelde, diabete, diarréia, disenteria, dispepsia, dor de dente, dor de estômago, escorbuto, estomatite, faculdades intelectuais, febre, ferida, feridas na boca e garganta, hemorragia, hipertensão, inchaço, inflamação, inflamação da garganta, inflamação vaginal, lepra, náusea, nematicida, queimadura, repelir insetos, resfriado, reumatismo, sarda, sífilis, tosse, tumor, úlcera, verruga. O óleo de sua casca é tóxico a muitos organismos inferiores causadores de doenças, como bactérias Staphylococcus.

Referências: Brako, L. et al. 1995, Revilla, J. 2002, Tchikaya, F.O. et al. 2011.

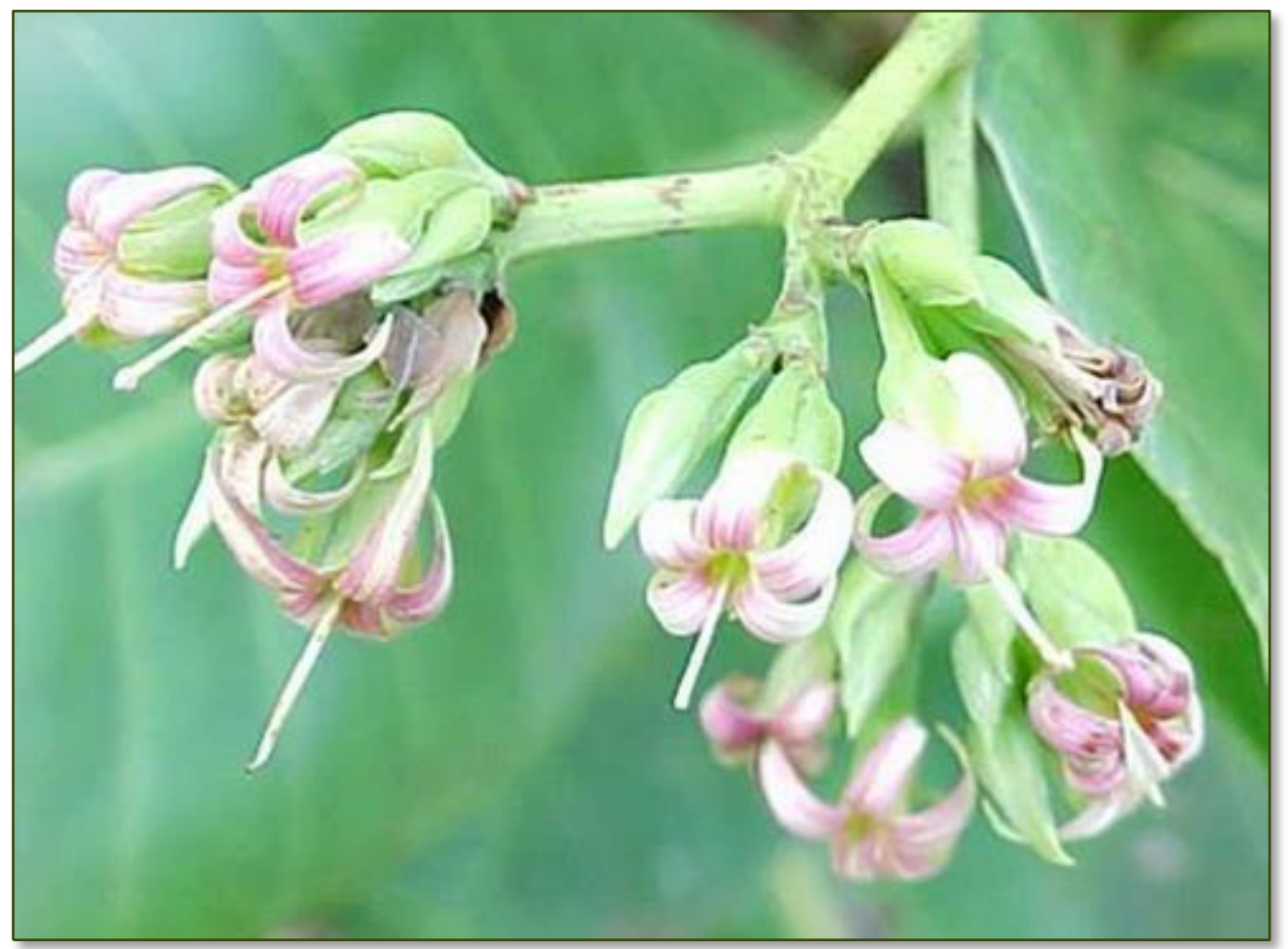

Fonte: Os autores (2015) 


\section{Descrição polínica}

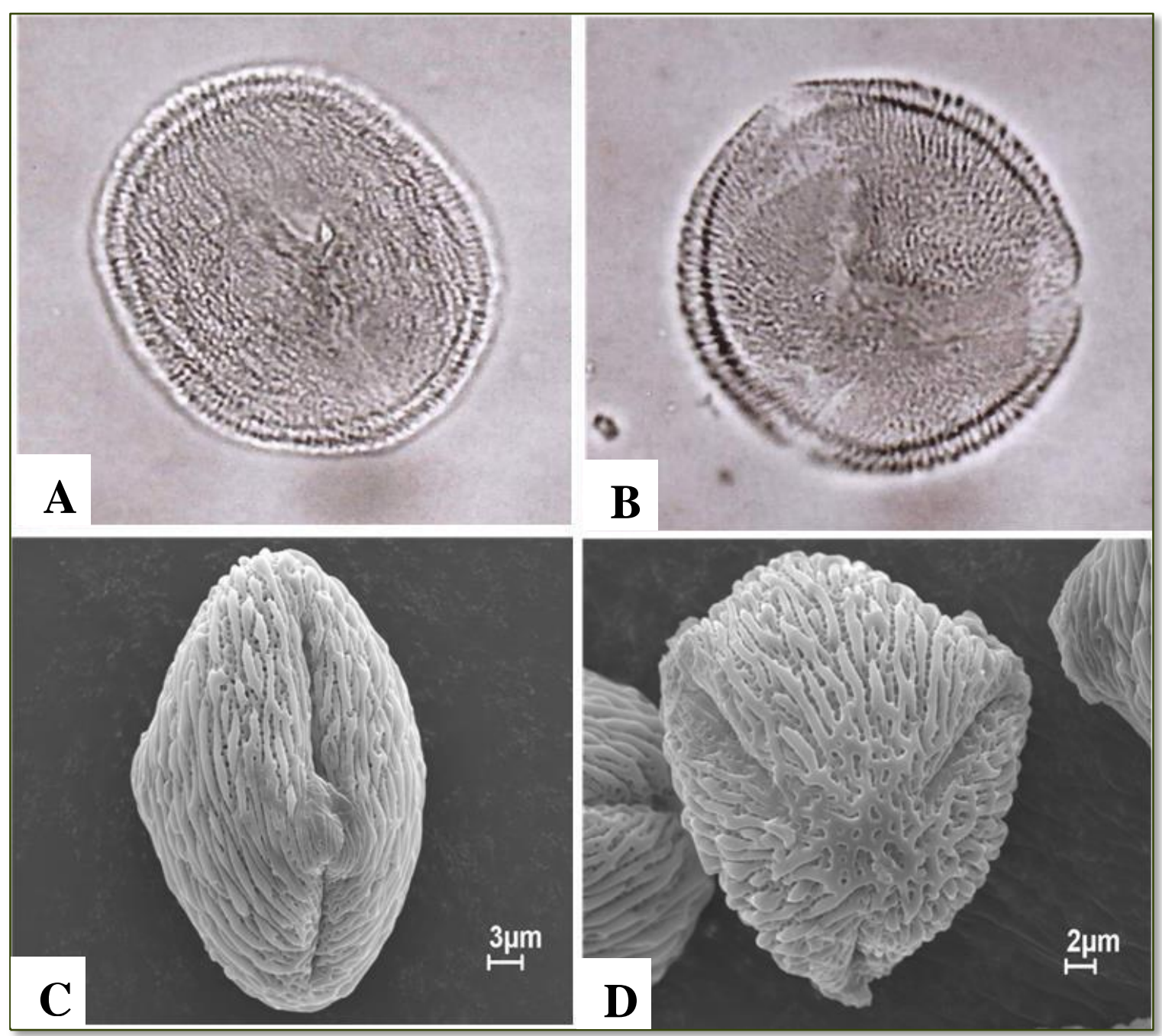

Fonte: Os autores (2015)

Forma - grãos de pólen médio subtriangular, prolato esferoidal, circular à triangular de lados bem convexos (MF (B) e (MEV (D)

Aberturas - grãos 3 - colporados, endoabertura lalongada, colpo bem evidente em vista polar e equatorial.

Exina - $\pm 2,5 \mu \mathrm{m}$ de espessura, espessa em toda superfície do grão com aspecto de reticulado, estriado ou pilado.

Sexina - estriada à reticulada com estrias paralelas ao colpos. Corte óptico apresentando báculos na superfície da exina (MF B).

Medidas - (micra) 27-32 $\mu \mathrm{m}$ em vista polar (P) e 25-28 $\mu \mathrm{m}$ em vista equatorial (E).

Material examinado - flores frescas coletadas em quintais de agricultores familiares. Referências - Carreira \& Barth, 2003, Erdtman, 1952, Melhem et al. 1993, SalgadoLabouriau, 1971.

Microscopia fotônica

Microscopia eletrônica de varredura 
Família: APIACEAE

Nome Científico: Eryngium foetidum L.

Nomes Comuns: Chicória

Descrição Botânica: Planta herbácea, ereta, com odor forte, glabra de até $40 \mathrm{~cm}$ de altura, apresenta uma roseta basal de folhas, estreitamente obovadas, obtusas, trilobadas ou dentadas e com espinhos. Flores pequenas, distribuídas em capítulos de cor esverdeada, rodeadas por brácteas espinhosas.

Origem: América Tropical

\section{Distribuição Geográfica: Região Amazônica}

Uso Medicinal: 0 chá das folhas serve para diarréia, febre e gripe. 0 chá da planta é utilizado no combate a bronquite e é sudorífico. A salada das folhas auxilia no tratamento da hepatite. Combate dores estomacais e insônia.

Referências: García, M.D. et al. 1999, Ramcharan, C. 1999, Revilla, J. 2002.

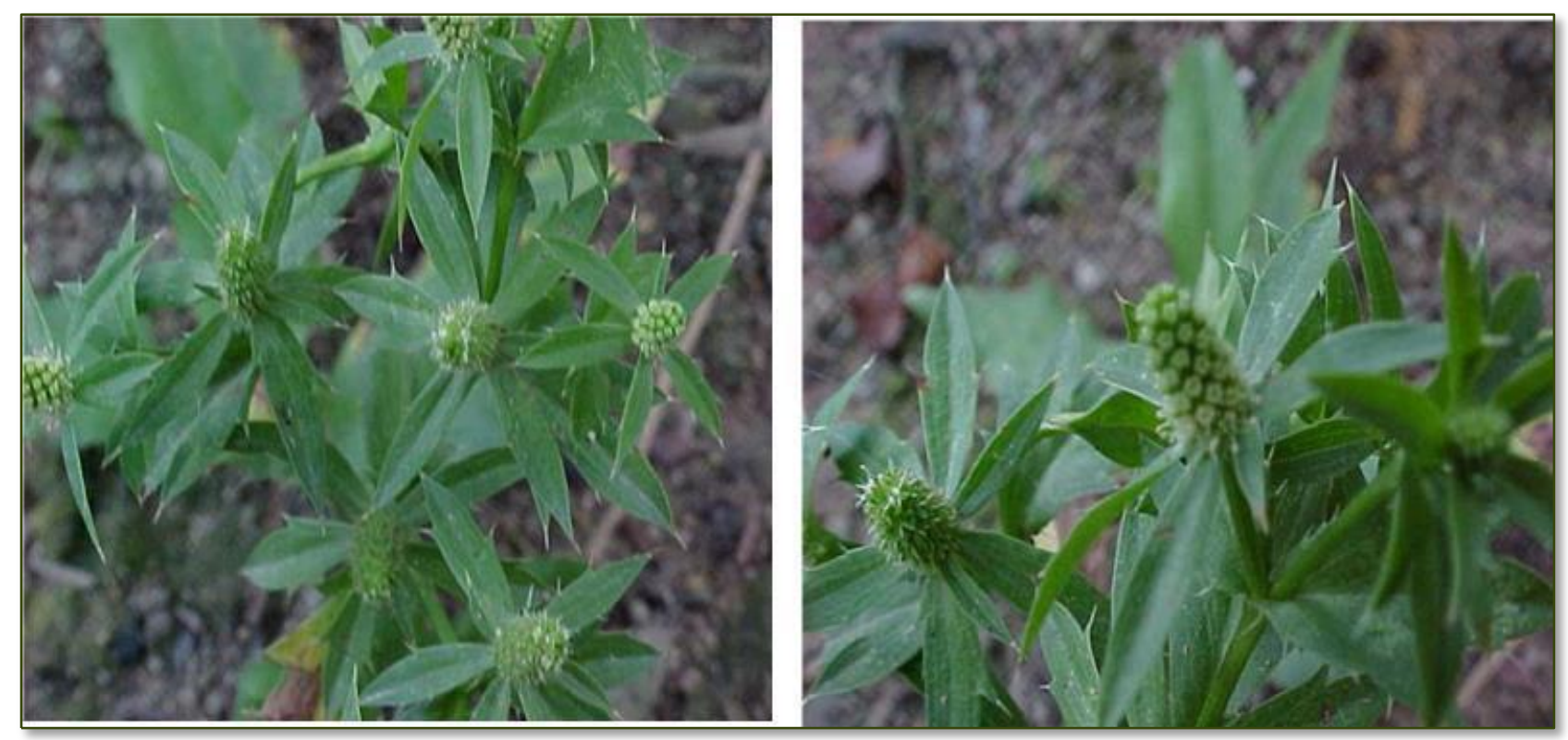

Fonte: Os autores (2015) 


\section{Descrição polínica}

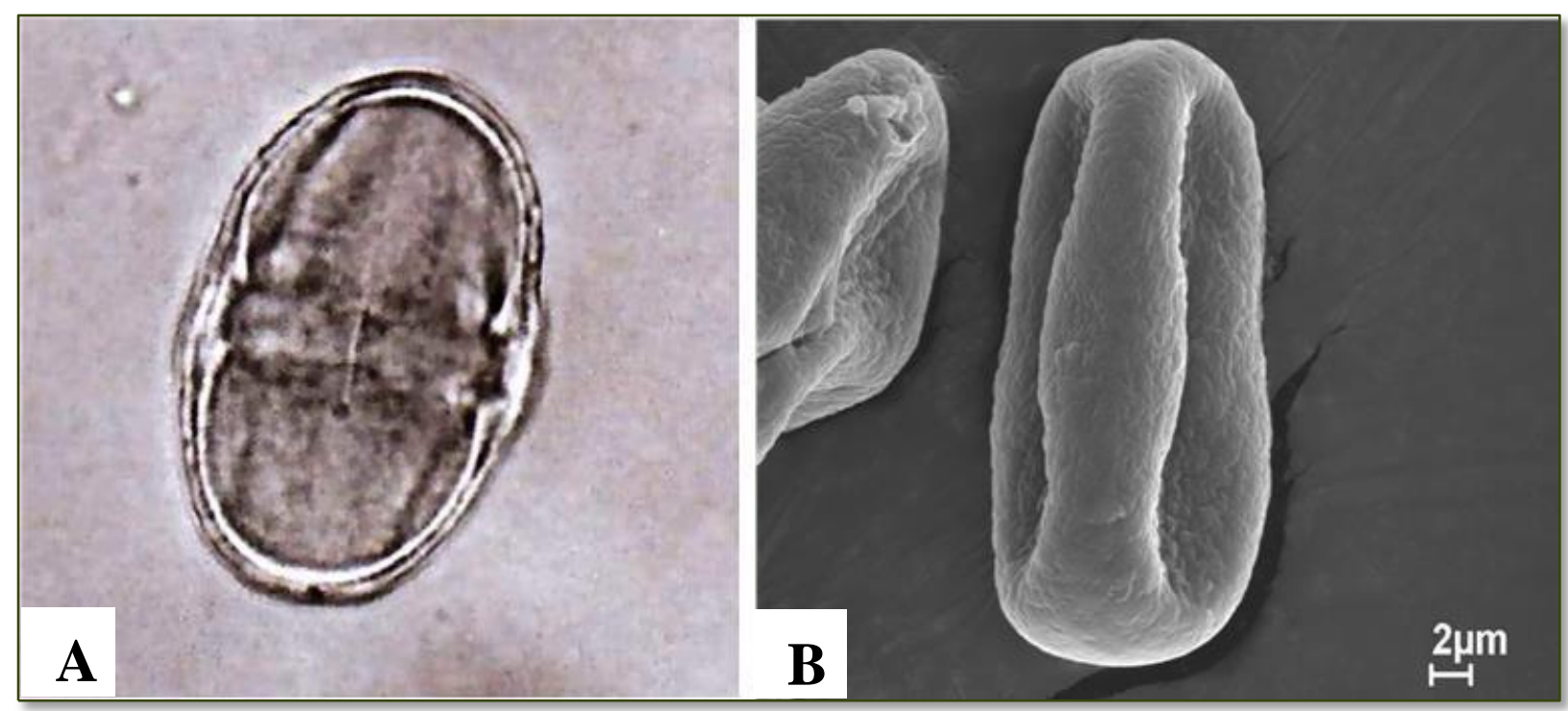

Fonte: Os autores (2015)

Forma - grãos de pólen médio, subretangular ou subelíptico, prolato a perprolato, tricolporado, fortemente contrito na região equatorial.

Aberturas - grãos 3-colporados, colpos longos e finos, endoabertura lalongada, membrana ornamentada, espessamentos internos ao redor dos poros visualizados em MF (A). Os poros podem ser circular, elíptico ou retangular perpendicular ao eixo polar do grão. Exina - $\pm 1,0 \mu \mathrm{m}$ de espessura, em toda superfície do grão aspecto reticulado a rugulado irregular, formando estrias na região equatorial.

Medidas - (micra) 13-20 $\mu \mathrm{m}$ em vista equatorial (E). Não foi possível visualizar a vista polar no material analisado.

Material examinado - flores frescas coletadas em quintais de agricultores familiares.

Referências - Erdtman, 1952, Loporchio et al. 2008, Melhem et al. 1993, Radaeski et al. 2011.

Microscopia fotônica 
Família: ASTERACEAE

\section{Nome Científico: Bidens bipinnata L.}

Nomes Comuns: Picão Preto, Beijo de moça, Carrapicho agulha.

Descrição Botânica: Planta de pequeno porte, até 1 metro de altura, ereta, anual, ramosa, glabra; folhas opostas, simples, pecioladas e fendidas; flores amarelas reunidas em inflorescências tipo capítulo; capítulos pleiomorfos com flores radiais liguladas, pentâmeras com cálice modificado formando o papilho que é transformado em arestas. Fruto linear do tipo aquênio.

\section{Origem: América do Sul}

\section{Distribuição Geográfica: Regiões Tropicais do mundo}

Uso Medicinal: Aconselhado para a cura da icterícia. Tem ação acentuada sobre o fígado e a bexiga, beneficiando a função hepática e restabelecendo a diurese normal. Aconselhado nas doenças das vias urinárias. Empregado também contra as dores do estômago e do intestino provocadas por flatulências, na gripe e nas febres em geral. 0 chá das folhas é útil na leucorréia, na diabete e nas inflamações da garganta. A raiz é um bom tônico expectorante. Auxiliar no tratamento do sistema nervoso, também benéfico em sacos de deficiência na menstruação.No Brasil em estudos da medicina tradicional indígena é citado como uma erva medicinal anticancer e com ação de inibir bactérias ( substâncias antibacterial).

Referências: Brako, L. et al. 1995, Di Stasi, L.C. \& Hiruma-Lima, C.A. 2002, Geissberg, P. \& Séquin, U. 1991, Kviecinski, M.R. et. al. 2008.

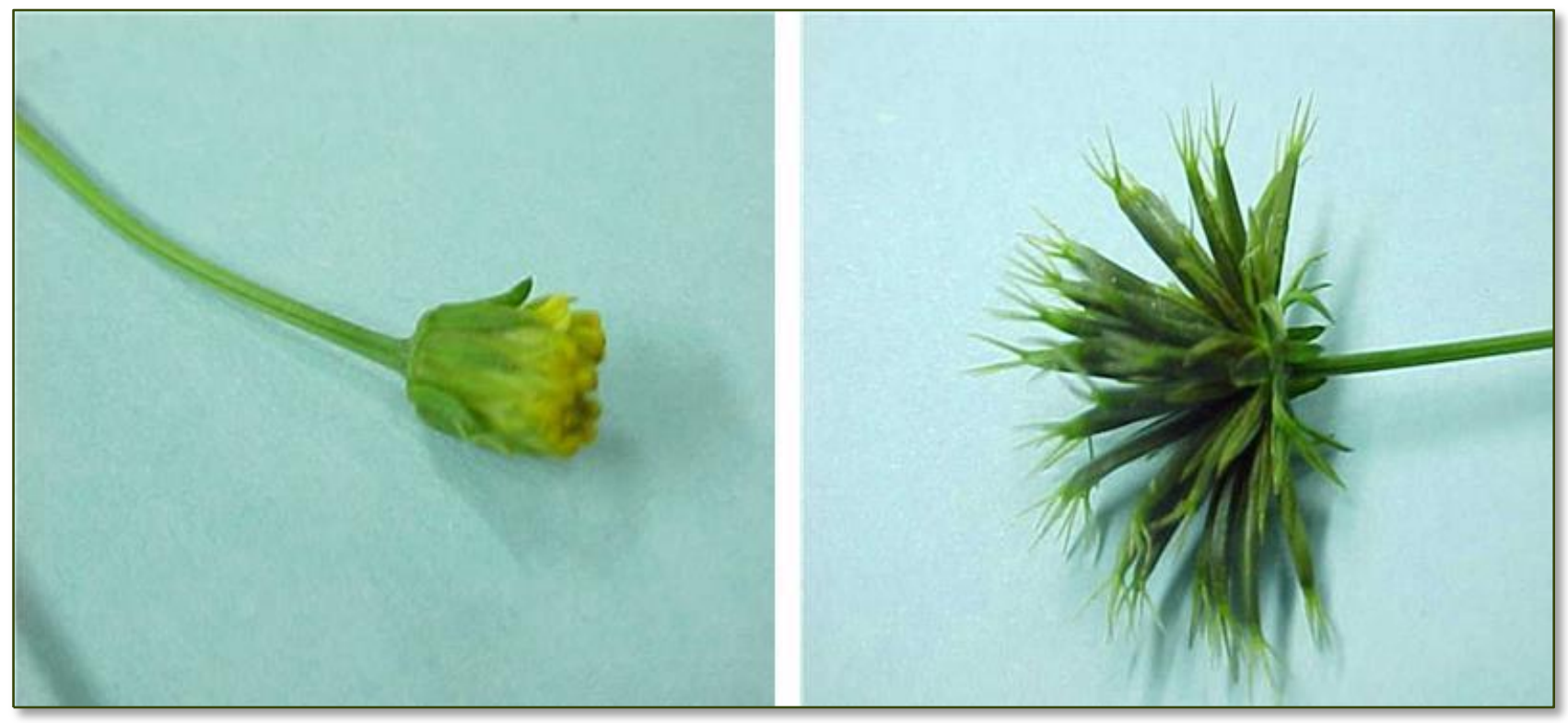

Fonte: Os autores (2015) 


\section{Descrição polínica}

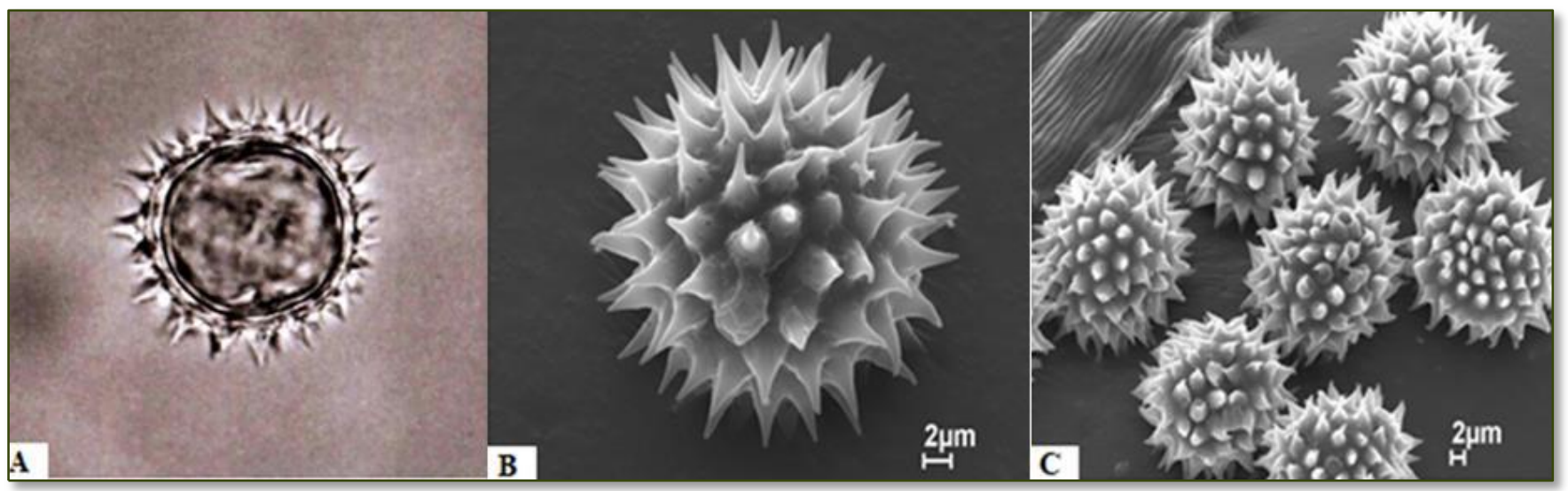

Fonte: Os autores (2015)

Forma - grãos de pólen médios, esféricos, âmbito circular a subtriangular, oblato-esferoidal. Aberturas - colporos e colpos pouco visíveis.

Exina - \pm 2.0 a $2,7 \mu \mathrm{m}$ de espessura, exina cavada nas bases dos espinhos e perfurada com columelas, espinhos grandes amplamente distribuídos, cônicos, columelados, ápices aguçados, com aproximadamente d 16 a 18 espinhos em vista polar (MF (A) e MEV (B/C).

Medidas - (micra) 37-46 $\mu \mathrm{m}$ em vista polar (P). Não foi possível visualizar a vista equatorial no material analisado.

Material examinado - flores frescas coletadas em quintais de agricultores familiares.

Referências - Erdtman, 1952, Loporchio et al. 2008, Melhem et al. 1993, Radaeski et al. 2011.

Microscopia fotônica

Microscopia eletrônica de varredura 


\section{Família: ASTERACEAE}

\section{Nome Científico: Spilanthes oleracea Jacq.}

\section{Nomes Comuns: Jambu}

Descrição Botânica: Planta anual, herbácea, de 20 a $30 \mathrm{~cm}$ de altura, quase rasteira, caule cilíndrico, carnoso, ramificado. Folhas simples, pecioladas, opostas, ovadas, membranáceas. Raiz principal pivotante, com abundantes ramificações laterais. Inflorescência em capítulo globoso terminal. Flores pequenas, amareladas, dispostas em capítulos que medem cerca de $1 \mathrm{~cm}$ de diâmetro. 0 fruto é aquênio pequeno com pericarpo cinza-escuro, quase preto, parcialmente envolvido por partes membranáceas.

Origem: África e América do Sul

Distribuição Geográfica: Em toda a região amazônica, principalmente nos estados do Pará e Amazonas.

Uso Medicinal: 0 chá das inflorescências é utilizado como analgésico para dores de dente, e o chá da planta utiliza-se como anti-inflamatório e anti-infeccioso para o fígado.

Referências: Maiga, A. et al. 2005, Revilla, J. 2002.

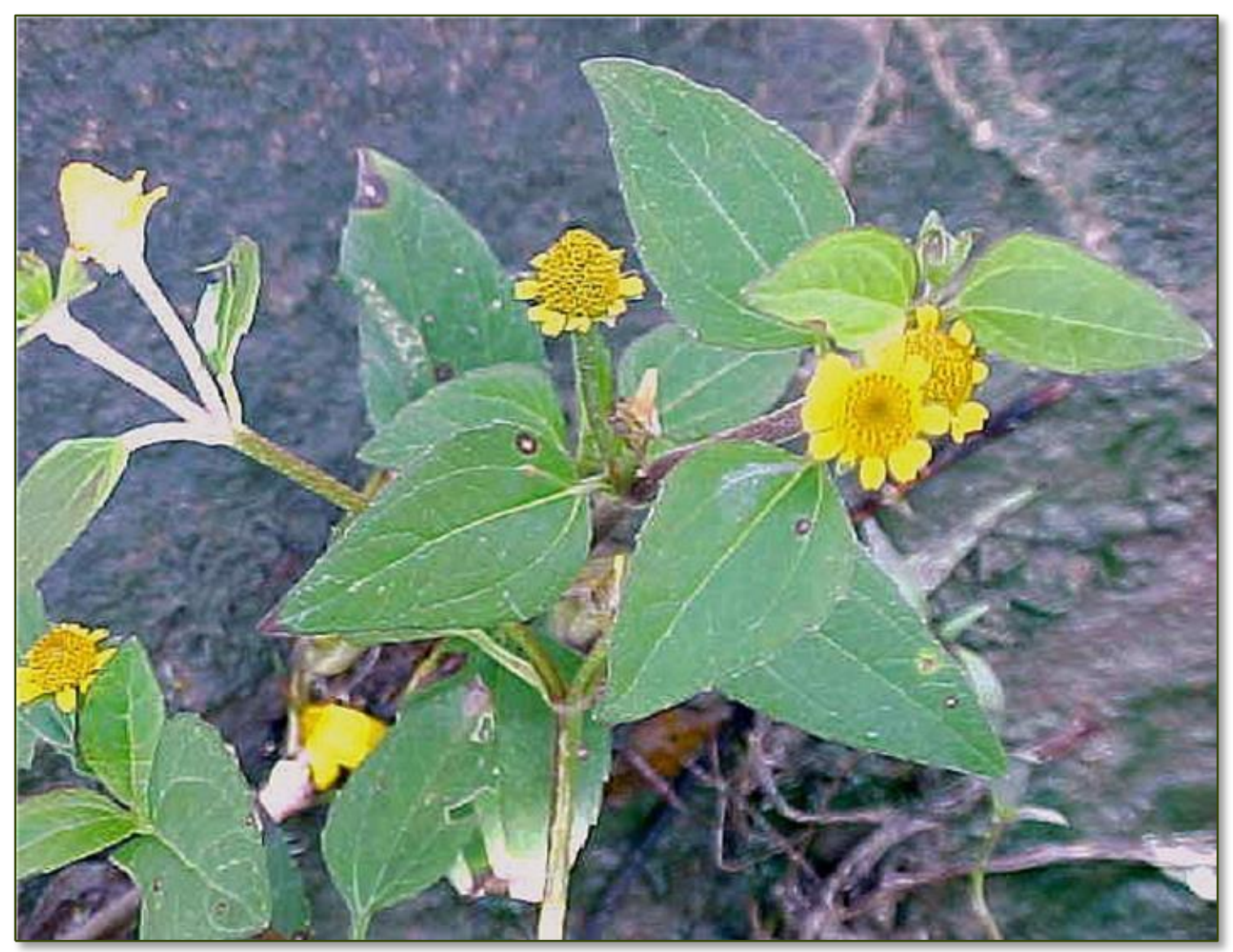

Fonte: Os autores (2015) 


\section{Descrição polínica}

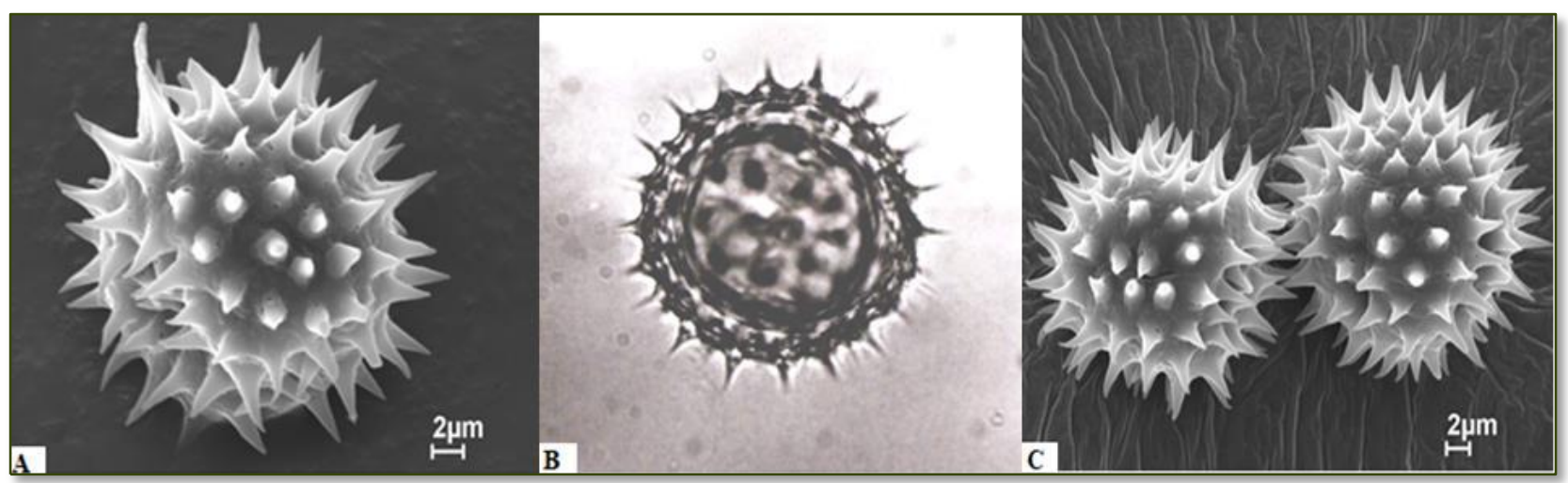

Fonte: Os autores (2015)

Forma - grãos de pólen médios, esféricos, âmbito circular a subtriangular, oblato-esfeirodal. Aberturas - colporos e colpos pouco visíveis.

Exina - \pm 2.0 a $2,7 \mu \mathrm{m}$ de espessura, exina cavada nas bases dos espinhos e perfurada com columelas, espinhos grandes amplamente distribuídos, cônicos, columelados, ápices aguçados, com aproximadamente d 16 a 18 espinhos em vista polar (MF (A) e MEV (B/C).

Medidas - (micra) 37-46 $\mu \mathrm{m}$ em vista polar (P). Não foi possível visualizar a vista equatorial no material analisado.

Material examinado - flores frescas coletadas em quintais de agricultores familiares.

Referências - Erdtman, 1952, Loporchio et al. 2008, Melhem et al. 1993, Radaeski et al. 2011.

Microscopia fotônica

Microscopia eletrônica de varredura 


\section{Família: BIGNONIACEAE}

\section{Nome Científico: Tecoma stans ( L.) Juss. Ex Kunth}

Nomes Comuns: Ipê de Jardim, sinos amarelos, guarã-guarã, amarelinho.

Descrição Botânica: Arbusto de 3 a $5 \mathrm{~m}$ de altura, com copa globosa ou piramidal e casca fissurada. Folhas pinadas com 3 a 9 folíolos opostos, de margem serrada, lanceoladas, cortante, pecioladas, acuminadas. Inflorescências axilares ou terminal pedicelos curtos, irregulares curtos, irregularmente curva ou torcida, brácteas reduzidas, cálice estreito glabro, corola amarelo brilhante, pouco campanulada, tubo estreito, ovário estreito cilíndrico, estilo glabro, estigma plano elíptico, cápsula linear com 10-20 cm de comprimento, 7-8 mm de largura, marrom quando maduro, tardiamente deiscente, sementes chatas, oblongas e com uma asa membranosa.

Origem: Arizona e Texas

Distribuição Geográfica: América Central, até norte da Argentina.

Uso Medicinal: É antissifilítico, diurético, tônico e vermífugo, antidiabético, anticâncer, antioxidante, antispasmódico e antifúngico.

Referências: Divya Sri, G. et al. 2014, Raju, S. et al. 2011, Revilla, J. 2002.

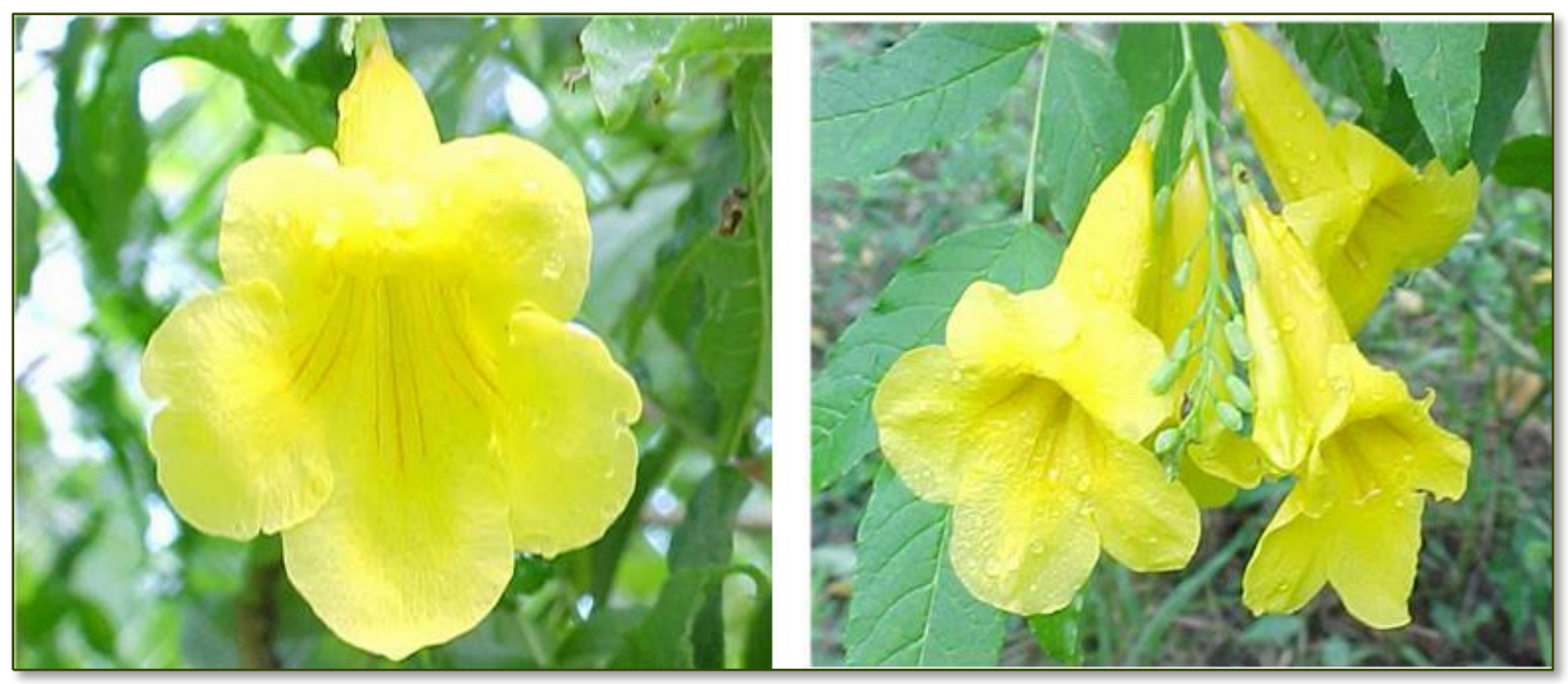

Fonte: Os autores (2015) 


\section{Descrição polínica}

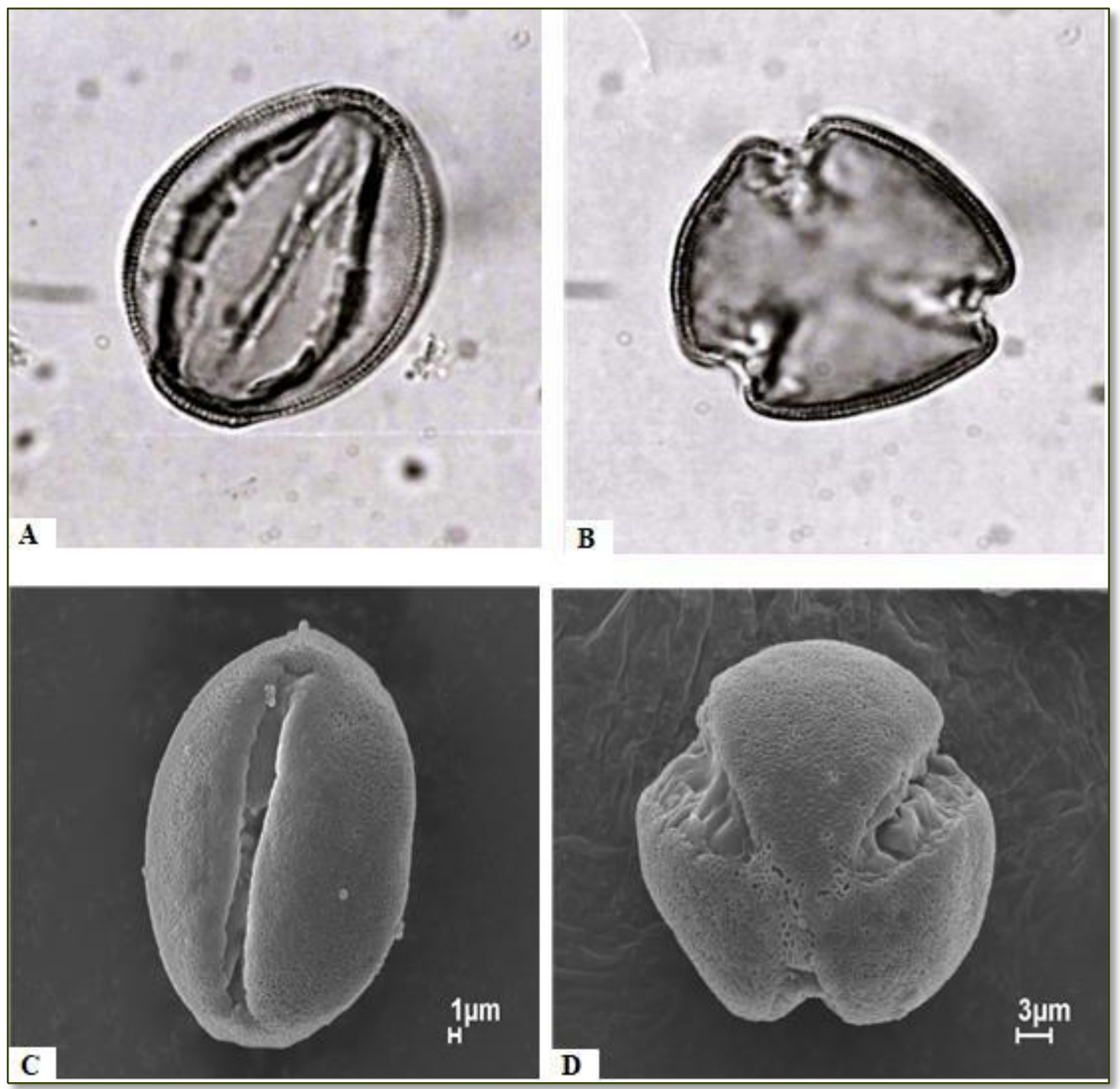

Fonte: Os autores (2015)

Forma - grãos de pólen grandes, isopolares, simetria radial oblatas-esfeirodal, superfície reticulada.

Aberturas - 3-colpados, colpo constrito (MF (A/B) e MEV ( C/D )

Exina - $\pm 0,7$ a $1,0 \mu \mathrm{m}$ de espessura, geralmente muito frágil, reticulada.

Medidas - (micra) 43-73 $\mu \mathrm{m}$ em vista polar (P) e 29-73 $\mu \mathrm{m}$ em vista equatorial (E).

Material examinado - flores frescas coletadas em quintais de agricultores familiares.

Referências - Carreira \& Barth, 2003, Erdtman, 1952, Loporchio et al. 2008, Melhem et al. 1993, Radaeski et al. 2011.

Microscopia fotônica

Microscopia eletrônica de varredura 
Família: BIXACEAE

\section{Nome Científico: Bixa orellana L.}

Nomes Comuns: Urucum, urucu, urucu-bravo açafroa, açafrão bastardo.

Descrição Botânica: Árvore pequena ou arbusto com folhagem densa, com uma altura de 3 a $5 \mathrm{~m}$ de altura, podendo chegar até $10 \mathrm{~m}$, tronco curto de 20 a $30 \mathrm{~cm}$ de diâmetro, casca cinza escuro com lenticelas em filas verticais. Folhas alternadas, pontiagudas de 10 a $20 \mathrm{~cm}$ de comprimento e 5 a $10 \mathrm{~cm}$ de largura, de cor verde em ambas as faces, pecíolo alargado, estipulas decíduas. Inflorescência em panícula terminal. Flores com pétalas rosadas ou brancas, hermafroditas, cálice com 5 sépalas, pétalas em número de 5 largas e arredondadas, estames numerosos, brancos ou amarelados. Fruto em forma de cápsula deiscente, bivalvar, coberta externamente com abundantes apêndices flexíveis de cor roxo, verde escuro ou pardo. Sementes poliédricas de até $6 \mathrm{~mm}$ de comprimento, geralmente piramidais, cobertas por uma membrana (arilo) polposa do roxo a alaranjada.

\section{Origem: Brasil}

Distribuição Geográfica: Ocorre das Guianas até o Sergipe; muito frequente no Amazonas.

Uso Medicinal: 0 fruto e a infusão do fruto e sementes, são antídotos contra o ácido cianídrico e o cianureto. 0 líquido das folhas moídas é antiemético (vômitos de sangue), antidiarréico, hemostático. Contra hemorróidas, anginas, abcessos. A infusão das folhas e sementes combate os males da garganta e afecções respiratórias (tosse, bronquite). A maceração aquosa das folhas é utilizada para inflamações dérmicas, vaginais, cicatrizante, hipertensão, conjuntivite. Febre e vômitos (a infusão das folhas). A maceração aquosa das sementes é tônico estomacal. A infusão das sementes é expectorante. A infusão das sementes e das folhas é cardiotônico. 0 chá das sementes e das folhas combate amigadalite.

Referências: Brako, L. et al. 1995, Ling, K.H. et al. 2009, Revilla, J. 2002, Vilar, D.A. et al. 2014.

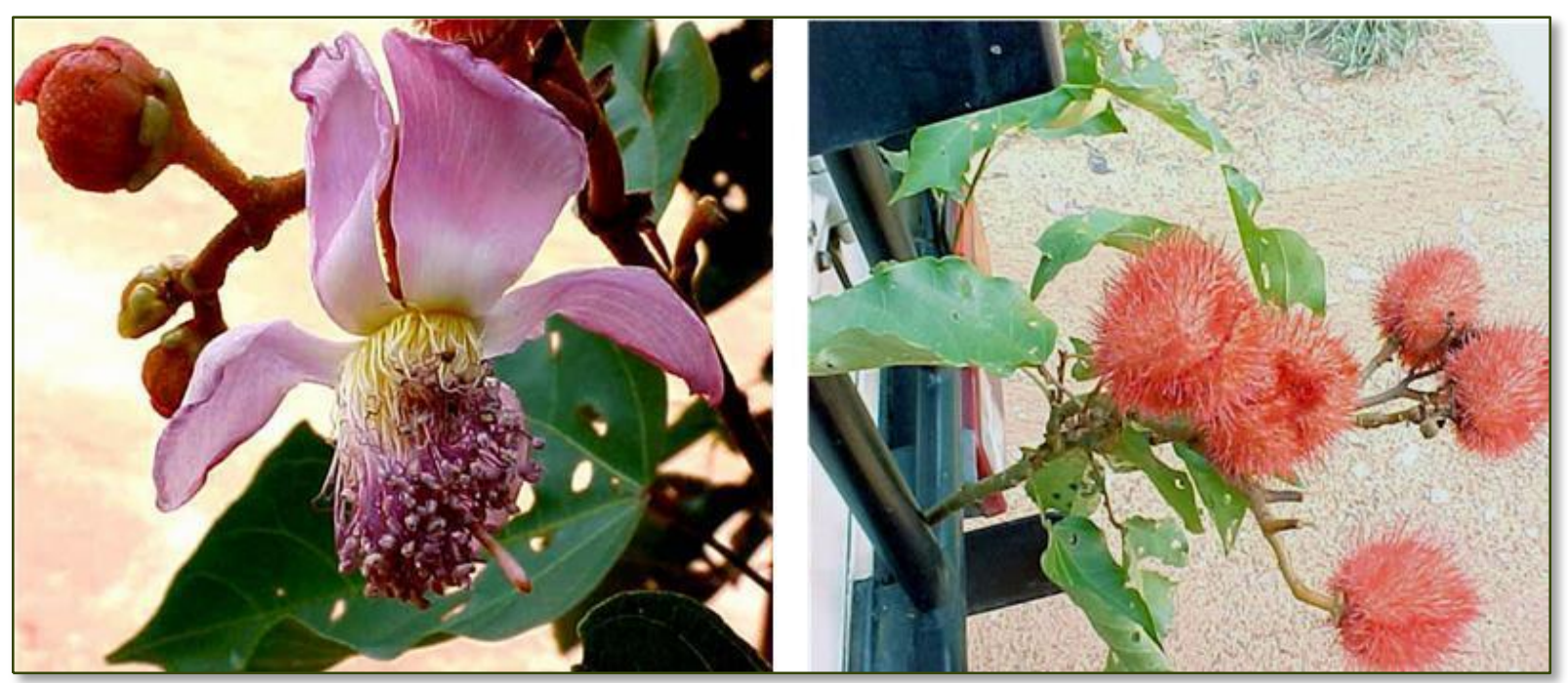

Fonte: Os autores (2015) 


\section{Descrição polínica}

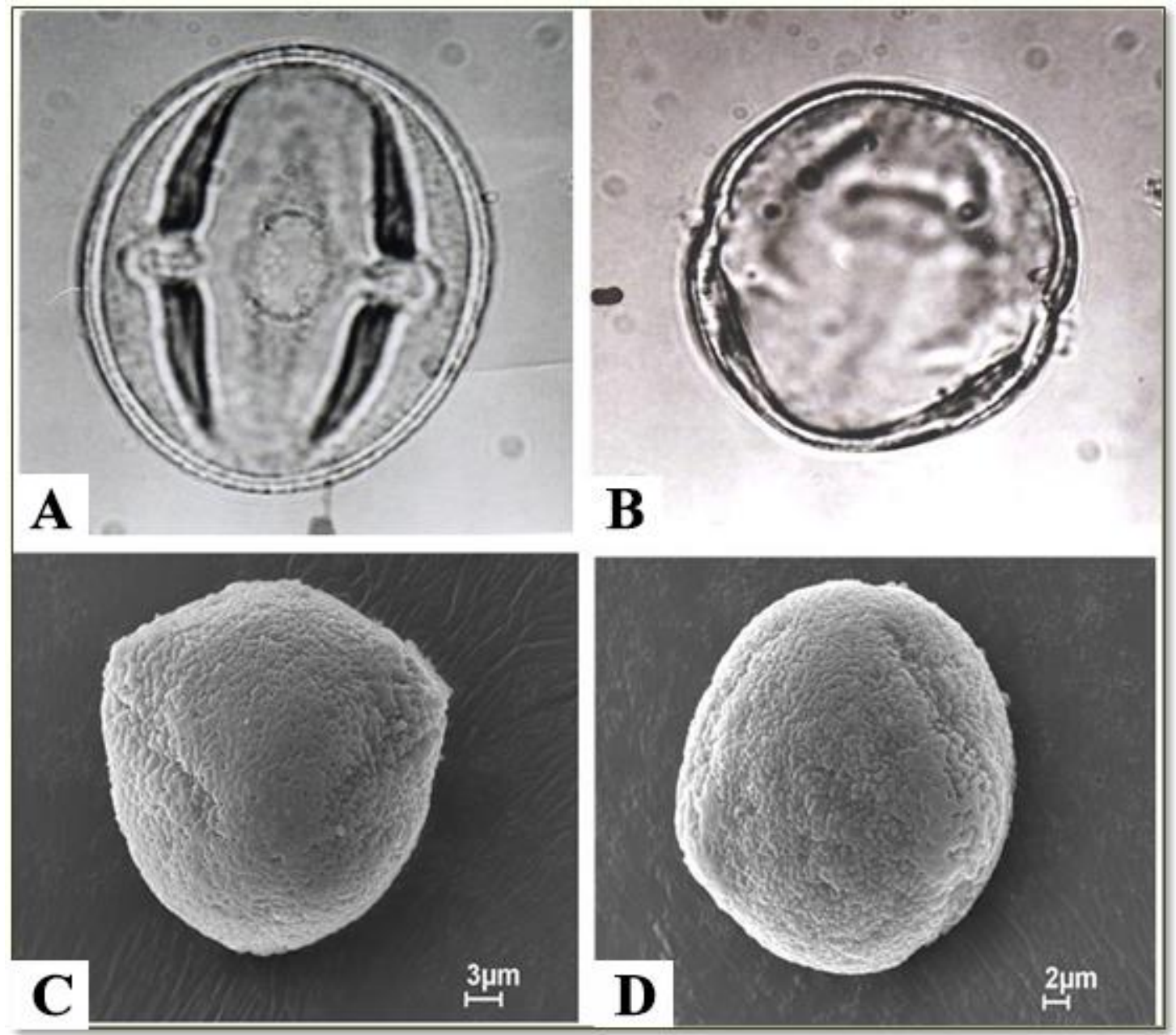

Fonte: Os autores (2015)

Forma - grãos de pólen pequenos a médios, suboblatos-esfeirodal, isopolares.

Aberturas - 3-colporados (MF ( A).

Exina - reticulada a rugulada.

Medidas - (micra) 28-34 $\mu \mathrm{m}$ em vista polar (P) e 30-35 $\mu \mathrm{m}$ em vista equatorial (E).

Material examinado - flores frescas coletadas em quintais de agricultores familiares.

Referências - Carreira \& Barth, 2003, Erdtman, 1952, Loporchio et al. 2008, Melhem et al. 1993, Radaeski et al. 2011.

Microscopia fotônica 


\section{Família: CARICACEAE}

\section{Nome Científico: Carica papaya L.}

\section{Nomes Comuns: Mamão}

Descrição Botânica: Árvore pequena e mediana que atinge até mais ou menos 7 metros de altura, dióica, de folhas grandes, dígito-lobadas, longamente pecíoladas; flores em compridos pedúnculos também chamados de corda e de cuja extremidade pendem os frutos na forma de baga, ocos, de polpa doce e tendo sementes pretas.

Origem: Originária da América Tropical

Distribuição Geográfica: Cultiva-se no Ceilão, Tanzânia, Hawaí, Flórida e Brasil.

Uso Medicinal: Cardiocinética, diurética, peitoral, sedativa, vermífuga, emoliente, desobstruente do fígado, digestiva, laxativa, antitussígenos, dispepsia, bronquite crônica, asma, resfriado, afecções das vias respiratórias, catarro crônico, fraqueza, anemia, clorose, fermento digestivo, cólica das crianças, diarreia com vermes, sarda, destruidora de calos, verrugas, impingem; pode ser usada sobre as placas diftéricas para dissolvê-las e na coalescência; rubefaciente, calmante. Suas folhas podem ser utilizadas cozidas tendo efeito contra a febre da dengue, inibição do crescimento de células cancerígenas, ação antimalárica e antiplasmódica e facilita a digestão.

Referências: Aravind, G. et al. 2013, Brako, L. et al. 1995, Ling, K.H. et al. 2009, Revilla, J. 2002.

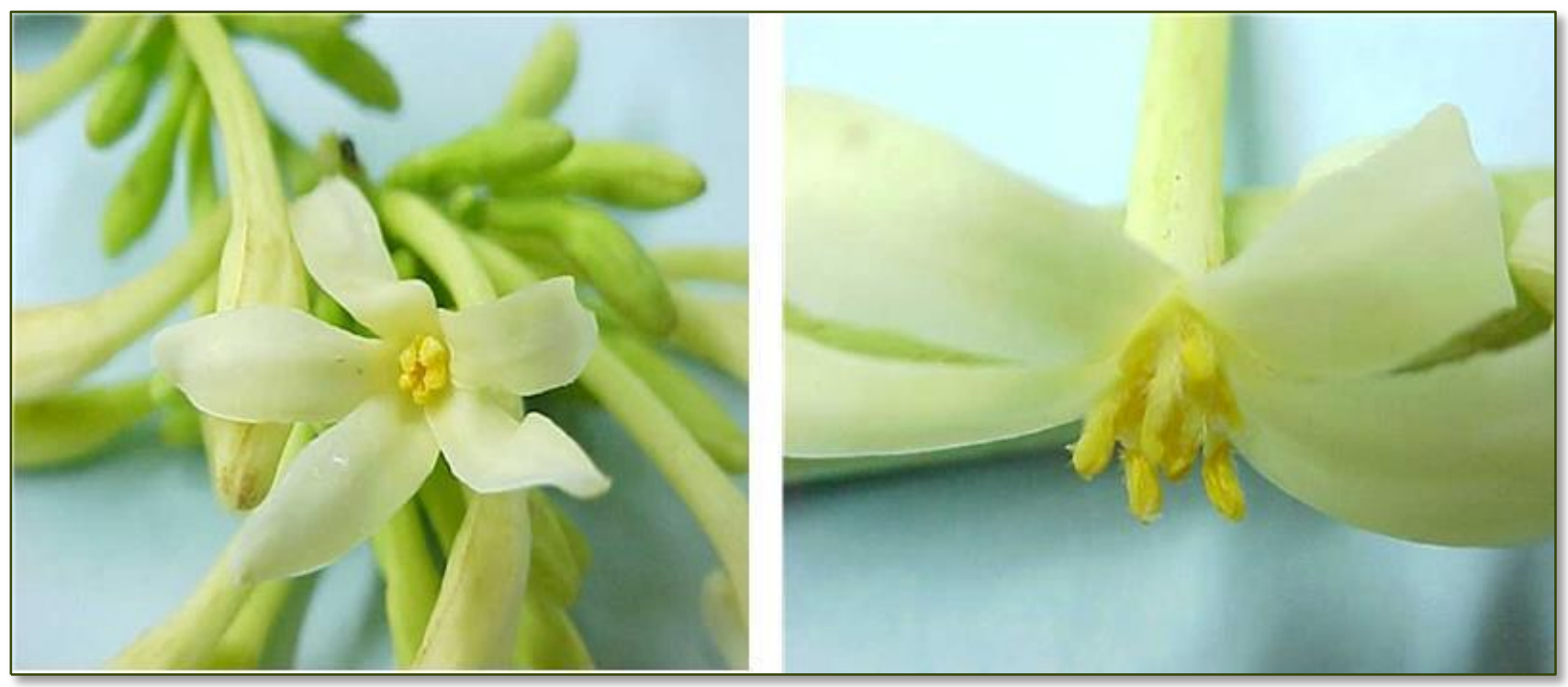

Fonte: Os autores (2015) 


\section{Descrição polínica}

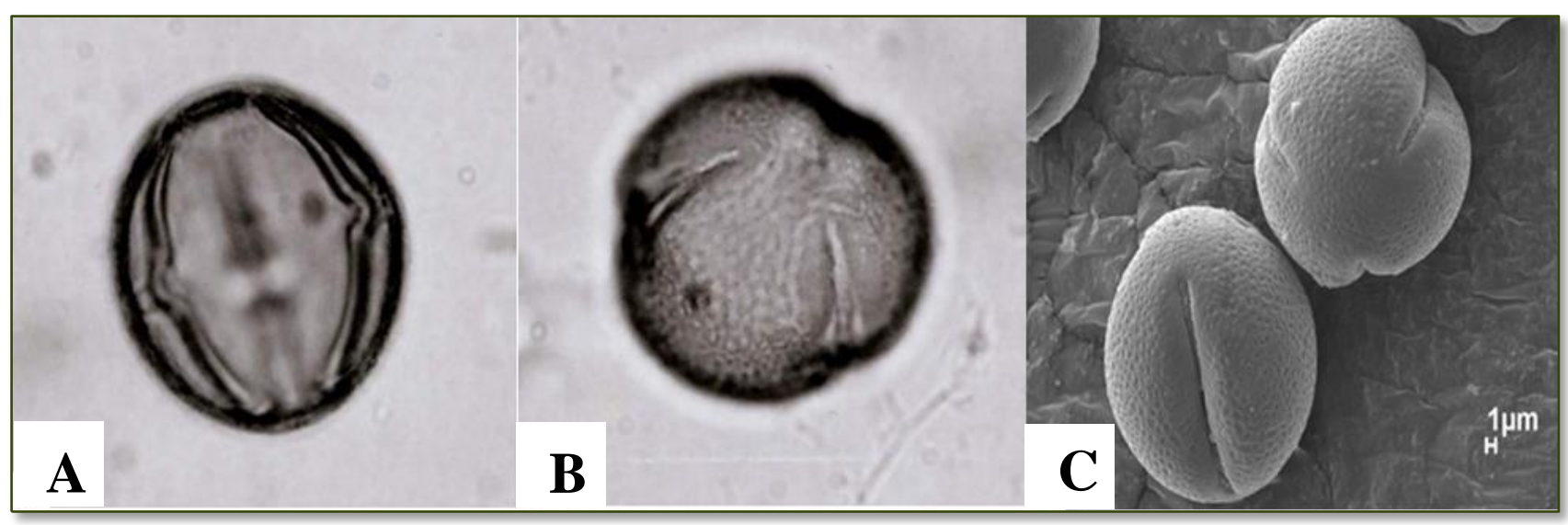

Fonte: Os autores (2015)

Forma - grãos de pólen médios, prolato-esfeirodal, isopolar, âmbito subcircular.

Aberturas - tricolporados, colpo longo, endoabertura lalongada.

Exina - microreticulada (MF (B) e MEV (C).

Medidas - (micra) 33-52 $\mu \mathrm{m}$ em vista polar (P) e 16-50 $\mu \mathrm{m}$ em vista equatorial (E).

Material examinado - flores frescas coletadas em quintais de agricultores familiares.

Referências - Carreira \& Barth, 2003, Erdtman, 1952, Loporchio et al. 2008, Melhem et al. 1993, Radaeski et al. 2011, Sierra et al. 2006.

\section{Microscopia fotônica}

Microscopia eletrônica de varredura 


\section{Família: CLUSIACEAE}

\section{Nome Científico: Vismia guianensis ( Aubl.) Pers.}

Nomes Comuns: Lacre vermelho, árvore-da-febre, goma-lacre, pau-de-lacre, lacre-branco.

Descrição Botânica: Árvores ou arbustos, ramos mais ou menos espalhando, com tricomas simples dentro das pétalas menores, estreladas nas gemas vegetativas, glândulas escuras, âmbar ou avermelhada e amarelo quando em exposição o látex escurece tornando-se laranjaavermelhado. Caule com entrenós podendo está disposto irregularmente em ângulo. Folhas opostas, pecioladas, flores mais ou menos numerosas, inflorescências terminais em forma de panículas apresentando homostilia ou heterostilia, 5 sépalas, 5 pétalas, branca indo para o amarelo ou verde, internamente esbranquiçada. 5 estame, apetalos; filamentos delgados, unidos até a metade; anteras pequenas. Ovário com 5 loculos, placentação axial, geralmente muitos óvulos por carpelos; 5 estiletes, espalhando a ascendente; estigmas amplamente capitato. 0 fruto é uma baga, sementes com pequenos cotilédones.

Origem: Sul do México

Distribuição Geográfica: Espalhou-se por toda a América Central

Uso Medicinal: Reumatismo, dermatose, impinges (Tinea corporea), ferimento por inseto, contra pano branco (Ptiriase versicolor) , tônico do sangue para criança quando associada a outra espécie a Canthium glabriflorum.

Referências: Di Stasi, L.C \& Hiruma-Lima, C.A. 2002, Revilla, J. 2002, Ribeiro, J.E.L.S. et al. 1999, Seo, E.K. et al. 2000.

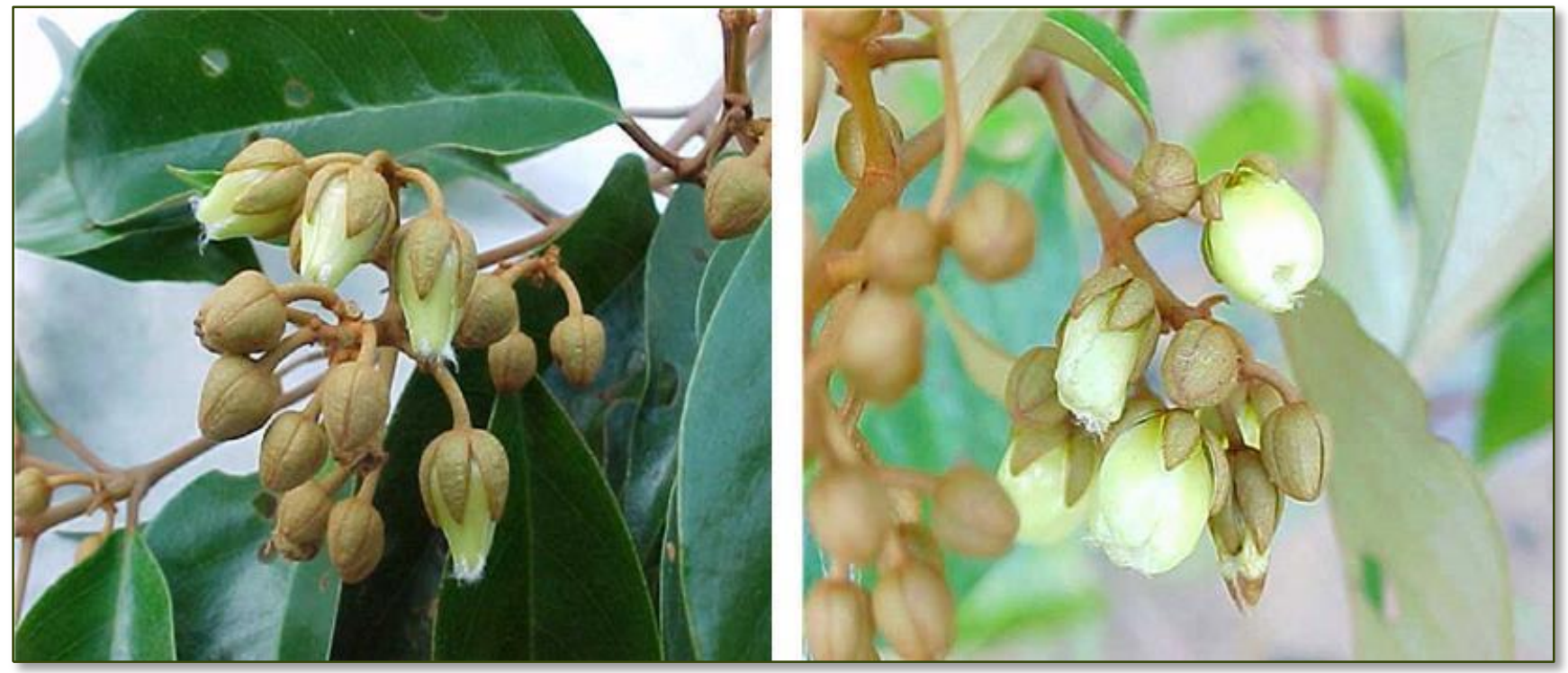

Fonte: Os autores (2015) 


\section{Descrição polínica}

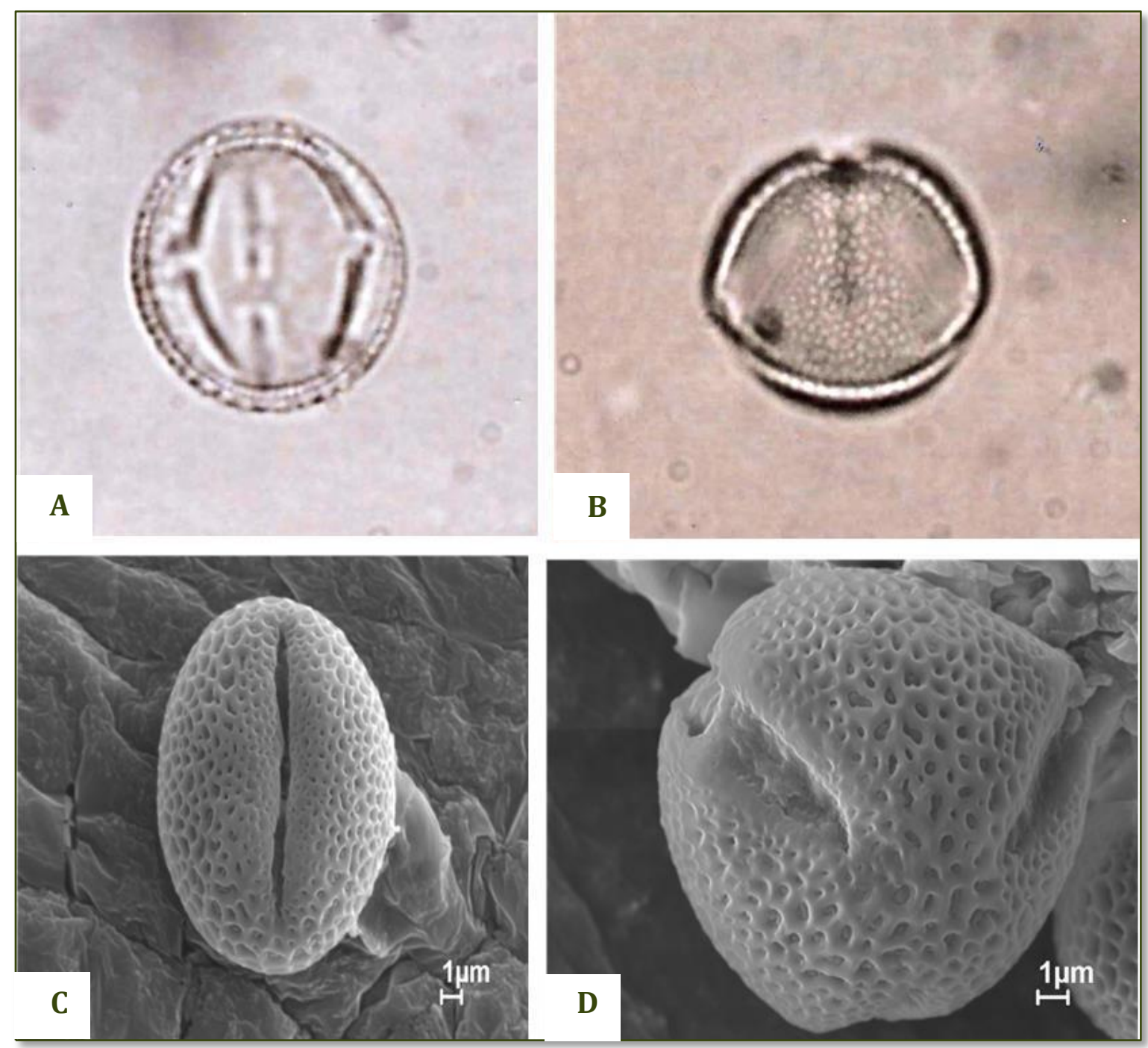

Fonte: Os autores (2015)

Forma - grãos de pólen pequenos a médios, prolatos a subprolatos, isopolares, radial, âmbito subtriangular.

Aberturas - 3-colporados, colpos constritos, endoabertura com aparência lalongada. Exina reticulada, heterobrocada mais espessa na região das endoaberturas, lúmens maiores nos mesocolpos MEV ( C/D).

Medidas - (micra) $\pm 24 \mu \mathrm{m}$ em vista polar (P) e $\pm 20 \mu \mathrm{m}$ em vista equatorial (E).

Material examinado - flores frescas coletadas em quintais de agricultores familiares.

Referências - Carreira \& Barth, 2003, Erdtman, 1952, Loporchio et al. 2008, Melhem et al. 1993, Radaeski et al. 2011, Sierra et al. 2006.

Microscopia eletrônica de varredura 
Família: COMBRETACEAE

\section{Nome Científico: Terminalia catappa $\mathrm{L}$.}

Nomes Comuns: Castanhola, castanholeira, amendoeira-da-Índia, amendoeira, amendoeira-do-Pará, guarda-sol.

Descrição Botânica: Árvore caducifolia de 6-12 metros de altura, podendo chegar mais de 15 m nos trópicos e até 20 metros nas regiões de origem. Com casca cinzenta, delgada e lisa. Ramos horizontais. Folhas alternas dispostas em ramalhetes nas extremidades dos galhos. São obovado-oblongas, de 10 a $30 \mathrm{~cm}$ de comprimento, com pecíolo grosso de $1 \mathrm{~cm}$ de comprimento, tomentoso. 0 ápice é abruptamente acuminado. Margem inteira. Face superior de cor verde lustroso, glabro, e inferior mais claro e às vezes com tomento marrom. As folhas podem cair em zonas áridas, tornando-se avermelhadas antes de se desprender. Espigas axilares menores que as folhas com numerosas flores pequenas e de coloração branco verdosa, sendo abundante nas flores masculinas. Flores sem pétalas, com 10 estames. Frutos em drupas elípticas, de 4 a $7 \mathrm{~cm}$ de comprimento, lisas e pontiagudas, com uma ou duas margens ligeiramente aladas. Quando maduros têm uma coloração vermelha ou marrom. São comestíveis.

Origem: Sudeste da Ásia (especialmente Índia, Malásia, Filipinas e Indonésia)

Distribuição Geográfica: 0 extrato de suas folhas na medicina popular é usado como antioxidante, antiinflamatória, hepatoprotetor, no tratamento de dermatites. Tem ainda ação adstringente, antiespasmódica, antidisentérica, contra a febre biliosa, vermífuga. Cultivada nas regiões tropicais e subtropicais.

Uso Medicinal: Adstringente, antiespasmódica, peitoral, antisentérica, contra a febre biliosa, vermífuga.

Referências: Fan, Y.M. et al. 2004, Kinoshita, S. et al. 2007, Revilla, J. 2002.

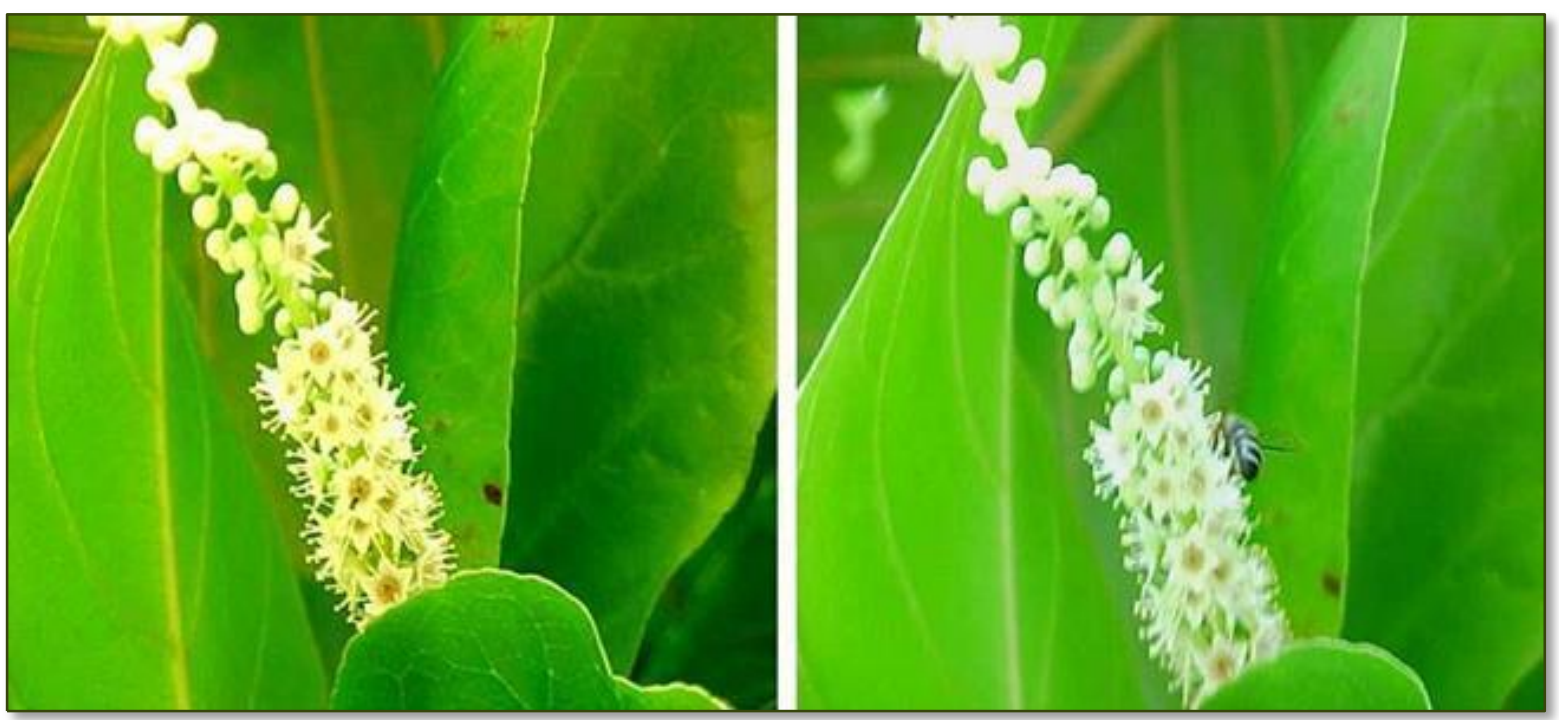

Fonte: Os autores (2015) 


\section{Descrição polínica}

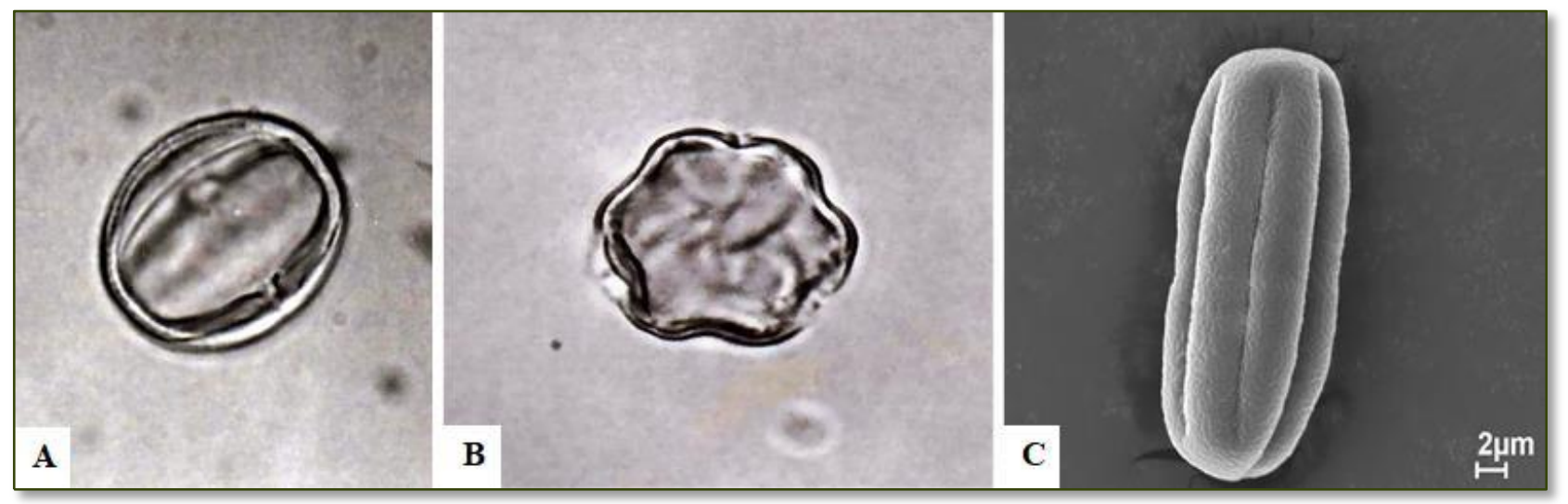

Fonte: Os autores (2015)

Forma - grãos de pólen pequenos a médios, prolatos-esfeirodal a subprolatos, âmbito hexagonal de lados convexos.

Aberturas - 3-pseudocolpos-3-colporos, colporos constritos, pseudocolpo alternado-se com colporo intercalados.

Exina - levemente reticulada (MEV (C).

Medidas - (micra) 19-20 $\mu \mathrm{m}$ em vista polar (P) e 15-17 $\mu \mathrm{m}$ em vista equatorial (E).

Material examinado - flores frescas coletadas em quintais de agricultores familiares.

Referências - Carreira \& Barth, 2003, Erdtman, 1952, Loporchio et al. 2008, Melhem et al. 1993, Salgado-Labouriau, 1971.

**Microscopia eletrônica de varredura 
Família: CONVOLVULACEAE

\section{Nome Científico: Bonamia ferruginea (Choisy) Hallier f.}

Nomes Comuns: Cipó tuíra

Descrição Botânica: Hábito escandente, herbácea. Folhas dorsalventral com uma única camada de tecido paliçádico na epiderme foram observadas tricomas glandulares multicelulares e tectores unicelulares. O caule apresenta um cilindro vascular completo e pecíolo com um feixe vascular mediano acompanhado de dois feixes acessórios laterais.

Origem: Brasil

Distribuição Geográfica: Região Amazônica: Nativa, endêmica, Norte (PA, AM, RO), Centro-Oeste (MT).

Uso Medicinal: 0 caule e as folhas são utilizados no tratamento de icterícia, hepatite e malária, sendo ainda indicada como ativador celular e desintoxicante da pele. Toda a planta, preparada por decocção, por possuir ação adstringente é usada em banhos contra a leucorréia.

Referências: Forzza, R.C. et al. 2010, Lopes, E.V et al. 2015, Tomchinsky, B. 2013.

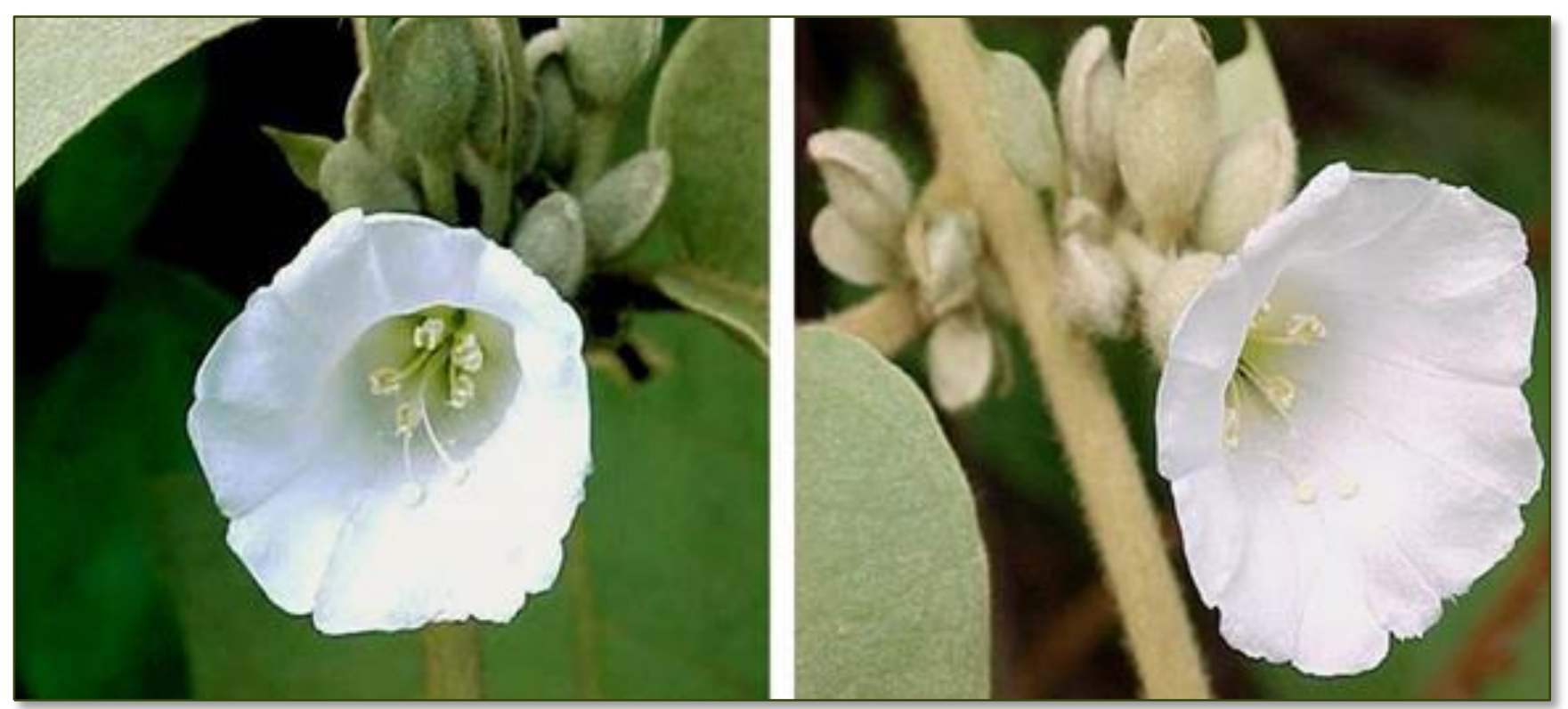

Fonte: Os autores (2015) 


\section{Descrição polínica}

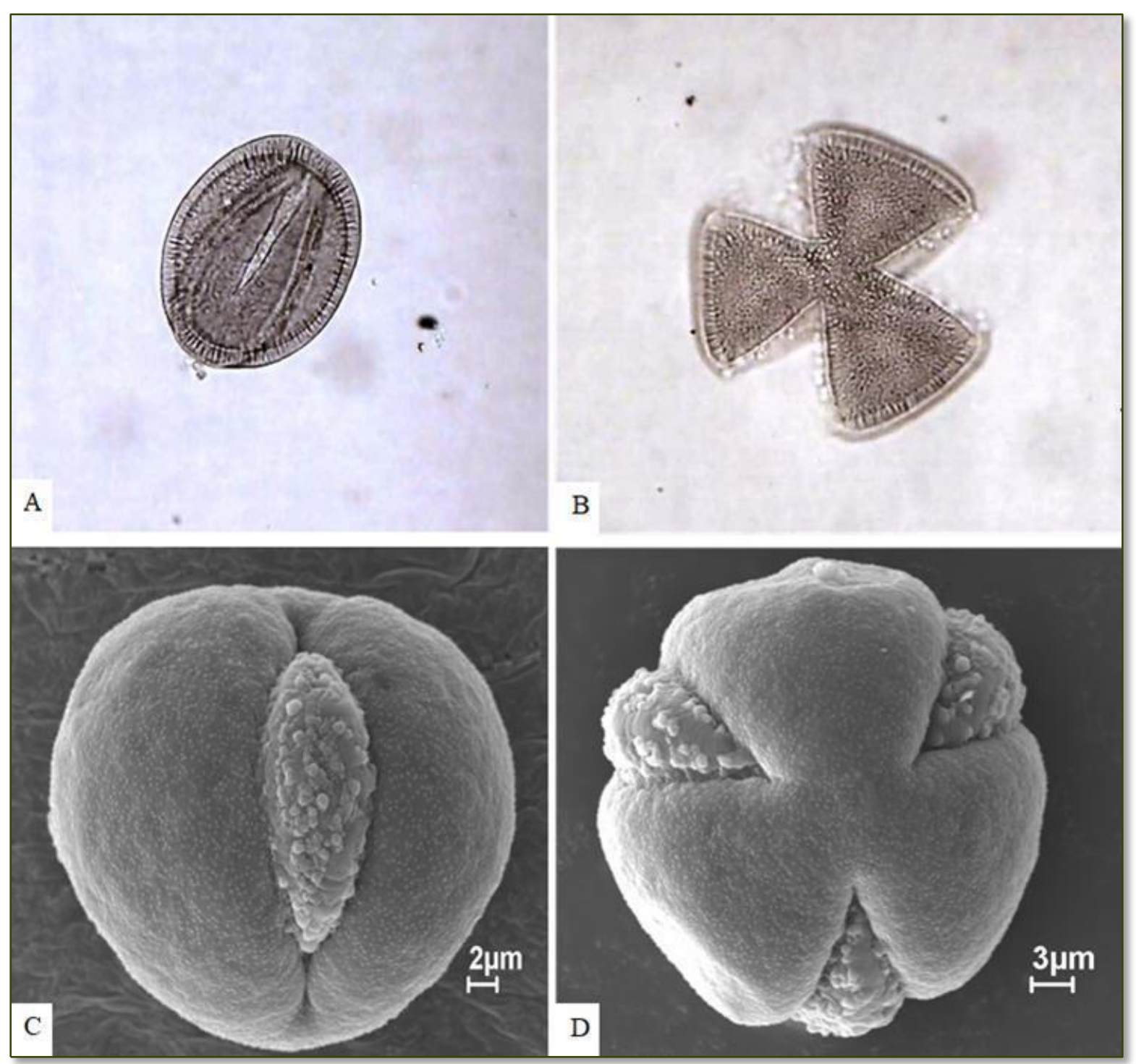

Fonte: Os autores (2015)

Forma - grãos de pólen grandes, oblato-esfeirodal, isopolares, radial, âmbito subtriangular. Aberturas - 3-colpados, colpos longos largos, com membranas finamente esculturadas com ornamentações de psilada e granulada (MEV (C/D).

Exina - baculada, báculos de diferentes tamanhos agrupados ou isolados (MEV (C/D).

Medidas - (micra) 52-58 $\mu \mathrm{m}$ em vista polar (P) e 59-63 $\mu \mathrm{m}$ em vista equatorial (E).

Material examinado - flores frescas coletadas em quintais de agricultores familiares.

Referências - Carreira \& Barth, 2003, Erdtman, 1952, Melhem et al. 1993, SalgadoLabouriau, 1971.

**Microscopia eletrônica de varredura 
Família: CONVOLVULACEAE

\section{Nome Científico: Merremia macrocalyx (Ruiz \& Pav.) 0’ Donell}

Nomes Comuns: Batatão, batata de purga, gitirana.

Descrição Botânica: Trepadeira herbácea, volúvel. Ramos hirsutos ou glabros. Folhas simples, alternas, 5-7 lobadas; lobos oblongos; lâmina 10-12x7,5-8,5 cm; face adaxial hirsuta; face abaxial velutina; ápice acuminado; margem inteira; base atenuada; nervação peninérvea. Inflorescências em panículas, axilares; multifloras; sépalas 2-2,5 cm comprimento, obtusas ou agudas; glabras; corola infundibuliforme, alva, linhas escuras nas interplicas, glabra; anteras rimosas. Cápsulas globosas, glabras, cálice persistente.

Origem: América Tropical.

Distribuição Geográfica: Distribuição Pantropical, Ásia, Africa, Bolívia, Colômbia, Equador, Honduras, Nicaragua, Paraguai, Venezuela, Brasil.

Uso Medicinal: Usado na forma de infusão, pó e cozimento. Com ação purgativa, antihemorróidário e anti-hipertensivo.

Referências: Ferrer-Pereira, H. et al. 2010, Martins, M.B. \& Oliveira, T.G. 2011, Paz, J.R.L. \&

Pigozzo, C.M. 2013.

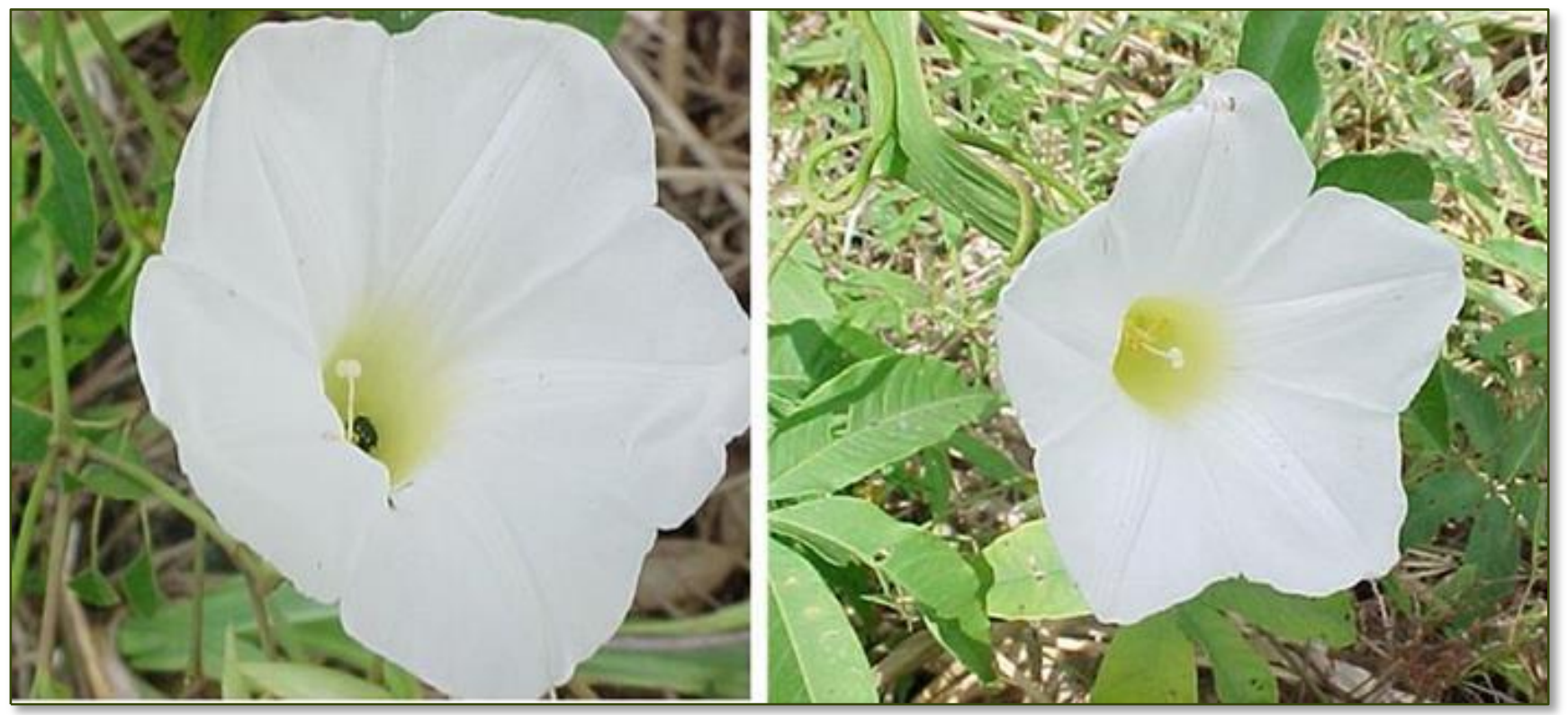

Fonte: Os autores (2015) 


\section{Descrição polínica}

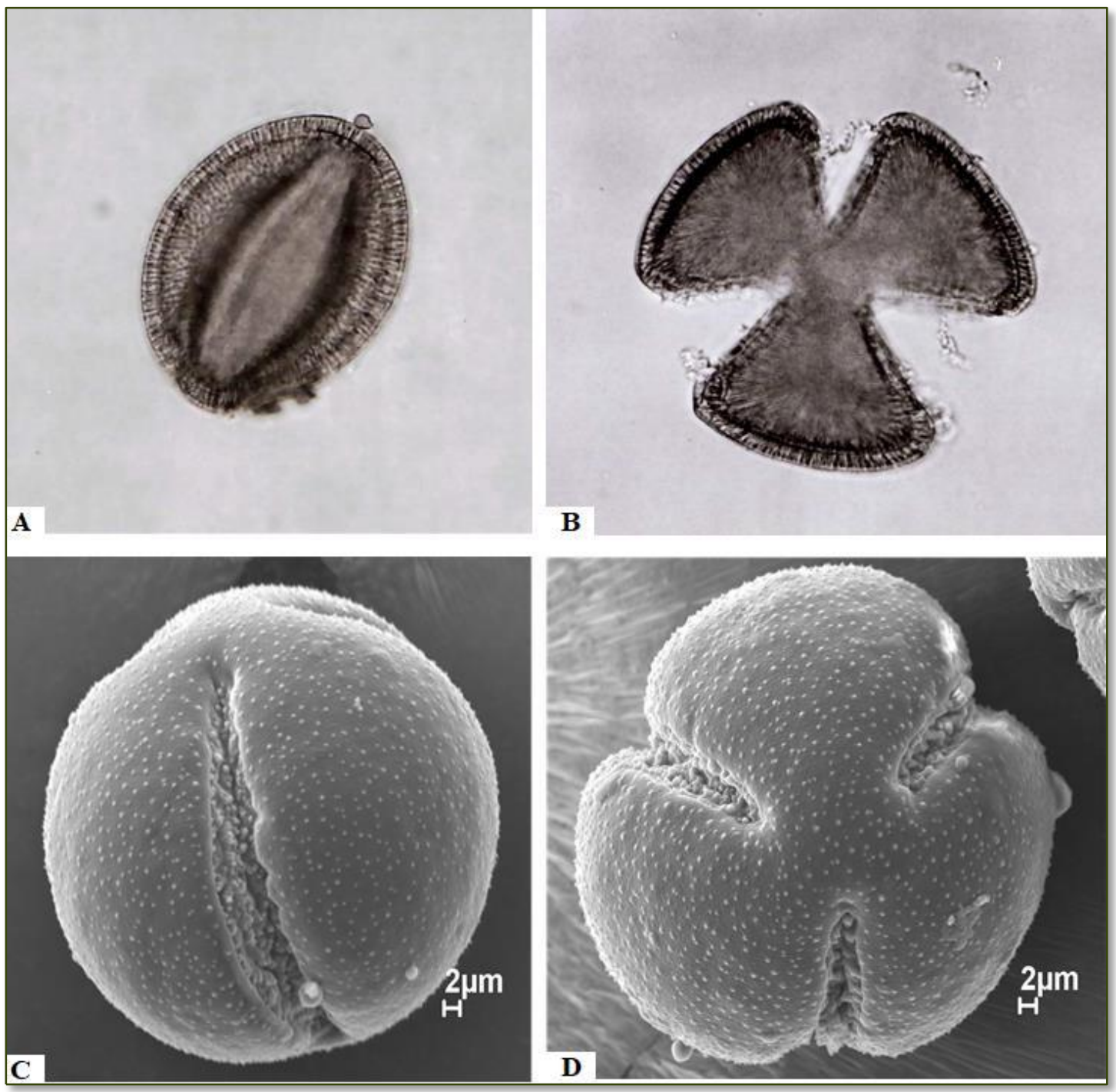

Fonte: Os autores (2015)

Forma - grãos de pólen grandes, isopolares, prolatos, âmbito sub-circular, recobertos por membrana granulada.

Aberturas - 3-colpados, colpos longos com contorno regular, extremidades afiladas e membrana apertural bem evidente (MEV (C/D).

Exina - espessa, teto fino e columelas delgadas

Medidas - (micra) $\pm 58 \mu \mathrm{m}$ em vista polar (P) e $\pm 63 \mu \mathrm{m}$ em vista equatorial (E).

Material examinado - flores frescas coletadas em quintais de agricultores familiares.

Referências - Carreira \& Barth, 2003, Erdtman, 1952, Melhem et al. 1993, SalgadoLabouriau, 1971.

**Microscopia eletrônica de varredura 
Família: CUCURBITACEAE

\section{Nome Científico Cucurbita cf. moschata (Duc. Ex Lam.) Duc. Ex Poir.}

Nomes Comuns: Jerimum, abóbora moscata, abóbora almiscarada

Descrição Botânica: Planta anual, herbácea, trepadeira. Talos angulosos e com tendência a produzir raízes nos nós. Folhas alternas, simples, com estípulas, pecioladas, 9 a $24 \mathrm{~cm}$ de comprimento, orbiculares e com 5 a 7 lóbulos arredondados e pouco pronunciados, não erguidas e com pequenas manchas esbranquiçadas na união das nervuras. As flores são solitárias, unissexuais, com 3 estaminoides, um estilete curto e 3 a 5 estigmas bilobados. Ovário tricarpelar, com 4 ou 5 carpelos. As flores masculinas estão sobre largos pedúnculos, solitárias ou em fascículos e apresentam anteras unidas. A corola, em ambos os sexos é grande, amarela, gametopétala e semilobulada. Fruto grande, globoso a ovóide ou uma baga cilíndrica indeiscente.

Origem: Os vestígios dessa espécie descobertos durante pesquisas arqueológicas não permitem afirmar com certeza que essa espécie é originária da América Central ou América do Sul.

Distribuição Geográfica: Sudoeste do México, América Central, Guatemala, Panamá, Colômbia e Peru, e como centro de diversidade e domesticação da espécie o Nordeste da América do Sul, possivelmente a costa Norte da Colombia e regiões tropicais e subtropicais, poucas espécies em regiões temperadas ou frias.

Uso Medicinal: Vermífugo, emoliente, laxativo, estomáquico, anti-inflamatório dos rins, fígado e baço, antitérmico, adstringente, contra queimaduras e erisipela, furúnculo, otite.

Referências: Caili, F. et al. 2006, Camurça-Vasconcelos, A.L.F. et al. 2005, Que, F. et al. 2008, Santos, J.O. 2013.

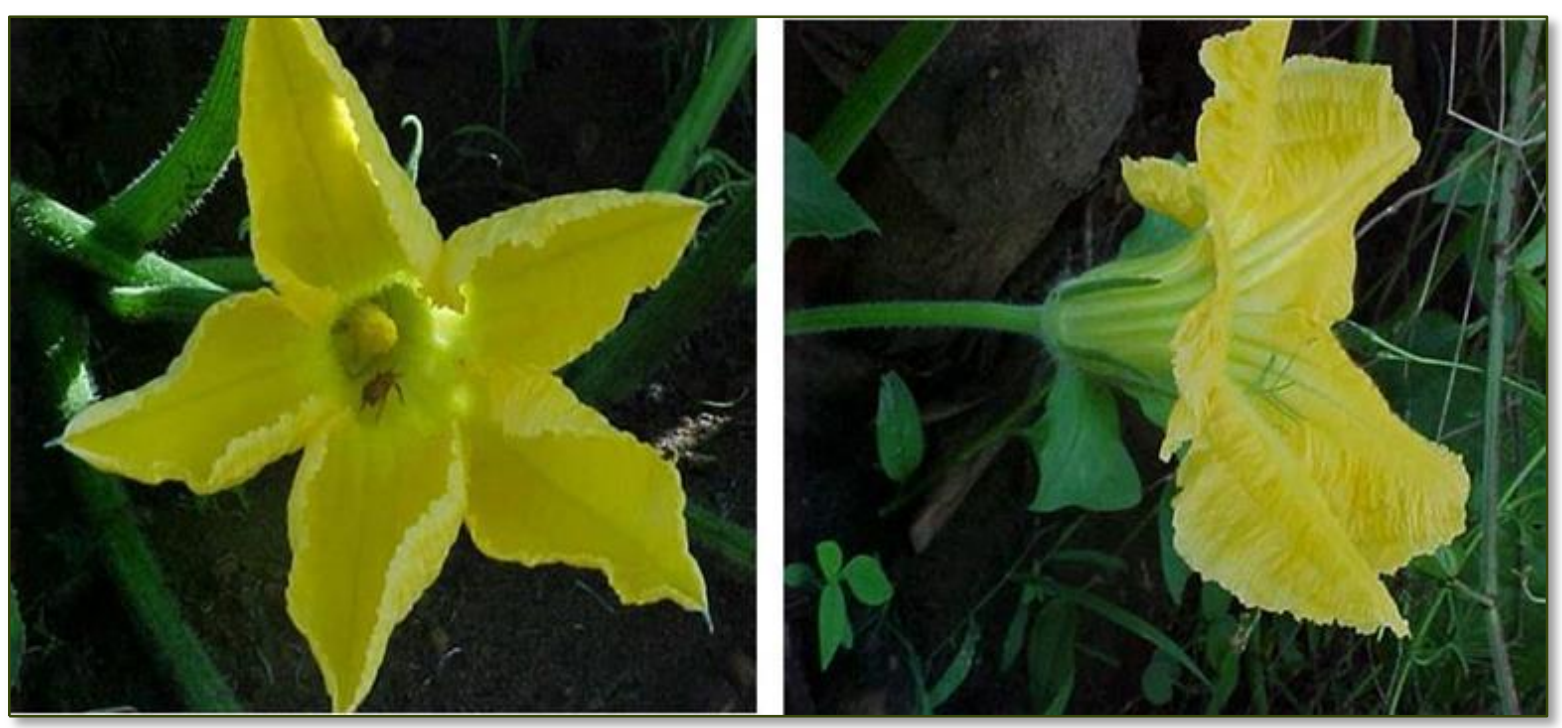

Fonte: Os autores (2015) 


\section{Descrição polínica}

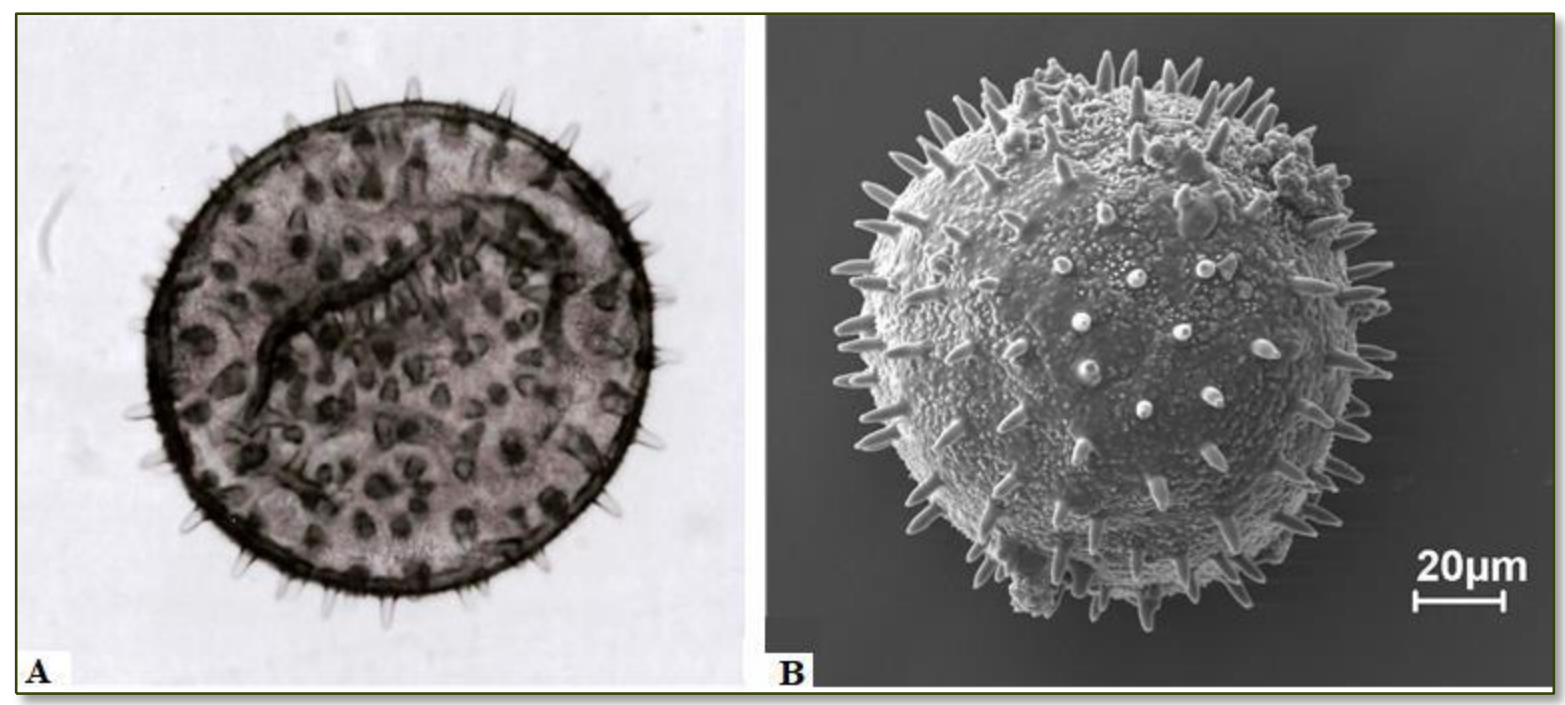

Fonte: Os autores (2015)

Forma - grãos de pólen grandes, âmbito circular, oblato-esferoidal, esférica com espinhos. Aberturas - poros circulares com opérculos espinhosos, 3,4(5)-porados.

Exina - sexina com espinhos e pilada entre os espinhos. Espinhos com pontas arredondadas (MEV (B).

Medidas - (micra) 45-114 $\mu \mathrm{m}$ em vista polar (P) e 47-115 $\mu \mathrm{m}$ em vista equatorial (E). Material examinado - flores frescas coletadas em quintais de agricultores familiares.

Referências - Carreira \& Barth, 2003, Erdtman, 1952, Melhem et al. 1993, SalgadoLabouriau, 1971.

**Microscopia eletrônica de varredura 
Família: EUPHORBIACEAE

\section{Nome Científico: Croton sacaquinha Croizat}

Nomes Comuns: Sacaquinha

Descrição Botânica: Arbusto geralmente dióico. Folhas alternas, com peçquenas glândulas no pecíolo. Lâmina inteira ou dentada, às vezes lobulada. Flores em espigas ou ramos terminais ou axilares. Cachos de flores bisexuais com poucas flores femininas, solitárias. Flores masculinas reunidas em grupos, com cálice de 4 a 6 lóbulos imbricados ou valvares; corola com 5 pétalas; androceu com 5 a 50 estames de filamentos livres, às vezes reduzidos ou ausentes. Fruto capsular que se divide em três cocos bivalvos.

Origem: Brasil (Amazônia)

\section{Distribuição Geográfica: Norte do Brasil}

Uso Medicinal: Suas ações medicinais são semelhantes à sacaca, o chá das folhas, em bochechos, combate a dor de dente, e o sumo é cicatrizante. Tem ação antidiarréica, usada no tratamento de diabetes, inflamação do fígado e rins e para baixar o colesterol. 0 chá das folhas ou da casca serve para distúrbios hepáticos e renais, baixa o colesterol.

Referências: Assis, R.M.A. et al. 2014, Berg, M.E. Van Den, 2010, Cavalcante, R. 2011, Trindade, M.J.S. \& Lameira, O.A. 2014.

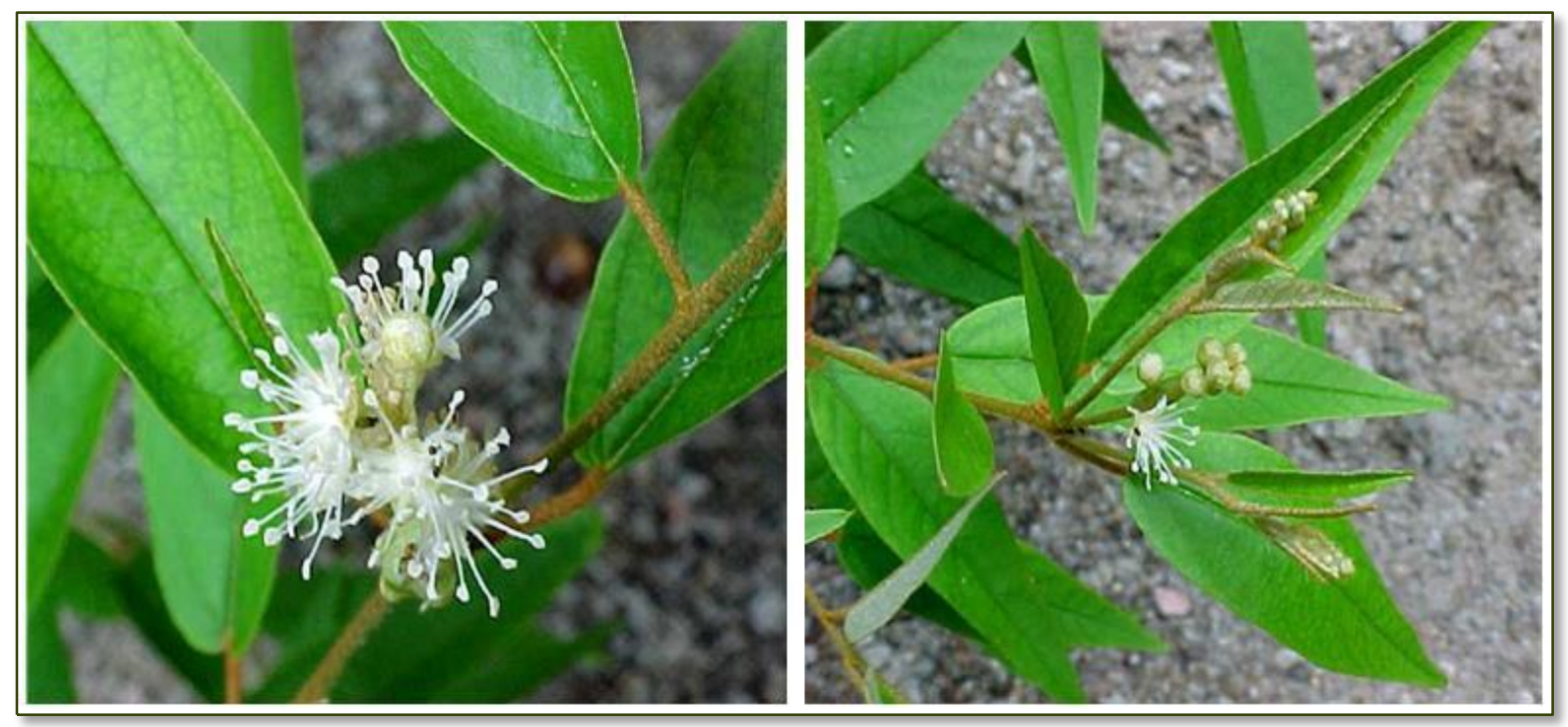

Fonte: Os autores (2015) 


\section{Descrição polínica}

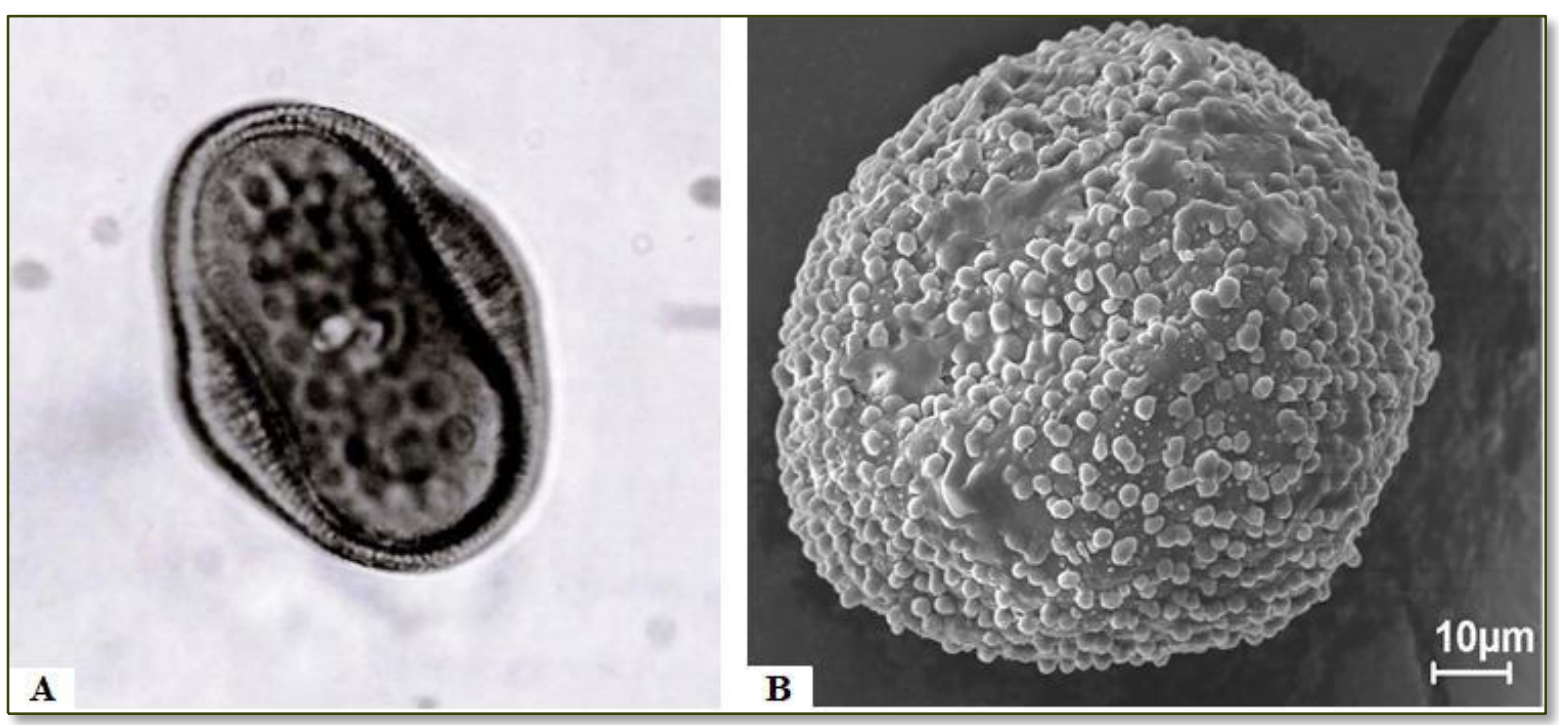

Fonte: Os autores (2015)

Forma - grãos de pólen grandes, forma esférica (MEV

(B), âmbito sub-circular devido ao espessamento desigual da exina, áreas circulares deprimidas distribuídas pela superfície do grão.

Aberturas - 3-colporados, colpos curtos com opérculo, endoabertura lalongada (MF (A)

Exina - espessa com pilas nas áreas circulares.

Medidas - (micra) $\pm 87 \mu \mathrm{m}$.

Material examinado - flores frescas coletadas em quintais de agricultores familiares.

Referências - Carreira \& Barth, 2003, Erdtman, 1952, Melhem et al. 1993, SalgadoLabouriau, 1971.

*Microscopia fotônica

**Microscopia eletrônica de varredura 
Família: EUPHORBIACEAE

\section{Nome Científico: Ricinus communis $\mathrm{L}$.}

\section{Nomes Comuns: Mamona}

Descrição Botânica: É um arbusto ou arvoreta de textura semi-lenhosa, perene. Caule único ereto e lenhoso em sua base, ramificado antes do final do primeiro ano de crescimento. Folhas brilhantes, alternas, palmadas, profundamente lobadas, com margens dentadas e sustentadas por longos e fortes pecíolos. Na forma típica da espécie, elas surgem com tonalidades avermelhadas que gradualmente vão atingindo a cor verde-escura. As flores são inflorescências terminais do tipo panícula. As flores femininas são geralmente de cor verde ou avermelhadas, as pétalas masculinas são amarelos esverdeados, com estames creme. Os frutos são cápsulas globosas, com 3 sementes cada, recobertas de espinhos podendo ser verdes ou avermelhadas, de acordo com a cultivar. As cápsulas secas se dividem em partes, expondo e liberando as sementes.

Origem: Sua origem não é bem definida, embora algumas evidências levem a crer que ela seja nativa do oeste da África e que, provavelmente, originou-se na Etiópia. Atualmente, a mamona é cultivada em quase todos os quadrantes do mundo, principalmente em zonas tropicais e subtropicais, inclusive no Brasil.

Distribuição Geográfica: Naturalizado nos climas temperados de todo 0 mundo. Encontrada em quase todo o Brasil.

Uso Medicinal: Indicado para alergias, infecções, dor, inflamações, constipação, verminoses, pele ressecada. Tem propriedades laxantes, das sementes, limpas as cascas, se obtém um óleo de efeito purgativo. 0 mesmo azeite também é utilizado para combater os vermes intestinais.

Referências: Figueiredo-Neto, A. et al. 2004, Jombo, G.T.A. \& Enenebeaku, M.N.O. 2008, Ling, K.H. et al. 2009.

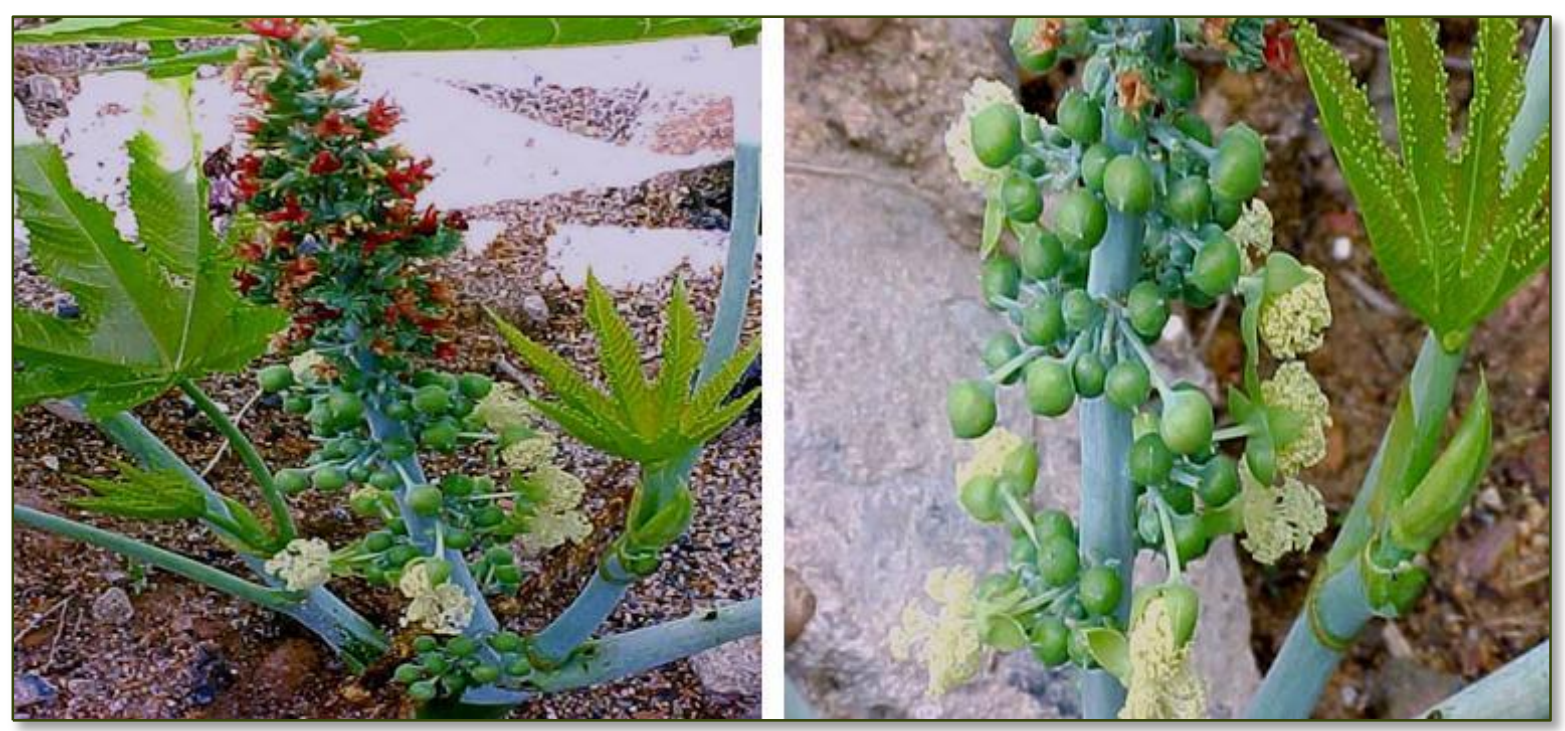

Fonte: Os autores (2015) 


\section{Descrição polínica}

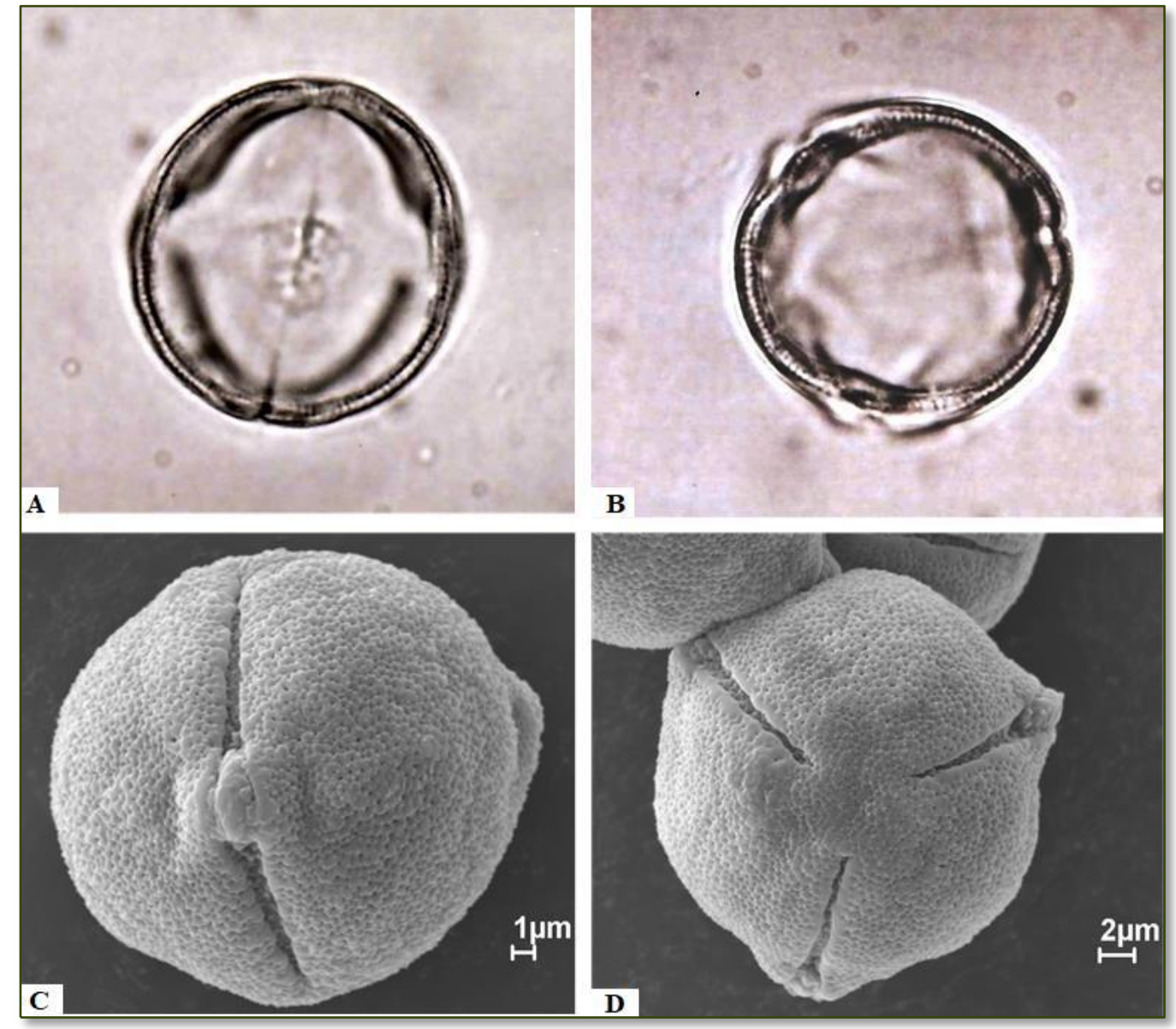

Fonte: Os autores (2015)

Forma - grãos de pólen médios, âmbito subtriangular, subesferoidal, lalongado.

Aberturas - 3-colporados, endoabertura lalongada, zonas aperturais bem definidas (MEV (C/D)

Exina - microreticulada, espessa e constante em todo grão, exceto nas margens das aberturas.

Medidas - (micra) 33-40 $\mu \mathrm{m}$ em vista polar (P) e 29-41 $\mu \mathrm{m}$ em vista equatorial (E).

Material examinado - flores frescas coletadas em quintais de agricultores familiares.

Referências - Carreira \& Barth, 2003, Erdtman, 1952, Melhem et al. 1993, SalgadoLabouriau, 1971.

**Microscopia eletrônica de varredura 
Família: FABACEAE

\section{Nome Científico: Bauhinia forficata Link}

Nomes Comuns: Pata de vaca, Pluma de Napoleão, Flamboyant, mariposa, unha de vaca, bauínia.

Descrição Botânica: As espécies desse gênero podem apresentar porte arbóreo ou arbustivo, apresentam as folhas fendidas no meio, formando dois lôbulos ou folíolos, que assemelham a uma pata de bovino. As flores são zigomorfas dispostas em racemos axilares que varia de acordo com a espécie e subespécie. Os frutos são legumes ou vargens, achatados e deiscentes.

Origem: América Tropical. Nativa da América do Sul.

Distribuição Geográfica: Argentina, Paraguai, Bolívia e Brasil ocorendo nos estados de Alagoas, Bahia, Espírito Santo, Minas gerais, Paraná, Pernambuco, Piauí, Rio de janeiro, Santa catarina e São Paulo.

Uso Medicinal: Usado no tratamento de diabetes no Brasil e na Nigéria e nas hemorragias pósparto. Antiglicêmico; os extratos obtidos das sementes tem sido relatado por sua ação hemaglutinante, inibindo a ação das tripsina e diminuição da atividade das dissacaridases. É ainda citado a ação antioxidante do flavonóide kaempferitrina, presente nesta espécie.

Referências: Ling, K.H. et al, 2009, Lusa, M.G. \& Bona, C. 2009, Onyije, F.M. \& Avwioro, O.G. 2012, Smith, A.C. 1985.

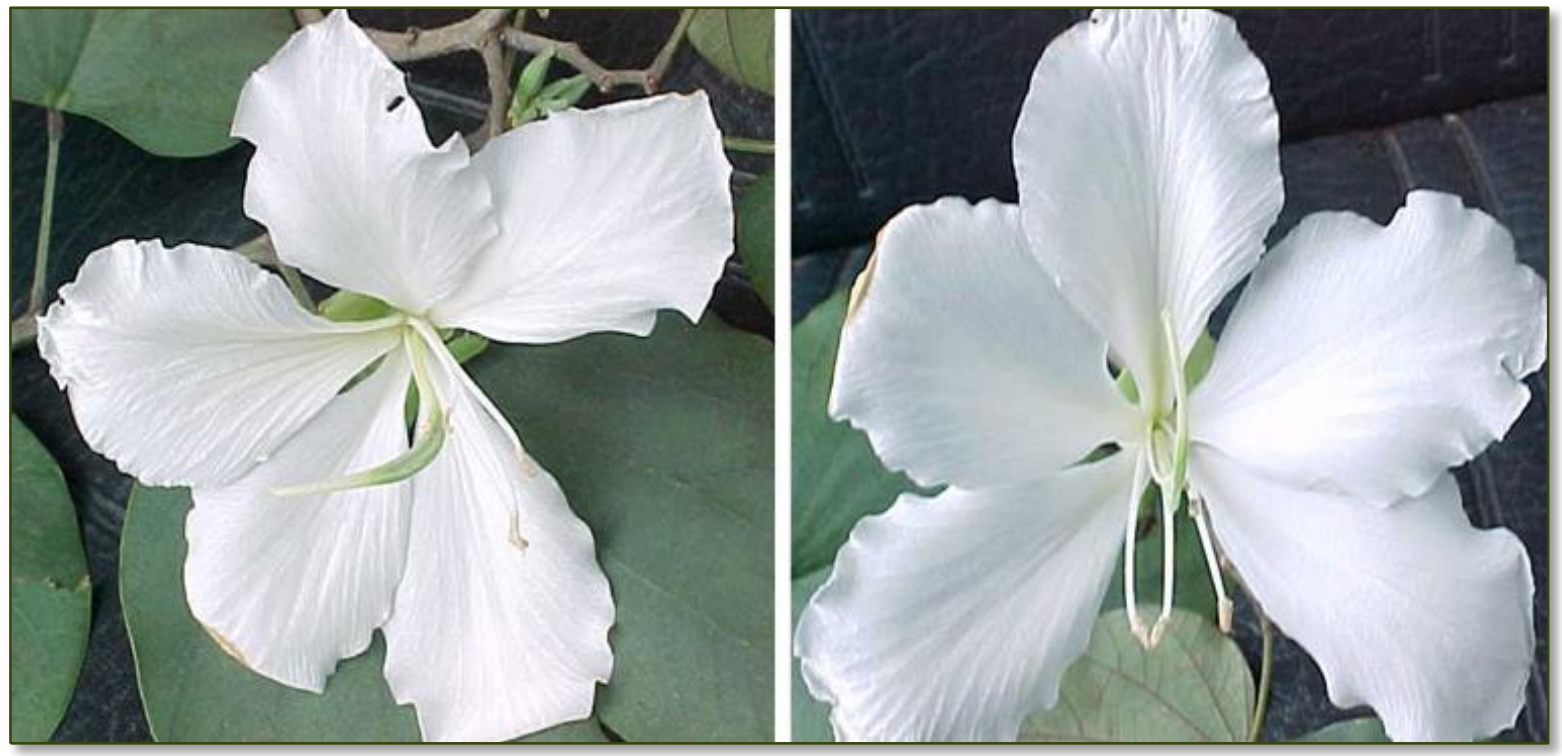

Fonte: Os autores (2015) 


\section{Descrição polínica}

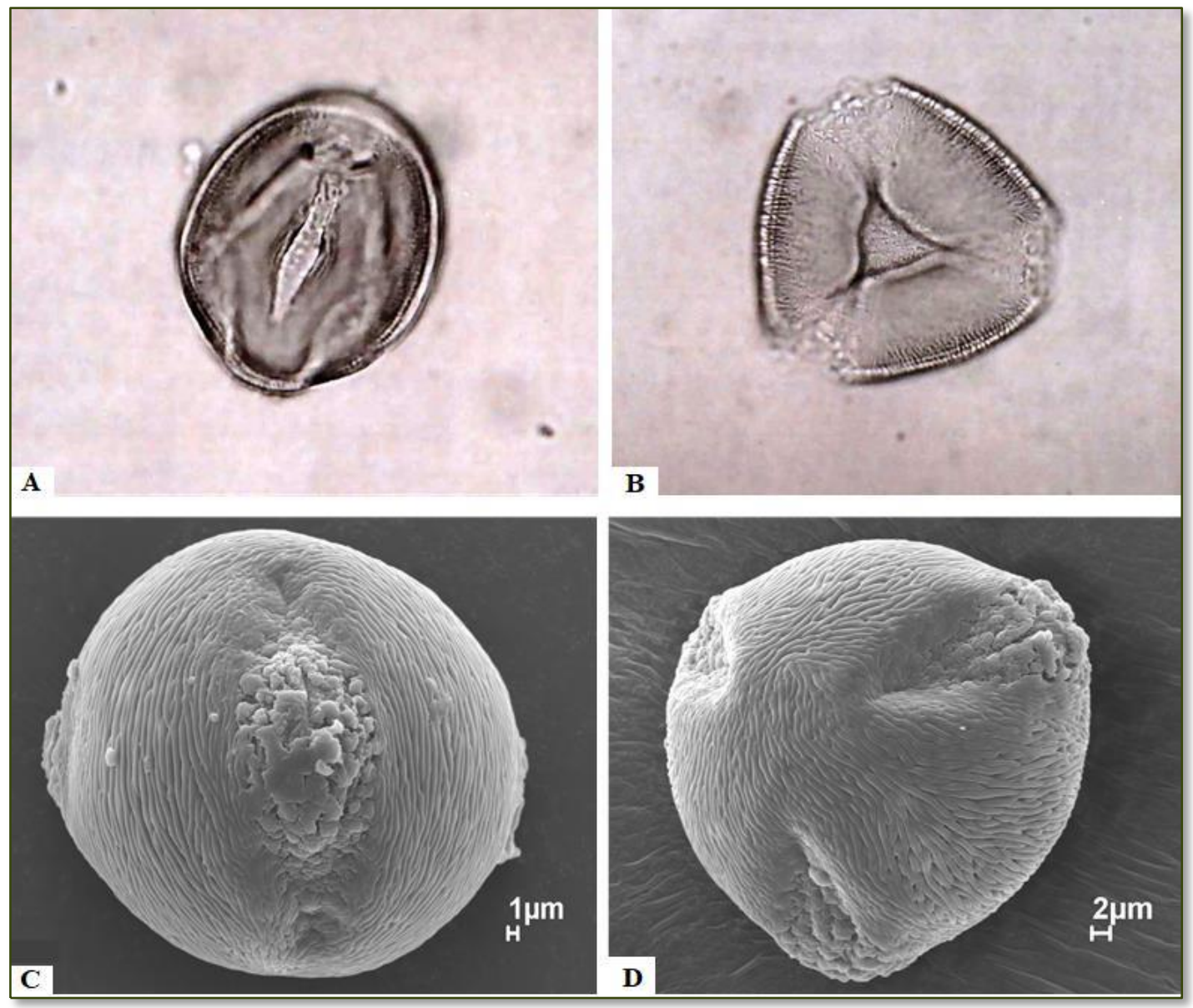

Fonte: Os autores (2015)

Forma - grãos de pólen grandes, oblatoesferoidal, com âmbito triangular, simetria radial. Aberturas - 3-colporados de forma irregular, localizadas nos ângulos dos triângulos (MEV (D).

Exina - reticulada com malhas visíveis, clavas e verrugas de diferentes tamanhos espalhadas irregularmente na superfície da sexina.

Medidas - (micra) $101 \mu \mathrm{m}$ em vista polar (P) e $105 \mu \mathrm{m}$ em vista equatorial (E).

Material examinado - flores frescas coletadas em quintais de agricultores familiares.

Referências - Carreira \& Barth, 2003, Erdtman, 1952, Melhem et al. 1993, SalgadoLabouriau, 1971.

**Microscopia eletrônica de varredura 


\section{Família: FABACEAE}

\section{Nome Científico: Bauhinia purpurea L.}

Nomes Comuns: Pata de vaca, árvore de orquídea roxa; árvore roxa da borboleta, árvore corde-rosa da borboleta.

Descrição Botânica: Arvoreta semicaducifolio de 4 a $5 \mathrm{~m}$ de altura, com galhos estendidos ou um pouco pendurados. Folhas alternas, simples, suborbiculares, de 8 a $15 \mathrm{~cm}$ de comprimento, com dois lóbulos agudos ou arredondados, com glabras. Pecíolos de $4 \mathrm{~cm}$ de comprimento. Cacho laterais ou terminais com flores de cálice tubular e corola com 5 pétalas estendidas de cor púrpura, sendo a superior mais escura. Androceu com 5 estames de filamentos rosados. Raramente produz frutos.

Origem: Sudeste da Ásia

\section{Distribuição Geográfica: Cultivada em todos os trópicos.}

Uso Medicinal: Ajuda a controlar a diabete, baixar colesterol e é utilizado também contra infecções em geral. Estudos revelaram que 2,5 mg/kg i.p. (intraperitonial) de extrato obtidos de suas folhas e administrado em ratas com disfunção tiroidiana, revelou que esta planta foi capaz de aumentar a atividade da glicose-6-fosfatase, assim como efeitos antiperoxidativos, indicado pela peroxidação lipídica hepática e aumento da atividade enzimática antioxidante, comprovando assim sua ação estimulante da tireoidiana em ratas.

Referências: Ling, K.H. et al. 2009, Miyake, E.T. et al. 1986, Silva, K.L. \& Filho, V.C. 2002.

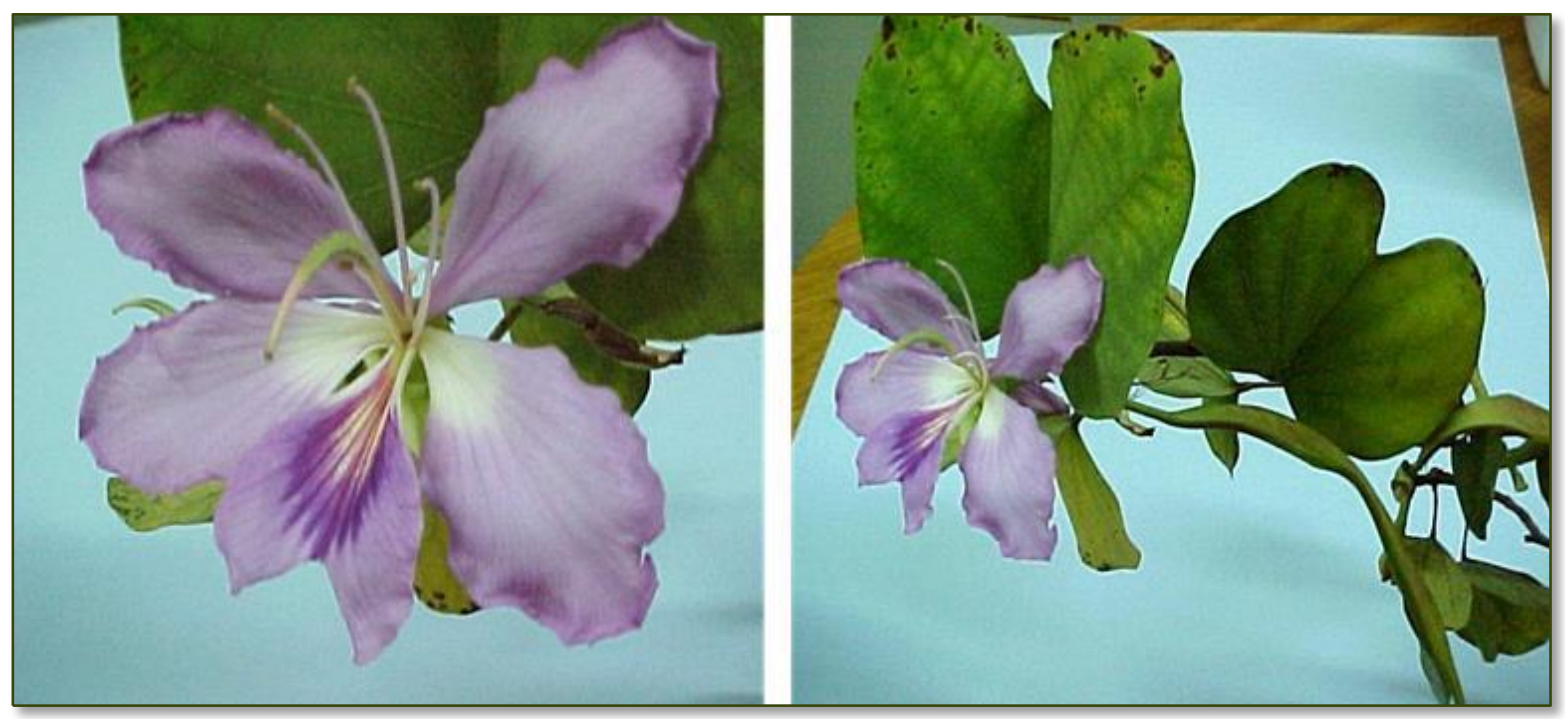

Fonte: Os autores (2015) 


\section{Descrição polínica}

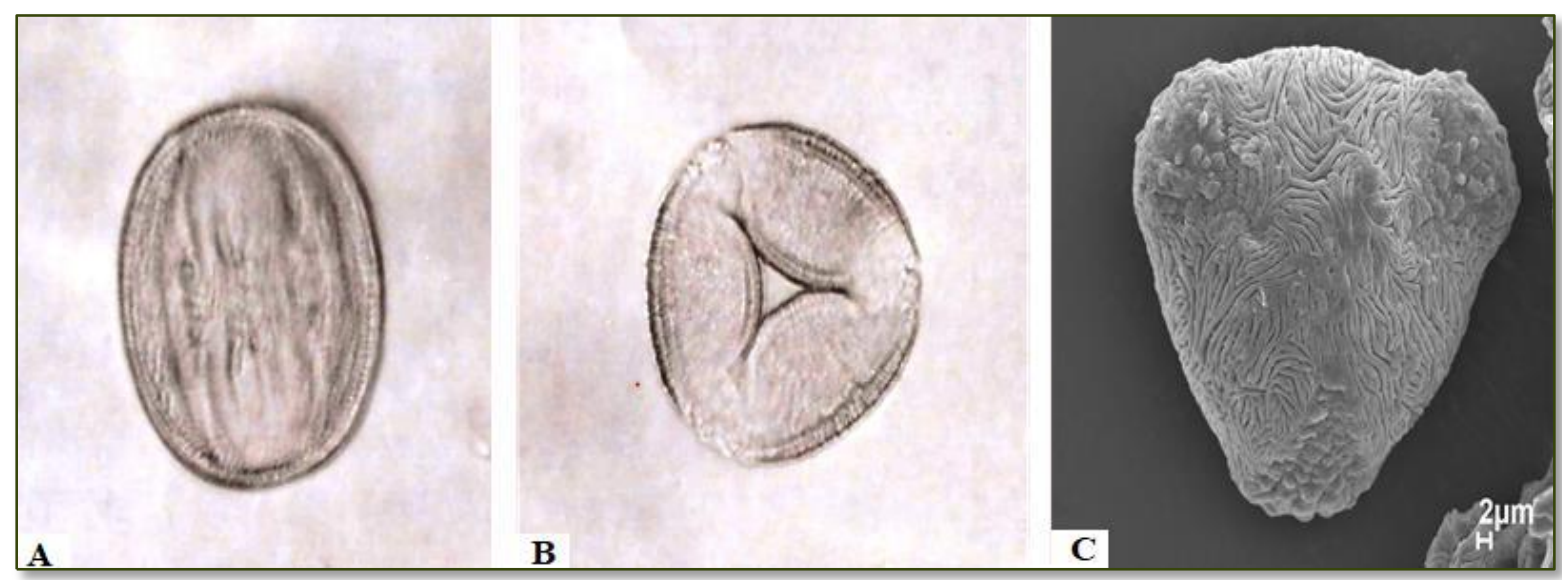

Fonte: Os autores (2015)

Forma - grãos de pólen grandes, prolatoesferoidal, com âmbito triangular, simetria radial.

Aberturas - 3-colporados de forma irregular, localizadas nos ângulos dos triângulos (MF (B) e MEV

Exina - reticulada estriada com malhas visíveis, clavas e verrugas de diferentes tamanhos espalhadas irregularmente na superfície da sexina, estrias vermiformes sem orientação aparente.

Medidas - (micra) 89-94 $\mu$ m em vista polar (P) e 132-135 $\mu \mathrm{m}$ em vista equatorial (E).

Material examinado - flores frescas coletadas em quintais de agricultores familiares.

Referências - Carreira \& Barth, 2003, Erdtman, 1952, Melhem et al. 1993, SalgadoLabouriau, 1971.

*Microscopia fotônica

**Microscopia eletrônica de varredura 


\section{Família: FABACEAE}

\section{Nome Científico: Caesalpinia ferrea Mart. ex Tul.}

Nomes Comuns: Jucá, jucaina, pau-ferro.

Descrição Botânica: Árvore média, madeira muito dura, difícil de ser trabalhada. Lenho roxo ou castanho. Cerne quase preto, maculado por manchas amarelas muito finas. Fibras finas e arrevessadas. Folhas verdes, ovais, dispostas em palmas. Flores amarelas em cachos piramidais. Frutos com vagem marrom.

Origem: Nativa do Brasil.

Distribuição Geográfica: Todo o território Nacional (encontrada principalmente na região Norte e Nordeste).

Uso Medicinal: Afecção catarral, afecção pulmonar, amídalas, asma, cicatrização, cólica intestinal, contusão, cicatrizantes de tecidos cutâneos, coqueluche, diabete, disenteria, garganta, gota, hemorragia nas hemoptises, infecção bronco pulmonar, reumatismo, sífilis, tosse, úlceras gastroduodenais, contra helmintos, enterocolite. Diabete, estômago, gastrite, bronquite, asma.

Referências: Revilla, J. 2002, Silva, C.S. et al. 2010, Soares, J.A. et al. 2013.

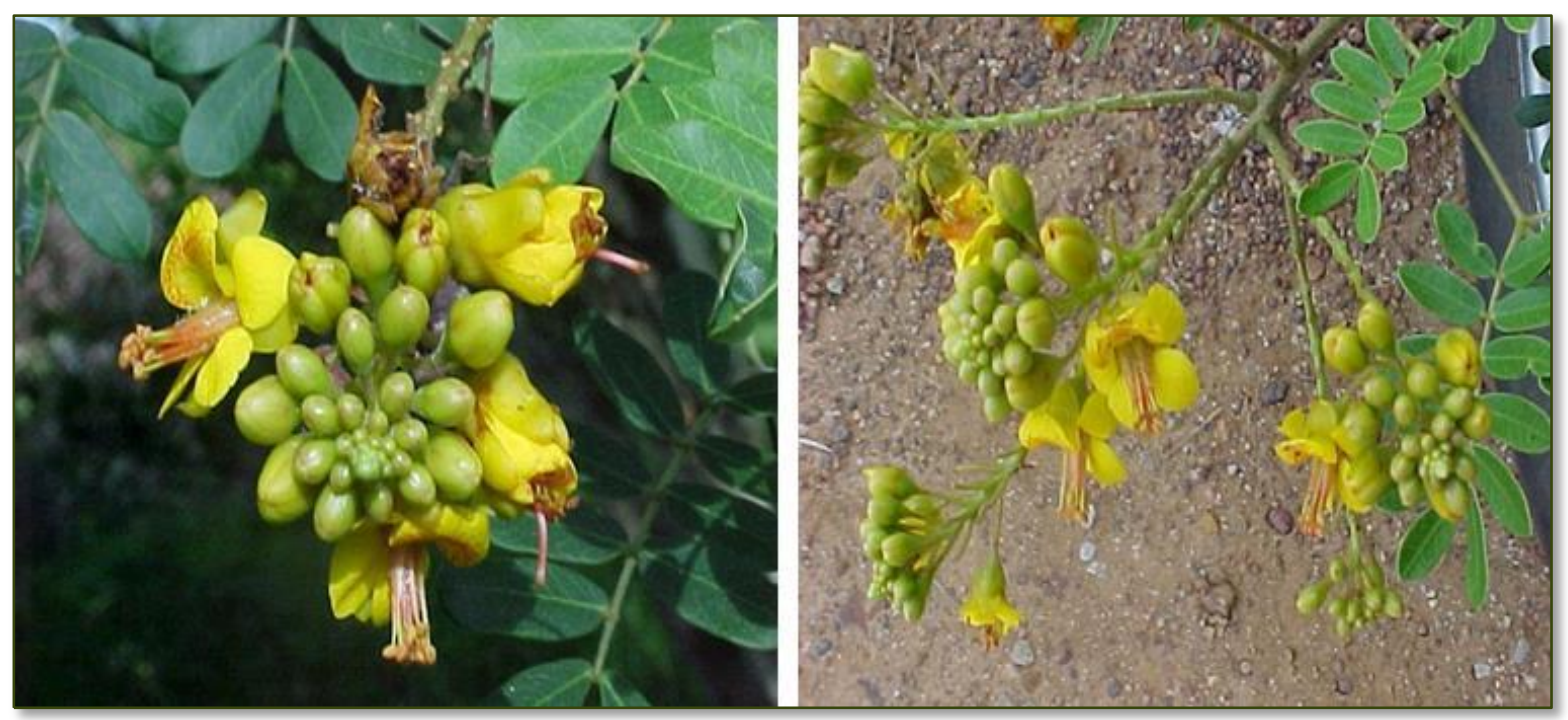

Fonte: Os autores (2015) 


\section{Descrição polínica}

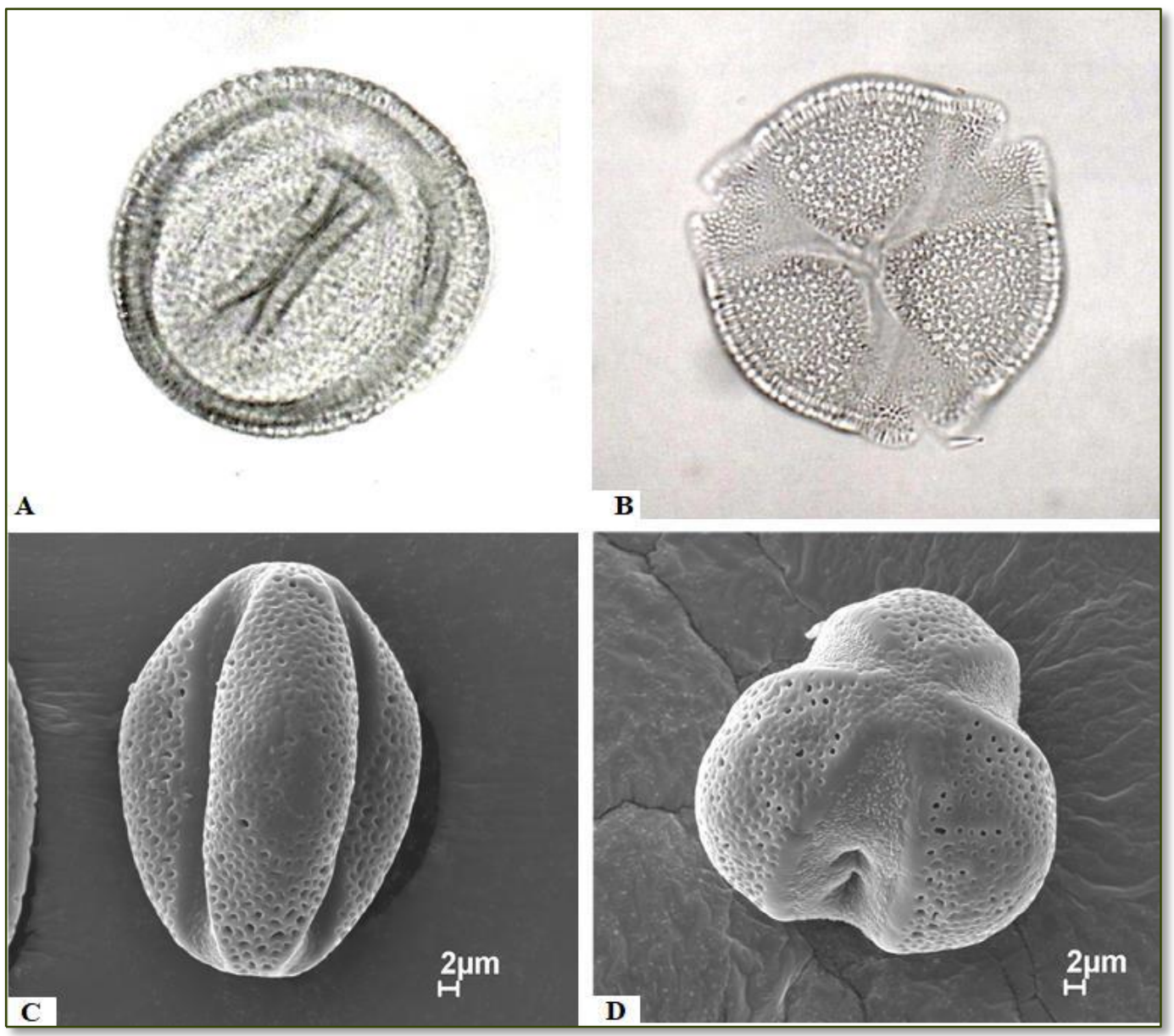

Fonte: Os autores (2015)

Forma - grãos de pólen médios a grandes, peroblatos a prolatos, âmbito geralmente circular ou triangular de lados bem convexos (MF

Aberturas - 3-colpados localizadas nos ângulos dos triângulos (MF

(B). Limites polares dos colpos não muito visíveis.

Exina - reticulada tegilada ou báculos infrategilados.

Medidas - (micra) 43-64 $\mu \mathrm{m}$ em vista polar (P) e 39-65 $\mu \mathrm{m}$ em vista equatorial (E).

Material examinado - flores frescas coletadas em quintais de agricultores familiares.

Referências - Carreira \& Barth, 2003, Erdtman, 1952, Melhem et al. 1993, SalgadoLabouriau, 1971.

**Microscopia fotônica 
Família: FABACEAE

\section{Nome Científico: Indigofera suffruticosa Mill.}

Nomes Comuns: Anil, anil-roxo, anileira-da-Índia, andu-do-mato, caachica, caa-obi, erva-anil, gurupá-timbó, timbó-mirim, tinta-dos-gentios.

Descrição Botânica: Subarbusto ou arbusto perene, ereto. Até 1,5 m de altura. Pêlos malpiguiáceos completamente estendidos, tendendo a estrigosos. Folha com 5-10 cm de comprimento, parcialmente caducas. Estípulas com 2-4 cm de comprimento. Com inflorescências em forma de rácemos, o fruto é um legume, curvo e com deiscência tardia, as sementes são acinzentadas, marmoreadas, tendendo a cubóides; hilo esférico.

Origem: América Tropical

Distribuição Geográfica: Nas regiões tropicais e subtropicais. Expandiu-se para América subtropical, Argentina, Brasil, Paraguai e Uruguai.

Uso Medicinal: Utiliza-se para limpeza de feridas com infecção; problemas do trato urinário, úlceras, sífilis, antipirético, purgativo, antiespasmódico, diurético, problemas estomacais, epilepsia; o creme misturado com vinagre é utilizado para picada de escorpião. Utiliza-se também para afecções do sistema nervoso, hepatite, sarnas, blenorragia, laringite aguda.

Referências: Eisinger, S.M. 1987, Revilla, J. 2002, Vieira, J.R.C. et al. 2006.

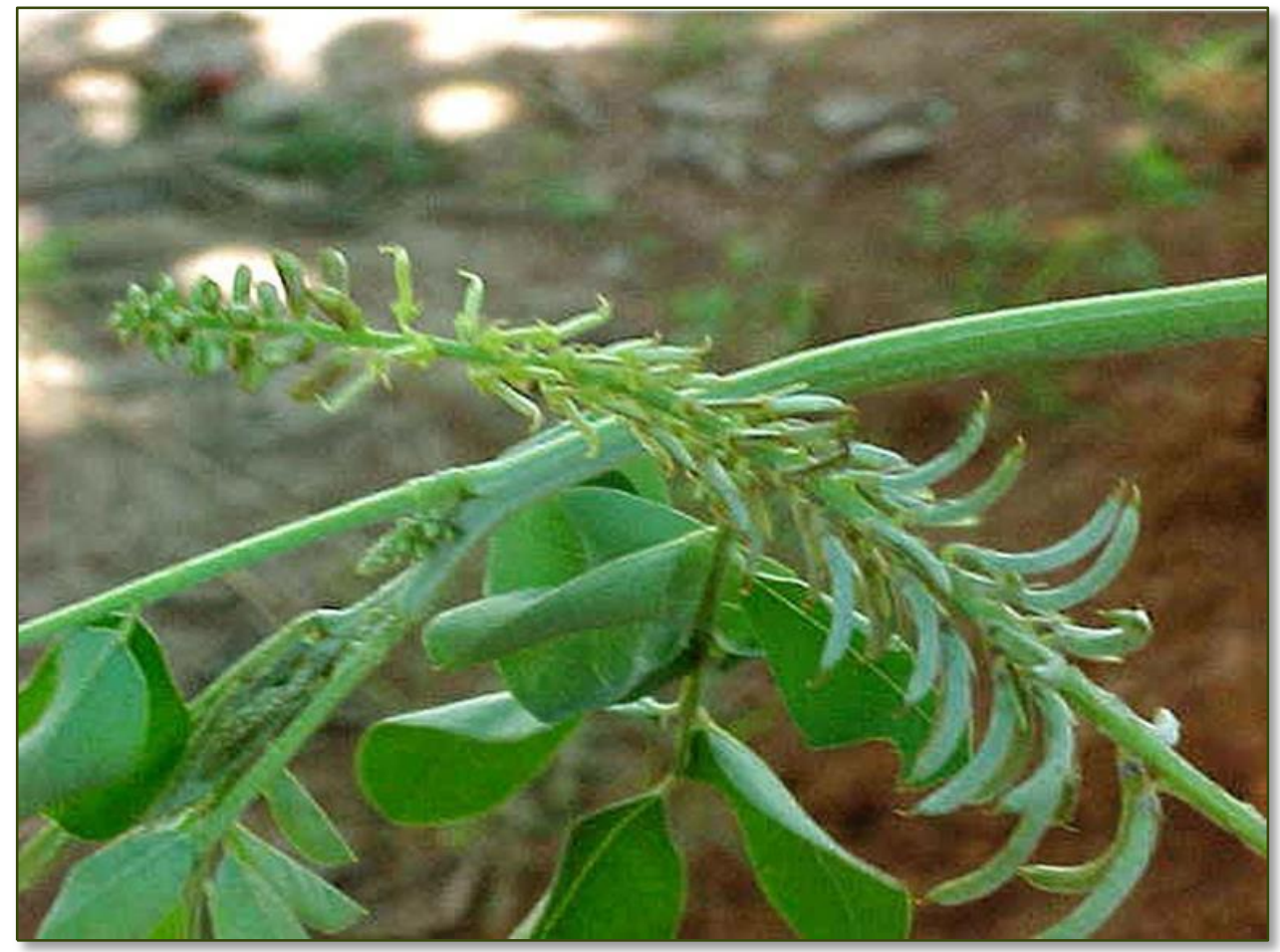

Fonte: Os autores (2015) 


\section{Descrição polínica}

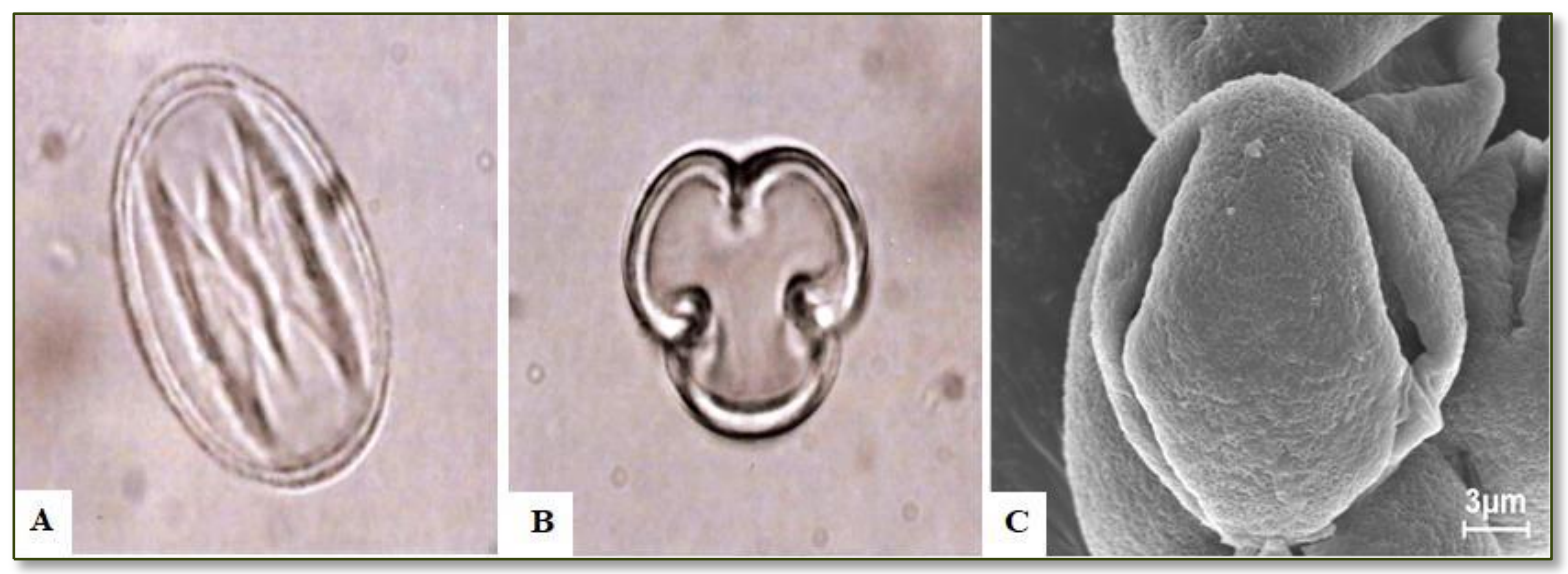

Fonte: Os autores (2015)

Forma - grãos de pólen médios, prolato-esferoidal, âmbito geralmente circular.

Aberturas - 3-colporados localizadas nos ângulos dos triângulos (MF (B). Limites polares dos colpos não muito visíveis.

Exina - superfície finamente reticulada (MEV (C).

Medidas - (micra) 25-32 $\mu \mathrm{m}$ em vista polar (P) e 23-27 $\mu \mathrm{m}$ em vista equatorial (E).

Material examinado - flores frescas coletadas em quintais de agricultores familiares.

Referências - Carreira \& Barth, 2003, Erdtman, 1952, Melhem et al. 1993, SalgadoLabouriau, 1971.

*Microscopia fotônica

**Microscopia eletrônica de varredura 
Família: FABACEAE

\section{Nome Científico: Senna alata (L.) Roxb.}

Nomes Comuns: Mata pasto, acapulco, fedegosão, mangerioba-do-pará, mangeriobagrande, mata-pasto-grande.

Descrição Botânica: Arbusto ereto, 1-2 m de altura, ramos glabros ou pubérulos. Estípulas triangulares, base auriculadas, 6-10 $\mathrm{mm}$ de comprimento. Folhas 7-11, 22-50cm comprimentos. Glândulas ausentes, folíolos obovados ou oblongos. Flores amarelas, vistosas em cachos terminais ou situados nas axilas superiores. 0 fruto é um legume quadrangular, alado, endocarpo seco, ascendente, retos, glabros ou pubérulos, 12-14x1,1-2 cm. Sementes 2-seriadas, rômbicas, castanhas ou oliváceas, 5-6×3-5 mm de largura.

Origem: América Tropical (nativa da América do Sul).

Distribuição Geográfica: Naturalizada e cultivada desde os Estados Unidos da América até a Argentina.

Uso Medicinal: Anemia, blenorragia, dispepsia febre, febre tifóide, fígado, hemorróida, herpes, impingem, infecção, malária, pano branco, prevenção da erisipela, sarna.

Referências: Rodrigues, I.M.C. et al. 2009, Rodrigues, R.S. et al. 2005.

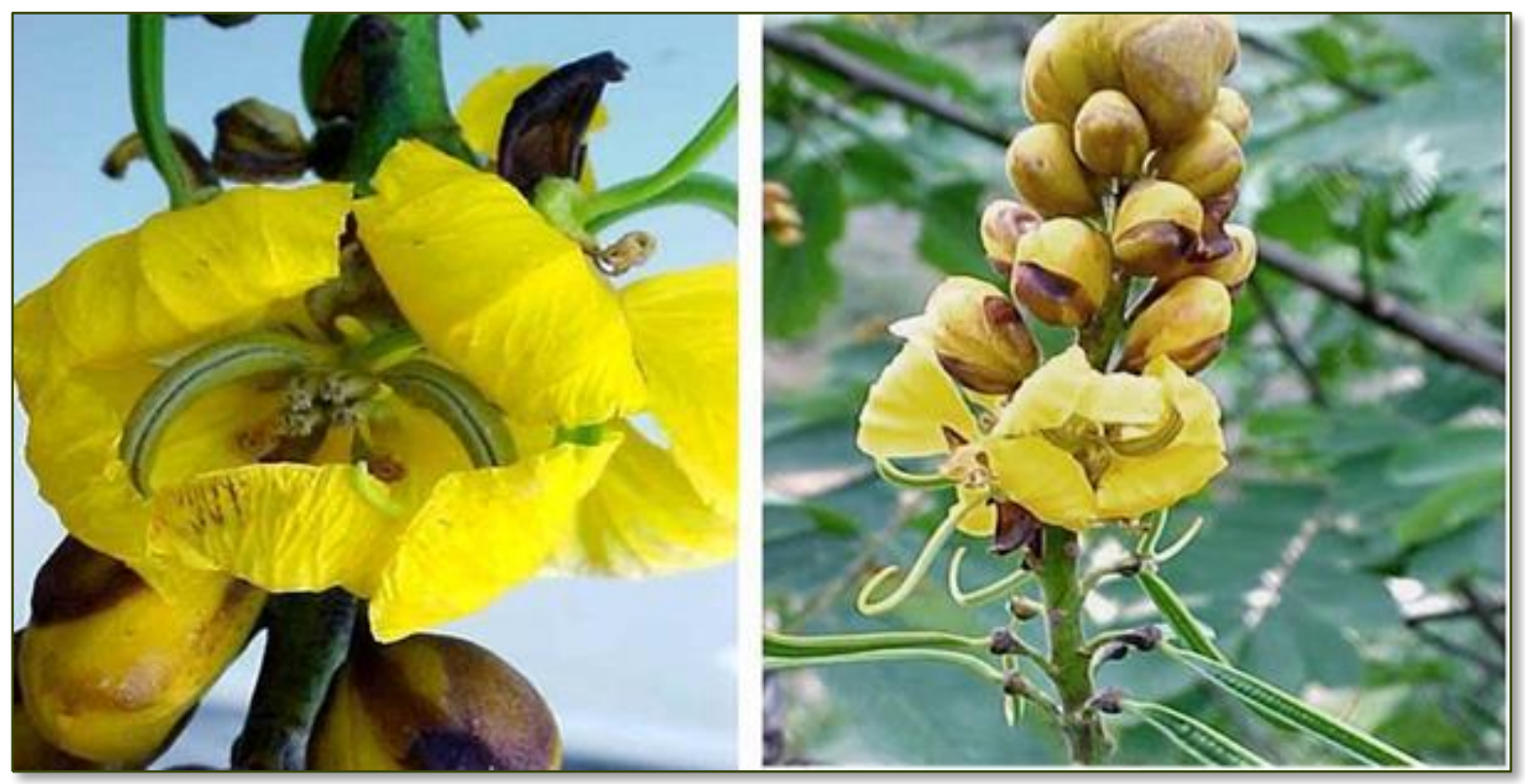

Fonte: Os autores (2015) 


\section{Descrição polínica}

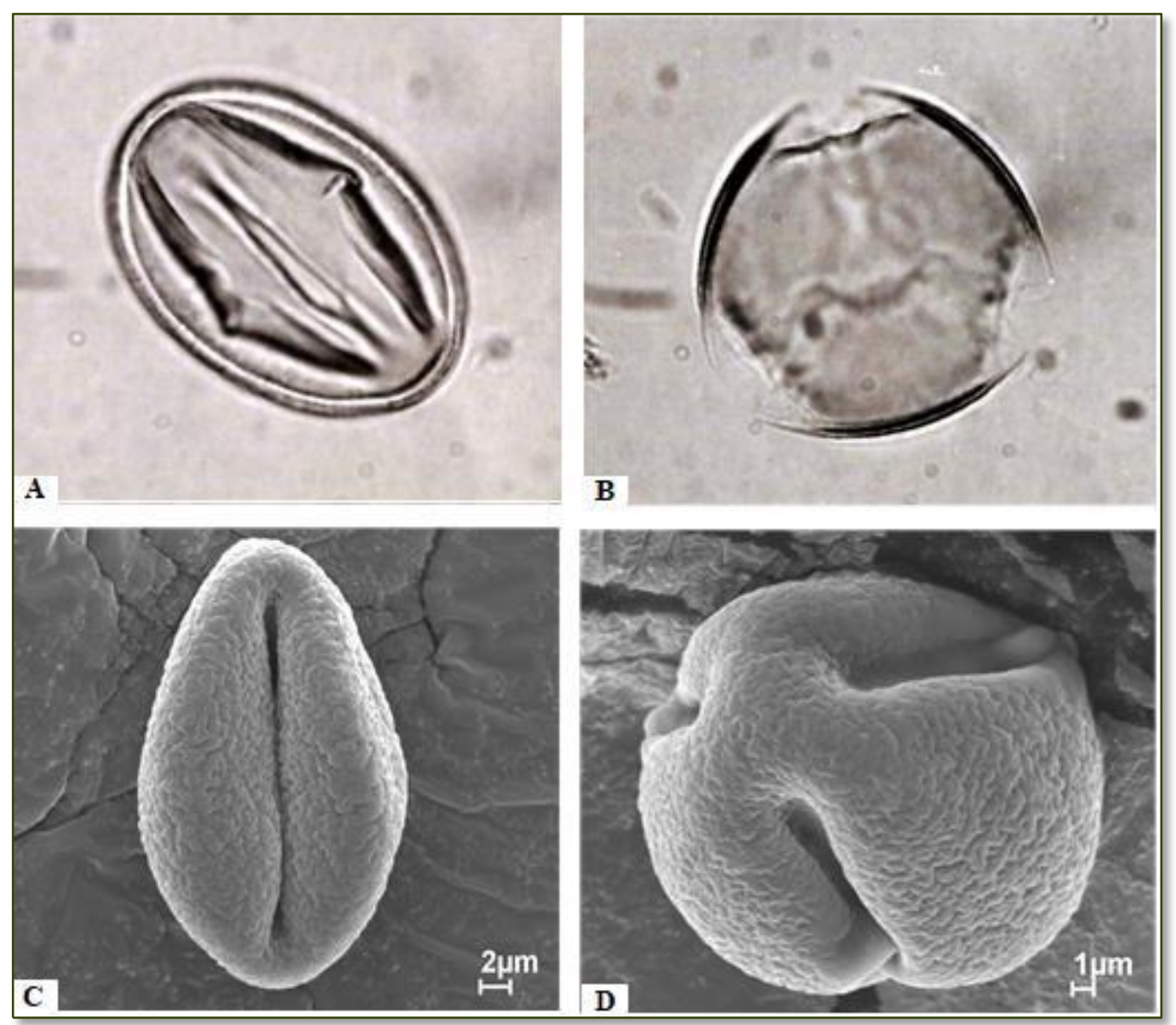

Fonte: Os autores (2015)

Forma - grãos de pólen médios, isopolares, oblatos, âmbito subtriangular e elípticos. Aberturas - tricolporados, colpos largos, endoaberturas lalongadas (MEV (C). Exina - rugulada, tectada, superfície fosulada (MEV (D).

Medidas - (micra) 18-20 $\mu \mathrm{m}$ em vista polar (P) e 30-32 $\mu \mathrm{m}$ em vista equatorial (E).

Material examinado - flores frescas coletadas em quintais de agricultores familiares.

Referências - Carreira \& Barth, 2003, Erdtman, 1952, Melhem et al. 1993, SalgadoLabouriau, 1971.

**Microscopia eletrônica de varredura 


\section{Família: FABACEAE}

\section{Nome Científico: Senna occidentalis (L.) Link.}

Nomes Comuns: Mangerioba, fedegoso, mata-pasto, café negro.

Descrição Botânica: Arbusto ruderal, sendo mais comum do cerrado, atingindo até 1,5m de altura; folhas compostas, coriáceas; inflorescências com flores amarelas; fruto tipo vagem, comprida de cor amarronzada.

Origem: América Tropical, naturalizada na África Oriental, Sul e Leste dos Estados Unidos (USA).

Distribuição Geográfica: Distribuição pantropical.

Uso Medicinal: É utilizado como diurético, para agravos do fígado, indicado contra febres e resfriados, é vermífugo. Por ser abortiva é contraindicado para mulheres gestantes. Indicado também para problemas de estômago, insuficiência biliar, malária, anemia, edema, fadiga, gonorréia, desordem menstrual, desordem urinária, tuberculose, fraqueza, verminose, pneumonia, edema, asma. A folha é usada contra dermatoses e queimaduras.

Referências: Lombardo, M. et al. 2009, Luna, V.S. 2013, Odeja, O.O. et al. 2014.

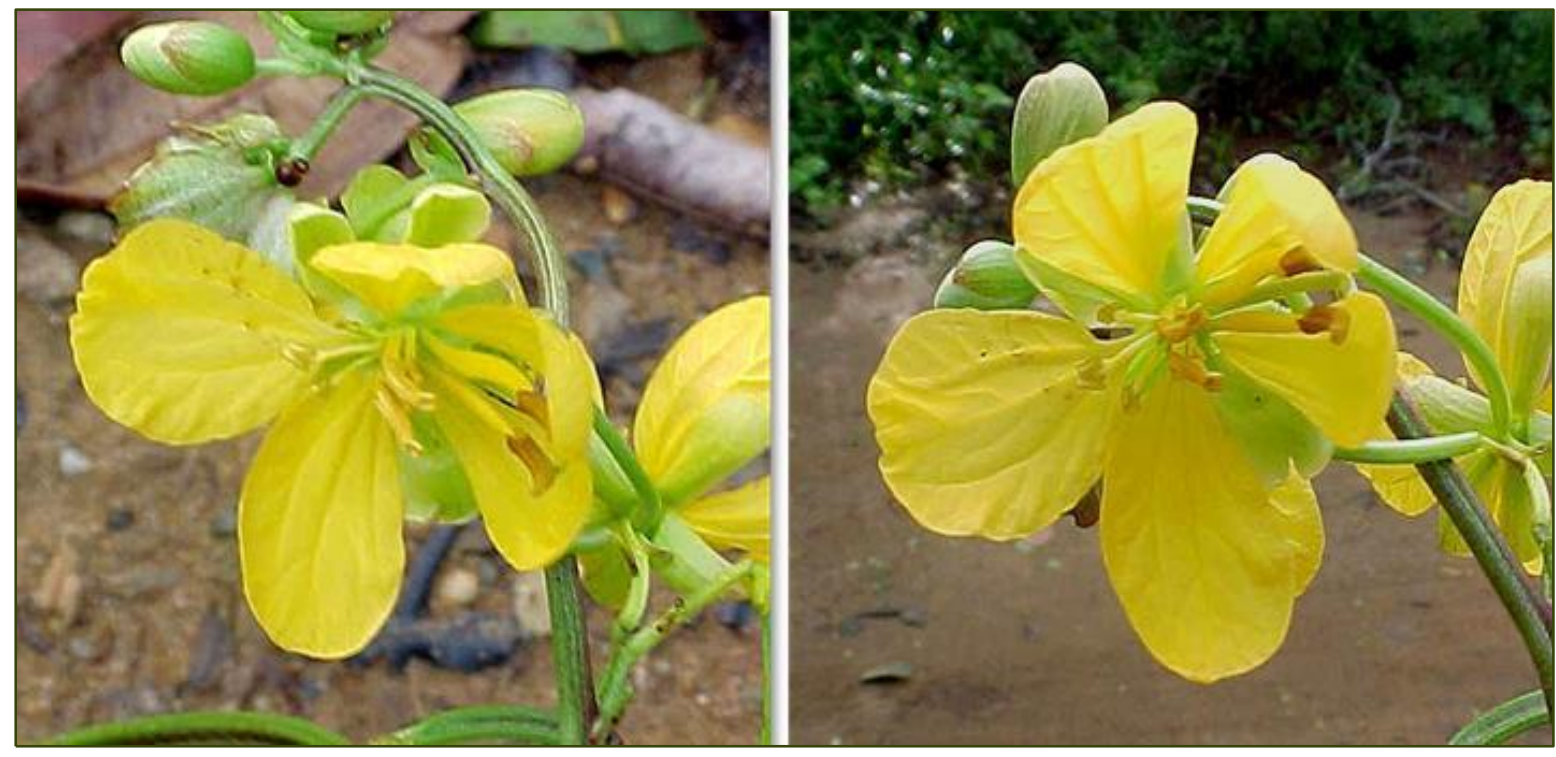

Fonte: Os autores (2015) 


\section{Descrição polínica}

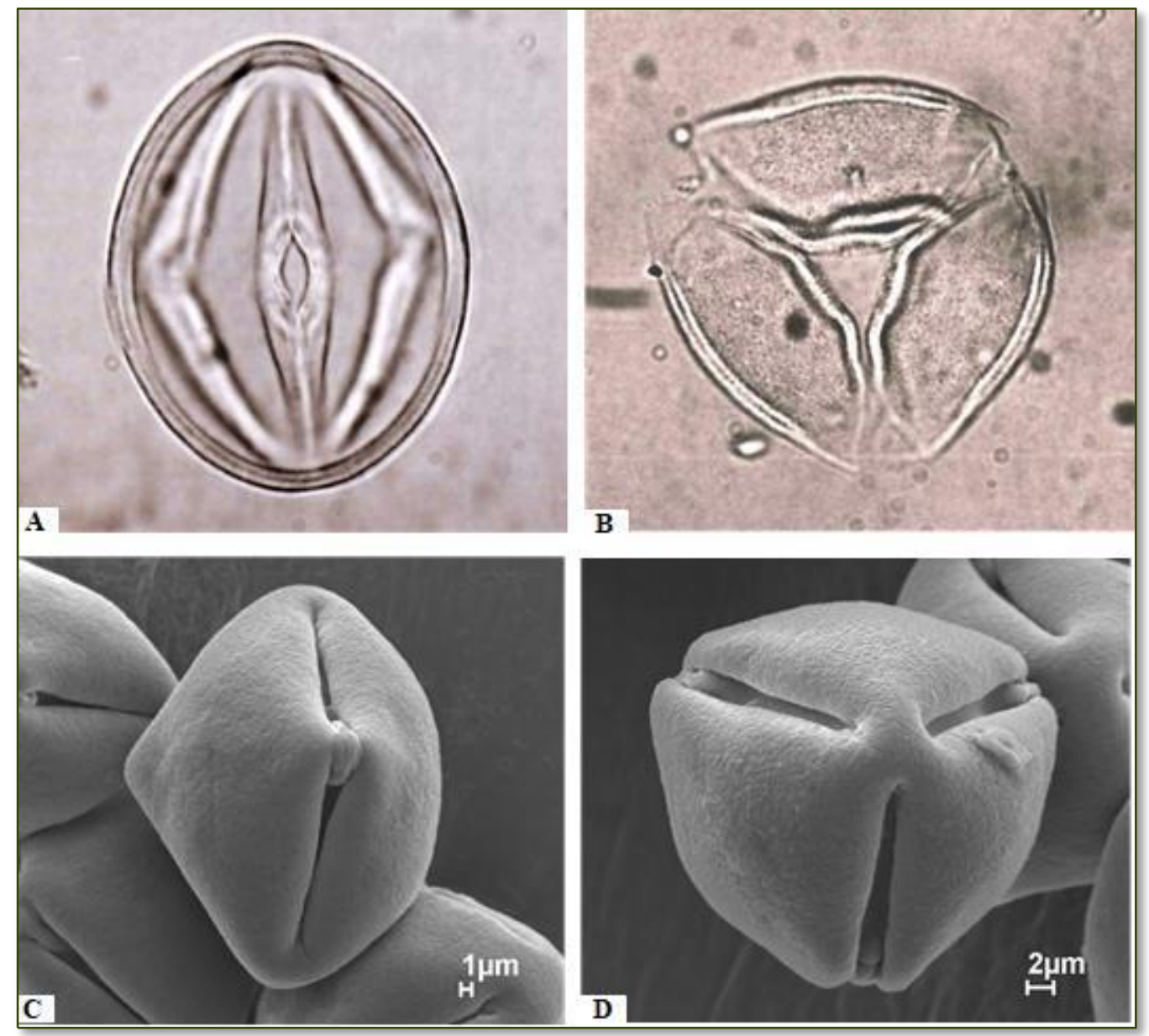

Fonte: Os autores (2015)

Forma - grãos de pólen médios, prolatos, isopolares, âmbito triangulares e elípticos.

Aberturas - tricolporados, colpos largos, endoaberturas lalongadas (MF (A) e MEV

Exina - rugulada, tectada (MEV (C/D).

Medidas - (micra) 34-36 $\mu \mathrm{m}$ em vista polar (P) e 30-32 $\mu \mathrm{m}$ em vista equatorial (E).

Material examinado - flores frescas coletadas em quintais de agricultores familiares.

Referências - Carreira \& Barth, 2003, Erdtman, 1952, Melhem et al. 1993, SalgadoLabouriau, 1971.

*Microscopia fotônica

**Microscopia eletrônica de varredura 
Família: FABACEAE

\section{Nome Científico: Senna reticulata (Willd.) H.S. Irwin \& Barneby}

Nomes Comuns: Mata pasto da várzea, manjerioba grande, maria mole.

Descrição Botânica: Árvore pequena de até 8 metros, folíolos 7-13 pares oblongos e obovados e assimétricos, inflorescências axilares a subterminais, multiflorais, sépalas oblongas obovadas, pétalas amarelas, oblongas obovadas ou obovadas-flabeldas, frutos legumes contendo em média 15 sementes tolerantes a dessecação, dispersas por hidro e anemocoria.

Origem: Amazônia.

Distribuição Geográfica: Em quase toda América Latina, considerada árvore pioneira das planícies Amazônicas, adapta-se rapidamente em planícies inundadas.

Uso Medicinal: Utilizada nas obstruções do fígado e no combate ao reumatismo, para a maioria desses gêneros há relatos da presença de antraquinonas, com revelante atividade biológica.

Referências: Grandis, A. 2010, Revilla, J. 2002, Santos, R.N. \& Silva, M.G.V. 2008.

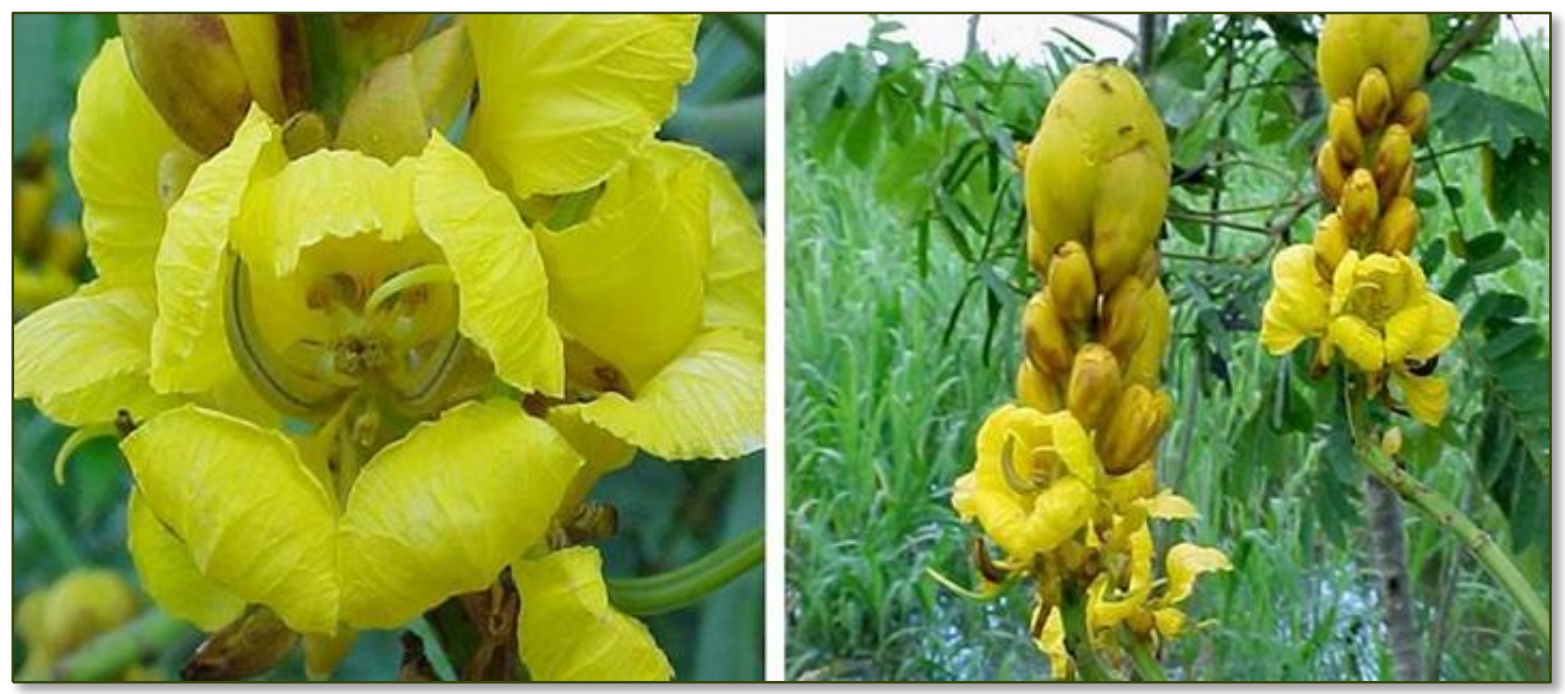

Fonte: Os autores (2015) 


\section{Descrição polínica}

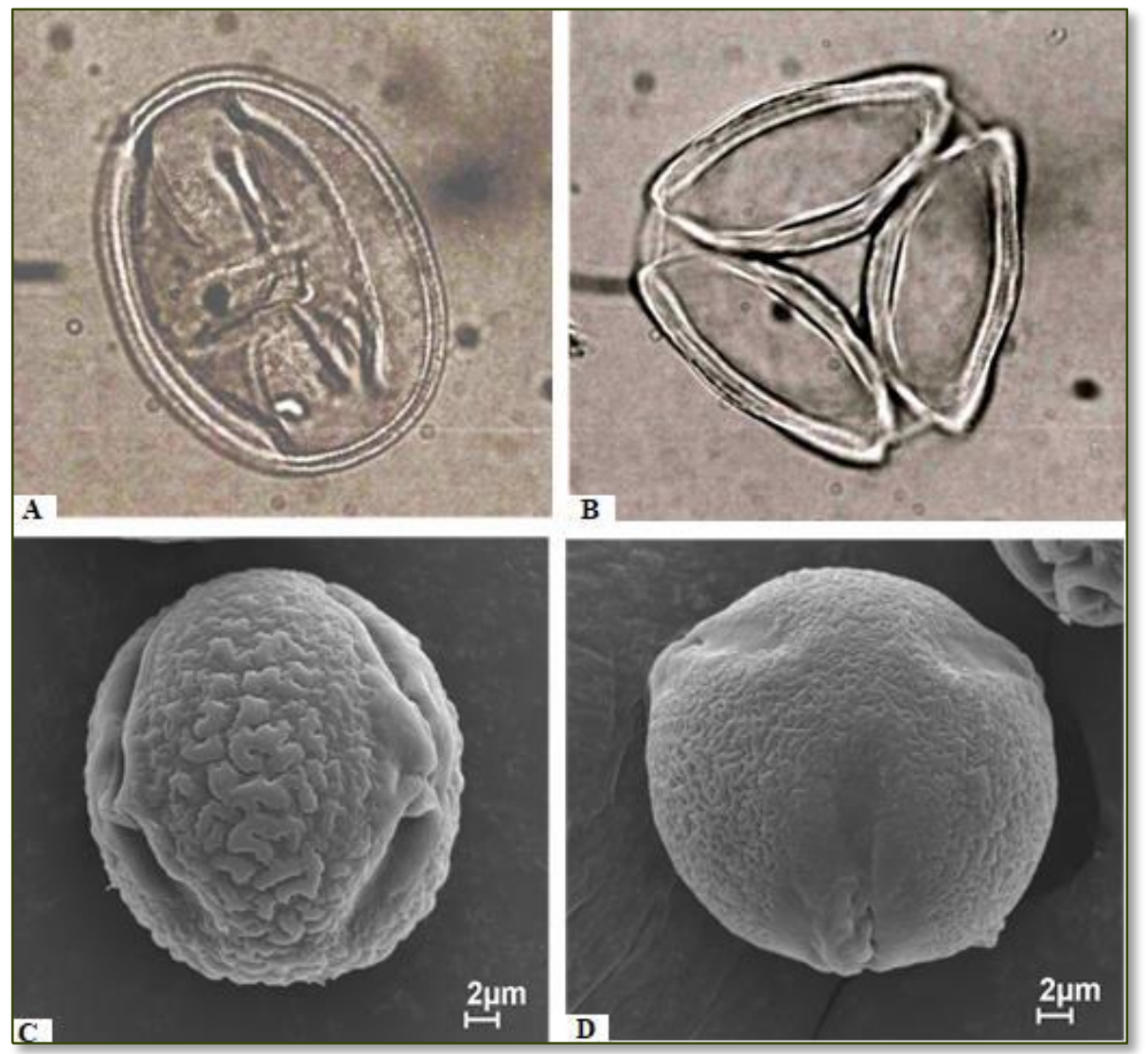

Fonte: Os autores (2015)

Forma - grãos de pólen médios a grandes, prolatos, isopolares, âmbito triangulares e elípticos.

Aberturas - tricolporados, colpos largos, endoaberturas lalongadas (MF (B) e MEV

Exina - rugulada, fosulada, vermiforme (MEV

(C).

Medidas - (micra) 40-51 $\mu \mathrm{m}$ em vista polar (P) e 58-64 $\mu \mathrm{m}$ em vista equatorial (E).

Material examinado - flores frescas coletadas em quintais de agricultores familiares.

Referências - Carreira \& Barth, 2003, Erdtman, 1952, Melhem et al. 1993, SalgadoLabouriau, 1971.

*Microscopia fotônica

***Microscopia eletrônica de varredura 
Família: FABACEAE

\section{Nome Científico: Senna tapajozensis (Ducke) H.S. Irwin \& Barneby}

\section{Nomes Comuns: Sena}

Descrição Botânica: Folhas compostas, alternas, paripenadas, com 2 pares de folíolos glabros. Inflorescência racemosa, terminal, com muitas flores amarelas, pediceladas. Pedúnculo do fruto com 3,25 a $4,63 \mathrm{~cm}$ comprimento, sublenhoso, estriado, cálice persistente, rígido, puberulento, pelos adpressos, castanhos claros. Folículo reto a ligeiramente encurvado, seco, deiscente, unilocular, monocarpelar, placentação marginal, polispérmico, bisseriado, 76 a 155 sementes por fruto, separadas por uma camada resinosa. Estenocárpico, estreitamente oblongo, ápice arredondado, apiculado. De 0,3 cm de comprimento, base cuneada atenuada, sub-estipitada, estipe espessado, com pelos semelhantes ao pedúnculo; margens ligeiramente impressas, em ambas as suturas, constrictas, abrindo-se pela sutura ventral, nervura dorsal caracterizada por uma linha rígida e saliente que vai do ápice do estipe ao fruto. Fruto imaturo verde, maduro em tons castanhos. Pericarpo maduro seco, sublenhoso, delgado, externamente opaco, irregular com depressões, faces suavemente onduladas, com nervuras transversais levemente elevadas e raros pelos simples, resina castanho escura, com aroma adocicado, constituindo os septos (em corte transversal apresentam-se semelhantes a favos) que separam as sementes, as quais ficam presas, mesmo após a deiscência do fruto.

Origem: América do Sul

Distribuição Geográfica: Todo o Brasil.

Uso Medicinal: Laxante, congestão encefálica, febre, excesso de bolo fecal. Não utilizar em gestantes e durante a menstruação.

Referências: Gurgel, E.S.C. et al. 2014, Souza, L.A.G. 2012.

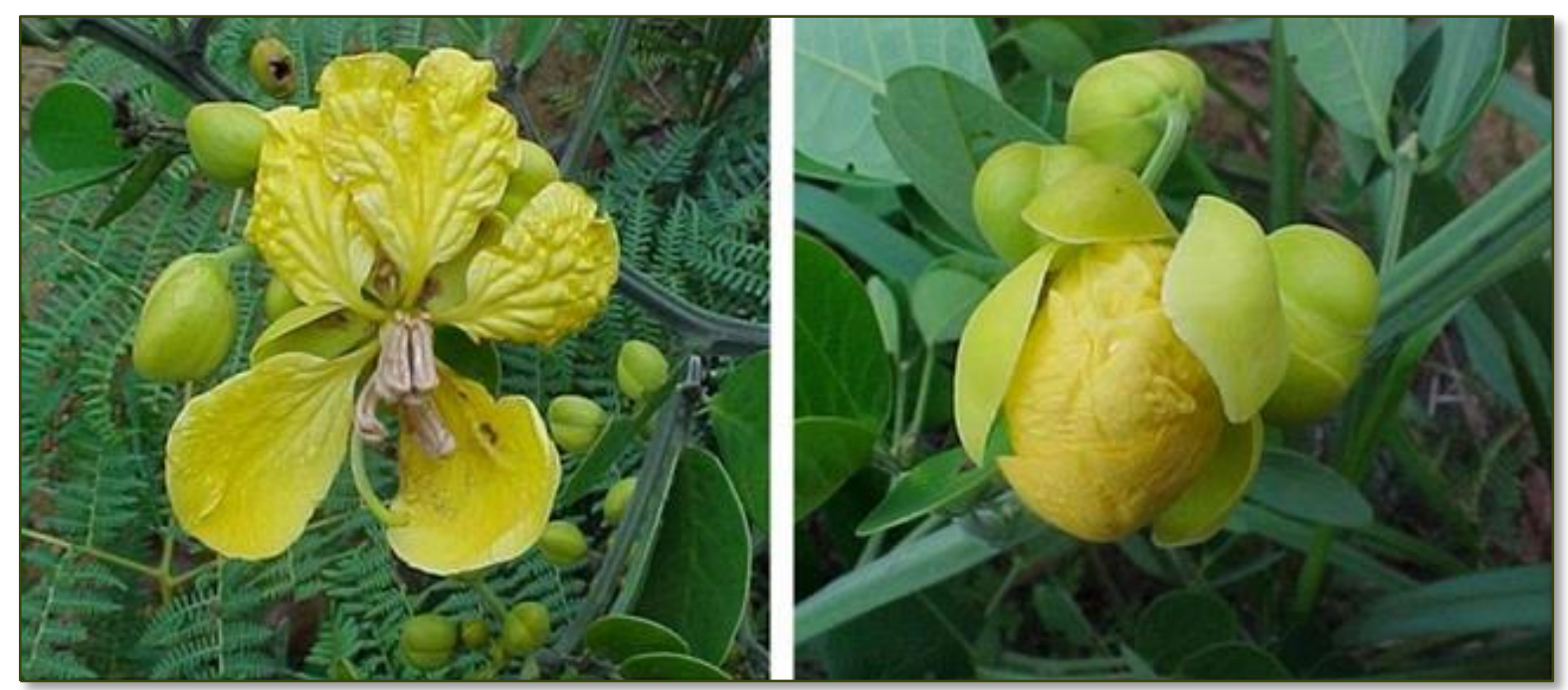

Fonte: Os autores (2015) 


\section{Descrição polínica}

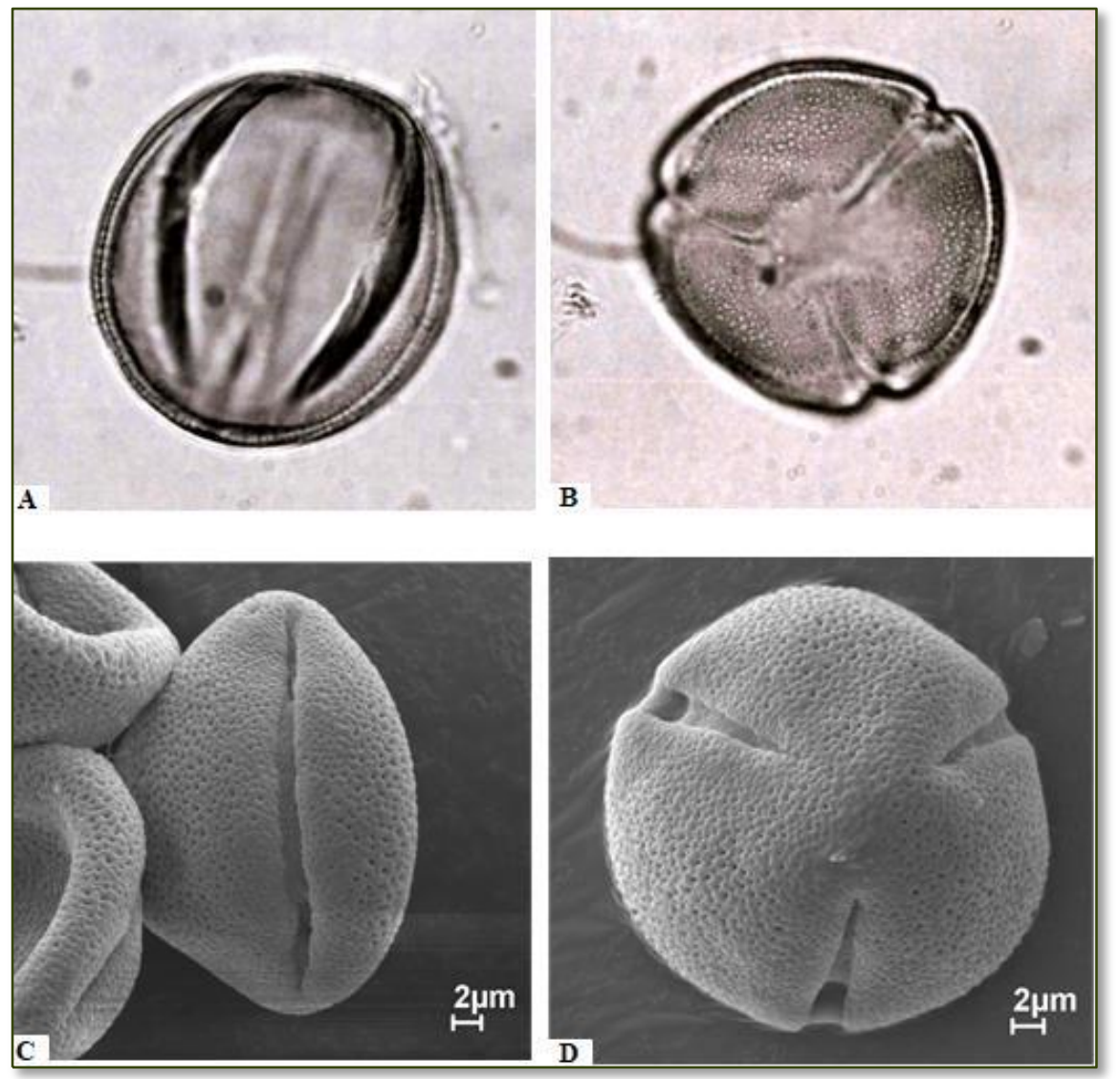

Fonte: Os autores (2015)

Forma - grãos de pólen médios, subprolatos a prolatos, isopolares, âmbito circular.

Aberturas - tricolporados, colpos longos, endoaberturas lalongada com poros bem visualizados (MEV

Exina - reticulada com perfurações no teto (MEV $\quad$ (C/D).

Medidas - (micra) 40-47 $\mu \mathrm{m}$ em vista polar (P) e 35-40 $\mu \mathrm{m}$ em vista equatorial (E).

Material examinado - flores frescas coletadas em quintais de agricultores familiares.

Referências - Carreira \& Barth, 2003, Erdtman, 1952, Melhem et al. 1993, SalgadoLabouriau, 1971.

*Microscopia fotônica

***Microscopia eletrônica de varredura 


\section{Família: FABACEAE}

\section{Nome Científico: Vatairea guianensis Aubl.}

Nomes Comuns: Faveira, fava-impigem, fava bolacha, fava mutum, faveiro, Angelim do igapó.

Descrição Botânica: Árvore monopodal, caducifólia, de 20 a $30 \mathrm{~m}$ de altura, de 0,5 a $2 \mathrm{~m}$ de diâmetro, de copa ampla, frondosa e heterogênea, com ramificação abundante de forma irregular, casca do tronco grossa e rugosa, com sucos longitudinais superficiais, de cor marrom a cinza esverdeada, de 2 a $2,5 \mathrm{~cm}$ de espessura, que exsuda resina translúcida. Folhas compostas, paripenadas alternas, com margens inteiras ou dentadas. Inflorescência em panículas terminais; flores numerosas, dioicas, pequenas, polígamas de cor amarelo esbranquiçada, frutos, drupas, ovoides, obovoides, casca fina e lisa de cor verde a amarelo. Endocarpo suculento com testa membranosa e relativamente grande contendo uma grande semente.

Origem: Região Amazônica.

Distribuição Geográfica: Distribuída desde o sul do México até o Sudeste do Brasil.

Uso Medicinal: Antimicótico, usado para tratar micoses superficiais.

Referências: Mariano, G.R.C. 2012, Ottobelli, I. et al. 2011, Revilla, J. 2000a, Revilla, J. \& Melo, L. 2000b.

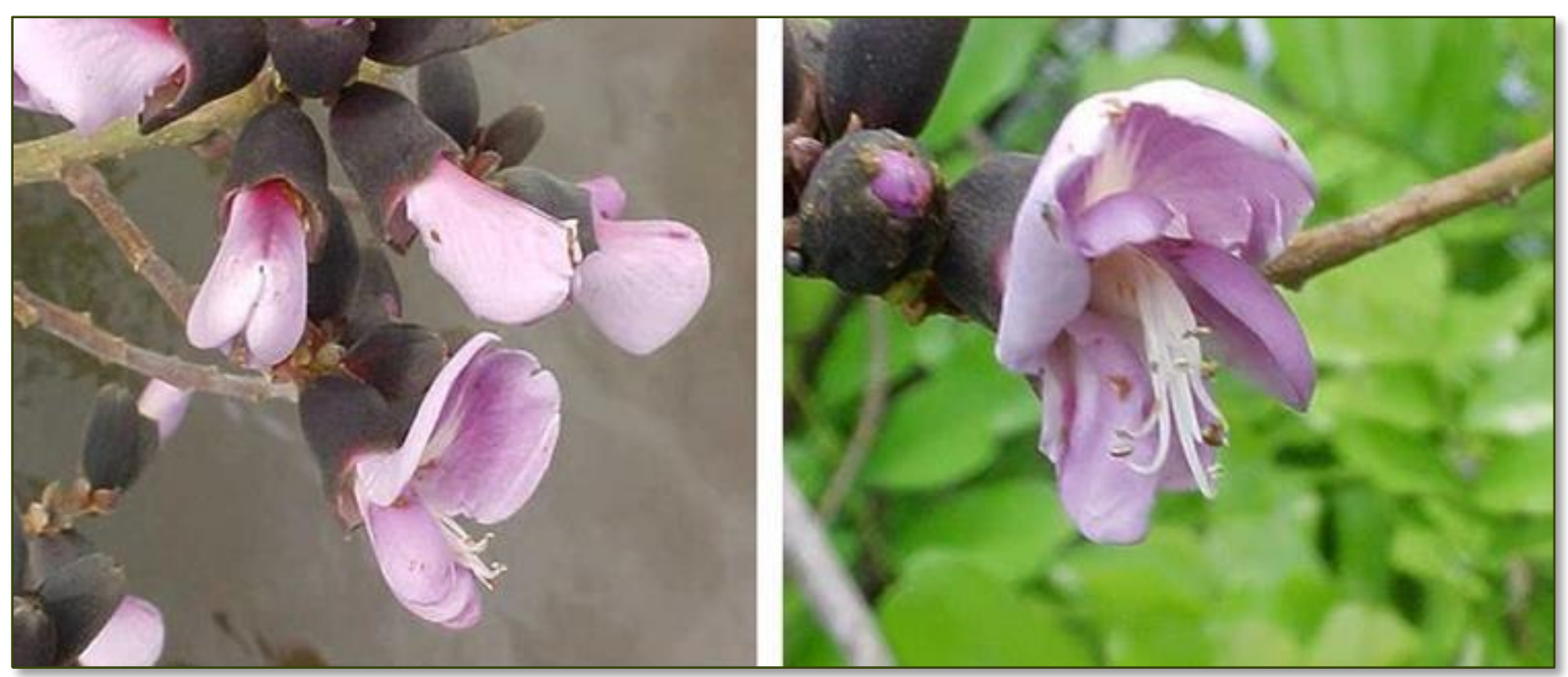

Fonte: Os autores (2015) 


\section{Descrição polínica}

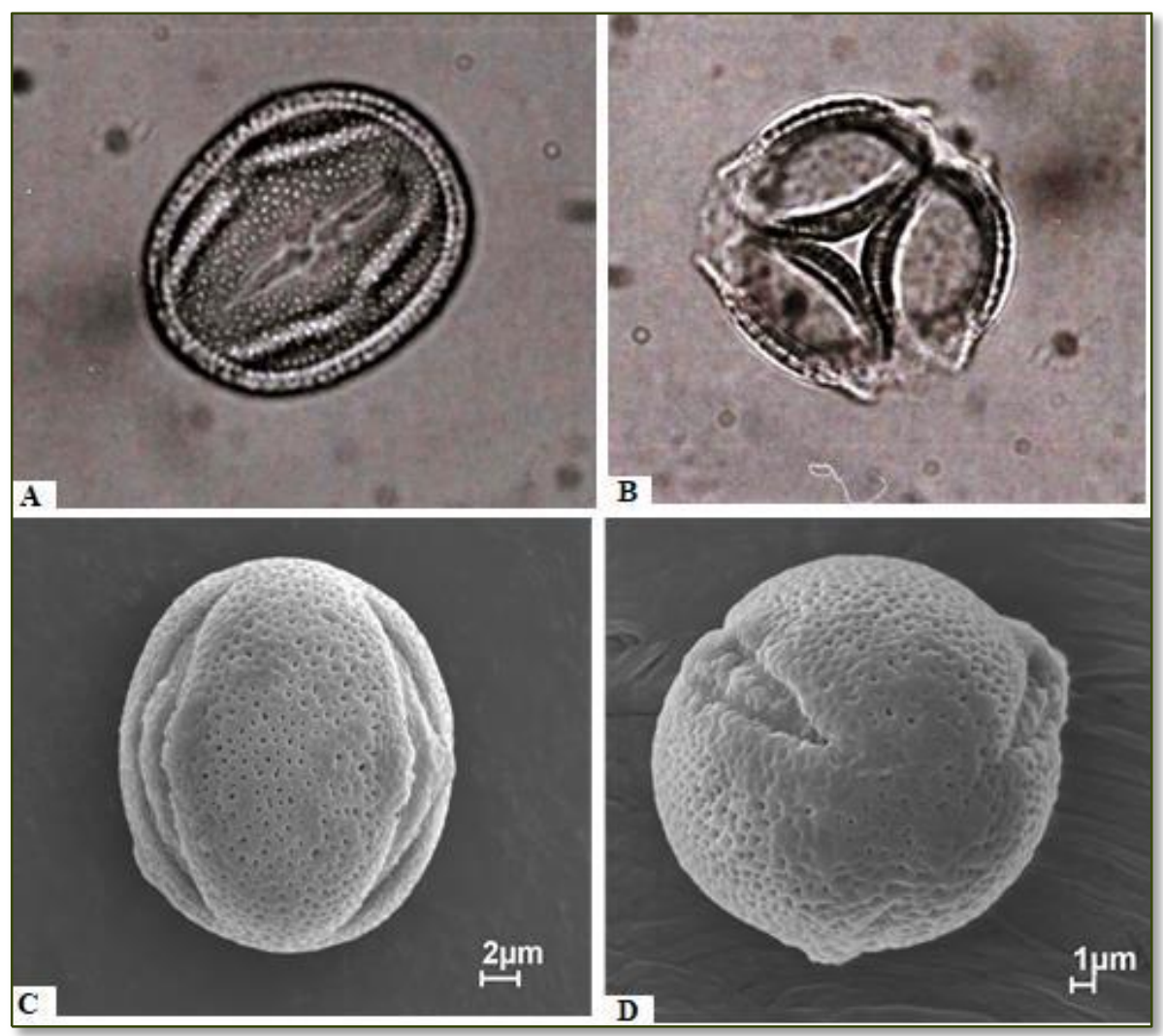

Fonte: Os autores (2015)

Forma - grãos de pólen médios, prolatos, isopolares, âmbito triangulares e elípticos.

Aberturas - tricolpados, colpos largos, endoaberturas lalongadas (MF (A) e MEV

Exina - reticulada com perfurações no teto (MEV (C/D).

Medidas - (micra) 42-50 $\mu \mathrm{m}$ em vista polar (P) e 35-37 $\mu \mathrm{m}$ em vista equatorial (E).

Material examinado - flores frescas coletadas em quintais de agricultores familiares.

Referências - Carreira \& Barth, 2003, Erdtman, 1952, Melhem et al. 1993, SalgadoLabouriau, 1971.

*Microscopia fotônica

**Microscopia eletrônica de varredura 
Família: LAMIACEAE

\section{Nome Científico: Ocimum micranthum Willd.}

Nomes Comuns: Alfavaca, alfavaca-da-América, alfavaca-do-campo, alfavaca-do-mato, manjericão-do-mato, segurelha, remédio-de-vaqueiro.

Descrição Botânica: Erva que cresce o ano inteiro, medindo de 1 a 3 palmos de altura, muito ramosa, com caule quadrangular, ereto, revestido com uma camada de pelos. As folhas são ovais, um tanto agudas, opostas, com os bordos denteados ou inteiros, quase lisas na face superior e esbranquiçadas na face inferior. Flores arroxeadas, avermelhadas brancas ou com diversas cores, organizadas em inflorescência na forma de espiga. Possui cheiro aromático e agradável.

Origem: Originária de países quentes inclusive o Brasil.

Distribuição Geográfica: Muito frequente em vários estados brasileiros. Ocorre também na Ásia tropical e Índia. É uma planta cultivada em todo o Mediterrâneo.

Uso Medicinal: Aromática, estimulante, carminativa, antifebril, sudorífera, diurética e estimulante, antiespasmódica, contra a dispepsia nervosa, galactagoga, contra a coqueluche, dores de cabeça, gripe e catarro no peito, estomáquica, antidiarréica, emoliente, contra os embaraços gástricos, elimina a areia dos rins, contra cólica renal, contra reumatismo, úlcera, tosse convulsiva, e irregularidade menstrual. Utiliza-se toda a planta, principalmente as folhas, sementes e essência.

Referências: Arogundade, 0.0. \& Adedeji, 0. 2009, Pattanayak, P. et al. 2010, Pereira, R.C.A. et al. 2009, Pereira, R.C.A. \& Moreira, A.L.M. 2011, Revilla, J. 2002, Rai, V. et al. 2004, Vieira, P.R.N. 2009.

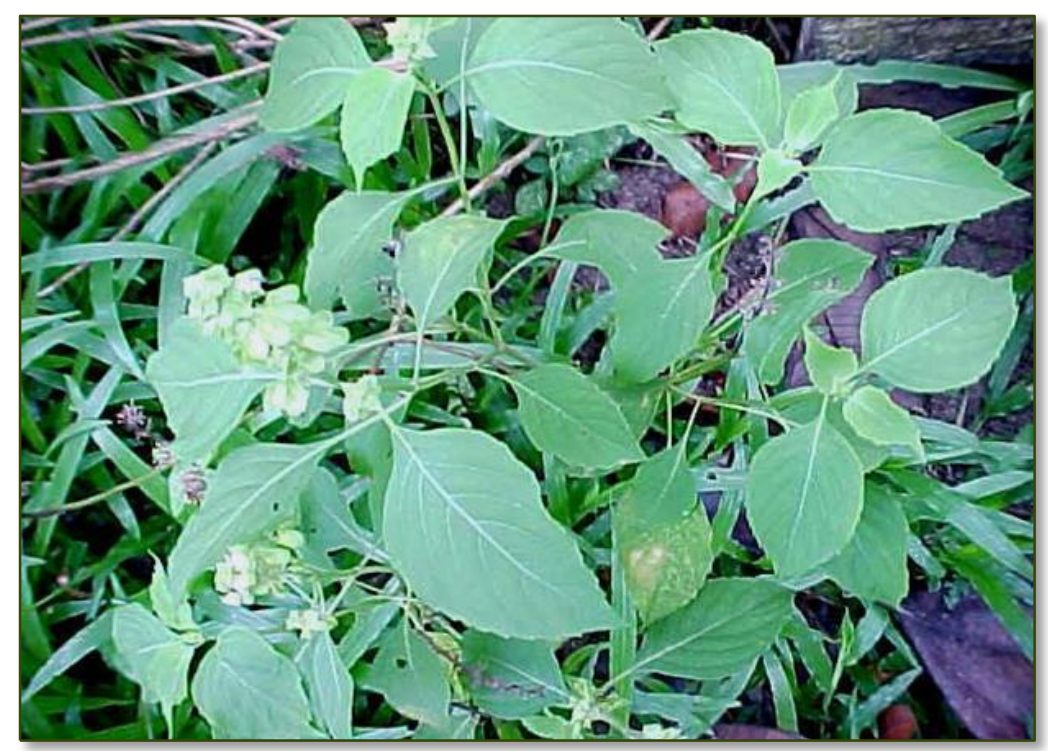

Fonte: Os autores (2015) 


\section{Descrição polínica}

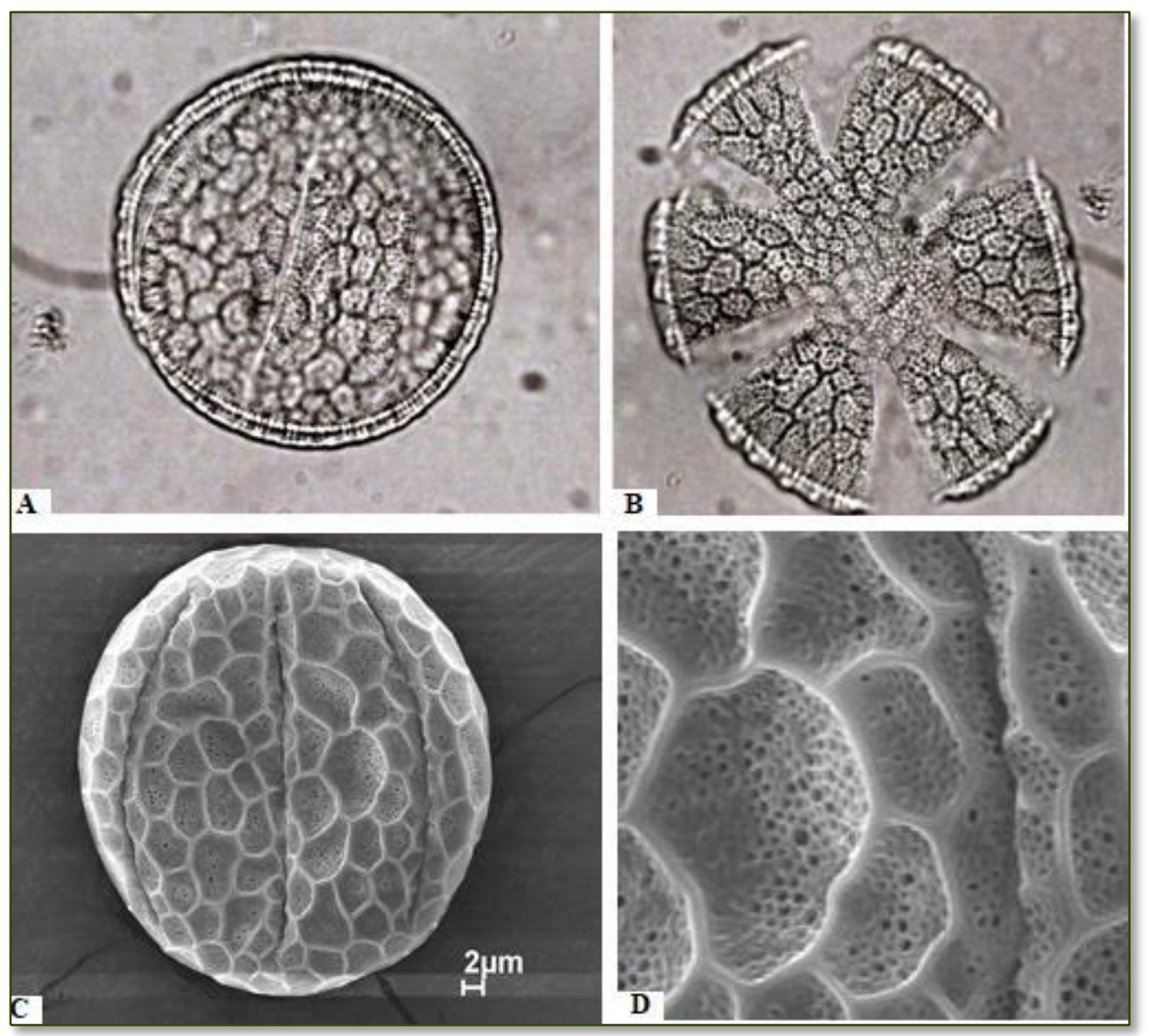

Fonte: Os autores (2015)

Forma - grãos de pólen médios, oblatos-esferoidais a prolatos, isopolares, âmbito circular ou elípticos.

Aberturas - 3(4) ou 6 colpados, colpos variando de acordo com a forma do grão, colpos zonoaperturados equidistantes, cobertos por membranas granuladas (MF (B) e MEV

Exina - reticulada, com reticulação grande bem visível (MEV $\quad$ (C/D).

Medidas - (micra) 25-47 $\mu \mathrm{m}$ em vista polar (P) e 26-49 $\mu \mathrm{m}$ em vista equatorial (E).

Material examinado - flores frescas coletadas em quintais de agricultores familiares.

Referências - Carreira \& Barth, 2003, Erdtman, 1952, Melhem et al. 1993, SalgadoLabouriau, 1971.

*Microscopia fotônica

**Microscopia eletrônica de varredura 
Família: LAMIACEAE

\section{Nome Científico: Scutellaria purpurascens Sw.}

\section{Nomes Comuns: Trevo roxo}

Descrição Botânica: A maioria das plantas desse gênero são plantas herbáceas anuais ou perenes de $5 \mathrm{~cm}$ a $1 \mathrm{~m}$ de altura, sendo alguns arbustos e aquáticas. Possuem 4 talos em ângulos e folhas opostas. As flores tem lábios superiores e inferiores. 0 gênero é reconhecido facilmente pela proteção típica no cálice que também incitou seu nome popular.

Origem: Nativa das Américas.

Distribuição Geográfica: América Tropical, o gênero é mundialmente encontrado em regiões temperadas e em montanhas tropicais.

Uso Medicinal: Otite (dor de ouvido).

Referências: Fernández-Alonso, J.L. et al. 2009, Forzza, R.C. et al. 2010, Rai, V. et al. 2012.

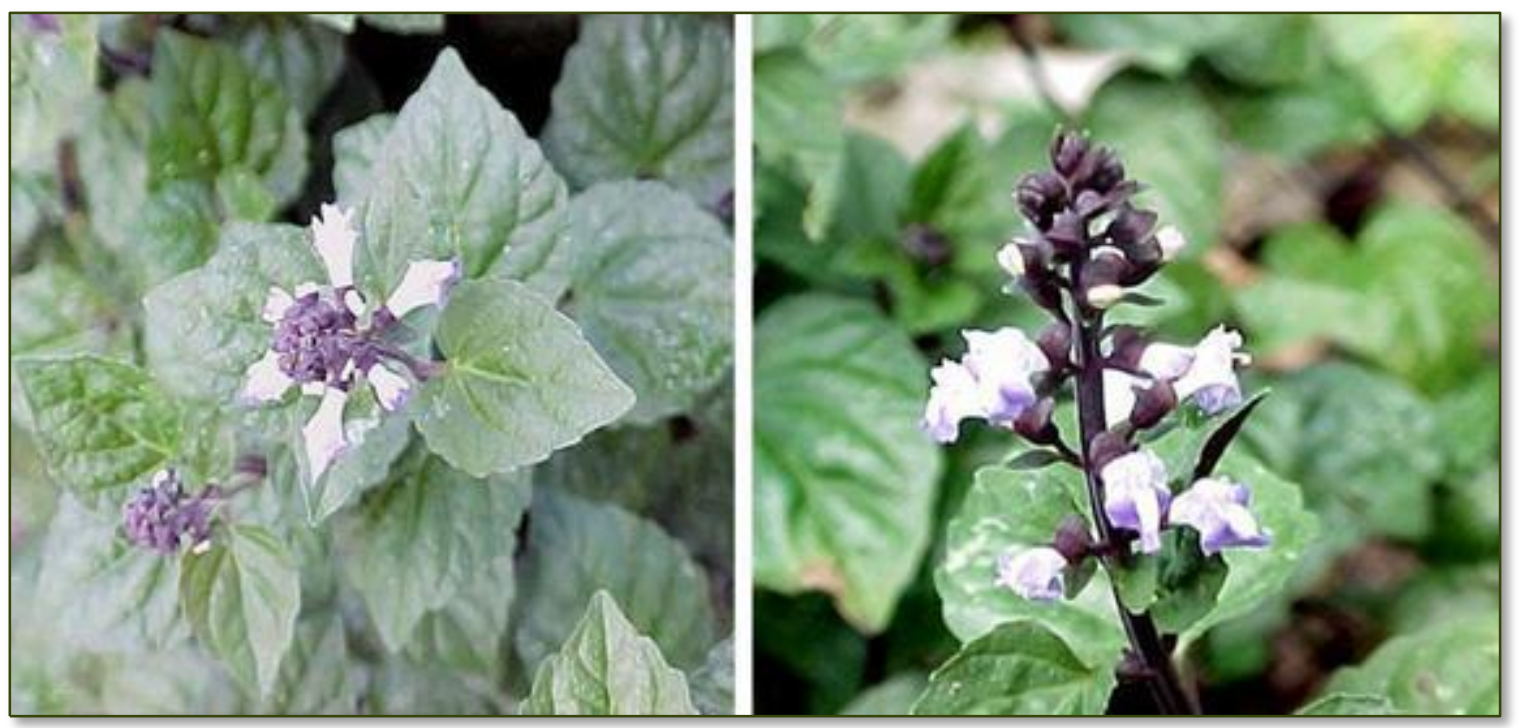

Fonte: Os autores (2015) 


\section{Descrição polínica}

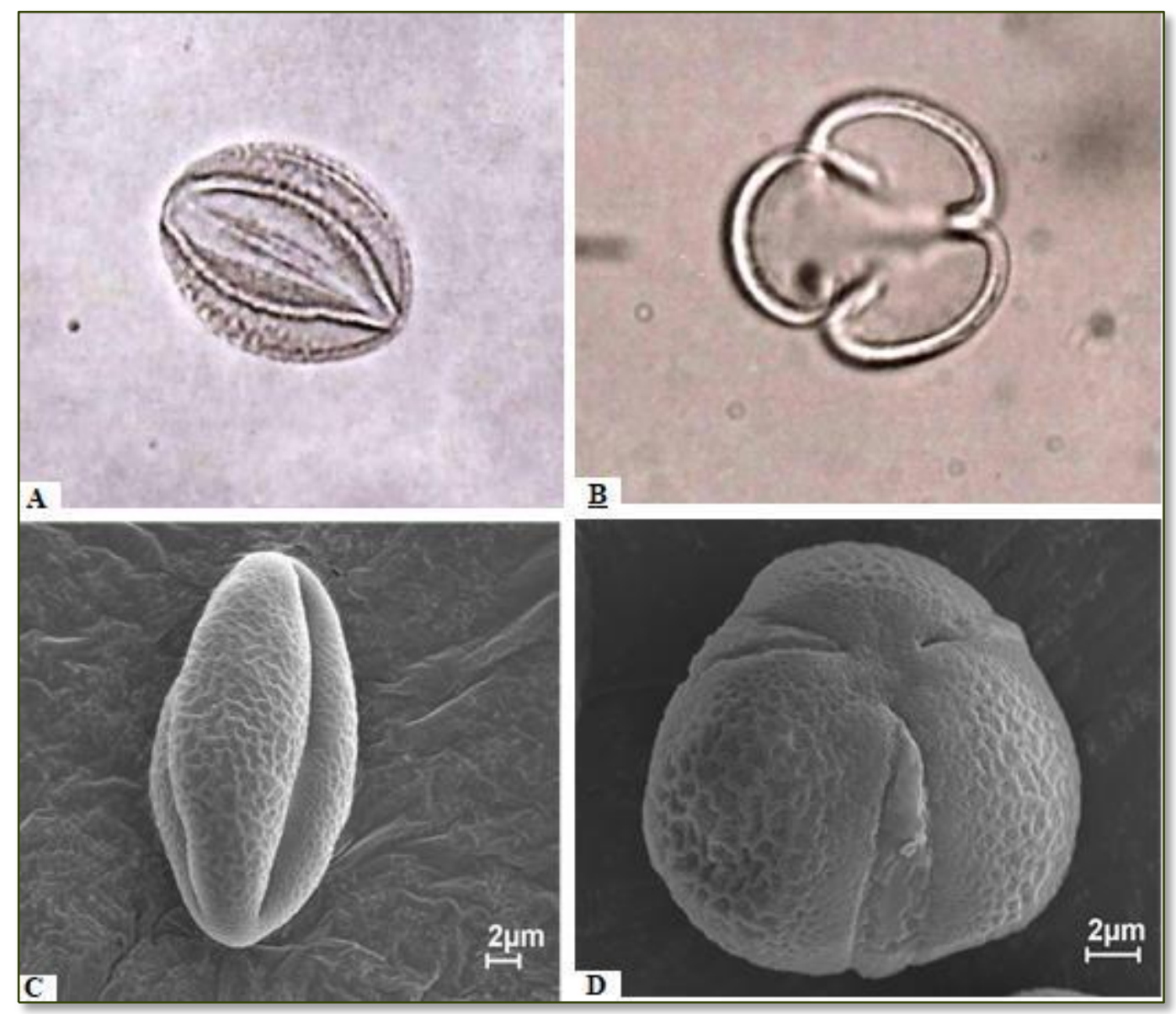

Fonte: Os autores (2015)

Forma - grãos de pólen pequenos a médios, prolatos, isopolares, âmbito circular ou elíptico. Aberturas - tricolpados, colpos largos, endoaberturas lalongadas (MF (A) e MEV (C/D).

Exina - reticulada, com reticulação com pontos de perfuração no teto (MEV (C/D).

Medidas - (micra) 20-22 $\mu \mathrm{m}$ em vista polar (P) e 10-16 $\mu \mathrm{m}$ em vista equatorial (E).

Material examinado - flores frescas coletadas em quintais de agricultores familiares.

Referências - Carreira \& Barth, 2003, Erdtman, 1952, Melhem et al. 1993, SalgadoLabouriau, 1971.

*Microscopia fotônica

***Microscopia eletrônica de varredura 
Família: LECYTHIDACEAE

\section{Nome Científico: Bertholletia excelsa Bonpl.}

Nomes Comuns: Castanha-do-Brasil, castanha da Amazônia, castanha-do-Pará.

Descrição Botânica: Árvore de grande porte, copa emergente, frequentemente atingindo de 30 a $50 \mathrm{~m}$ de altura. 0 tronco é ausente de galho até perto da copa, ereto e cilíndrico, medindo até 2,5 m de diâmetro à altura do peito, é revestido com uma casca áspera de cor cinza amarronzada com fissuras longitudinais conspícuas. A copa possui galhos bem separados e emerge no dossel da floresta, com tronco medindo de 100 a $180 \mathrm{~cm}$ de diâmetro. As folhas simples, arranjadas alternadamente nos galhos, macias em ambas as superfícies, com bainhas coriáceas oblongas, medindo 25 a $35 \mathrm{~cm}$ de comprimento por 8 a 15 $\mathrm{cm}$ de largura, fixadas em um pecíolo de 5 a $6 \mathrm{~cm}$ de comprimento. A inflorescência é, axilar em panículas terminais, de poucos ramos, eretas, ráquis angulosos de 12 a $16 \mathrm{~cm}$ de longitude. As flores são arranjadas em ramos, com uma ou duas ramificações, sendo raro mais de uma flor por inflorescência vingar fruto, elas medem de 3 a $4 \mathrm{~cm}$ de diâmetro quando completamente abertas, com seis pétalas, cada uma medindo $3 \mathrm{~cm}$ de comprimento, de tom amarelado pálido a branco cremoso. Os frutos apresentam-se em formas de cápsulas (ouriços) grandes e arredondados (10 a $20 \mathrm{~cm}$ de diâmetro), bastante pesadas $(0,5$ a 2,5 $\mathrm{kg}$ ), com aspecto lenhoso, contendo 10 a 25 sementes em seu interior. As sementes possuem corte transversal e triangulares e medem 3,5 a $5 \mathrm{~cm}$ de comprimento por $2 \mathrm{~cm}$ de largura e pesam 4 a 10 gramas cada uma. A parte comestível do fruto é de fato, a semente, conhecida como castanha na linguagem popular.

Origem: Brasil.

Distribuição Geográfica: Região Amazônica.

Uso Medicinal: É emoliente, excelente fonte alimentar, antioxidante devido o alto teor de selênio, inseticida, energizante e hidratante. Utilizado no tratamento de hepatite, anemia, diabetes, albumina, icterícia e outras enfermidades do sistema hepático. Também pode ser utilizado como cicatrizante e no combate a desnutrição.

Referências: Gonçalves, A.L. 2007, Revilla, J. 2002.

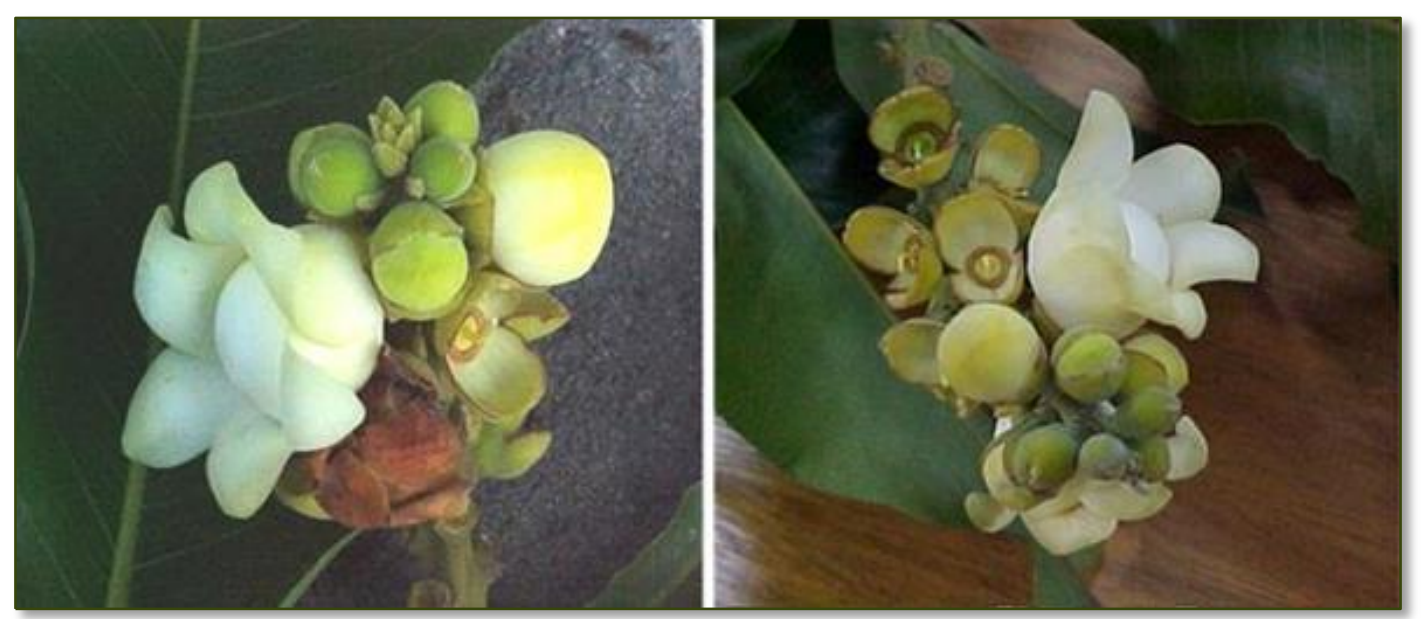

Fonte: Os autores (2015) 


\section{Descrição polínica}

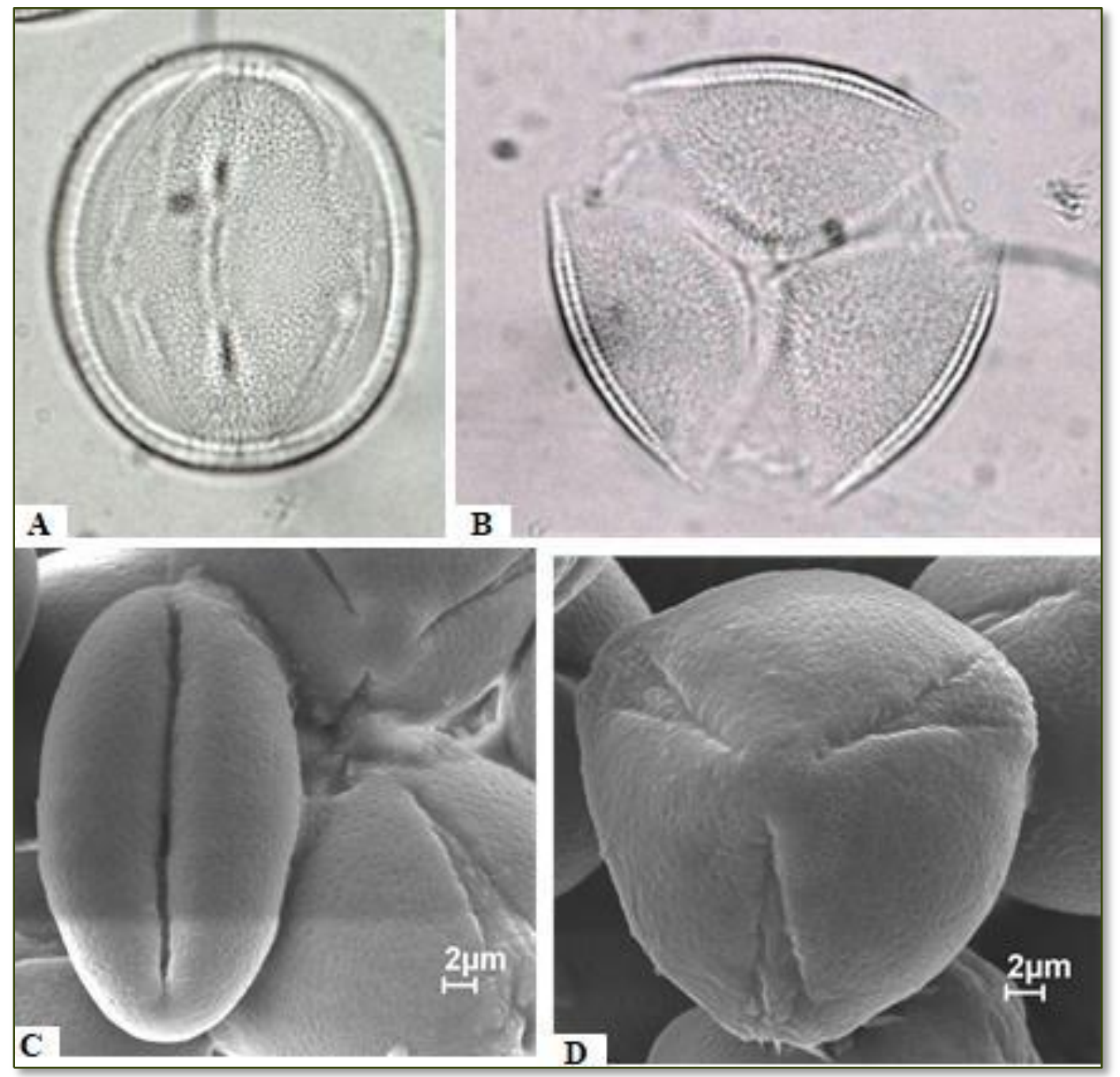

Fonte: Os autores (2015)

Forma - grãos de pólen médios a grandes, subprolatos a oblato-esferoidais, isopolares, âmbito elíptico.

Aberturas - tricolporados, colpos cobertos por membranas granuladas, endoaberturas lalongadas (MEV (D).

Exina - reticulada, com reticulação com pontos de perfuração no teto (MEV IC/D).

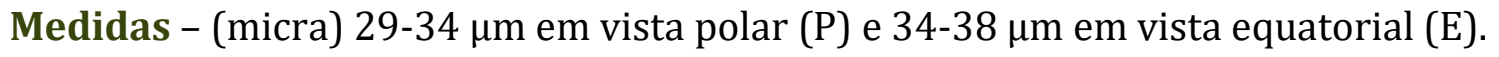

Material examinado - flores frescas coletadas em quintais de agricultores familiares.

Referências - Carreira \& Barth, 2003, Erdtman, 1952, Melhem et al. 1993, SalgadoLabouriau, 1971.

**Microscopia eletrônica de varredura 
Família: LORANTHACEAE

Nome Científico: Psittacanthus cucullaris (Lam.) G. Don Sinonímia: Psittacanthus falcifrons (Mart) Mart. [Kuijt, 2009]

Nomes Comuns: Conhecida como erva-de-passarinho.

Descrição Botânica: Arbusto hemiparasita, raras vezes arbóreo terrestres, erectos escandescentes, com flores amarelas ou alaranjadas, de igapó, monoicos, dioicos ou hermafroditas, algumas vezes com raízes aéreas, fixando ao hospedeiro por meio de haustórios mais ou menos lenhosos. Folhas simples, opostas, subpostas, raramente verticiladas ou alternas, algumas vezes reduzidas a escamas ou ausentes; lâmina inteira, coriácea ou papirácea, com cloroplastos mascarados por pigmentos amarelados. Inflorescências espiciforme, racemiforme, paniculiforme ou umbeliforme, sendo a unidade básica um dicásio. Flores bissexuais ou unissexuais, actinomorfas, sésseis ou pendunculadas, vistosas diclamídeas; caulículo presente, cálice iguais ou diferentes em tamanho e forma; pétalas livres ou unidas formando um tubo; estames 4-6 (-8), opostos algumas vezes epipétalos as pétalas, anteras dorsifixas ou basifixas, algumas vezes ditrimórficas; pólen trilobado, exina dentada, ovário ínfero, 3-4 carpelos, unilocular, óvulo solitário e não claramente diferenciado. Fruto uma baga, raramente uma drupa, sementes desnudas, testa ausente, e pericarpo envolto no endosperma, endosperma composto com ou sem clorofila.

\section{Origem: Amazônia.}

Distribuição Geográfica: São distribuídas em sua grande maioria nas regiões tropicais e subtropicais do mundo, especialmente no hemisfério sul.

Uso Medicinal: Utilizado como fitoterápico, na Colômbia seu uso é principalmente caseiro sem comprovação científica, as folhas são usadas como emenagogo, abortivo, diurético, hipotensor, antipirético, o cozimento de suas folhas e flores é utilizado para tratar feridas e a água destilada das mesmas são utilizadas como cosméticos; contém um alcalóide que é purgante; a decocção de uma parte da planta é usada em gargarejos e cura angina e amidalites crônicas. No Amazonas algumas Loranthaceae são utilizadas em emplastros para curar fraturas ósseas.

Referências: Dueñas-Gomez, H.C. \& Franco-Roselli, P. 2001, Kuijt, J. 2009, Revilla, J. 2002, Sinha, A. et al. 1999.

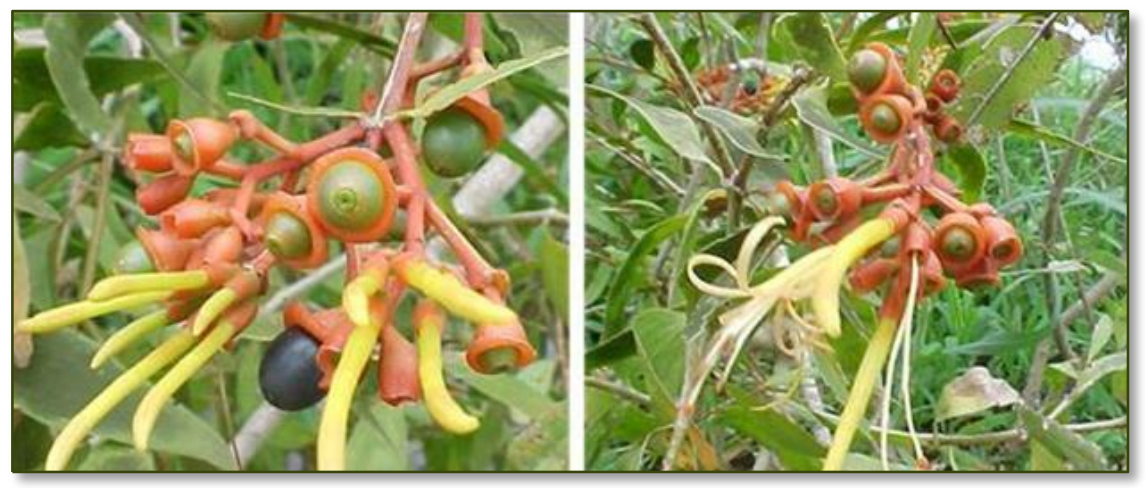

Fonte: Os autores (2015) 


\section{Descrição polínica}

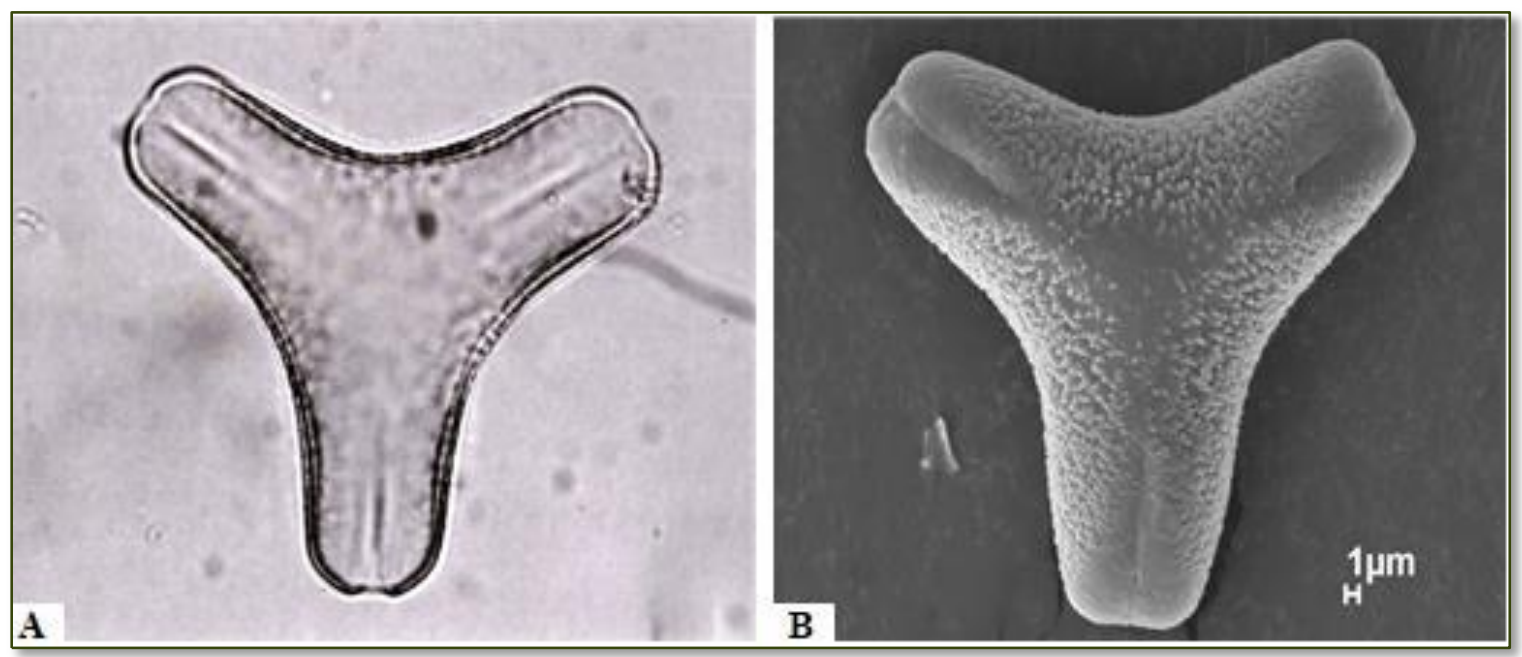

Fonte: Os autores (2015)

Forma - grãos de pólen médios, oblato, âmbito triangular, com os lados ligeiramente côncavos e vértices achatados.

Aberturas - tricolpados, sincolpados, colpos com margens não muito largas, psiladas (MF (A) MEV (B).

Exina - reticulada, baculada, com reticulação de forma cilindrica (MEV

Medidas - (micra) 42-48 $\mu \mathrm{m}$ em vista polar triangular (P).

Material examinado - flores frescas coletadas em quintais de agricultores familiares.

Referências - Carreira \& Barth, 2003, Erdtman, 1952, Melhem et al. 1993, SalgadoLabouriau, 1971.

*Microscopia fotônica

**Microscopia eletrônica de varredura 


\section{Família: MALVACEAE}

\section{Nome Científico: Gossypium barbadense L.}

Nomes Comuns: Algodão roxo, algodoeiro, algodão creoulo, algodão da costa, algodão folha de parreira.

Descrição Botânica: Arbusto a árvore pequena de folhas muito diferentes em formas, flores amarelas com brácteas verdes,fibras longas e finas, diferentes cores desde o branco a marrom,sem lunagem, fruto uma cápsula dura, dividida em celdas, sementes separadas pretas. 0 nome do gênero Gossypium descrito por Carl Linnaeus vem de gossium (barrete), papo (se refere a cápsula).

Origem: América Central.

Distribuição Geográfica: América Tropical, e distribuídas a todas as zonas tropicais e subtropicais do mundo.

Uso Medicinal: Utiliza-se a raiz, folha, flores e sementes para os mais variados fins como: diurético, curar feridas, dor de ouvido, fungos, antisséptico, tosse, hepatite, cefaléia, febres, gases, cólicas dores menstruais, reumatismo, anti-hipertensivo. É expectorante, antimalárico; contra hemorragias do ovário no desarranjo menstrual.

Referências: Almeida, V.C. 2007, Hasrat, J.A. et al. 2004, Panizza, F. et al. 2009, Revilla, J. 2002, Wendel, J.F. et al. 1992.

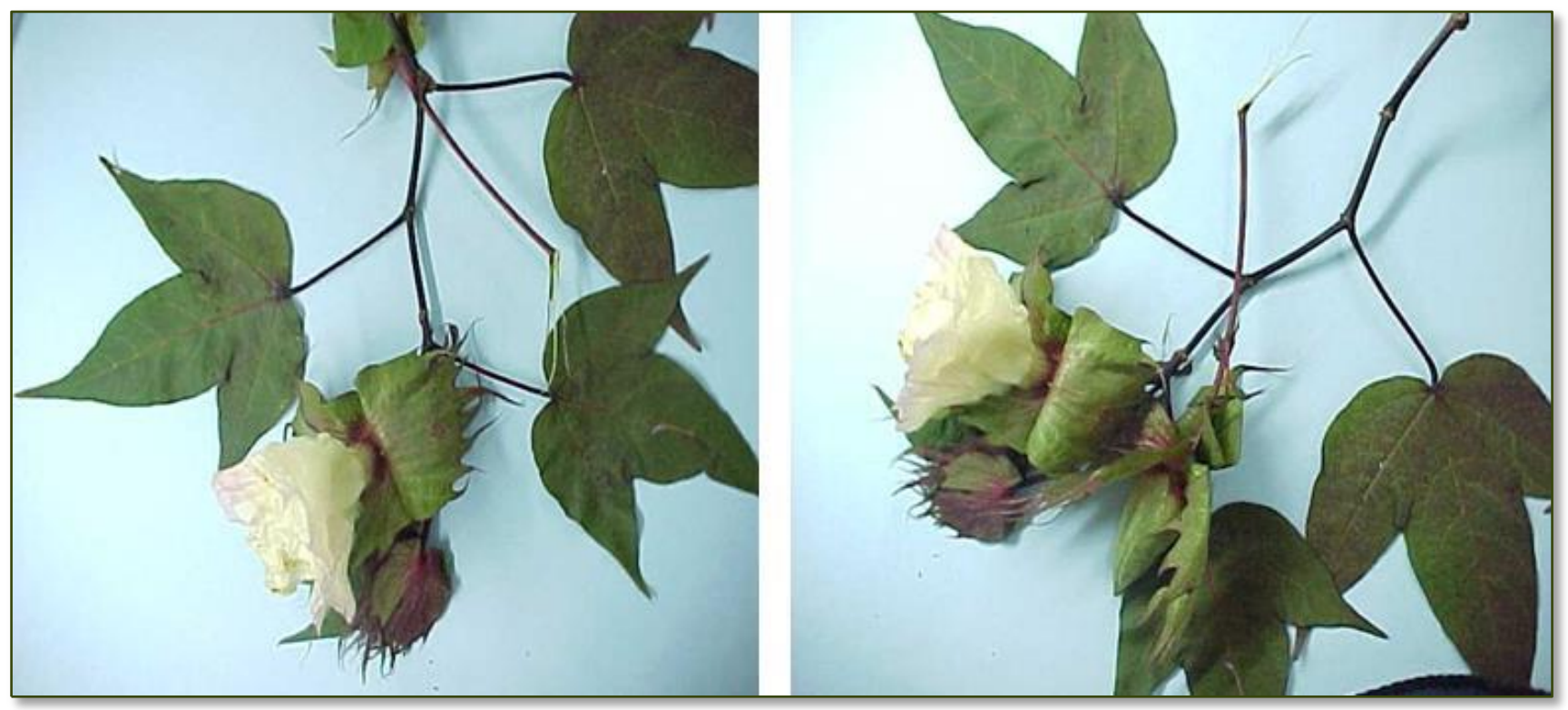

Fonte: Os autores (2015) 


\section{Descrição polínica}

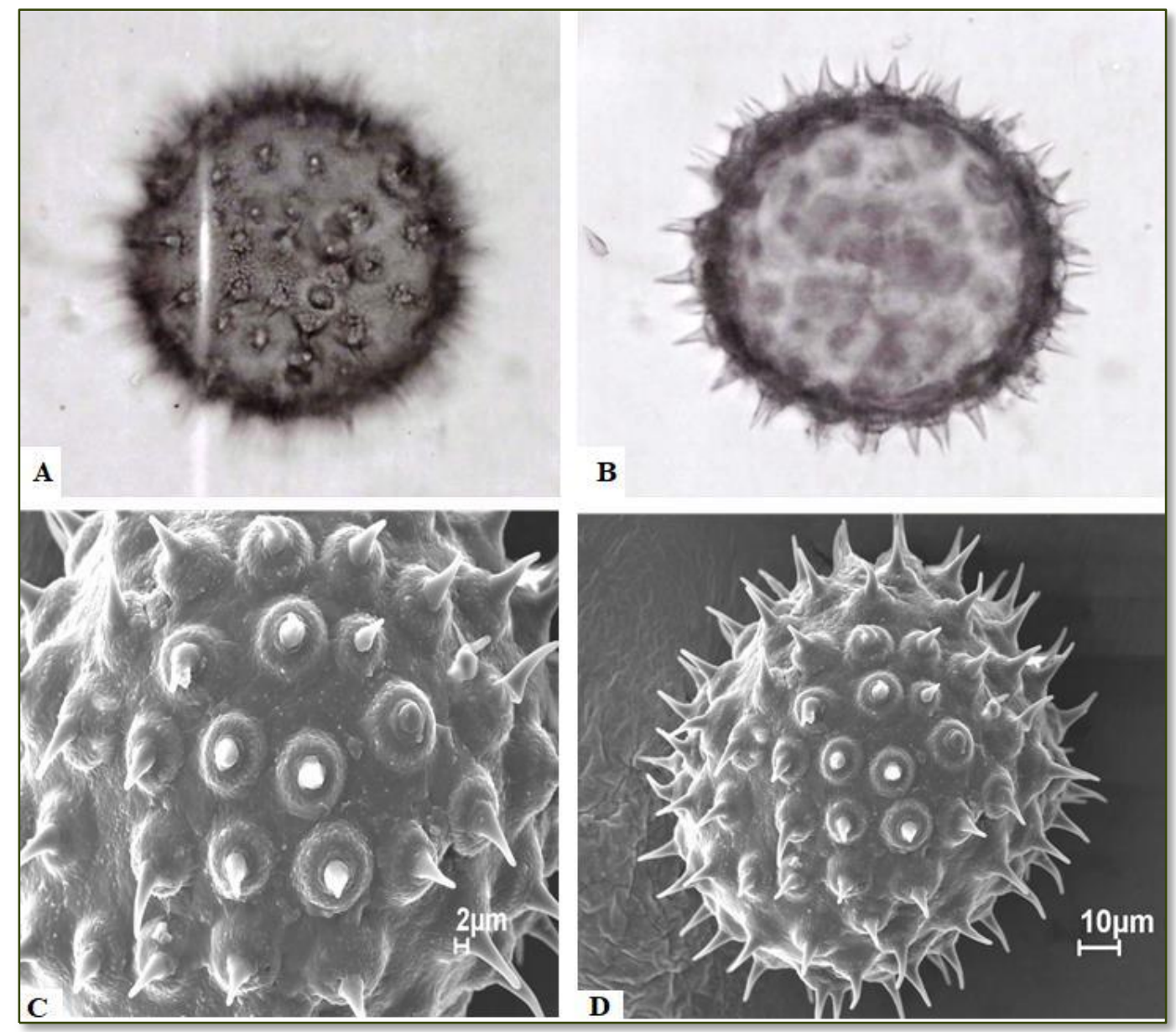

Fonte: Os autores (2015)

Forma - grãos de pólen grandes, esféricos (MF (A/B).

Aberturas - pantoporado, poros operculados.

Exina - tectada, com espinhos retos, curvos, obfurcados de tamanho variável (MEV

(C/D).

Medidas - (micra) 77-125 $\mu \mathrm{m}$.

Material examinado - flores frescas coletadas em quintais de agricultores familiares.

Referências - Carreira \& Barth, 2003, Erdtman, 1952, Melhem et al. 1993, SalgadoLabouriau, 1971.

*Microscopia fotônica

**Microscopia eletrônica de varredura 


\section{Família: MALVACEAE}

\section{Nome Científico: Gossypium hirsutum L.}

Nomes Comuns: Algodão branco.

Descrição Botânica: Subarbusto anual, de até $1,5 \mathrm{~m}$ de altura; ramos de dois tipos: vegetativo e frutificação; folhas alternas, pecioladas, palmada 3-5 lóbulos, lâmina cordada medindo de 7,5-15 cm; flores em número de 6-8 sobre cada ramo férteis, grande, branca ou amarela, sustentada por um cálice reduzido com 3-4 brácteas grandes e verdes; estilo composto por uma coluna estaminal composto de 100 ou mais estames; ovário supero com 3-5 carpelos; o fruto é uma cápsula deiscente medindo de 4-6 cm de comprimento, esférico, liso, verde claro, contendo poucas glândulas de óleo; sementes medindo $1 \mathrm{~cm}$ de comprimento, oval, marrom escuro, cerca de 36 por fruto, contendo dois tipos de fibras na epiderme: fibras longas e fibras curtas ligadas fortemente a semente chamada de algodão; o peso de 100 sementes equivale de 10-13 g; raiz primária bem desenvolvida com inúmeras raízes laterais penetrantes podendo chegar até $3 \mathrm{~m}$. aproximadamente 3 meses após o plantio, variando de acordo com a localidade.

Origem: América Central.

Distribuição Geográfica: Disseminou-se para regiões temperadas tropicais, Africa, América do Sul, Norte do Brasil, Rússia, Norte da Índia e Paquistão.

Uso Medicinal: Útil para problemas uterinos (fibrose e alguns tipos de câncer); para combater a cárie; combater pólipos nasais; combate bronquite, asma, diarreia e hemorragia. As flores são diuréticas, emolientes e emenagoga, hemostática, lactagoa, parturiente, adstringente, anti-hemorroidal, vasoconstrictor.

Referências: Ahmad, M. et al. 2012, Corrêa, M.P. 1984, Omojasola, P.F. \& Awe, S. 2004, Wendel, J.F. et al. 1992.

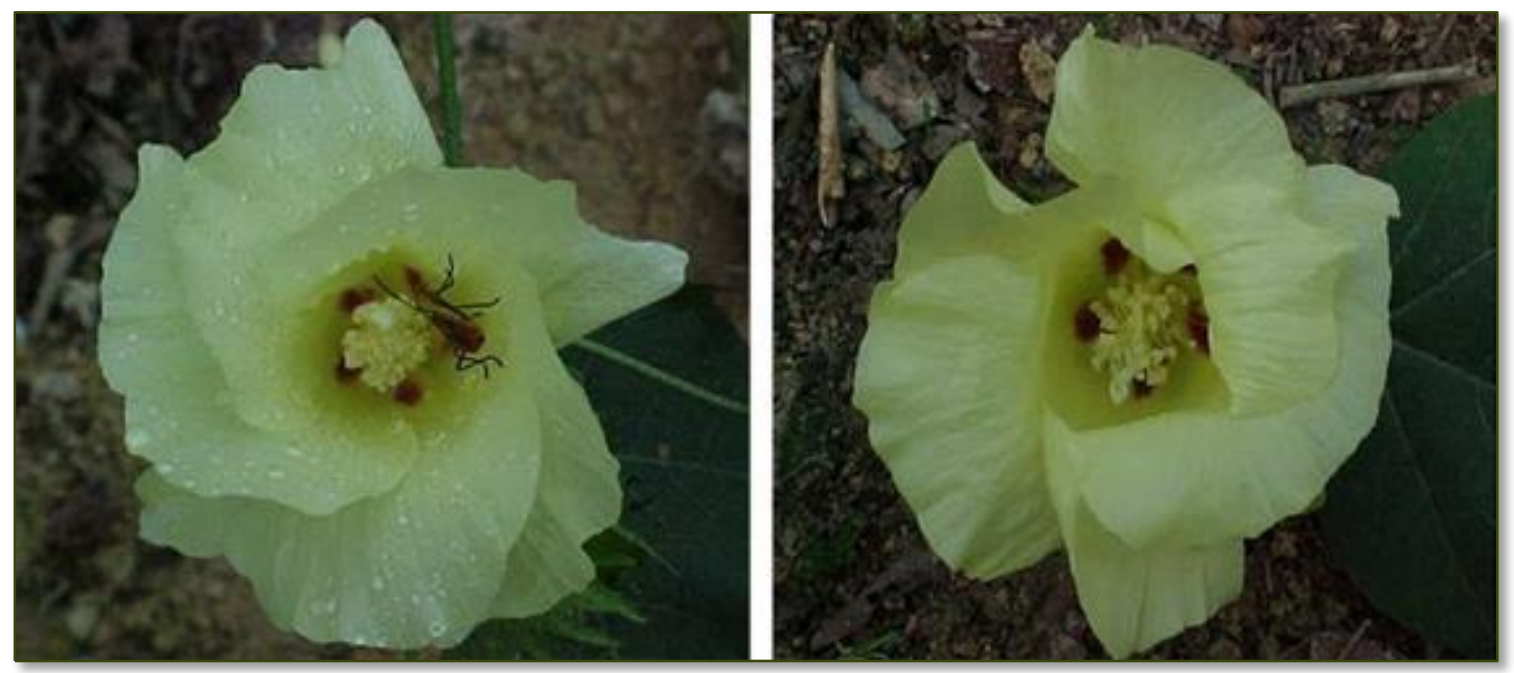

Fonte: Os autores (2015) 


\section{Descrição polínica}

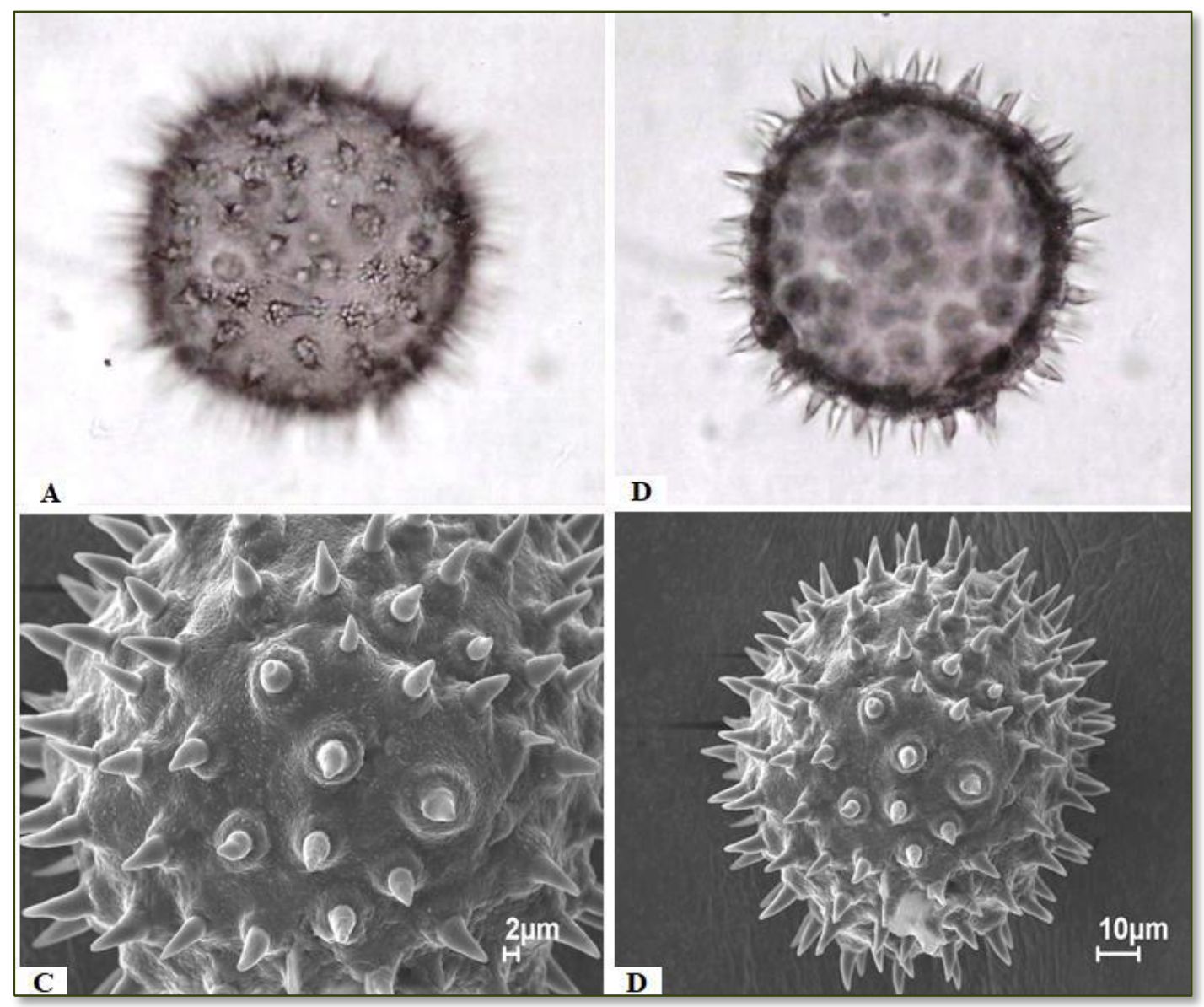

Fonte: Os autores (2015)

Forma - grãos de pólen grandes, esféricos (MF (A/B).

Aberturas - pantoporado, poros operculados.

Exina - tectada, com espinhos retos, curvos, obfurcados de tamanho variável (MEV

(C/D).

Medidas - (micra) 94-109 $\mu \mathrm{m}$.

Material examinado - flores frescas coletadas em quintais de agricultores familiares.

Referências - Carreira \& Barth, 2003, Erdtman, 1952, Melhem et al. 1993, SalgadoLabouriau, 1971.

*Microscopia fotônica

***Microscopia eletrônica de varredura 
Família: MELIACEAE

\section{Nome Científico: Carapa guianensis Aubl.}

Nomes Comuns: Andiroba, andirova, carapa, andiroba saruba, purga-de-santo-inácio.

Descrição Botânica: Árvore de grande porte, atingindo $30 \mathrm{~m}$ em altura,m com fuste cilíndrico reto e sapopemas em sua base. A casaca é grossa e amarga e desprende-se facilmente em grandes placas. Copa ampla bastante esgalhada, folhas compostas, longo pecioladas, com 30-60 cm de comprimento e $50 \mathrm{~cm}$ de largura. Os folíolos opostos (até 19 pares) apresentam um tom verde escuro, com forma oval oblonga e extremidade apical curta, textura macia, superfície plana e margens completas. A inflorescência é uma panícula axilar, principalmente na extremidade dos galhos, e mede cerca de $30 \mathrm{~cm}$ de comprimento. As flores são subsésseis, glabras, globulosas de cor creme. 0 fruto é uma cápsula glabosa a subglabosa, deiscente de quatro valvas que se separam quando caem ao solo pelo impacto da queda e liberam 4 a 6 sementes. As sementes pesam em média 21g. A germinação é do tipo hipógena e cripto cotiledonar.

Origem: América Central, América do Sul, Caribe e África tropical. No Brasil ocorre em toda a Bacia Amazônica, principalmente em regiões de várzeas e áreas alagáveis ao longo dos igapós.

Distribuição Geográfica: Ilhas do Baixo Tocantins, Baixo e Alto Amazonas, Rio Solimões, Alto Rio Eperecuru e Bahia.

Uso Medicinal: Utiliza-se o chá das cascas das folhas e o óleo como cicatrizante, amargotônica, antifebril, diurética, vermífuga, contra a malária, empingem, purgativa, antireumática, contra a úlcera crônica, contra as picadas de insetos, contra o tétano, contra a hepatite, impetigo e outras moléstias da pele, para desinfetar ferimentos, atua na inchação causada pela erisipela, contra piolhos da cabeça, herpes circinada e sarna.

Referências: Menezes, A.J.E.A. 2005, Oliveira, F.D.S. 2012, Penido, C. et al. 2006, Revilla, J. 2002.

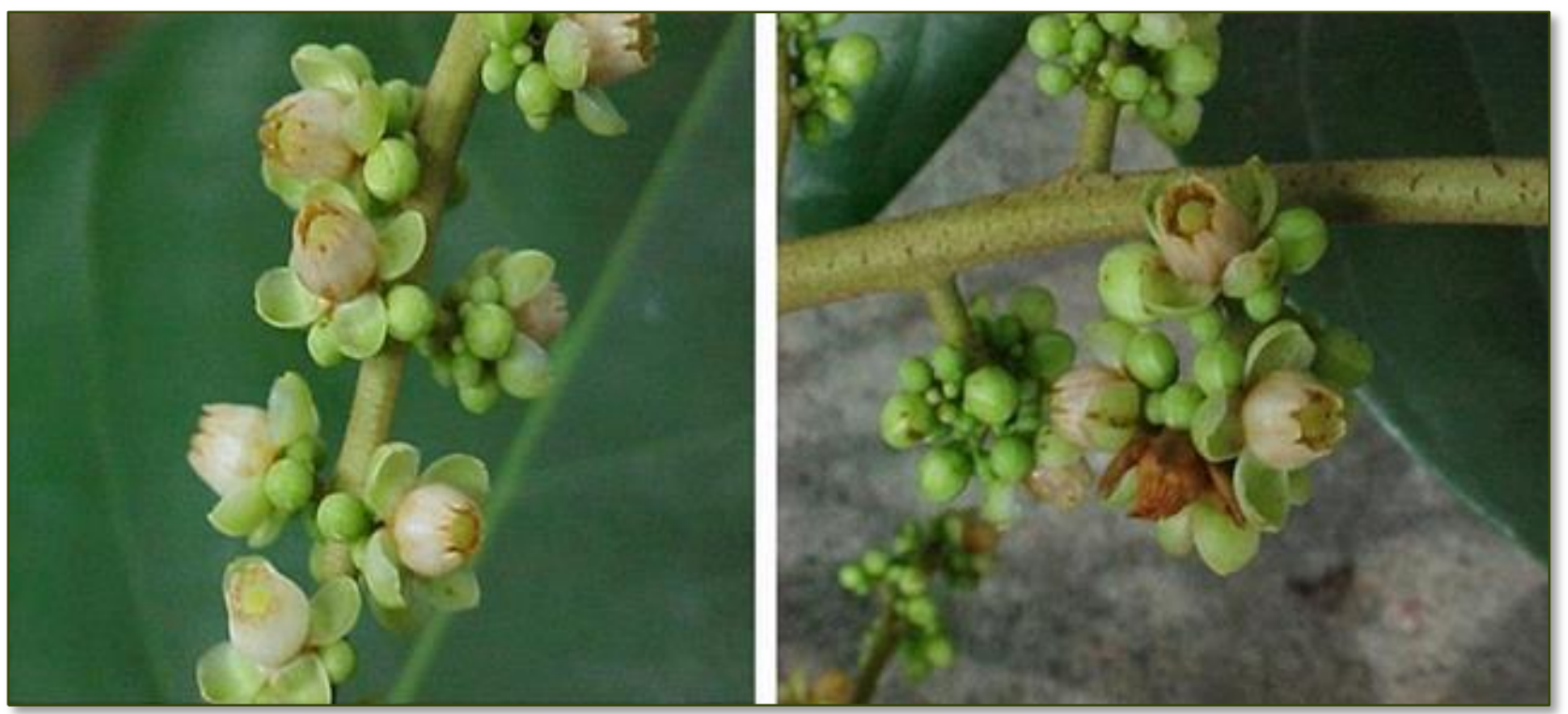

Fonte: Os autores (2015) 


\section{Descrição polínica}

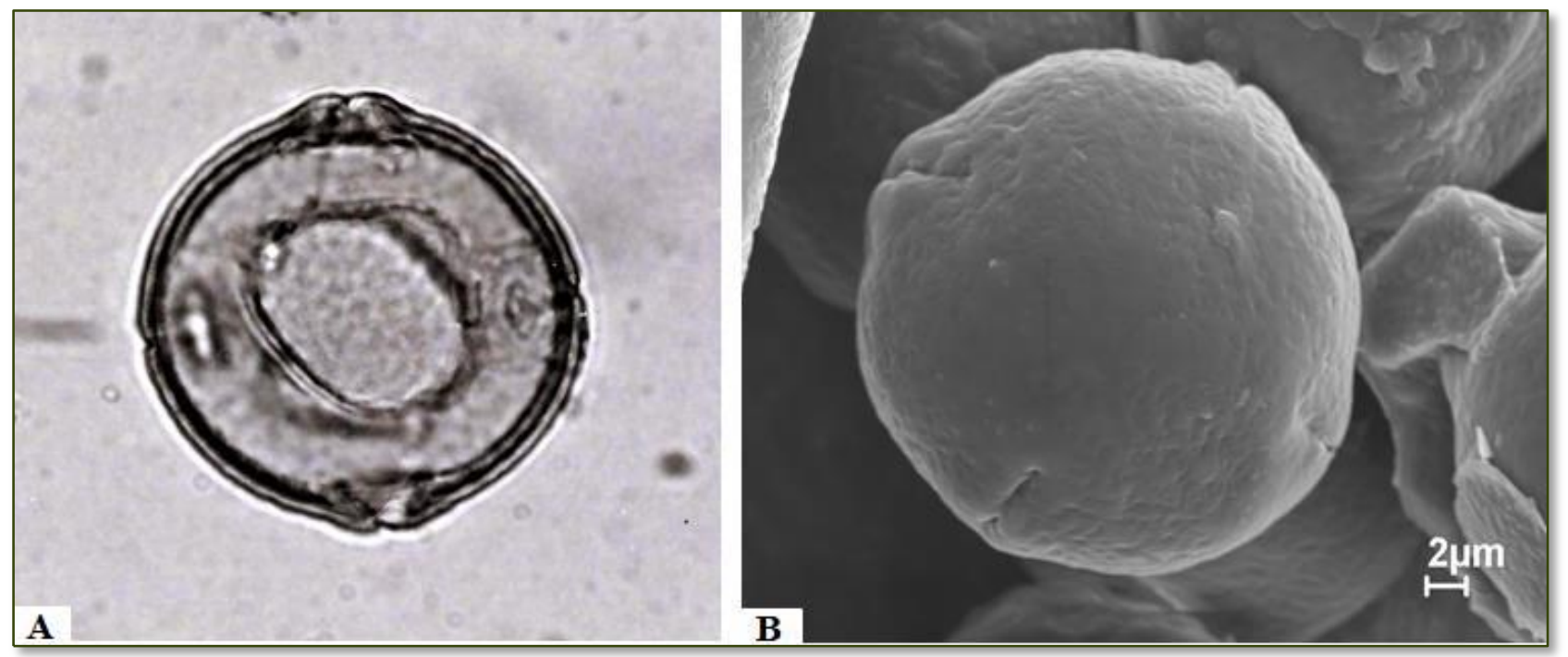

Fonte: Os autores (2015)

Forma - grãos de pólen médios, esféricos, prolatos-esferoidais a subprolatos, âmbito circular, aparentemente poligonais, lados do polígono sempre convexos (MF (A) e MEV (B).

Aberturas - 4-colporados, colpos sem margem e com ós circular a lalongados.

Exina - psilada a reticulada, mais fina na região polar (apocólpio) (MEV (B).

Medidas - (micra) 24-29 $\mu \mathrm{m}$ em vista polar (P).

Material examinado - flores frescas coletadas em quintais de agricultores familiares.

Referências - Carreira \& Barth, 2003, Erdtman, 1952, Melhem et al. 1993, SalgadoLabouriau, 1971.

*Microscopia fotônica

***Microscopia eletrônica de varredura 
Família: MYRTACEAE

\section{Nome Científico: Eugenia stipitata Mc Vaugh}

Nomes Comuns: Aracá boi

Descrição Botânica: Árvore pequena que alcança $3 \mathrm{~m}$ de altura. Os galhos começam próximos ao chão formando uma copa ampla. As folhas são sésseis, opostas, de forma elíptica com ápice acuminado, lâmina lisa ou ligeiramente pubescente com nervuras que não sobressaem na face superior nem na inferior. A dimensão das folhas varia entre 8 e $12 \mathrm{~cm}$ de comprimento por 3 a $6 \mathrm{~cm}$ de largura. As flores se encontram tanto solitárias como agrupadas em racemos axilares de até cinco unidades. Tem quatro sépalas verde amareladas, quatro pétalas brancas e ao redor de 100 estames livres. 0 fruto é verde quando estiver novo e amarelo quando estiver amadurecendo, com exocarpo liso e aveludado até $10 \mathrm{~cm}$ de diâmetro e pesa em média de $200 \mathrm{~g}$, podendo chegar até 750 (Paulo Cavalcante) g. 0 número de sementes por fruto varia de 1 a 20.

Origem: Nativa da Bolívia, Brasil e abrangendo toda a Amazônia Ocidental, Colômbia e Peru.

Distribuição Geográfica: Espalhou-se por toda a América do Sul

Uso Medicinal: Por conter alto teor de vitamina C, é utilizada contra gripes e resfriados

Referências: Franco, M.R.B. \& Shibamoto, T. 2000, Orwa, C. et al. 2009, Revilla, J. 2002.

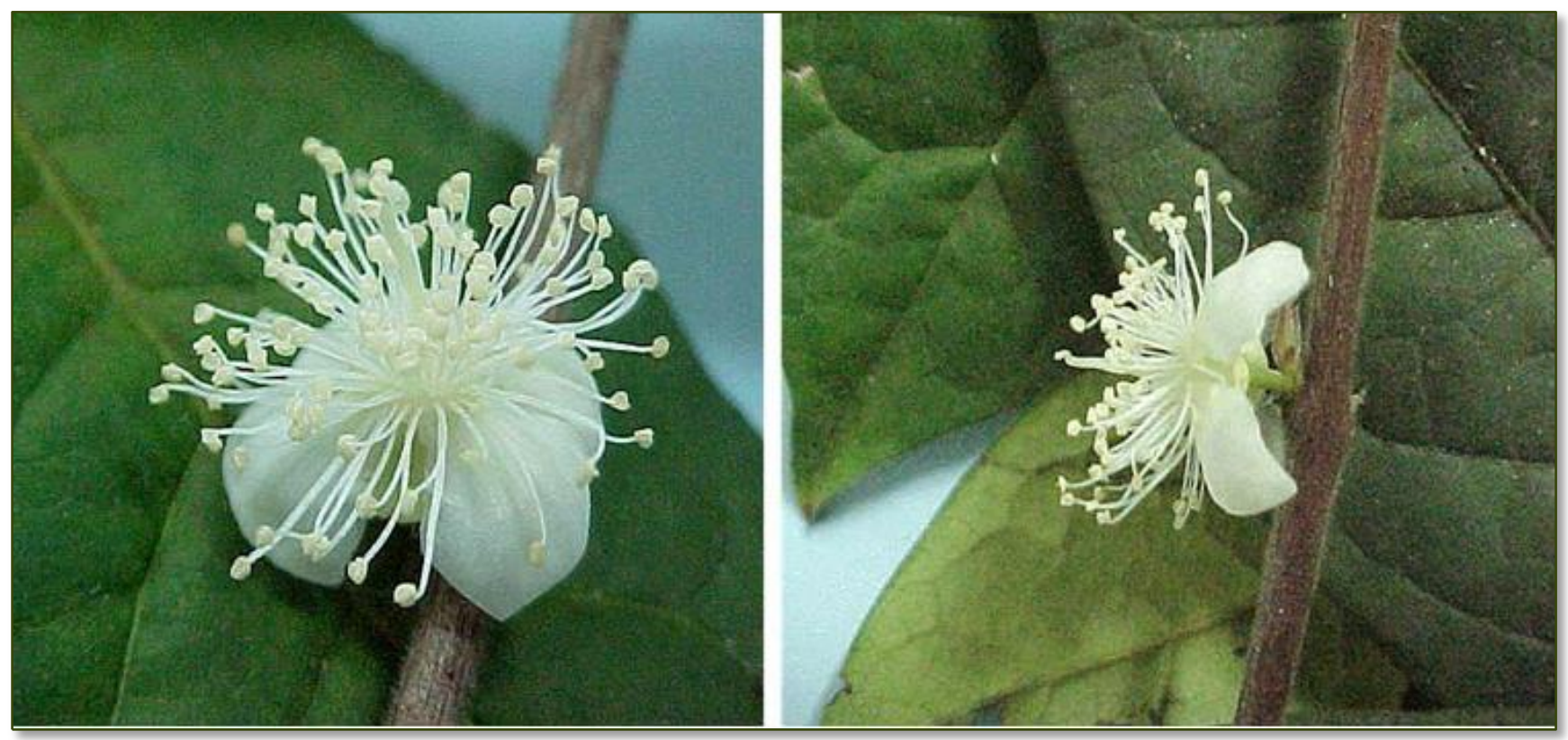

Fonte: Os autores (2015) 


\section{Descrição polínica}

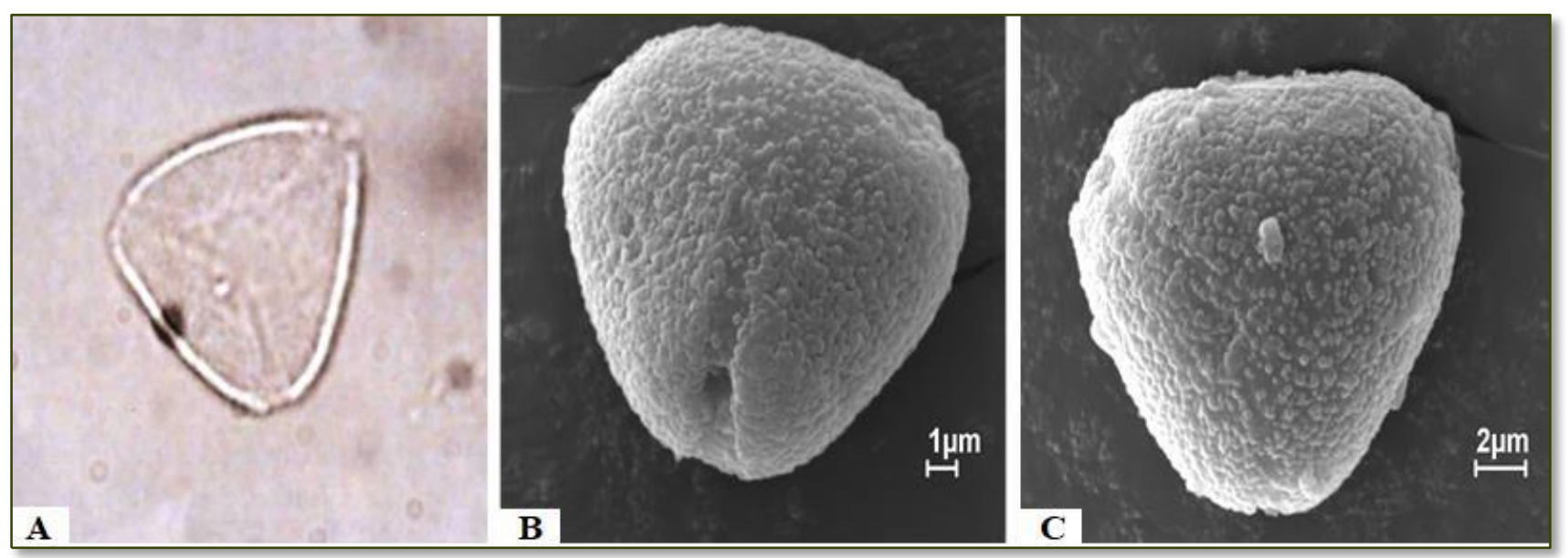

Fonte: Os autores (2015)

Forma - grãos de pólen pequenos a médios, triangulares, isopolares, oblatos, âmbito triangular (MF (A) e MEV (B/C).

Aberturas - tricolporados, colpos sincolpados, endoaberturas lalongadas.

Exina - psilada, granulada e escabrada (MEV (B/C).

Medidas - (micra) 12-20 $\mu \mathrm{m}$ em vista polar (P).

Material examinado - flores frescas coletadas em quintais de agricultores familiares.

Referências - Carreira \& Barth, 2003, Erdtman, 1952, Melhem et al. 1993, SalgadoLabouriau, 1971.

*Microscopia fotônica

**Microscopia eletrônica de varredura 


\section{Família: MYRTACEAE}

\section{Nome Científico: Eugenia uniflora L.}

\section{Nomes Comuns: Pitanga}

Descrição Botânica: Arbusto de até $8 \mathrm{~m}$ de altura, com casca de coloração acinzentada, com fissuras. Folhas opostas, oval-elípticas, de ápice acuminado, glabras de 3 a $6 \mathrm{~cm}$ de comprimento. Flores brancas, solitárias, aromáticas, de 1 a 1,5 cm de diâmetro, dispostas sobre grandes pedúnculos. Fruto ovóide, globoso, liso nas duas extremidades, de coloração amarela a vermelha, geralmente uma única semente.

Origem: América do Sul (Brasil)

Distribuição Geográfica: Disseminou-se pelo Brasil, Paraguai, Uruguai e Argentina.

Uso Medicinal: Eupéptico, tônico estimulantes, colites, acidez, febrífugo, antipalúdico, antirreumático, adstringentes, hipercolesterolemia, hiperuricemia, eupéptico, carminativo, diarreia e diurético, hipertensão e inflamações

Referências: Queiroz, J.M.G. et al. 2015, Revilla, J. 2002, Silva, I.M. et al. 2014.

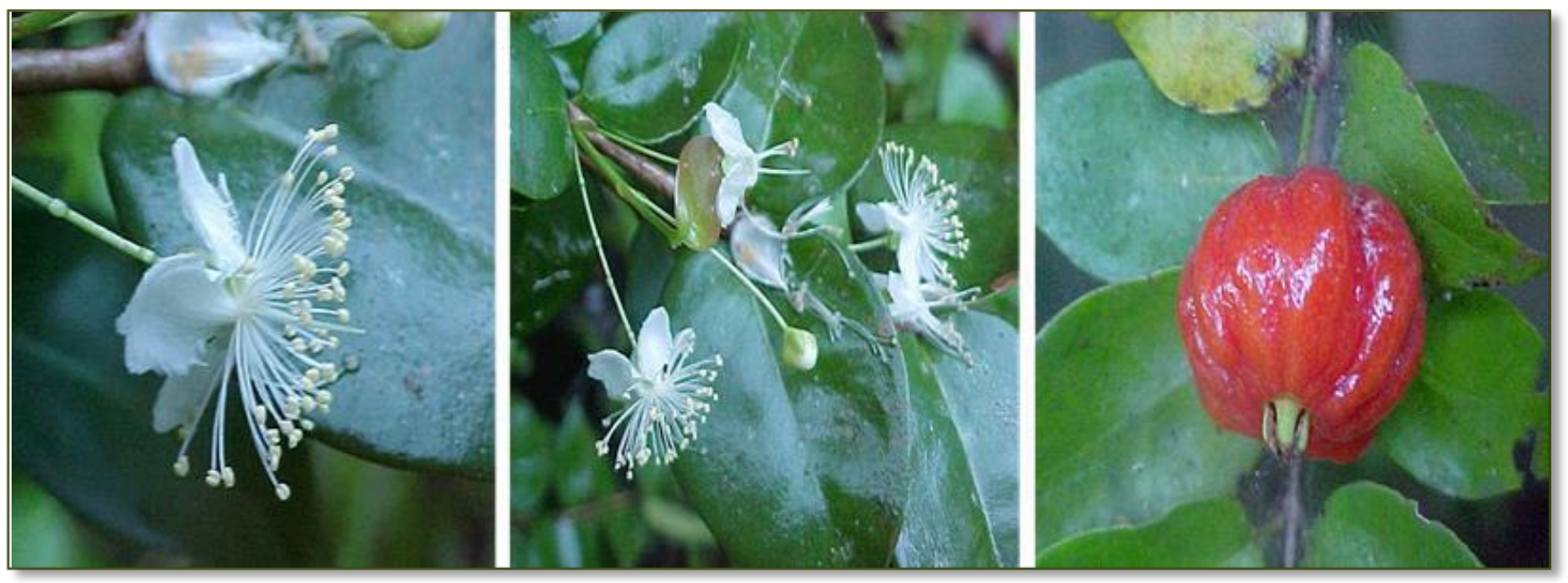

Fonte: Os autores (2015) 


\section{Descrição polínica}

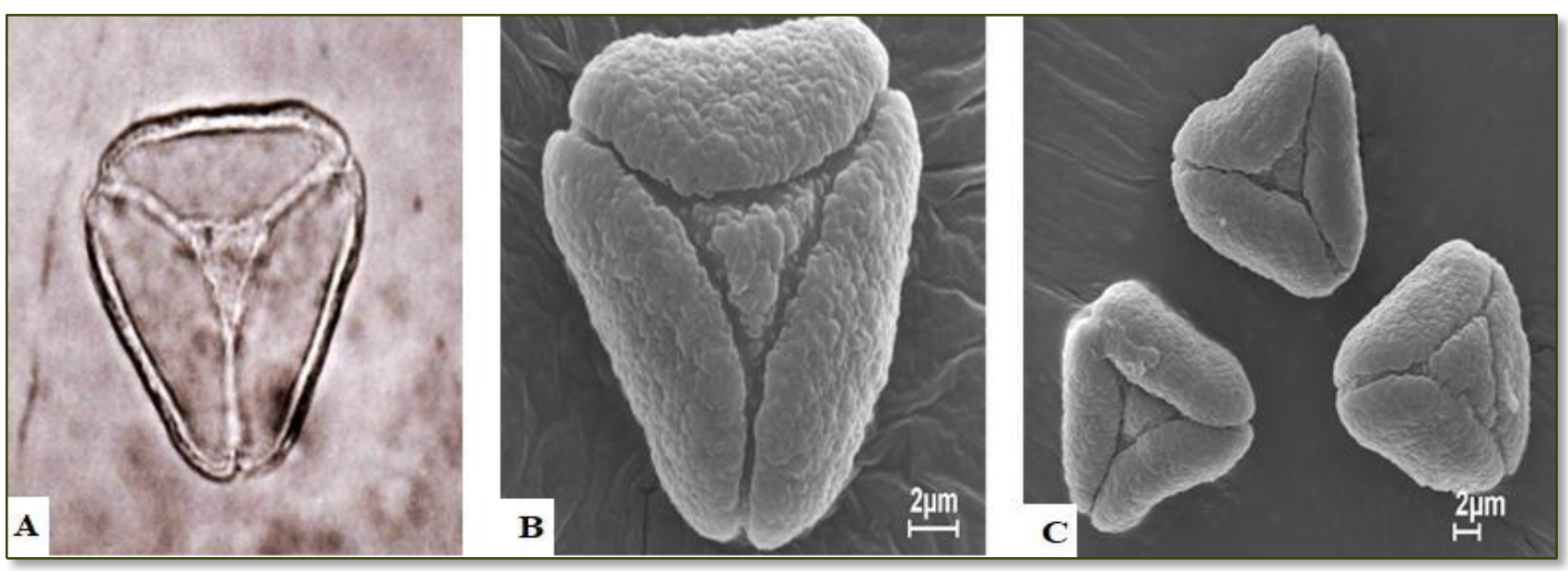

Fonte: Os autores (2015)

Forma - grãos de pólen pequenos a médios, triangulares, isopolares, oblatos, âmbito triangular (MF (A) e MEV (B/C).

Aberturas - tricolporados, colpos sincolpados, endoaberturas lalongadas.

Exina - granulada e escabrada (MEV (B/C).

Medidas - (micra) 16-27 $\mu \mathrm{m}$ em vista polar (P).

Material examinado - flores frescas coletadas em quintais de agricultores familiares.

Referências - Carreira \& Barth, 2003, Erdtman, 1952, Melhem et al. 1993, SalgadoLabouriau, 1971.

*Microscopia fotônica

** Microscopia eletrônica de varredura 


\section{Família: RUBIACEAE}

\section{Nome Científico: Genipa americana L.}

Nomes Comuns: Genipapo, jenipapeiro, jenipa, jenipapo-da-américa, jenipaba.

Descrição Botânica: Árvore de porte elegante, até $10 \mathrm{~m}$ de altura. Copa ramificada e bastante frondosa, com galhos pendentes e fracos. Folhas simples, opostas cruzadas, pecíolos curtos, obovadas até oblongas, ápice afilado ou arredondado, base estreita, subcoriácea, glabras. Flores grandes, hermafroditas, na forma de tubos longo, brancas logo que se abre passando a amareladas, levemente aromáticas, reunidas em grupos terminais axilares, às vezes poucas ou apenas uma flor. Fruto baga, globosa, amarelada quando madura, aromática, com polpa delicada, de coloração vinosa-escura e sabor adocicado.

Origem: América Central.

Distribuição Geográfica: Regiões Tropicais de diversos países da América, Ásia e África.

Uso Medicinal: Afecções em geral, amigdalite, anemia, asma, icterícia, escorbuto, diarréia, doença venérea, enterite, faringite, hidropisia, sífilis, úlcera, vomitório, doenças do fígado e do baço, provocando ligeiro efeito diurético. reduz inflamações do sistema respiratório e combate o reumatismo. A raiz é purgativa.

Referências: Carvalho, P.E.R. 2003, Revilla, J. 2002, Souza, C.N. 2007.

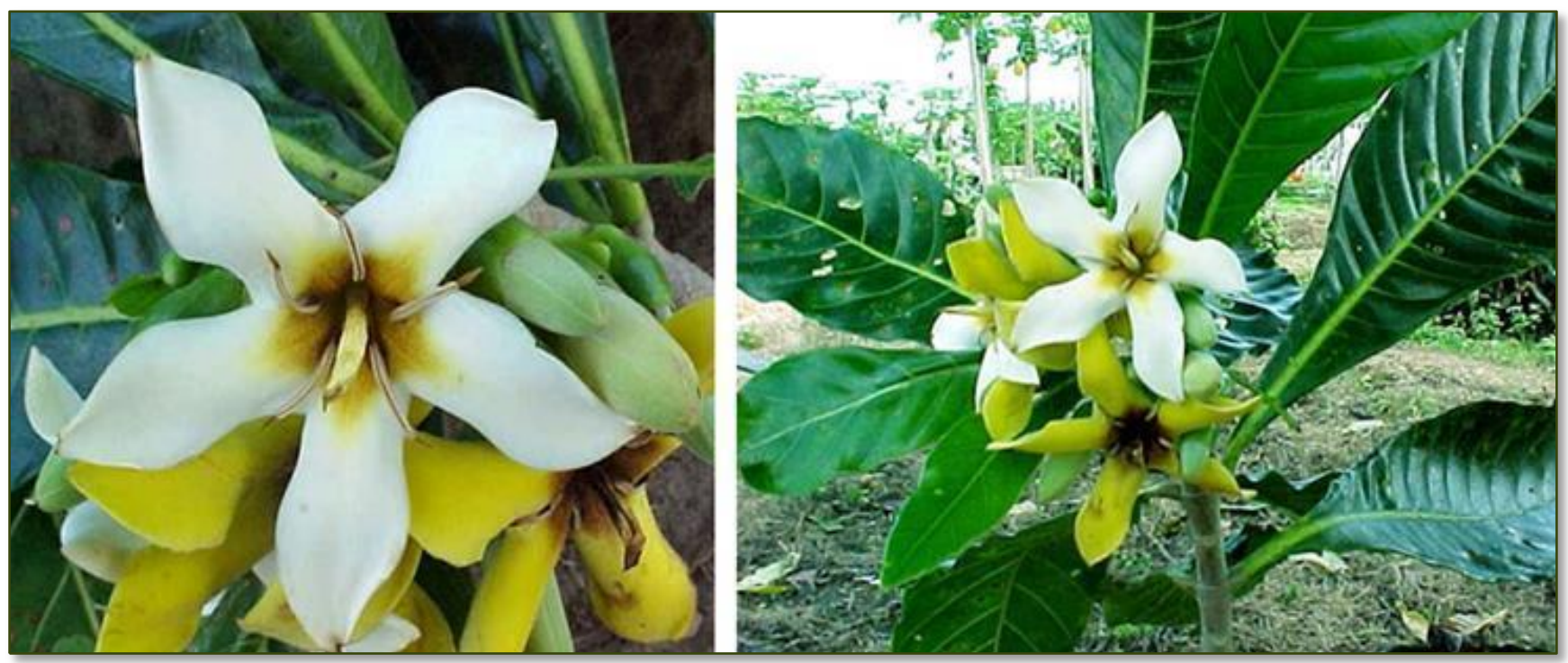

Fonte: Os autores (2015) 


\section{Descrição polínica}

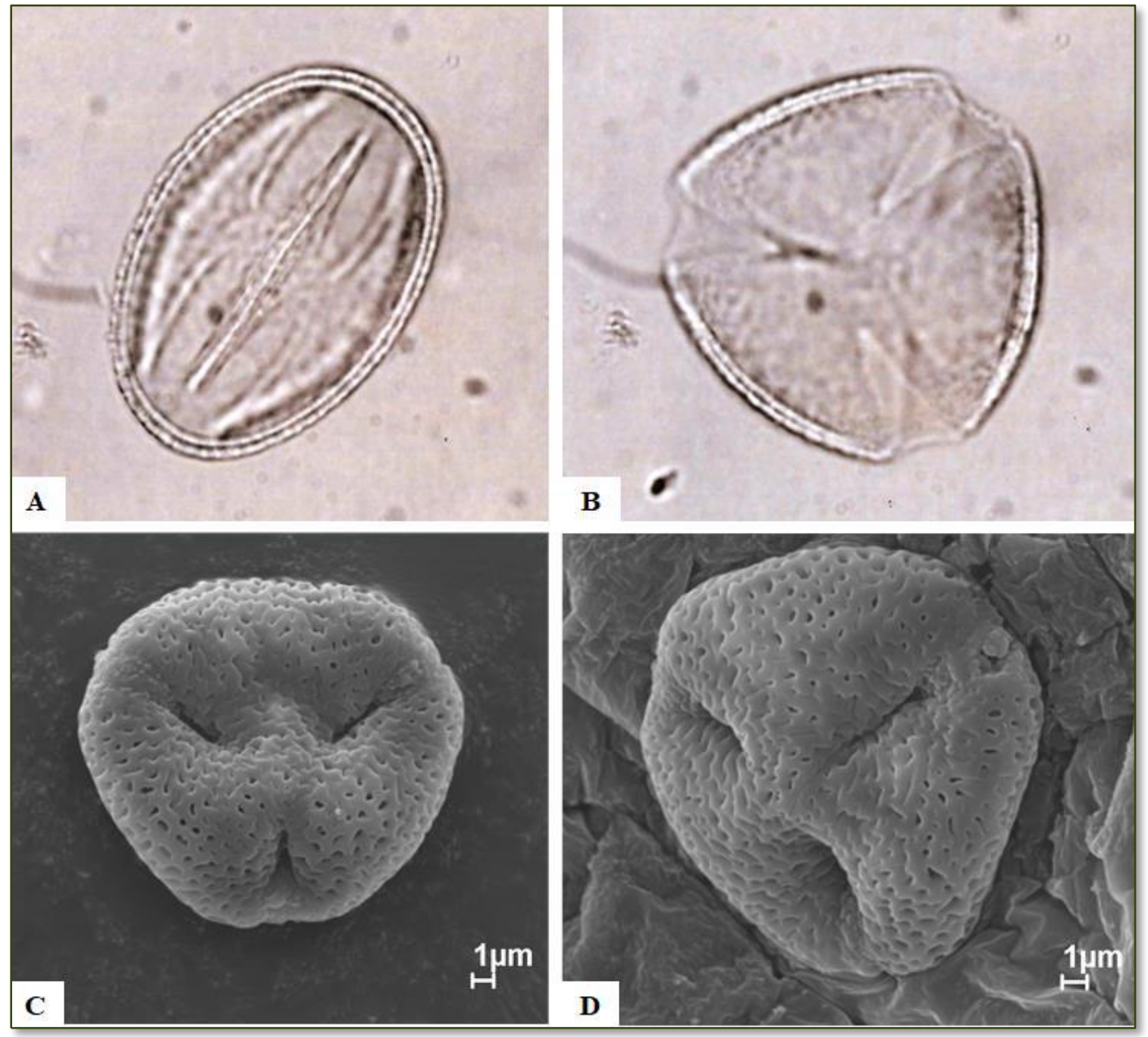

Fonte: Os autores (2015)

Forma - grãos de pólen pequenos a médios, suboblatos a oblatos-esferoidais, âmbito circular a semi-angular (MF (A/B) e MEV (C/D).

Aberturas - tricolporados, colpos longos, endoabertura lalongada (MF (A)

Exina - reticulada, rugulada (MEV (C/D).

Medidas - (micra) 21-25 $\mu \mathrm{m}$ em vista polar (P) e 25-34 $\mu \mathrm{m}$ em vista equatorial (E).

Material examinado - flores frescas coletadas em quintais de agricultores familiares.

Referências - Carreira \& Barth, 2003, Erdtman, 1952, Melhem et al. 1993, SalgadoLabouriau, 1971.

*Microscopia fotônica

**Microscopia eletrônica de varredura 


\section{Família: SIMAROUBACEAE}

\section{Nome Científico: Simaba guianensis Aubl.}

\section{Nomes Comuns: Cajurana}

Descrição Botânica: Arvoreta de até $1 \mathrm{~m}$ de altura. Folhas alternas, pinadas, sem estípulas. As flores formam inflorescências em espigas ou panículas, são unissexuais com o perianto formado por um cálice gamossépalo de 5 elementos e uma corola com 5 pétalas livres. 0 androceu está normalmente formado por 10 estames e o gineceu se compõe de 4 a 5 carpelos. 0 fruto é uma noz alada. 0 caule é lenhoso, porém fino, com $1 \mathrm{~cm}$ de largura.

Origem: Neotropical.

Distribuição Geográfica: Regiões Subtropicais a Tropicais

Uso Medicinal: Contra a febre amarela e malária, possui princípios antimaláricos.

Referências: Alves, G.G,N. 2015, Cabral, J.A.S. et al. 1993, Cáuper, G.C.B. 2006, Cavalcante, P.B. 1983, Franceschinelli, E.V. \& Thomas, W.W. 2000, Gilbert, B. 2006, Revilla, J. 2002.

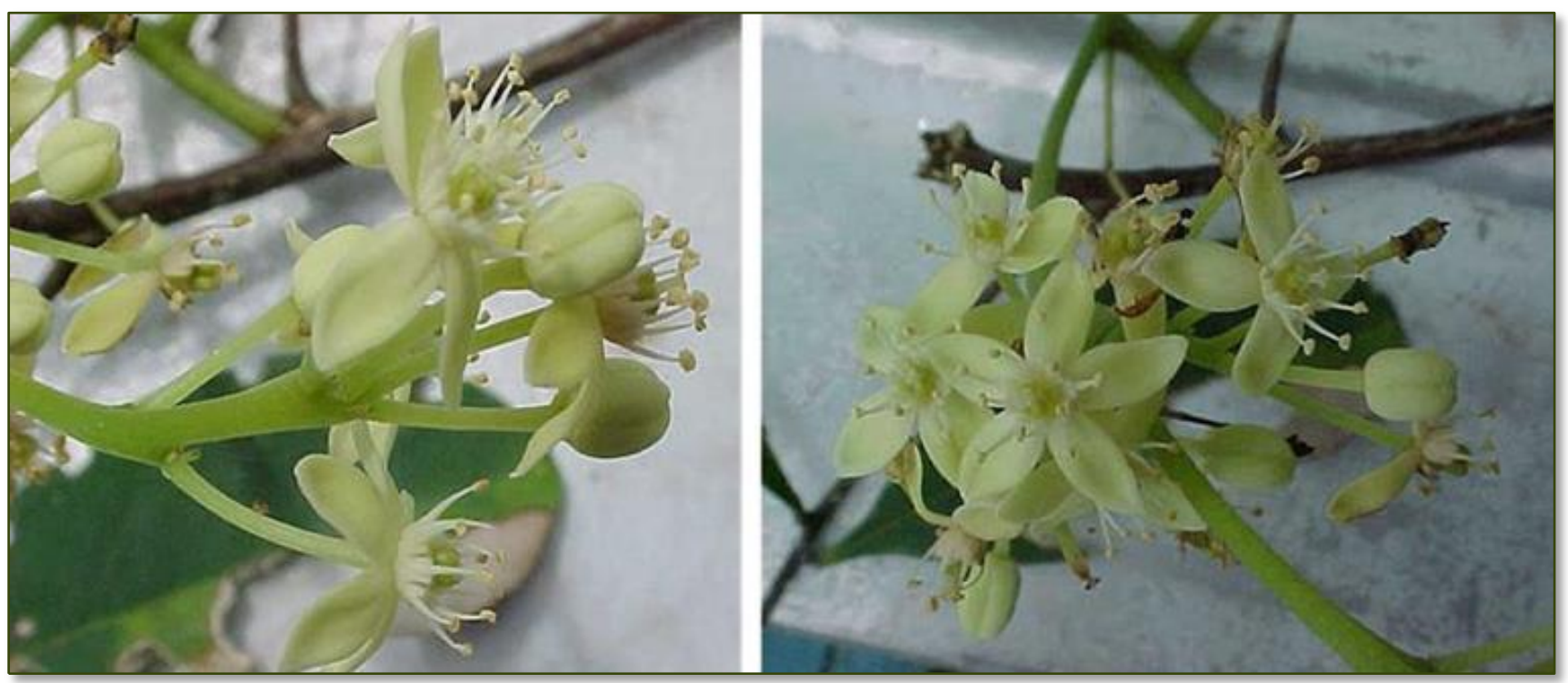

Fonte: Os autores (2015) 


\section{Descrição polínica}

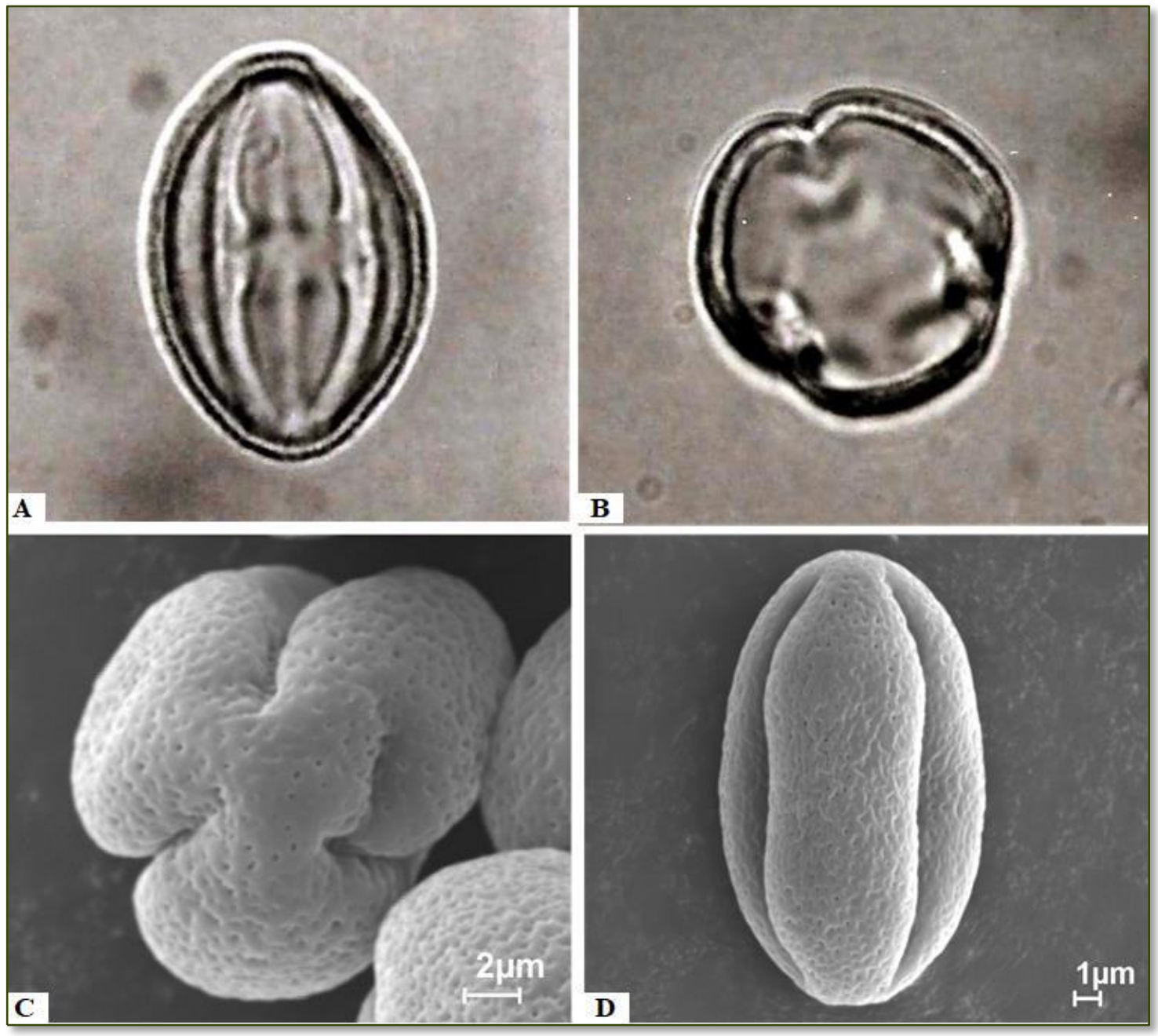

Fonte: Os autores (2015)

Forma - grãos de pólen pequenos a médios, oblatos a prolatos, âmbito circular (MF (A) e MEV (C).

Aberturas - tricolporados, colpos longos, endoabertura lalongada (MF (A) e (MEV

Exina - reticulada, com estrias e pontos de perfuração no teto (MEV ～(C/D).

Medidas - (micra) 18-34 $\mu \mathrm{m}$ em vista polar (P) e 14-32 $\mu \mathrm{m}$ em vista equatorial (E).

Material examinado - flores frescas coletadas em quintais de agricultores familiares.

Referências - Carreira \& Barth, 2003, Erdtman, 1952, Melhem et al. 1993, SalgadoLabouriau, 1971.

*Microscopia fotônica

**Microscopia eletrônica de varredura 


\section{Família: SOLANACEAE}

\section{Nome Científico: Physalis angulata $\mathrm{L}$.}

Nomes Comuns: Canapu, camapu, bucho-de-rã, juá-de-capote, mata-fome.

Descrição Botânica: Subarbusto ruderal, bastante ramificado, de frutos globosos, doces ou insípidos, envolvidos completamente pelo cálice formando um balão anguloso. Seu fruto é comestível mas de pouco valor, contém numerosas sementes chatas e arredondadas. Atinge até $80 \mathrm{~cm}$ de altura, de caule ereto, fistuloso, de quatro a cinco faces; suas folhas são pecioladas, oval-agudas, denteadas ou não. Flor pequenina, pedunculada de cor creme com o cetro alaranjado, tendo cinco pétalas soldadas.

Origem: Brasil

Distribuição Geográfica: Freqüente na Amazônia até o Rio de Janeiro.

Uso Medicinal: Depurativa, desobstruente, diurética, calmante, antiinflamatório, antireumática, empingem, afecções da pele, dor de ouvido, contra as moléstias do fígado, distúrbios do aparelho respiratório, expectorante e combate de forma eficaz as tosses, as folhas são um pouco narcótica. Também é anti helmíntico e anti malárico, anti séptico, contra hemorróidas.

Referências: Carvalho, C.A. et al. 2011, Revilla, J. 2002, Silva, M.T.G. et al. 2005, Souza, N.K.R. \& Amorim, S.M.C. 2009.

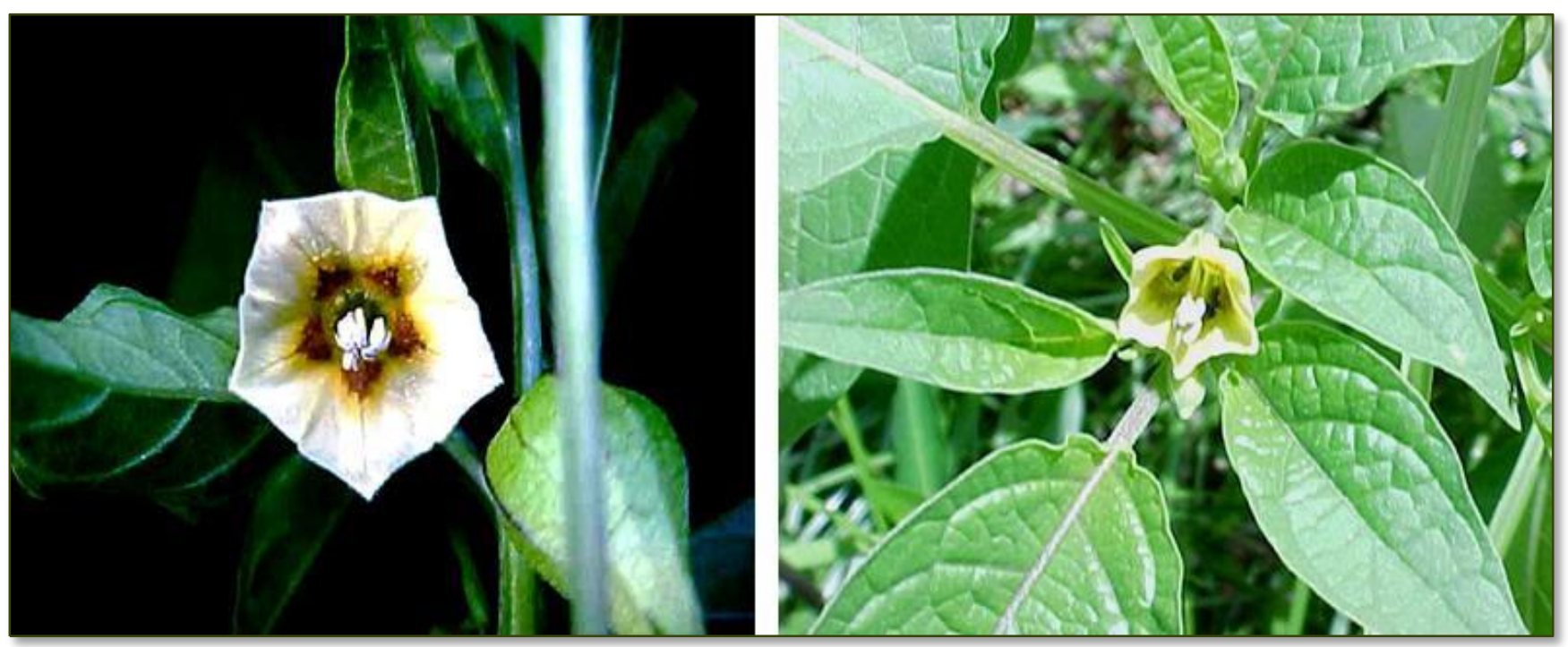

Fonte: Os autores (2015) 


\section{Descrição polínica}

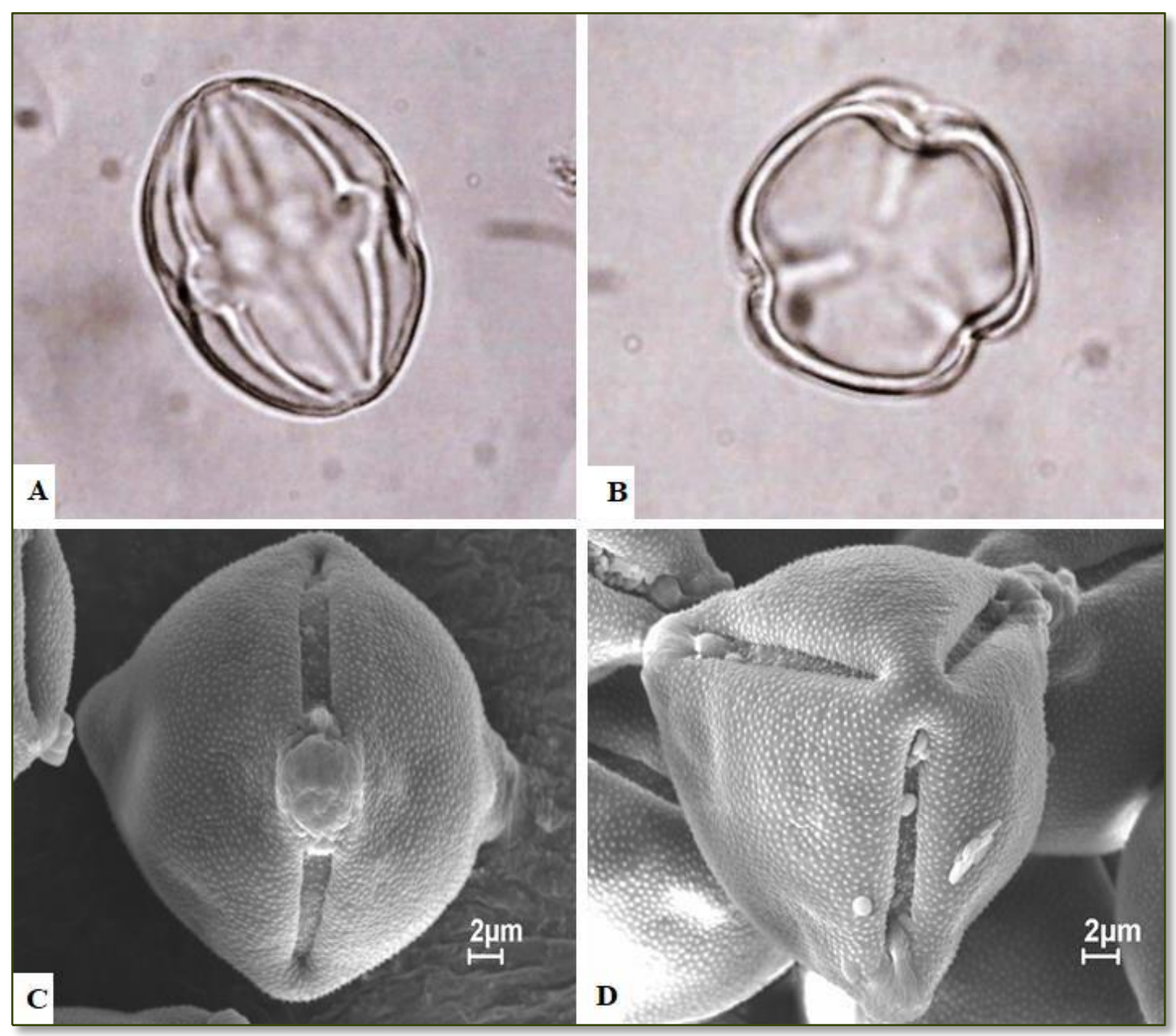

Fonte: Os autores (2015)

Forma - grãos de pólen pequenos a médios, prolatos-esferoidais, âmbito subcircular a subtriangular (MF (A) e MEV (C/D).

Aberturas - tricolporados, colpos longos, endoabertura com constrição mediana, presença de fastígio conspícuo (MF (A) e MEV

Exina - microreticulada, granulada com pontos supratectais (MEV (C/D).

Medidas - (micra) $32 \mu \mathrm{m}$ em vista polar (P) e $34 \mu \mathrm{m}$ em vista equatorial (E).

Material examinado - flores frescas coletadas em quintais de agricultores familiares.

Referências - Carreira \& Barth, 2003, Erdtman, 1952, Melhem et al. 1993, SalgadoLabouriau, 1971.

*Microscopia fotônica

**Microscopia eletrônica de varredura 


\section{Família: SOLANACEAE}

\section{Nome Científico: Solanum crinitum Lam.}

Nomes Comuns: Jurubeba, loubeira, fruta-de-lobo, juá-bravo.

Descrição Botânica: Subarbusto a arvoreta, medindo de 2 a $3 \mathrm{~m}$ de altura de folhas sinuosas, angulares, glabras no limbo, tomentosas no dorso; flores em inflorescências tipo cimeira; fruto uma baga globosa verde canescente, velutíneo a tomentoso, lanceiforme, mucilaginoso, de gosto amargo; numerosas sementes.

\section{Origem: Brasil}

Distribuição Geográfica: Ampla distribuição na America do Sul. No Brasil é encontrada nas regiões Norte, Nordeste e Sudeste. Dos limites das Guianas até São Paulo. Muito abundante no Nordeste.

Uso Medicinal: Desobstruente, tônica, amarga, anti-ictérica, contra o ingurgitamento e inflamação do fígado e baço, diurética, sudorífera, antifebril, antiperiódica, antidispéptica atônica, antidiabética, anti-hidrópica, contra tumor no útero e abdômen, catarro da bexiga, úlcera, tumor granuloso, erisipela, inapetência, atonia gástrica, impaludismo, cólica, constipação e secura biliar.

Referências: Araújo, N.D. et al. 2010, Lima, R.A. et al. 2014, Ling, K.H. et al. 2009.

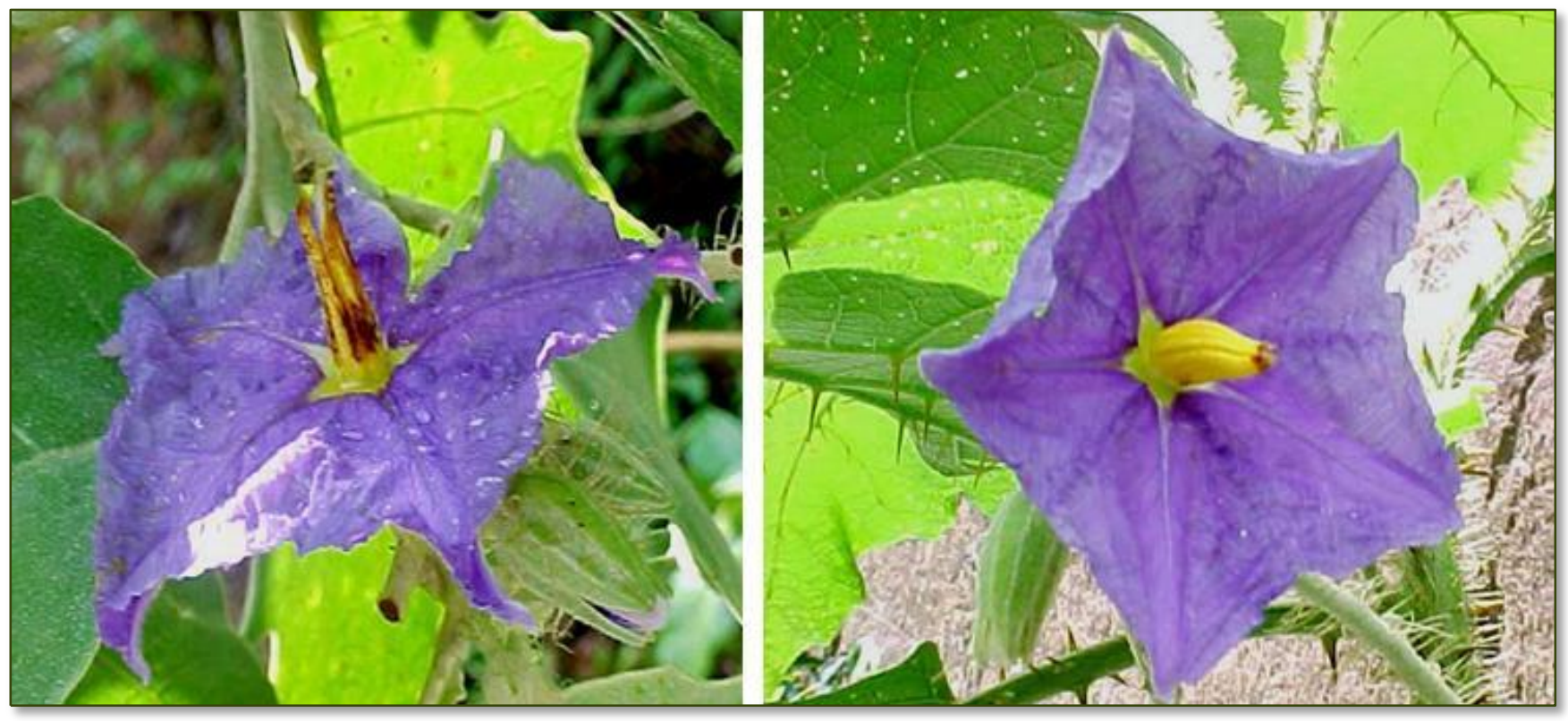

Fonte: Os autores (2015) 


\section{Descrição polínica}

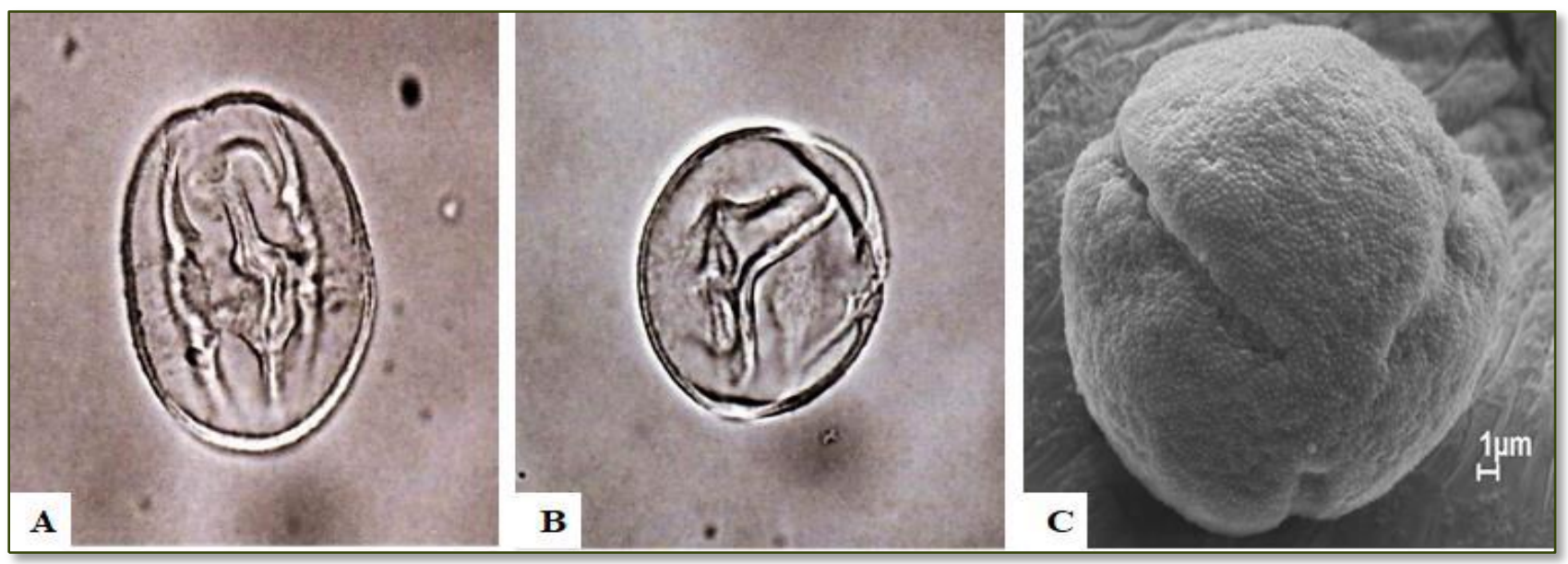

Fonte: Os autores (2015)

Forma - grãos de pólen médios, oblatos-esferoidais, âmbito subtriangular, ângulos arredondados (MF (A) e MEV (C).

Aberturas - tricolporados, colpos longos, endoabertura circular (MF (A) e MEV

Exina - microreticulada, granulada com pontos supratectais (MEV (C).

Medidas - (micra) 14-20 $\mu \mathrm{m}$ em vista polar (P) e 13-28 $\mu \mathrm{m}$ em vista equatorial (E).

Material examinado - flores frescas coletadas em quintais de agricultores familiares.

Referências - Carreira \& Barth, 2003, Erdtman, 1952, Melhem et al. 1993, SalgadoLabouriau, 1971.

*Microscopia fotônica

***Microscopia eletrônica de varredura 


\section{Família: VERBENACEAE}

\section{Nome Científico: Lantana camara Schauer}

\section{Nomes Comuns: Chumbinho}

Descrição Botânica: arbusto vigoroso que pode crescer até 2-4 metros de altura. A folha é ovaladas ou ovaladas oblongo, $2-10 \mathrm{~cm}$ de comprimento e 2-6 cm de largura, dispostas em pares opostos. Folhas são grossas e pilosas, com margens serrilhadas e aromáticas. A haste em variedades cultivadas muitas vezes é não-espinhoso e em variedades de convivência com espinhos recurvadas. É lenhosa, quadrada na seção transversal, com pêlos quando jovem, cilíndrico medindo até $15 \mathrm{~cm}$ de espessura à medida que envelhece. É capaz de subir a $15 \mathrm{~m}$ com o apoio de outros tipos de vegetação. As flores são pequenas, numerosas, tubulosas, contendo de 20 - 40 flores, normalmente com $2,5 \mathrm{~cm}$ de diâmetro; a cor varia do branco, creme ou amarelo para laranja rosa, roxo e vermelho. Os frutos são de cor azul-preto esverdeado, 5-7 mm de diâmetro, brilhantes, com 1-20 sementes por flor, chegando cada planta a produzir até 12.000 sementes por ano. A germinação das sementes ocorre quando estiver presente humidade suficiente; germinação é reduzida em condições de baixa luminosidade. 0 sistema radicular é muito forte com uma raiz principal e muitas raízes laterais superficiais.

Origem: América Tropical.

Distribuição Geográfica: Em toda a América Tropical. No Brasil são encontradas em todos os Estados, desde o Amazonas até o Rio Grande do Sul.

Uso Medicinal: Anti reumático, febrífugo, béquico e expectorante, antimicrobiano, fungicida, inseticida.

Referências: Corrêa, M.P. 1984, Watanabe, M.A. 2007, Zenimori, S. \& Pasin, L.A.A.P. 2006.

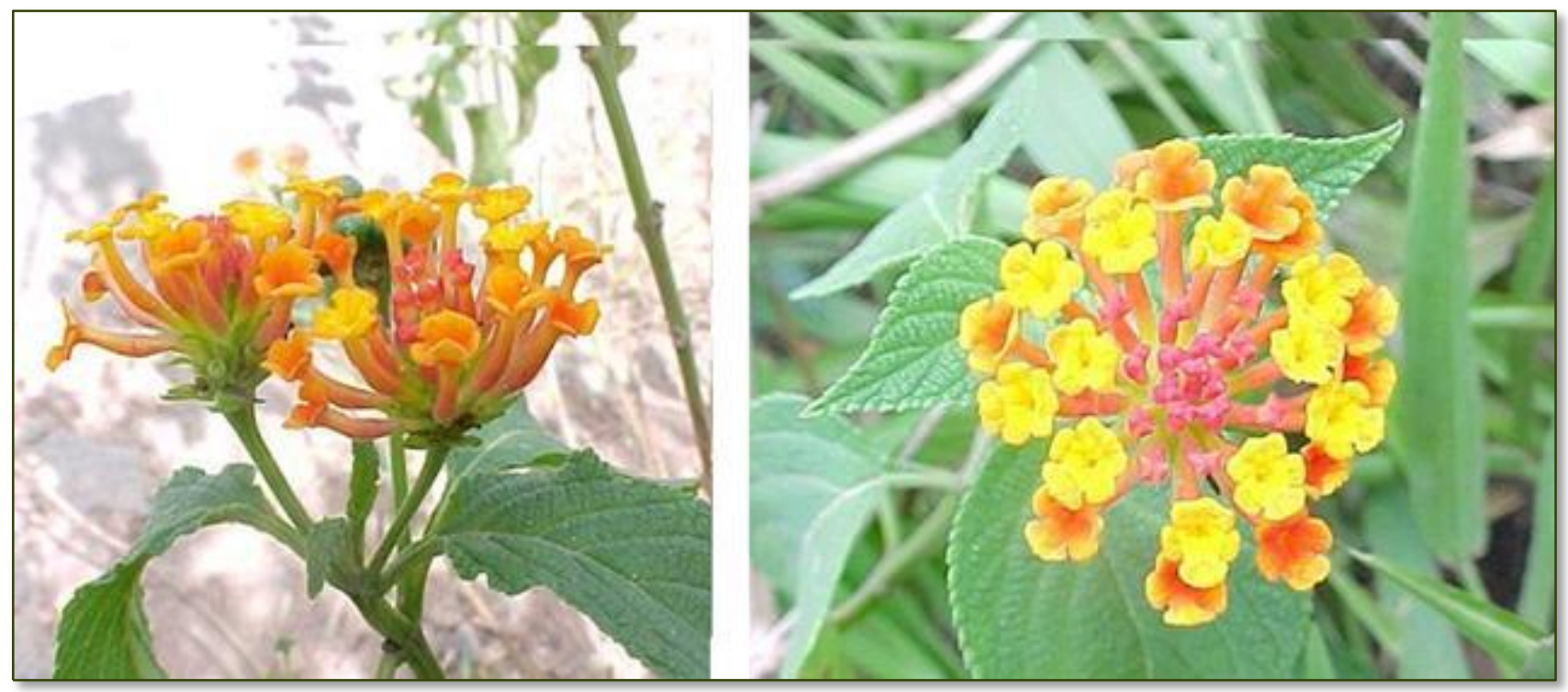

Fonte: Os autores (2015) 


\section{Descrição polínica}

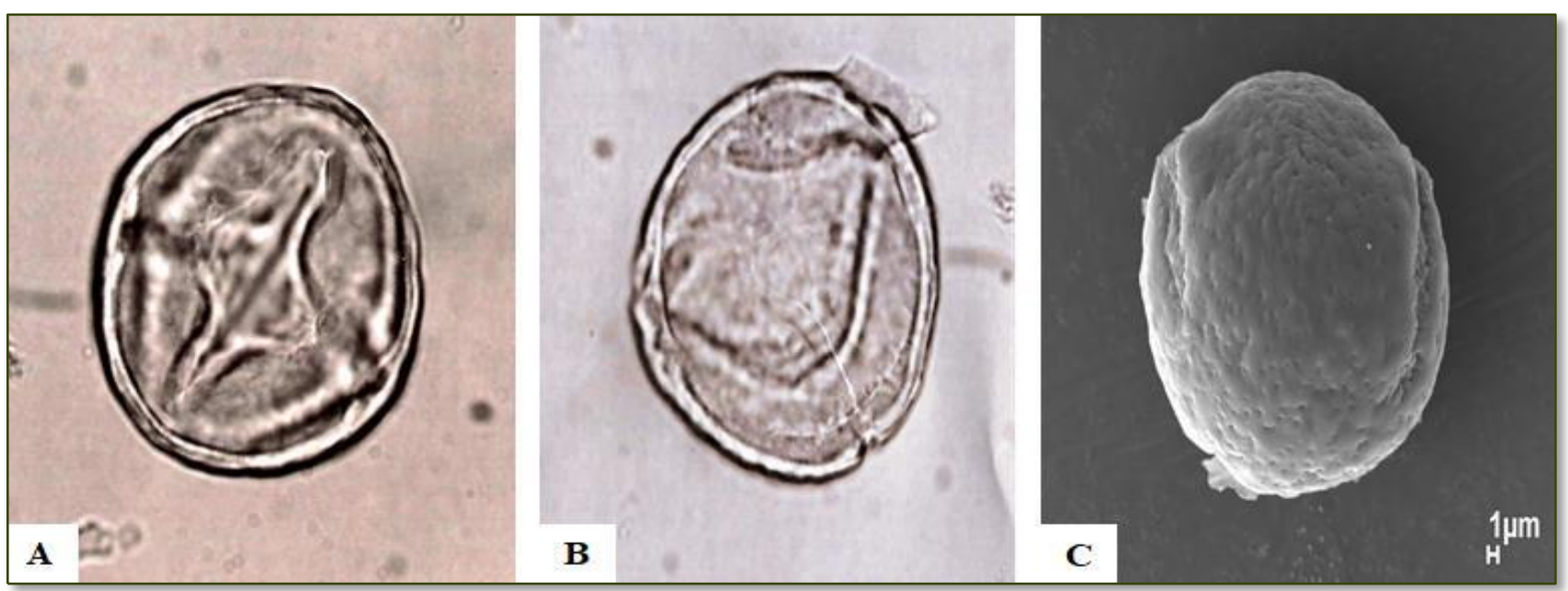

Fonte: Os autores (2015)

Forma - grãos de pólen médios, oblatos-esferoidais, âmbito circular a subtriangular, ângulos arredondados (MF (A) e MEV (C).

Aberturas - tricolporados, colpos longos de contorno irregular, endoabertura lalongada (MF (A) e MEV (C)

Exina - rugulada, com pontos de perfuração no teto (MEV (C).

Medidas - (micra) 34-36 $\mu \mathrm{m}$ em vista polar (P) e 35-40 $\mu \mathrm{m}$ em vista equatorial (E).

Material examinado - flores frescas coletadas em quintais de agricultores familiares.

Referências - Carreira \& Barth, 2003, Erdtman, 1952, Melhem et al. 1993, SalgadoLabouriau, 1971.

*Microscopia fotônica

***Microscopia eletrônica de varredura 


\section{Família: VITACEAE}

\section{Nome Científico: Cissus sicyoides L.}

Nomes Comuns: Cipó puçá, mãe-boa, cipó-puci, insulina, insulina vegetal.

Descrição Botânica: Arbusto perene de até $6 \mathrm{~m}$ de altura, com gavinhas opostas. Folhas, alternas, pecioladas, ovadas e assimétricas de base cordada, de coloração verde e muito aromáticas. Flores de cor esbranquiçadas, dioicas e agrupadas em corimbos, inseridos nas axilas das folhas e na extremidade dos ramos. Florescem no inverno ou na primavera. Cálice pequeno ou ligeiramente dentado ou lobulado, pétalas livres. Androceu com estames livres, opostos às pétalas. Gineceu com 2 carpelos unidos, ovário bilocular. 0 fruto é uma baga mono bilocular, com 2 sementes em cada lóculo e de coloração escura.

Origem: América Central (Chile).

Distribuição Geográfica: Distribui-se em regiões tropicais e subtropicais.

Uso Medicinal: Usada contra abscesso, beribéri, derrame, coração, hidropsia, reumatismo, taquicardia, diurético, úlceras, emenagogo. Usado também em afecções respiratórias, enfermidades hepáticas, antiinflamatórias e antidiabéticas. No nordeste principalmente é muito utilizada para o combate de açúcar na urina, sendo usadas as partes aéreas das plantas.

Referências: Beltrame, F.L. et al. 2001, Ling, K.H. et al. 2009, Matos, F.J.A. 1999, Revilla, J. 2002.

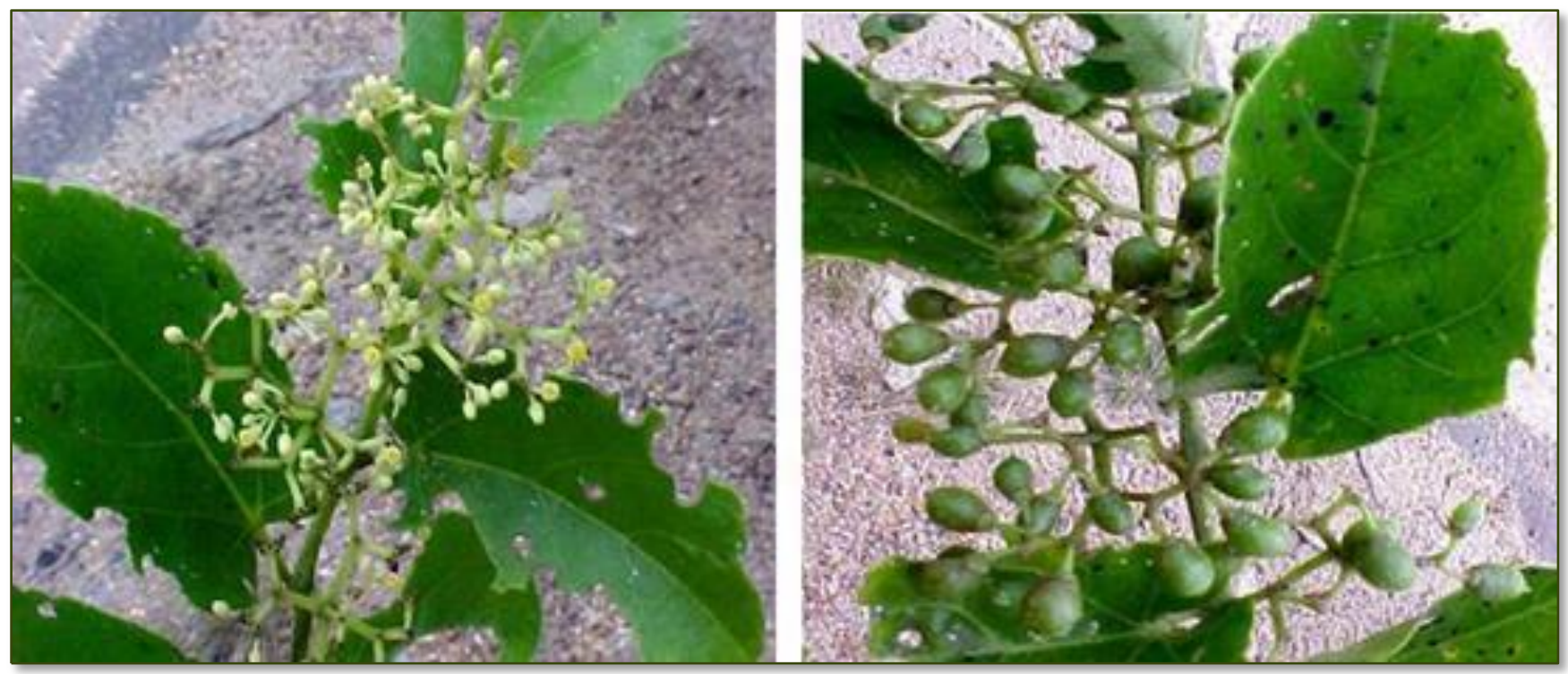

Fonte: Os autores (2015) 


\section{Descrição polínica}

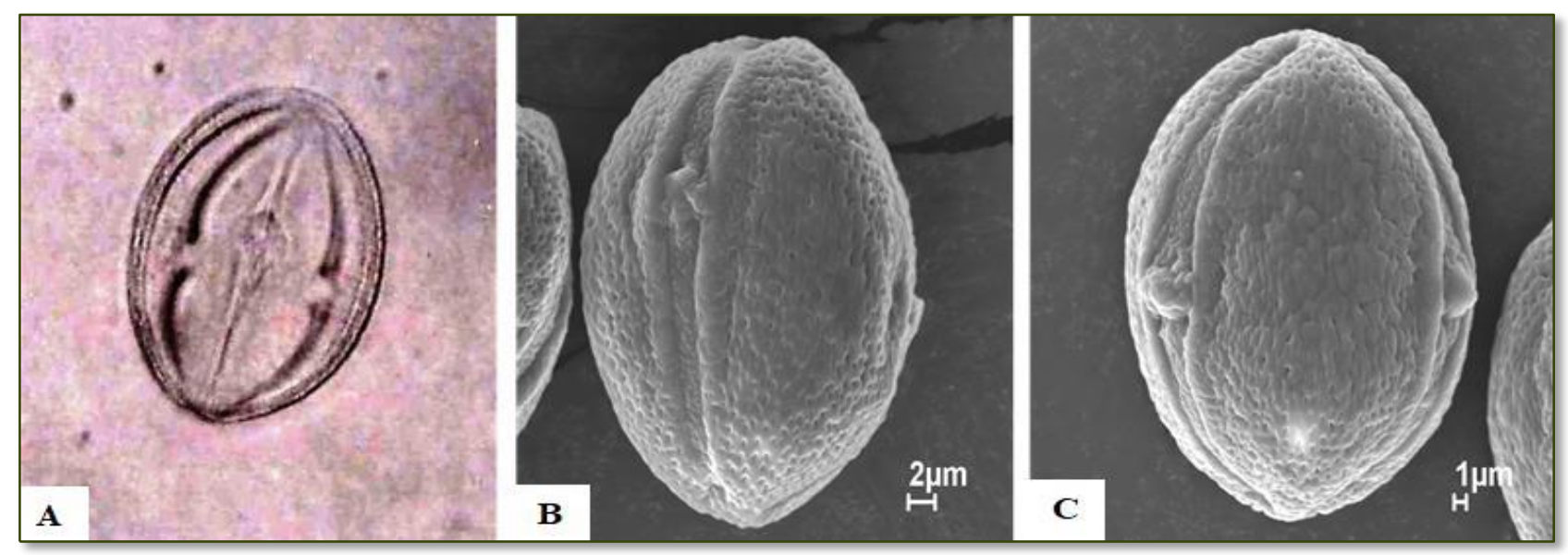

Fonte: Os autores (2015)

Forma - grãos de pólen médios a grandes, isopolares, oblatos-esferoidais a prolatos, âmbito subcircular (MF (A) e MEV (B/C).

Aberturas - tricolporados, colpos longos, endoabertura lalongada (MF (A) e MEV (B/C)

Exina - rugulada a microreticulada, com pontos de perfuração no teto (MEV $\quad$ (B/C).

Medidas - (micra) 38-47 $\mu \mathrm{m}$ em vista polar (P) e 41-43 $\mu \mathrm{m}$ em vista equatorial (E).

Material examinado - flores frescas coletadas em quintais de agricultores familiares.

Referências - Carreira \& Barth, 2003, Erdtman, 1952, Melhem et al. 1993, SalgadoLabouriau, 1971.

*Microscopia fotônica

**Microscopia eletrônica de varredura 


\section{ÍNDICE DOS NOMES CIENTÍFICOS}

A

Anacardium occidentale L. (Anacardiaceae)

B

Bauhinia forficata Link (Fabaceae)

Bauhinia purpurea L. (Fabaceae)

Bertholletia excelsa Bonpl. (Lecythidaceae)

Bidens bipinnata L. (Asteraceae)

Bixa orellana L. (Bixaceae) $\begin{aligned} & \text { Bonamia ferruginea (Choisy) Hallier f. } \\ & \text { (Convolvulaceae) }\end{aligned}$

C

Caesalpinia ferrea Mart. ex Tul. (Fabaceae)

Carapa guianensis Aubl. (Meliaceae)

Carica papaya L. (Caricaceae)

Celosia argentea L. (Amaranthaceae)

Cissus sicyoides L. (Vitaceae)

Croton sacaquinha Croizat (Euphorbiaceae)

Cucurbita cf. moschata (Duc. Ex Lam.) Duc. Ex Poir. (Cucurbitaceae)

\section{E}

Eryngium foetidum L. (Apiaceae)

Eugenia stipitata Mc Vaugh (Myrtaceae)

Eugenia uniflora L. (Myrtaceae)

G

Genipa americana L. (Rubiaceae)

Gossypium barbadense L. (Malvaceae)

Gossypium hirsutum L. (Malvaceae)

I

Indigofera suffruticosa Mill. (Fabaceae)
L

Lantana camara Schauer (Verbenaceae)

M

Merremia macrocalyx (Ruiz \& Pav.) O' Donell (Convolvulaceae)

0

Ocimum micranthum Willd. (Lamiaceae)

$\mathbf{P}$

Pfaffia glomerata (Sprengel) Pedersen (Amaranthaceae)

Physalis angulata L. (Solanaceae)

Psittacanthus cucullaris (Lam.) G. Don (Loranthaceae)

$\mathbf{R}$

Ricinus communis L. (Euphorbiaceae)

S

Scutellaria purpurascens Sw. (Lamiaceae)

Senna alata (L.) Roxb. (Fabaceae)

Senna occidentalis (L.) Link. (Fabaceae)

Senna reticulata (Willd.) H.S. Irwin \& Barneby

Senna tapajozensis (Ducke) H.S. Irwin \& Barneby

Simaba guianensis Aubl. (Simaroubaceae)

Solanum crinitum Lam. (Solanaceae)

Spilanthes oleracea Jacq. (Asteraceae)

Tecoma stans (L.) Juss. Ex Kunth (Bignoniaceae)

Terminalia catappa L. (Combretaceae)

Vatairea guianensis Aubl. (Fabaceae)

Vismia guianensis (Aubl.) Pers. (Clusiaceae) 


\section{AGRADECIMENTOS}

Nossos agradecimentos às Instituições Governamentais e as pessoas que se seguem:

- Ao Instituto Nacional de Pesquisas da Amazônia (INPA).

- Ao Ministério da Ciência, Tecnologia, Inovações e Comunicações (MCTIC).

- À Coordenação de Biodiversidade (CBIO)

- Ao Conselho Nacional de Desenvolvimento Científico e Tecnológico (CNPq) pelo apoio financeiro na realização deste projeto.

- Ao Laboratório de Geologia do Museu Paraense Emílio Goeldi (MPEG) pelas fotografias eletrônicas de varredura.

- À Dra. Izonete de Jesus Araújo Aguiar pela revisão do texto.

- Ao Sr. José Ferreira Ramos pelo apoio nas identificações botânicas das espécies estudadas.

- Ao Sr. José Ramos pela ajuda de campo. 


\section{REFERÊNCIAS}

[1] Ahmad, M.; Khan, M. A., Zafar, M.; Sultana, S. 2012. Practical Handbook on BiodiselProduction and Properties. CRC Press Taylor \& Francis Group. 167p. ISBN 9781466507432.

[2] Almeida, V. C. 2007. Caracterização genética e in situ de Gossypium barbadense na região norte do Brasil. Dissertação de Mestrado. Natal. Universidade Federal do Rio Grande do Norte. 67p.

[3] Alves, G. G. N. 2015. Estudos estruturais como subsídios à taxonomia de Simaba Aubl. (Simarubaceae). Dissertação de Mestrado. Instituto de Biociências, Universidade de São Paulo, São Paulo. 95p. <http://www.teses.usp.br/teses/disponiveis/41/41132/tde-28092015-092512/>.

[4] Araújo, N. D.; Coelho, V. P. de M.; Agra, M. de F. 2010. Estudo farmacobotânico comparativo de folhas de Solanum crinitum Lam., Solanum gomphodes Dunal e Solanum lycocarpum A. St.-Hil., Solanaceae. Revista Brasileira de Farmacognosia. 20(5): 666-674. ISSN 0102-695X. <http://dx.doi.org/10.1590/S0102-695X2010005000016>.

[5] Aravind, G.; Bhowmik, D.; Duraivel, S.; Harish. G. 2013. Traditional and medicinal uses of Carica papaya. Journal of Medicinal Plants Studies, 1 (1): 7-15. ISSN 2320-3862. <www.plantsjournal.com>.

[6] Arogundade, 0. 0.; Adedeji, 0. 2009. Pollen grain morphology of three species and Ocimum Linn. (Lamiaceae) in southwestern Nigeria. Journal of Science and Technology, v. 29, n. 3, 1-7p. <http://dx.doi.org/10.4314/just.v29i3.50028>.

[7] Assis, R. M. A.; Lameira, O. A.; Portal, R. K. V. P.; Rocha, T. T. 2014. Avaliação dos aspectos fenológicos da espécie Croton sacaquinha Croizat (Euphorbiaceae). Belém, PA. 18ㅜ․ Seminário de Iniciação Científica e 2․ Seminário de Pós-graduação da Embrapa Oriental. 12 a 14 de agosto. Resumo expandido. 5p.

[8] Beltrame, F. L.; Sartoretto, J. L.; Bazotte, R. B.; Cuman, R. N.; Cortez, D. A. G. 2001. Estudo fitoquímico e avaliação do potencial antidiabético do Cissus sicyoides L. (Vitaceae). Quim. Nova. 24(6):783-785.

[9] Berg, M. E. van den. 2010. Plantas medicinais na Amazônia: contribuição ao seu conhecimento sistemático. 3 ed. Belém, PA: Museu Paraense Emílio Goeldi, 268 p. il. ISBN 978-85-61377-19-9.

[10] Bishayee, A.; Sarkar, A.; Chatterjee, M. 1996. Chemoprotective role of Mikania cordata in experimental hepatocarcinogenesis. Phytomedicina, v. 3 (suppl. 1): p.13.

[11] Brako, L.; Rossman, A. Y.; Farr, D. F. 1995. Scientific and Common Names of 7,000 Vascular Plants in the United States. American Phytopathological Society; 1 edition, St. Paul, MN. 301 p. ISBN 0-89054-171-X.

[12] Carreira, L. M. M.; Barth, O. M. 2003. Atlas de pólen da vegetação de canga da Serra de Carajás. Belém, Pará, Brasil. Museu Paraense Emílio Goeldi. 1-112 p., il.

[13] Cavalcante, R. 2011. Plantas da Amazônia na saúde bucal. Rio Branco, AC. 2a. ed. 260p. ISBN 978-85-907853-3-1. <www.clubedeautores.com.br $>\leq$ www.agbook.com.br $>$.

[14] Chase, M. W.; Reveal, J. L. 2009. A phylogenetic classification of the land plants to accompany APG III. The Linnean Society of London, Botanical Journal of the Linnean Society, 161, 122-127.

[15] Cho, J. Y.; Lee, J.; Parrk, M. H. 1988. Isolation of inhibitory components on tumor necrosis factoralpha production from Angelica koreana. Yakhak Hoeji, v. 42(2): p. 125-131.

[16] Cabral, J. A.; Mcchesney, J. D.; Milhous, W. K. 1993. A new antimalarial quassinoid from Simaba guianensis. Journal of Natural Products. 56 (11): 1954-1961. <http://dx.doi.org/10.1021/np50101a014>.

[17] Caili, F.; Huan, S.; Quanhong, L. 2006. A review on pharmacological activities and utilization technologies of pumpkin. Plant Foods for Human Nutrition, 61: 73-80. Springer Science+Bussines Media, Inc. <http://dx.doi.org/10.1007/S11130-006-0016-6>.

[18] Camurça-Vasconcelos, A. L. F; Morais, S. M.; Santos, L. F. L.; Rocha, M. F. G.; Bevilaqua, C. M. L. 2005. Validação de plantas medicinais com atividade anti-helmíntica. Rev. Bras. Pl. Med. Botucatu, SP., v.7, n.3, p.97-106.

[19] Corrêa, M. P. 1984. Dicionário das plantas úteis do Brasil e das exóticas cultivadas. Rio de Janeiro, RJ: IBDF, Ministério da Agricultura, v. 1.774p.

[20] Cabral, J. A. S.; McChesney, J. D.; Milhous, W. K. 1993. A new antimalarial quassinoid from Simaba guianensis. J. Nat. Pmd., 56 (11): 1954-1961.

[21] Carvalho, P. E. R. 2003. Jenipapeiro. Colombo, PR. Circular Técnica 80. ISSN 1517-5278. 14p. 
[22] Carvalho, C. A.; Osuna, J. T. A.; Queiroz, S. R. O. D.; Filho, W. F. M. 2011. Influência dos diferentes tipos de substratos orgânicos no desenvolvimento da cultura do camapú (Physalis angulata L.). Doc. Internet. 41-44p. <http://www2.uefs.br/semic/upload/2011/2011XV-030CLE379-120.pdf>.

[23] Cáuper, G. C. B. 2006. Biodiversidade amazônica - Flora amazônica - Volume III. Documento Centro Cultural dos Povos da Amazônia (CCPA). Manaus, AM. 116p. <www.povosdamazonia.am.gov.br/pdf/bio vol3.pdf>.

[24] Cavalcante, P. B. 1983. Revisão taxonômica do gênero Simaba Aubl. (Simarubaceae) na América do Sul. Publicações Avulsas do Museu Paraense Emílio Goeldi. n.37. Belém, PA, 85p.

[25] Di Stasi, L. C.; Hiruma-Lima, C. A. 2002. Plantas medicinais na Amazônia e na Mata Atlântica. 2 ed. rev. ampl. São Paulo: Editora UNESP. 604p. ISBN 85-7139-411-3.

[26] Divya Sri, G.; Narendra Babu, A.; Sathish Kumar, M.; Venkateswarlu, V.; Ashok Kumar, K. 2014. Pharmacognostical characteristics and medicinal uses of Tecoma stans: A review. Journal of Medical and Pharmaceutical Innovation, 1 (2), 1-4.

[27] Dueñas-Gómez, H. C.; Franco-Roselli, P. 2001. Sinopsis de las Loranthaceaes de Colombia. Caldasia 23 (1); 81-89.

[28] Eisinger, S. M. 1987. O gênero Indigofera L. (Leguminosae-Papilionoideae-Indigofereae) no Rio Grande do Sul-Brasil. Acta Bot. Bras., 1 (2): 123-140. ISSN 0102-3306. < 33061987000200004>.

[29] Erdtman, G. 1952. Pollen Morphology and Plant Taxonomy. Angiosperms. Almqvist and Wiksell, Stockholm, $539 \mathrm{p}$.

[30] Erdtman, G. 1960. The acetolysis method, a revised description. Svensk Bot. Tidskr., vol. 54: 561-564.

[31] Fan, Y. M.; Xu, L. Z.; Gao, J.; Wang, Y.; Tang, X. H.; Zhao, X. N.; Zhang, Z. X. 2004. Phytochemical and antiinflammatory studies on Terminalia catappa Fitoterapia, 75: 253-260. <www.elsevier.com/locate/fitote>.

[32] Fao. 1991. L'arbre Source de Vie. Journeé Mondiale de L'Alimentation. 26p.

[33] Fernández-Alonso, J. L.; Vega, N.; Pérez, G. 2009. Lectin prospecting in colombian Labiatae. A systematicecological approach - III. Mainly exotic species (cultivated or naturalised). Caldasia 31 (2): $227-245$. $\leq$ www.unal.edu.co/icn/publicaciones/caldasia.htm>.

[34] Ferrer-Pereira, H.; Vivas-Arroyo, Y.; Hokche, O.; Nozawa, S.; Pérez-Cortéz, S.; Rodríguez, L.; Mostacero, J.; Estrada-Sánchez, J. 2010. El género Merremia (Convolvulaceae) en Venezuela. Rodriguésia, 61(4): 639-660. <http://rodriguesis.jbrj.gov.br>.

[35] Figueiredo-Neto, A.; Almeida, F. A. C.; Gouveia, J. P. G.; Nóbrega, M. B. M.; Carneiro, R. M.; Pedroza, J. P. 2004. Divergência genética em acessos de mamona (Ricinus communis L.) baseada nas características das sementes. $\begin{array}{llllllll}\text { Revista de Biologia e } \quad \text { Ciências da } & \text { Terra. } 4 & \text { (2): } & 1-8 . & \text { ISBN } & 1519-5228 .\end{array}$ <http://www.redalyc.org/articulo.oa?id=500402001>.

[36] Forzza, R. C., org. et al., 2010. Catalago de plantas e fungos do Brasil [on line]. Rio de Janeiro: Andréia Jakobsson Estúdio: Instituto de Pesquisas Jardim Botânico do Rio de Janeiro, v. 2 il., p. 879-1699. ISBN 978-85-8874243-7. Scielo Books <http://books.scielo.org>.

[37] Franceschinelli, E. V.; Thomas, W. W. 2000. Simaba guianensis sub. Huberi, a new Venezuelan taxon of Simaroubaceae. Brittonia, 52 (4): 311-314.

[38] Franco, M. R. B.; Shibamoto, T. 2000. Volatile composition of some brasilian fruits: umbu-cajá (Spondias citherea), camu-camu (Myrciaria dubia), araçá-boi (Eugenia stipitata), and cupuaçu (Theobroma grandiflorum). J. Agric. Food Chem. 48: 1263-1265.

[39] García, M. D.; Sáenz, M. T.; Gómez, M. A.; Fernández, M. A. 1999. Tropical antiinflammatory activity of phytosterols isolated from Eryngium foetidum on chronic and acute inflammation models. Phytotherapy Research 13, 78-80.

[40] Geissberg, P.; Séquin, U. 1991. Constituents of Bidens pilosa L.: do the components found so far explain the use of this plant in tradicional medicine?. Acta Tropica, 48: 251-261.

[41] Gilbert, B. 2006. Produtos naturais industrializavéis da Amazônia. Revista Fitos., 2 (3):30-38. 
[42] Gonçalves, A. L. 2007. Estudo da atividade antimicrobiana de algumas árvores medicinais nativas com potencial de conservação/recuperação de florestas tropicais. Tese de Doutorado. Rio Claro, SP. Universidade Estadual Paulista - UNESP. 193p.

[43] Grandis, A. 2010. Respostas fotossintéticas e de crescimento da espécie amazônica Senna reticulata sob elevada concentração de $\mathrm{CO}_{2}$. Dissertação de Mestrado. São Paulo, Instituto de Biociências da Universidade de São Paulo. 126p.

[44] Gurgel, E. S. C.; Silva, M. F.; Lucas, F. C. A.; Carreira, L. M. M.; Santos, J. U. M. 2014. Morfologia do fruto e da semente de três espécies de Senna Mill. (Leguminosae - Caesalpinioideae). Biota Amazônia, 4 (2): 80-86. ISSN 21795746.

[45] Hasrat, J. A.; Pieters, L.; Vlietinck, A. J. 2004. Medicinal plants in Suriname: hypotensive effect of Gossypium barbadense. Journal of Pharmacy and Pharmacology, 56:381-387. <http://dx.doi.org/10.1211/0022357029917>. ISSN 0022-3573.

[46] Jombo, G. T. A.; Enenebeaku, M. N. O. 2008. Antibacterial profile of fermented seed extracts of Ricinus communis: findings from a preliminary analysis. Nigerian Journal of Physiological Sciences. 23 (1-2): 55-59. <http://www.bioline.org.br/np $>\leq w w w . a j o l . i n f o / j o u r n a l s . n j p s>\leq w w w . c a s . o r g>$.

[47] Kinoshita, S.; Inoue, Y.; Nakama, S.; Ichiba, T.; Aniya, Y. 2007. Antioxidant and hepatoprotective actions of medicinal herb, Terminalia catappa L. from Okinawa Island and its tannin corilagin. Phytomedicine 14: 755-762. <http://dx.doi.org/10.1016/i.phymed.2006.12.0172>.

[48] Kuijt, J. 2009. Monograph of Psittacanthus (Loranthaceae). Systematic Botany Monography 86: 1-361.

[49] Kviecinski, M. R.; Felipe, K. B.; Schoenfelder, T.; Wiese, L. P. L.; Rossi, M. H.; Gonçalez, E.; Felicio, J. D.; Filho, W. D.; Pedrosa, R. C. 2008. Study of the antitumor potential of Bidens pilosa (Asteraceae) used in Brazilian folk medicine. Journal of Ethno-pharmacology, 117: 69-75. <http://dx.doi.org/10.1016/i.jep.2008.01.017>.

[50] Lima, R. A.; Santos, M. R. A. dos; Smozinski, C. V.; 2014. Flora de Rondônia, Brasil: Solanum L. (Solanaceae). Porto Velho-RO: EDUFRO, 102p.: il. ISBN 978-857764-072-0

[51] Ling, K. H.; Kian, C. T.; Hoon, T. C. 2009. A guide to Medicinal Plants: An Illustrated, Scientific and Medicinal Approach. Ed. by World Scientífic Publishing Co. Pte. Ltd., New Jersey, 292p. ISBN-13 978-981-283-709-7.

[52] Lombardo, M.; Kiyota, S.; Kaneto, T. M. 2009. Aspectos étnicos, biológicos e químicos de Senna occidentalis (Fabaceae). Rev. Ciênc. Farm. Básica Apli. 30(1): 9-17.

[53] Lopes, E. V.; Dias, H. B.; Torres, Z. E. dos S.; Chaves, F. C. M.; Siani, A. C.; Pohlit, A. M. 2015. Coumarins, triterpenes and a hemiterpene from Bonamia ferruginea (Choisy) Hallier f. BiochemicalSystematics and Ecology. 61: 67-69.< http://dx.doi.org/10.1016/j.bse.2015.04.0374 >.

[54] Loporchio, F., Evaldt, A. C. P., Bauermann, S. G. 2008. Análises polínicas do gênero Eryngium L. no Rio Grande do Sul. Boletim de Resumos. XII Simpósio Brasileiro de Paleobotânica e Palinologia. p. 117.

[55] Luna, V. S. 2013. Padronização química e botânica de Senna occidentalis. Dissertação de Mestrado. Recife, Universidade Federal de Pernambuco, 125p il.

[56] Lusa, M. G.; Bona, C. 2009. Análise Morfoanatômica comparativa da folha de Bauhinia forficata Link e B. Variegata Linn. (Leguminosae, Caesalpinioideae). Acta bot. bras. 23 (1): $196-211$. <http://www.botanica.org.br/acta/ojs > swww.scielo.br./abb>.

[57] Maiga, A.; Diallo, D.; Bye, R.; Paulsen, B. S. 2005. Determination of some toxic and essential metal ions in medicinal and edible plants from Mali. J. Agric. Food Chem. 53: 2316-2321.

[58] Mariano, G. R. C. 2012. Avaliação da toxidade pré-clínica aguda do extrato hidroalcoólico bruto das sementes de Vatairea guianensis (AUBLET). Macapá. Dissertação de Mestrado, Universidade Federal do Amapá. 113p.

[59] Marques, L. C.; Galvão, S. M. P.; Espínola, E.; Dias, R. F.; Mattei, R.; Oliveira, M. G. M.; Carlini, E. L. de A. 2004. Psychopharmacological assessment of Pfaffia glomerata roots (extract BNT-08) in rodents. Phytother. Res. 18, 566572.

[60] Martins, M. B.; Oliveira, T. G. 2011. Amazônia Maranhense: diversidade e conservação. Belém: MPEG. 328 p.: il. ISBN: 978-85-61377-52-6.

[61] Matos, F. J. A. 1999. Plantas da Medicina Popular do Nordeste: propriedades atribuídas e confirmadas. Fortaleza: EUFC, 80p. 
[62] Melhem, T. S.; Cruz-Barros, M. A. V.; Corrêa, A. M. S.; Makino-Watanabe, H.; Silvestre-Capelato, M. S. F.; Esteves, V. L. G. 1993. Variabilidade polínica em plantas de Campo de Jordão (São Paulo, Brasil). São Paulo, Boletim do Instituto de Botânica, n.16, 104 p., publicado em 2003. ISSN 0074-0055.

[63] Menezes, A. J. E. A. 2005. O histórico do sistema extrativo e a extração de óleo de andiroba cultivado no município de Tomé-Açu, Estado do Pará. XLIII Congresso da SOBER, 11p.

[64] Miranda, I. P. A.; Clement, C. R. 1990. Germination y almacenamiento del pollen de pejibaye (Bactris gasipaes H. B. K., Palmae). Ver. Biol. Trop. 38 (1): 29-33.

[65]

Miranda, I. P. A. 1993. Estudo de alguns parametros biologicos, químicos e bioquímicos do polen da pupunheira (Bactris gasipaes Kunth). Tese de Doutorado, INPA/FUA. 151p.

[66] Miyake, E. T.; Akisue, G.; Akisue, M. K. . 1986. Caracterizaçao farmacognostica da pata-de- vaca Bauhinia $\begin{array}{llllllll}\text { forficata Link. Revista Brasileira de Farmacognosia. } 1 & \text { (1):58-60. ISSN } & \text { 0102-695X. }\end{array}$ < http://dx.doi.org/10.1590/S0102-695X1986000100007>.

[67] Nidavani, R. B.; Mahalakshmi, A. M.; Shalawadi, M. 2013. Towards a better understanding of an updated ethnopharmacology of Celosia argentea L. International Journal of pharmacy and pharmaceutical Sciences, v. 5, suppl 3, p. 54-59. ISSN: 0975-1491.

[68] Odeja, O. O.; Obi, G.; Ogwuche, C. E.; Elemike, E. E.; Oderinlo, O. 0. 2014. Phytochemical screening, antioxidant and antimicrobial activities of Senna occidentalis (L) leaves. International Journal of Herbal Medicine. 2(4): 26-30.

[69] Oliveira, C. M. F. 1998. Estudo sobre a reprodução de fáfia (Pfaffia glomerata (Spreng.) Pedersen. 1998. Dissertação (Mestrado em Agronomia- Produção vegetal) - UFPR, Curitiba, 87p.

[70] Oliveira, F. D. S. 2012. Atividade antifúngica do óleo de Carapa guianensis (Meliaceae) frente a cepas padrões de Candida spp. Dissertação de Mestrado. Macapá. Fundação Universidade Federal do Amapá. 75p.

[71] Omojasola, P. F.; Awe, S. 2004. The antibacterial activity of the leaf extracts of Anacardium occidentale and Gossypium hirsutum against some selected microorganisms. Bioscience Reseaech Commnications, 16 (1): $25-28$.

[72] Onyije, F. M.; Avwioro, O. G. 2012. Effect of ethanolic extract of Bauhinia monandra leaf on the liver of alloxan induced diabetic rats. Journal of physiology and pharmacology advances. 2 (1): 59-63. ISSN 2251-7693. <www.grjournals.com>.

[73] Ottobelli, I.; Facundo, V. A.; Zuliani, J.; Luz, C. C.; Brasil, H. O. B.; Militão, J. S. L. T.; Braz-Filho, R. 2011. Estudo químico de duas plantas medicinais da Amazônia: Philodendron scabrum k. Krause (araceae) e Vatairea guianensis Aubl. (fabaceae). Manaus, Acta amazônica, 41 (3): 393-400.

[74] Orwa, C.; Mutua, A.; Kindt, R.; Jamnadass, R.; Anthony, S. 2009. Agroforestree database: a tree reference and selection guide version 4.0 World Agroforestry Kentre, <http://www.worldagroforestry.org/sites/tree/treedbs/treedatabases.asp>

[75] Panizza, F.; Cardoso, J.; Guimarães, J. M. da S.; Neregato, L. H.; Boas, P. V.; Neregato, V. L. M. 2009. Centro de terapias complementares.108p.

[76] Pattanayak, P.; Behera, P.; Das, D.; Panda, S. K. 2010. Ocimum sanctum Linn. A reservoir plant for therapeutic applications: an overview. Pharmacogn Rev. 4 (7): 95-105. <http://dx.doi.org/10.4103/0973-7847.65323>.

[77] Paz, J. R. L.; Pigozzo, C. M. 2013. Biologia floral e polinização de Merremia dissecta var. edentada (Meisn.) O’Donell (Convovulaceae) em fragmento urbano de mata Atlântica, Bahia. Lundiana, 11(1/2): 9-16. ISSN 1676-6180.

[78] Pedersen, T. M. 1967. Studies in South American Amaranthaceae. Darwiniana 14, (1-2): 448-449.

[79] Penido, C.; Conte, F. P.; Chagas, M. S. S.; Rodrigues, C. A. B.; Pereira, J. F. G.; Henriques, M. G. M. O. 2006. Antiinflammatory effects of natural tetranortriterpenoids isolated from Carapa guianensis Aublet on zymosaninduced arthritis in mice. Inflammation Research 55: 457-464.1023-3830/06/110457-08. <http://dx.doi.org/10.1007/s00011-006-5161-8>.

[80] Pereira, R. C. A.; Moreira, M. R.; Lima, R. B. 2009. Cultivo de Alfavaca-de-galinha (Ocimum micranthum Willd.). Fortaleza, CE. Comunicado Técnico on line 138, 2p.; I. ISSN 1679-6535. 
[63] Menezes, A. J. E. A. 2005. O histórico do sistema extrativo e a extração de óleo de andiroba cultivado no município de Tomé-Açu, Estado do Pará. XLIII Congresso da SOBER, 11p.

[64]

Miranda, I. P. A.; Clement, C. R. 1990. Germination y almacenamiento del pollen de pejibaye (Bactris gasipaes H. B. K., Palmae). Ver. Biol. Trop. 38 (1): 29-33.

[65]

Miranda, I. P. A. 1993. Estudo de alguns parametros biologicos, químicos e bioquímicos do polen da pupunheira (Bactris gasipaes Kunth). Tese de Doutorado, INPA/FUA. 151p.

[66] Miyake, E. T.; Akisue, G.; Akisue, M. K. . 1986. Caracterizaçao farmacognostica da pata-de- vaca Bauhinia $\begin{array}{lllllll}\text { forficata Link. Revista Brasileira de Farmacognosia. } 1 & \text { (1):58-60. ISSN } & \text { 0102-695X. }\end{array}$ <http://dx.doi.org/10.1590/S0102-695X1986000100007>.

[67] Nidavani, R. B.; Mahalakshmi, A. M.; Shalawadi, M. 2013. Towards a better understanding of an updated ethnopharmacology of Celosia argentea L. International Journal of pharmacy and pharmaceutical Sciences, v. 5, suppl 3, p. 54-59. ISSN: 0975-1491.

[68] Odeja, O. O.; Obi, G.; Ogwuche, C. E.; Elemike, E. E.; Oderinlo, O. 0. 2014. Phytochemical screening, antioxidant and antimicrobial activities of Senna occidentalis (L) leaves. International Journal of Herbal Medicine. 2(4): 26-30

[69] Oliveira, C. M. F. 1998. Estudo sobre a reprodução de fáfia (Pfaffia glomerata (Spreng.) Pedersen. 1998. Dissertação (Mestrado em Agronomia- Produção vegetal) - UFPR, Curitiba, 87p.

[70] Oliveira, F. D. S. 2012. Atividade antifúngica do óleo de Carapa guianensis (Meliaceae) frente a cepas padrões de Candida spp. Dissertação de Mestrado. Macapá. Fundação Universidade Federal do Amapá. 75p.

[71] Omojasola, P. F.; Awe, S. 2004. The antibacterial activity of the leaf extracts of Anacardium occidentale and Gossypium hirsutum against some selected microorganisms. Bioscience Reseaech Commnications, 16 (1): 25 -28.

[72] Onyije, F. M.; Avwioro, O. G. 2012. Effect of ethanolic extract of Bauhinia monandra leaf on the liver of alloxan induced diabetic rats. Journal of physiology and pharmacology advances. 2 (1): 59-63. ISSN 2251-7693. $<$ www.grjournals.com $>$.

[73] Ottobelli, I.; Facundo, V. A.; Zuliani, J.; Luz, C. C.; Brasil, H. O. B.; Militão, J. S. L. T.; Braz-Filho, R. 2011. Estudo químico de duas plantas medicinais da Amazônia: Philodendron scabrum k. Krause (araceae) e Vatairea guianensis Aubl. (fabaceae). Manaus, Acta amazônica, 41 (3): 393-400.

[74] Orwa, C.; Mutua, A.; Kindt, R.; Jamnadass, R.; Anthony, S. 2009. Agroforestree database: a tree reference and $\begin{array}{llllll}\text { selection } & \text { guide } & \text { version } & \text { World } & \text { Agroforestry } & \text { Centre, }\end{array}$ <http://www.worldagroforestry.org/sites/tree/treedbs/treedatabases.asp >

[75] Panizza, F.; Cardoso, J.; Guimarães, J. M. da S.; Neregato, L. H.; Boas, P. V.; Neregato, V. L. M. 2009. Centro de terapias complementares.108p.

[76] Pattanayak, P.; Behera, P.; Das, D.; Panda, S. K. 2010. Ocimum sanctum Linn. A reservoir plant for therapeutic applications: an overview. Pharmacogn Rev. 4 (7): 95-105. <http://dx.doi.org/10.4103/0973-7847.65323>.

[77] Paz, J. R. L.; Pigozzo, C. M. 2013. Biologia floral e polinização de Merremia dissecta var. edentada (Meisn.) O’Donell (Convovulaceae) em fragmento urbano de mata Atlântica, Bahia. Lundiana, 11(1/2): 9-16. ISSN 1676-6180.

[78] Pedersen, T. M. 1967. Studies in South American Amaranthaceae. Darwiniana 14, (1-2): 448-449.

[79] Penido, C.; Conte, F. P.; Chagas, M. S. S.; Rodrigues, C. A. B.; Pereira, J. F. G.; Henriques, M. G. M. O. 2006. Antiinflammatory effects of natural tetranortriterpenoids isolated from Carapa guianensis Aublet on zymosaninduced arthritis in mice. Inflammation Research 55: 457-464.1023-3830/06/110457-08. <http://dx.doi.org/10.1007/s00011-006-5161-8>.

[80] Pereira, R. C. A.; Moreira, M. R.; Lima, R. B. 2009. Cultivo de Alfavaca-de-galinha (Ocimum micranthum Willd.). Fortaleza, CE. Comunicado Técnico on line 138, 2p.; I. ISSN 1679-6535.

[81] Pereira, R. C. A.; Moreira, A. L. M. 2011. Manjericão: cultivo e utilização. Fortaleza, CE. Documentos/Embrapa Agroindústria Tropical 136, 31p.;I. ISSN 2179-8184.

[82] Que, F.; Mao, L.; Fang, X.; Wu, T. 2008. Comparison of hot air-drying and freeze-dryng on the physicochemical properties and antioxidant activities of pumpkin (Cucurbita moschata Duch.) flours. International Journal of Food Science and Technology, 43: 1195-1201. <http://dx.doi.org/10.1111/j.1365-2621.2007.01590.x>. 
[83] Queiroz, J. M. G.; Suzuki, M. C. M.; Motta, A. P. R.; Nogueira, J. M. R.; Carvalho, M. de. 2015. Ascpectos populares e científicos do uso de espécies de Eugenia como fititerápico. Revista Fitos, 9 (2):73-159. <http://dx.doi.org/10.5935/2446-4775.20150008>.

[84] Radaeski, J. N., Evaldt, A. C. P., Lima, G. L., Bauermann, S. G. 2011. Grãos de pólen das formações campestres sul-brasileiras. Revista de Iniciação Científica da Universidade Luterana do Brasil, Canoas, n. 9, p. 59-67.

[85] Rai, V.; Vajpayee, P.; Singh, S. N.; Mehrotra, S. 2004. Effect of chromium accumulation on photosynthetic pigments, oxidative stress defense system, nitrate reduction, proline level and eugenol content of Ocimum tenuiflorum L. Plant Science, 167: 1159-1169. www.elsevier.com/locate/plantsci. <http://dx.doi.org/10.1016/j.plantsci.2004.06.016>.

[86] Rai, M.; Geoffrey, A. C.; Martinez, J. L.; Marinoff, M.; Rastrelli, L. 2012. Medicinal Plants: Bioversity and Drugs. Taylor \& Francis Group, LLC. NW. 685p.

[87] Raju, S.; Kavimani, S.; Uma Maheshwara rao, V.; Sreeramulu Reddy, K. 2011. Tecoma strans (L.) Juss. ex Kunth (Bignoniaceae): Ethnobotany, phytochemistry and pharmacology. Journal of Pharmaceutical and Biomedical Sciences, 8 (07): 1-5.

[88] Ramcharan, C. 1999. Culantro: A much utilized, little understood herb. p. 506-509. In: J. Janick (ed), Perspectives on new crops and new uses. ASHS Press, Alexandria, VA.

[89] Revilla, J. 2002. Plantas Úteis da Bacia Amazônica. Manaus-AM: SEBRAE/INPA, 2v., il., v. 1 p. 1-444, v. 2 p. 445-858. ISBN 85-87324-11-X.

[90] Revilla, J. 2000 a. Plantas da Amazônia: oportunidades econômicas e sustentáveis. Programa de Desenvolvimento Empresarial e Tecnológico. Manaus, Amazonas, Brasil. 405p.

[91] Revilla, J.; Melo, L. 2000 b. Levantamento florístico e econômico da flora do município de Manaquiri-AM. Relatório dos alunos do Curso de Inventário Florístico. Curso de Pós-Graduação em Botânica/INPA-UFAM. ManausAM, Brasil, 26p.

[92] Ribeiro, J. E. L. S.; Hopkins, M. J. G.; Vicentini, A.; Sothers, C. A.; Costa, M. A. da S.; Brito, J. M. de; Souza, M. A. D. de; Martins, L. H. P.; Lohmann, L. G.; Assunção, P. A. C. L.; Perreira, E. da C.; Siva, C. F. Da; Mesquita, M. R.; Procópio, C. 1999. Flora da Reserva Ducke: Guia de identificação das plantas vasculares de uma floresta de terra-firme na Aamazônia Centrtal. 1 ed. INPA/DFID: Midas Printing Ltda. 799p.

[93] Rodrigues, I. M. C.; Souza Filho, A. P. S.; Ferreira, F. A. 2009. Estudo fitiquímico de Senna alata por duas metodologias. Planta Daninha, v.27, n.3, p.507-513.

[94] Rodrigues, R. S.; Flores, A. S.; Miotto, S. T. S.; Baptista, L. R. M. 2005. 0 gênero Senna (Leguminosae, Caesalpinioideae) No Rio Grande do Sul, Brasil. Acta Bot.. Bras.19 (1):1-16.

[95] Salgado-Labouriau, M.L., 1971. Contribuição à palinologia dos Cerrados. Acad. Brasil. Ciên., Rio de Janeiro. 291 p.

[96] Santos, J. 0. 2013. Adaptabilidade e estabilidade de pré-cultivares de abóbora (Cucurbita moschata D.) nas condições do norte e do noroeste fluminense. Campos dos Goytacazes, RJ. Universidade Estadual do Norte Fluminense Darcy Ribeiro - UENF. Tese de doutorado, 128p.

[97] Santos, R. N.; Silva, M. G. V. 2008. Constituintes químicos do caule de Senna reticulata Willd. (Leguminoseae). Quim. Nova, 31 (8): 1979-1981.

[98] Seo, E. K.; Wani, M. C.; Wall, M. E.; Navarro, H.; Mukherjee, R.; Farnsworth, N. R.; Kinghorn, A. D. 2000. New bioactive aromatic compounds from Vismia guianensis. Phytochemistry. 55 (200): $35-42$. $<$ www.elsevier.com/locate/phytochem $>$.

[99] Sierra, C. L. S., Caetano, C. M., Lagos. T. C., Servia, J. L. C. 2006. Palinologia de Carica y Vasconcellea (Caricaceae). Acta Agron. (Palmira) 55 (3): 33-38.

[100] Silva, C. S.; Nunes, P. O.; Mescouto, C. S. T.; Müller, R. C. S.; Palheta, D. C.; Fernandes, K. G. 2010. Avaliação do uso da casca do fruto e das folhas de Caesalpinia ferrea Martins como suplemento nutricional de Fe, Mn e Zn. Ciênc. Tecnol. Aliment., 30 (3): 751-754. ISSN 0101-2061. <http://dx.doi.org/10.1590/S0101-20612010000300028>.

[101] Silva, I. M.; Koroyva, P.; Gutierrez, T.; Silva, A. M. 2014. Utilização de folhas de pitangueira (Eugenia uniflora) no controle da hipertensão arterial sistêmica de usuários do sistema único de saúde. II Simposio de Assistencia Farmaceutica. Sao Paulo, SP. Centro Universitario Sao Camilo. 3p. 
[102] Silva, K. L.; Filho, V. C. 2002. Plantas do genero Bauhinia: comparaçao química e potencial farmacologico. Quim. Nova. 25 (3): 449-454. <www.quimicanova.sbq.org.br/>. ISSN 1678-7064.

[103] Silva, M. T. G.; Simas, S. M.; Batista, T. G. F. M.; Cardarelli, P.; Tomassini, T. C. B. 2005. Studies on antimicrobial activity, in vitro, of Physalis angulata L. (Solanaceae) fraction and physalin B bringing out the importance of assay determination. Mem. Inst. Oswaldo Cruz 100(7):779-782.

[104] Sinha, A.; Taylor, W. H.; Khan, I. H.; McDaniel, S. T.; Esko, J. D. 1999. Glycoside Primers of Psttacanthus cucullaris. J. Nat. Prod. 62:1036-1038.

[105] Smith, A.C. 1985. Flora vitiensis nova: A new flora of Fiji (Spermatophytas Only). Lawai, Kauai, Hawai. National Tropical Botanical Garden, v. 3, 758p. ISBN 0-915809-22-2.

[106] Soares J. A.; Barros, M.; Gonçalez, W. P.; Crisci, A. R.; Jorge, M. H. S. 2013. Avaliação da atividade cicratizante da Caesalpinia ferrea ex. TUL. var ferrea e da Aloe vera (L.) Burm. f. Em lesões cutâneas totais em ratos. Persp. Online: biol. \& saúde. Campos dos Goytacazes, 11(3):33-40. ISSN 2236-8868. <www.seer.perspectivaonline.com.br>.

[107] Souza, C. N. 2007. Características físicas, físico-químicas e químicas de três tipos de jenipapos (Genipa americana L.). Dissertação de mestrado. Ilhéus, BA. Universidade Estadual de Santa Cruz. 58p.

[108] Souza, L. A. G. 2012. Guia da biodiversidade de fabaceae do Alto Rio Negro. Manaus, 118p., il. CDD 19 ed. 583.322.

[109] Souza, N. K. R.; Amorim, S. M. C. 2009. Crescimento e desenvolvimento de Physalis angulata Lineu submetida ao déficit hídrico. Rev. Acad., Ciências Agrárias Ambiental, 7 (1): 65-72. ISSN 0103-989X.

[110] Tchikaya, F. O.; Bantsielé, G. B.; Kouakou-Siransy, G.; Datté, J. Y.; Yapo, P. A.; Zirihi, N. G.; Offoumou, M. A. 2011. Anacardium occidentale Linn. (Anacardiaceae) stem bark extract induces hypotensive and cardio-inhibitory effects in experimental animal models. Afr. J. Tradit. Complement Altern. Med. 8 (4):452-461. <http://dx.doi.org/10.4314/ajtcam.v8i4.18>.

[111] Tomchinski, B. 2013. Etnobotânica de plantas antimaláricas em Barcelos, Amazonas. Botucatu, SP. Dissertação de mestrado. Faculdade de Ciências Agronômicas UNESP. 189 p.

[112] Trindade, M. J. S.; Lameira, O. A. 2014. Espécies úteis da família Euphorbiaceae no Brasil. Revista Cubana de Plantas Medicinales, 19 (1): 292-309. <http://scielo.sld.cu>.

[113] Vieira, J. R. C.; Souza, I. A.; Nascimento, S. C.; Leite, S. P. 2006. Indigofera suffruticosa: an altenative anticancer therapy. Evid. Based Complement. Alternat. Med. eCam 4 (3): 355-359. <http://dx.doi.org/10.1093/ecam/nel102>.

[114] Vieira, P. R. N. 2009. Atividade antifúngica dos óleos essenciais de espécies de Ocimum frente a cepas de Candida spp. e Microsporum canis. Dissertação de Mestrado. Fortaleza, CE. Faculdade de Veterinária da Universidade Estadual do Ceará. 89p.

[115] Vilar, D. A.; Vilar, M. S. A.; Moura, T. F. A. L.; Raffin, F. N.; Oliveira, M. R.; Franco, C. F. O. ; Athayde-Filho, P. F.; Diniz, M. F. F. M.; Barbosa-Filho, J. M. 2014. Traditional uses, chemical constituents, and biological activities of Bixa orellana L.: A Review. Volume 2014 (2014), Artigo ID 857292, 11 p. <http://dx.doi.org/10.1155/2014/857292>.

[116] Watanabe, M. A. 2007. Fatores que influenciam a ocorrência de Ácaros em flores de Lantana camara L. Boletim de Pesquisa e Desenvolvimento, 43. Embrapa Meio Ambiente, 24p. ISSN 1516-4675.

[117] Wendel, J. F.; Brubaker, C. L.; Percival, A. E. 1992. Genetic diversity in Gossypium hirsutum and the origin of upland cotton. American Journal of Botany 79 (11): 1291-1310. <http://lib.dr.iastate.edu/bot pubs/9>.

[118] Zenimori, S.; Pasin, L. A. A. P. 2006. Aspectos da biologia floral de Lantana (Lantana camara L.). São José dos Campos, SP, v. 13, n. 24. Revista UNIVAP, ed., esp. Ciências Biológicas, p. 8. ISSN 1517-3275. 


\section{SITES CONSULTADOS}

- <Missouri Botanical Garden>. 25/02/2016. <http://www.tropicos.org/Name/11003266>.

- <BEFS Rapid Appraisal - Crops Catalogue>. <http://www.fao.org/energy/befs/86187/es/>. 15/03/2016.

- <http://naturell.com.br/wp-content/uploads/2015/02/Literatura_Algodoeiro.pdf>. 14/03/2016.

- $\quad$ http://florawww.eeb.uconn.edu/198500662.html>. 03/02/2016.Tecoma stans - EEB Greehouse University Connecticut.

- <http://www.cpra.pr.gov.br/arquivos/File/Abobora.pdf>. 22/03/2016.

- <www.jardineiro.net/plantas/mamona-ricinus-communis.html>. 03/02/2016.

- <http://www.plantasquecuram.com.br/ervas/mamona.html\#.VznbQSHjhck>. 03/02/2016.

- $\quad$ http://www.bonsaihunk.us/info/CaesalpinaFerrea.html>. 03/02/2016.

- $\quad$ http://www.thegardener.co.za/kb/article.php?id=383>. 03/02/2016.

- <https://www.infoteca.cnptia.embrapa.br/bitstream/doc/709707/1/doc127arborizacaodepastagens.pdf>. 03/02/2016.

- <https://www.infoteca.cnptia.embrapa.br/infoteca/bitstream/doc/657248/1/cot138.pdf>. 23/03/2016.

- $\quad$ http://www.tudosobreplantas.com.br/asp/plantas/ficha.asp?id_planta=14190>. 29/03/2016.

- $\quad$ https://en.wikipedia.org/wiki/Cissus_sicyoides>. 29/03/2016.

- $\quad<$ https://pt.wikipedia.org/wiki/Andiroba>. 14/03/2016.

- $\quad$ <https://en.wikipedia.org/wiki/Eugenia_stipitata>. 07/04/2016.

- $\quad$ <https://sites.google.com/site/florasbs/myrtaceae/pitanga-vermelha>. 10/03/2016.

- <https://pt.wikipedia.org/wiki/Pitanga>.13/03/2016.

- <http://keyserver.lucidcentral.org/weeds/data/media/Html/ricinus_communis.htm>. 13/03/2016.

- <http://keyserver.lucidcentral.org/weeds/data/media/Html/eugenia_uniflora.htm>. 13/03/2016.

- <http://keyserver.lucidcentral.org/weeds/data/media/Html/lantana_camara.htm>. 13/03/2016.

- $\quad$ http://keyserver.lucidcentral.org/weeds/data/media/Html/senna_alata.htm>. 16/05/2016.

- <http://keyserver.lucidcentral.org/weeds/data/media/Html/senna_occidentalis.htm>. $16 / 05 / 2016$.

- <http://keyserver.lucidcentral.org/weeds/data/media/Html/tecoma_stans.htm>. 16/05/2016.

- <http://archives.evergreen.edu/webpages/curricular/20052006/walkingthewheel/projects/aldo/skullcap.pdf>. 22/03/2016.

- $\quad$ http://archives.evergreen.edu/webpages/curricular/20062007/healinggardens0607/healinggardens/skullcap/index.html>. 22/03/2016. 


\section{AUTORES}

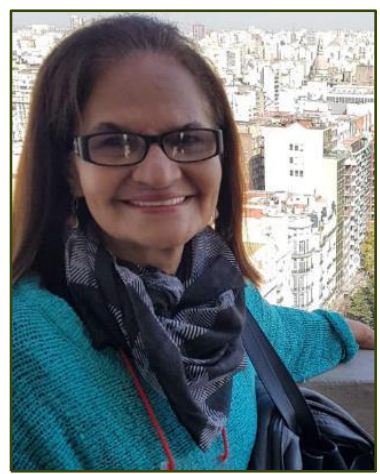

\section{Ires Paula de Andrade Miranda}

Possui graduação em Ciências Biológicas pela Universidade Federal do Amazonas (UFAM), Mestre em Ciências Biológicas, área Botânica pelo Instituto Nacional de Pesquisas da Amazônia e Universidade Federal do Amazonas (INPA/UFAM) Doutora em Ciências Biológicas, Doutorado em Ciência Biológicas, tipo sandwich na área de Botânica com ênfase em Biopalinologia, pelo Centre National de Recherche Scientifique (CNRS/INPA) no Museum National D'Histoire Naturelle de Paris (MNHN) e Institut Pasteur em 1993.

Pesquisadora Titular do Instituto Nacional de Pesquisas da Amazônia (INPA), Líder do Grupo de Pesquisas em Estudos de Palmeiras da Amazônia (LABPALM/COBIO/INPA). Docente e Membro do Conselho do Programa de Pós-Graduação da Rede Bionorte. Coordenou vários projetos interinstitucionais e multidisciplinares e atua na formação de recursos humanos em cursos de pósgraduação e graduação especialmente em Cadeias Produtivas Regionais.

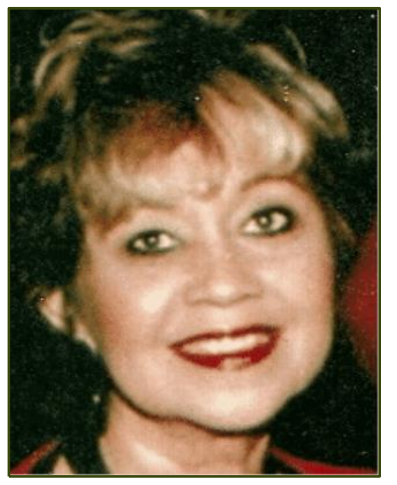

\section{Léa Maria Medeiros Carreira}

Possui graduação em Farmácia e Bioquímica pela Universidade Federal do Pará (1972), mestrado em Botânica pelo Instituto Nacional de Pesquisas da Amazônia (1975) e doutorado em Ciências Biológicas (Botânica) pelo Instituto Nacional de Pesquisas da Amazônia (1983). Exerceu função de pesquisador no Instituto Nacional de Pesquisas da Amazônia e de pesquisador titular - A-III no Museu Paraense Emílio Goeldi, professora credenciada nos cursos de pós-graduação do Instituto Nacional de Pesquisas da Amazônia-AM.

Desenvolve projetos de pesquisa na área de Botânica, com ênfase em Palinologia, atuando principalmente nos temas: Morfologia Polínica, Estudos Melissopalinológicos, Palinotaxonomia de espécies da Amazônia Brasileira e Ecopalinologia. Foi Bolsista de Produtividade de Pesquisa do CNPq/MCT no período de 1986 a 2009. A partir de 10 de abril de 2015 está aposentada e na condição de pesquisadora voluntária desenvolve projetos de pesquisa referentes as áreas de atuação acima citadas no Museu Paraense Emílio Goeldi - Coordenação de Botânica. 


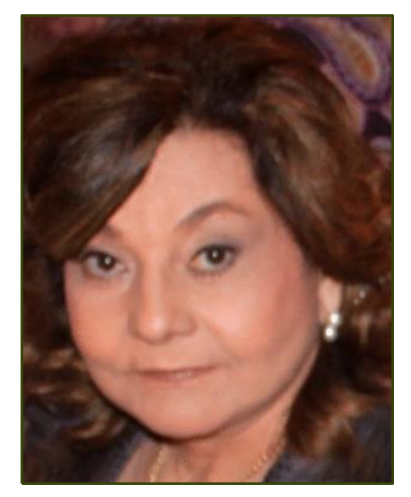

\section{Maria Lúcia Absy}

Possui graduação em História Natural pela Pontifícia Universidade Católica do Paraná (PUCPR), 1968, mestrado em Ciências Biológicas (Botânica) pela Universidade de São Paulo (USP), 1972, doutorado em Matemática e Ciências pela Universidade de Amsterdam (UvA), 1979 e Pós- Doutorado pela Universidade de Amsterdam (UvA), 1990. Pesquisadora titular do Instituto Nacional de Pesquisas da Amazônia (INPA), atualmente colaboradora.

Em 1975, criou o Laboratório de Palinologia do INPA iniciando junto com o Prof. Warwick E. Kerr os estudos pioneiros de pólen coletado por abelhas nativas da Amazônia. Paralelamente, realizou pesquisas de pólen de sedimentos do Quaternário iniciadas em Amsterdam sob a orientação do Professor Thomas van der Hammen. Por esses estudos palinológicos pioneiros de Quaternário da Amazônia foi homenageada pela Dra. Carina Hoorn da Universidade de Amsterdam, com o pólen fóssil do Mioceno: Retimonocolpites absyiae. Entre os prêmios e homenagens recebidas, se destacam:

Menção Honrosa WARWICK ESTEVAM KERR em 2013 pela contribuição para o desenvolvimento da pesquisa científica e tecnológica e da inovação no âmbito da Pós-Graduação. Instituto Nacional de Pesquisas da Amazônia (INPA). Em 2004, recebeu a MEDALHA "GRANDE MÉRITO" DA ORDEM DO MÉRITO LEGISLATIVO DO ESTADO DO AMAZONAS. Assembléia Legislativa do Estado do Amazonas (ALEAM). Admitida na ORDEM NACIONAL DO MÉRITO CIENTÍFICO em 15 de agosto de 2002, CLASSE DE COMENDADOR pelo Presidente da República Federativa do Brasil, Fernando Henrique Cardoso. Publicou até o momento mais de 70 artigos em periódicos nacionais e internacionais, 24 capítulos de livros e 4 Organizações/Edições de livros. Participou na formação de recursos humanos com a orientação de 20 alunos de Mestrado, 14 de Doutorado entre outros de Iniciação Científica e estagiários. Tem experiência na área de Botânica, com ênfase em Palinologia, atuando principalmente nos seguintes temas: Amazônia, Paleoecologia e pólen coletado por abelhas. 


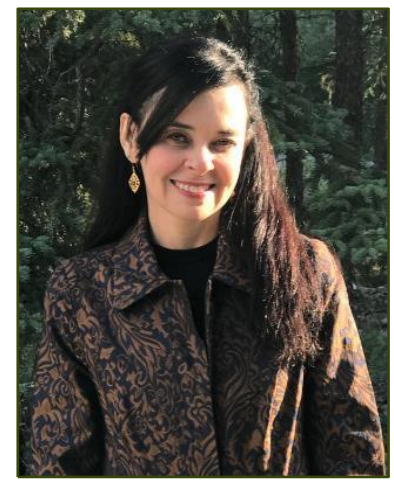

\section{Flávia Cristina Araújo Lucas}

Graduação em Ciências Biológicas, Universidade Federal do Pará e Mestrado em Agronomia, Área Biologia Vegetal Tropical, Universidade Federal Rural da Amazônia. Doutorado em Ciências Biológicas, Instituto Nacional de Pesquisas da Amazônia - Núcleo Biologia Tropical e Recursos Naturais, Manaus-AM. Desenvolveu estágio de pós-doutorado na Faculdade de Farmácia, Observatório Interação Planta-Medicamento, Universidade de Coimbra, Portugal.

Na Universidade do Estado do Pará (UEPA) é Professor Adjunto IV, e Professora Permanente dos Programas de Pós Graduação Stricto Senso - Mestrado Acadêmico em Ciências Ambientais e Mestrado em Ciências da Religião. É professora colaboradora do Programa de Doutorado em Rede, Bionorte. É curadora do Herbário Profa. Dra. Marlene Freitas da Silva (MFS), no qual desenvolve atividades em parceria com o Museu Paraense Emílio Goeldi (Coordenação de Botânica) e Embrapa Amazônia Oriental. É líder do Grupo de Pesquisa "Estudos interdisciplinares em Botânica".

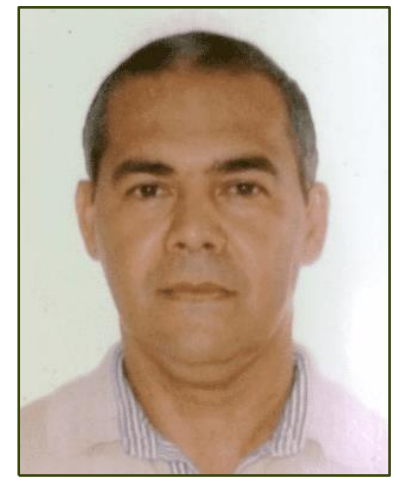

\section{Edelcilio Marques Barbosa}

Possui graduação em Engenharia Agronômica pela Universidade Federal Rural de Pernambuco(1982), mestrado em Ciências de Florestas Tropicais pelo Instituto Nacional de Pesquisas da Amazônia (1988) e doutorado em Ciências Biológicas (Botânica) pela Universidade Estadual Paulista Júlio de Mesquita Filho(1995). Atualmente é Pesquisador titular III do Instituto Nacional de Pesquisas da Amazônia.

Tem experiência na área de Botânica, com ênfase em Fisiologia Vegetal. Atuando principalmente nos seguintes temas: composição florística, ecofisiologia, razão isotópica 13C12C, CO2, Amazônia e Reserva Adolpho Ducke.

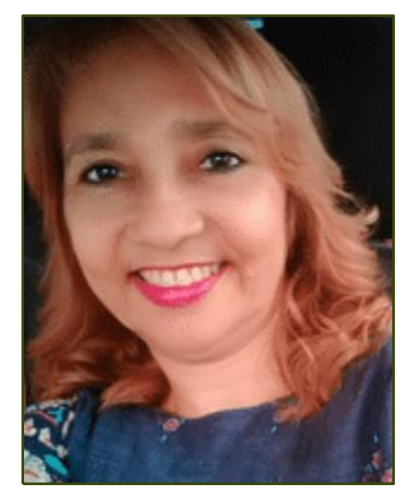

\section{Filomena Ferreira Santiago}

Possui graduação em Licenciatura Plena em Ciências Biológicas pela Universidade Federal do Amazonas (1987) e mestrado em Ciências Biológicas (Botânica) pelo Instituto Nacional de Pesquisas da Amazônia (1994). Técnica do Instituto Nacional de Pesquisas da Amazônia. Tem experiência na área de Botânica, com ênfase em Palinologia, atuando principalmente nos seguintes temas: Biologia floral, palmeiras, polinização, Amazônia e cynometra bauhiniifolia. 


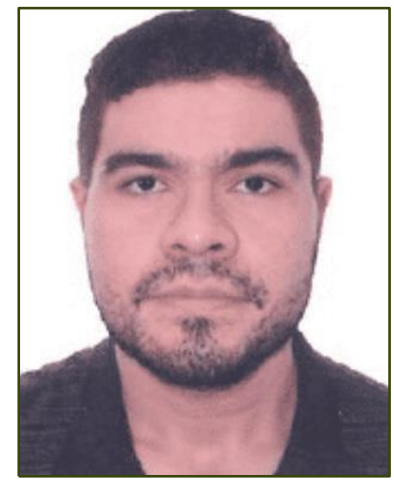

\section{David de Paula Andrade Miranda}

Possui graduação em Design Gráfico no ano de 2016 pelo Centro Universitário do Norte (UNINORTE). Com o projeto "INTERFACE DIGITAL PARA JOGO ELETRÔNICO INSPIRADO NA LENDA DO UIRAPURU". Atualmente é colaborador do projeto gráfico do Grupo de Estudos em Palmeiras da Amazônia do Instituto Nacional de Pesquisas da Amazônia.

Tem experiência na área de Ciência da Computação, com ênfase em Processamento Gráfico (Graphics), Criatividade em Empreendedorismo, Produção Gráfica, Design Sustentável, Direção de Arte e Desenho Editorial, Sistema de Identidade Visual, Ergonomia e Marketing, Adobe Dreamweaver. Colaborou de forma voluntária em 2014 no desenvolvimento do projeto gráfico do relatório de atividades da Fundação de Amparo à Pesquisa do Estado do Amazonas (FAPEAM) pelo Departamento de Difusão do Conhecimento (DECON). Possui experiência em aplicativos: ILLUSTRATOR E INDESIGN, além de exercer atividades relacionadas à 3D Studio, Photoshop e Coreldraw.

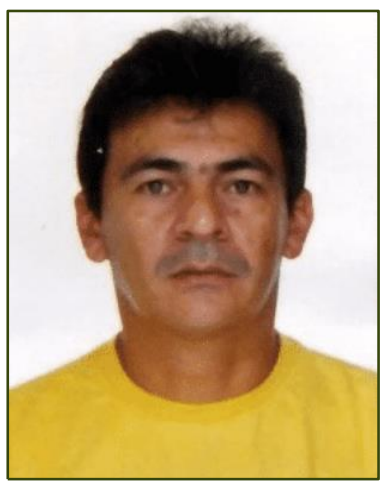

\section{Luiz de Souza Coelho}

Graduado em Licenciatura Plena em Ciências Biológicas pela Escola Superior Batista do Amazonas (2006), pós-graduação lato sensu em Biotecnologia pelo Centro Universitário do Norte (2008), técnico do Instituto Nacional de Pesquisas da Amazônia (INPA/COBIO), no Laboratório de Inventário Florístico e Botânica Econômica. Membro do Grupo de Pesquisas em Palmeiras do INPA;

Membro do Grupo de Pesquisa Ecologia e Genética de Populações de Árvores Tropicais do INPA; Membro (Colaborador com mais de 100 hectares de inventários florísticos realizados na Amazônia) do Banco de Dados de Inventários Florestais e Florístico da ATDN - AMAZON TREE DIVERSITY NETWORK, Vice Coordenador e Professor do Centro de Treinamento de Produtores Rurais em Negócios Sustentáveis em Manaquiri - AM, Coordenador do Banco de Dados de Inventário Florístico e Botânica Econômica da COBIO/INPA. Tem experiência na área de Botânica, com ênfase em Fitomassa (Biomassa vegetal), Inventário Florístico e Potencialidade Econômica das Espécies Vegetais, atuando principalmente nos seguintes temas: Inventário Florístico, Fitomassa, Fitossociologia, Composição Florística, Botânica Econômica, Potencialidade Econômica das Espécies Vegetais, Relatórios Técnico/Científicos e Impactos na Amazônia. 


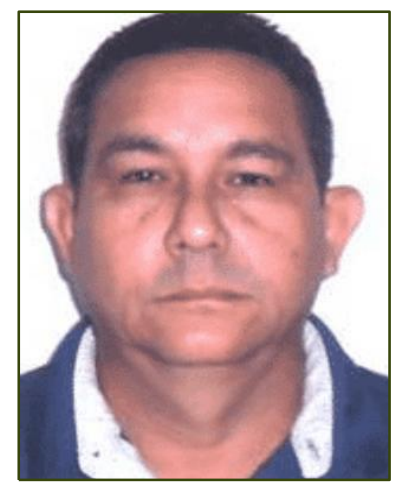

\section{José Benayon Bessa de Moura}

Técnico do Instituto Nacional de Pesquisas da Amazônia. Membro do Grupo de Pesquisas em Palmeiras do INPA (LABPALM/COBIO/INPA. Tem experiência na área de banco de dados botânicos, técnico de campo em expedições científicas para coleta e inventários de dados e administração de projetos. 
